\title{
DIRECT AND INDIRECT INTERACTIONS OF NATIVE AND INTRODUCED SPECIES IN COASTAL HABITATS
}

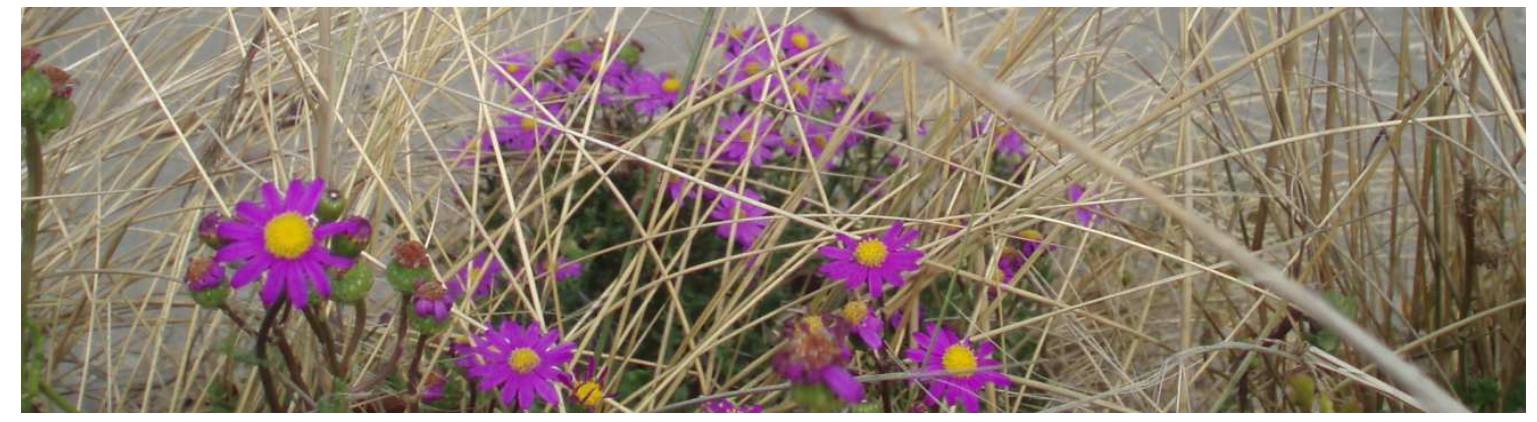

\section{by \\ Susanne Claudia Krejcek}

\author{
A thesis \\ submitted to the Victoria University of Wellington \\ in fulfilment of the requirements for the degree of \\ Doctor of Philosophy
}

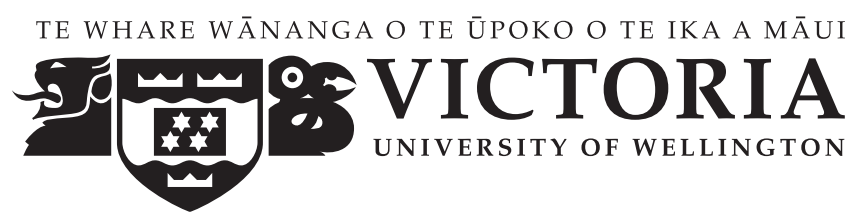

Victoria University of Wellington 

This thesis was conducted under the supervision of:

\author{
Dr Stephen Hartley (Primary supervisor) \\ Victoria University of Wellington, \\ Wellington, New Zealand
}

\author{
Dr David Bergin \\ Environmental Restoration Ltd \\ Rotorua, New Zealand \\ and \\ Dr Jon Sullivan \\ Lincoln University \\ Christchurch, New Zealand
}





\section{ABSTRACT}

Direct and indirect interactions of native and introduced species in coastal habitats

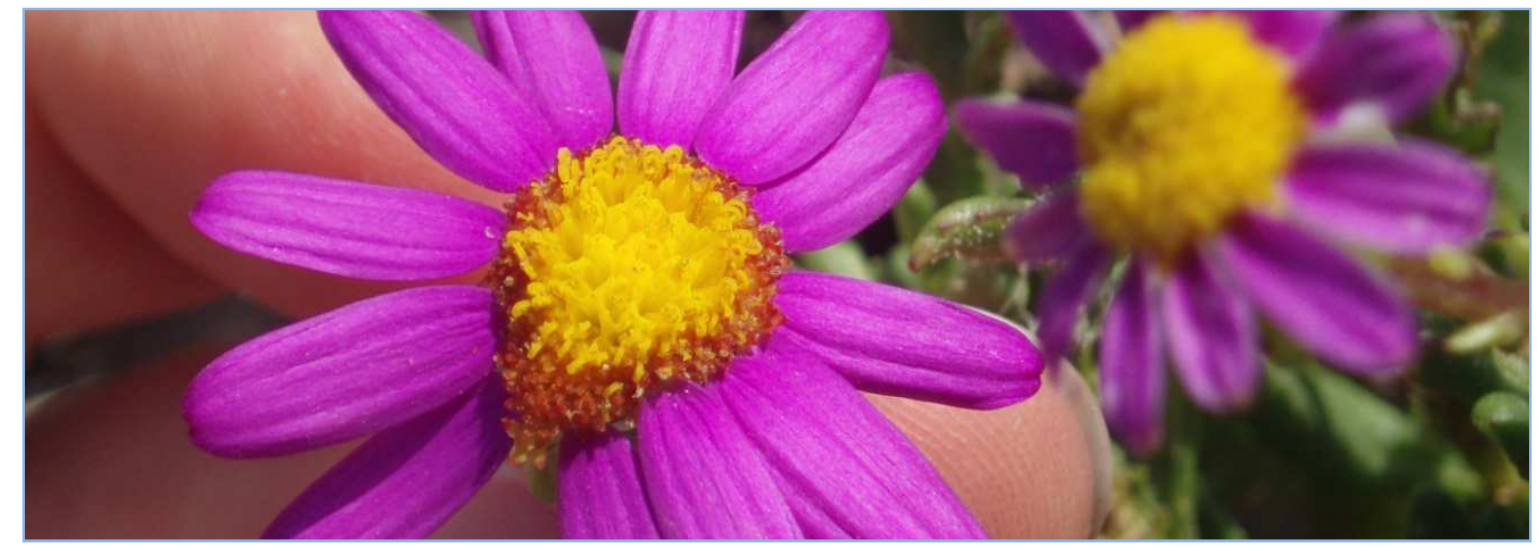

Senecio elegans flower 
Current research has emphasized the need to identify and quantify the effects of positive and negative interactions (both direct and indirect) between species, taking into account the influence of abiotic conditions and spatial scales. In this research it is particularly challenging to adequately assess and predict the impact of introduced species on native communities. This study examined interactions of introduced and native species on coastal sand dunes in New Zealand. Substantial areas of this habitat have become dominated by the highly competitive exotic sand-binder marram grass (Ammophila arenaria) and other exotic weeds, replacing native species, including the native eco-engineering spinifex (Spinifex sericeus).

First, I examined direct interactions (competition and facilitation) between marram and spinifex along an abiotic stress gradient where experimental plots were subject to different restoration management techniques. In my large-scale dune experiment I planted 2475 spinifex seedlings in three different treatments (bare sand, live marram, dead marram) including an unplanted control, and monitored the plots for one year along exposed marram grass-dominated dune fields near Whanganui, West Coast, North Island/New Zealand. The stress gradient hypothesis predicts facilitation will be greatest where stress is most severe. I hypothesized facilitation of spinifex plantings and other self-colonizing plants in dead sprayed marram compared to live marram and a change of interaction between spinifex and marram grass along an abiotic stress gradient. Spinifex survival was not significantly different across treatments, but the interaction between treatment and location from the sea as well as pre-existing marram cover were significant predictors of plant growth in a linear mixed effect model. Exotic weeds such as Senecio elegans, Conyza canadensis, dandelions and legumes were facilitated by sprayed marram grass relative to abundances in live marram grass, while grasses other than marram grass and spinifex performed best in bare sand, in the absence of competitors. For S. elegans, abundances were higher closer to the sea. Spinifex growth was greatest in plots closest to the sea. Comparing spinifex growth in live marram grass and dead marram showed similar patterns at the fore, mid and back dune, but sprayed maram showed better facilitation of spinifex. For restoration plantings it is only recommended to plant into dead marram if the site is not weed prone as weeds were facilitated in the same way as spinifex and in some instances appeared to hinder spinifex 
growth. Crucial for a successful conversion from marram to spinifex is that the initial marram cover is not too high prior to spraying- lower densities allow for better spinifex growth.

Second, I examined indirect competition with a survey of natural populations and a common garden experiment at a shingle beach. I was interested in determining the influence of plant density at different spatial scales as well as plant morphology on insect abundances. I studied indirect interactions by choosing native and introduced Senecio spp. as host plants for insect colonization and incorporated fine scale plant density $\left(50 \mathrm{~cm}\right.$ radius circle, area $\left.=0.8 \mathrm{~m}^{2}\right)$ and coarse scale plant density $(6 \mathrm{~m}$ quadrat annulus, area $=32 \mathrm{~m}^{2}$ ) as predictors for insect colonization in addition to plant morphology. I surveyed Senecio spp. over a period of three growth seasons and conducted an experiment where I manipulated densities of pairs of species of either introduced Senecio elegans, S. skirrhodon and native S. lautus. My survey of natural populations and the manipulative field experiment show a negative impact of high conspecific and heterospecific plant density on the colonization of the seed head predator fly Sphenella fascigera. Along with plant density, plant size was a significant predictor of insect abundances. Higher densities of introduced S. elegans indirectly facilitated S. lautus at fine spatial scales by reducing the incidence of $S$. fascigera. This supports the resource dilution hypothesis which predicts higher insect herbivore numbers on isolated resource patches. Thus, my results provide empirical evidence for apparent facilitation of a native plant by an introduced plant via a shared herbivore.

For future assessments of the impacts of invasive species it will be important to consider the net-outcome of direct and indirect competitive and facilitative interactions. In particular, for restoration purposes in stressful environments removal of invasive species may have to occur in a carefully controlled manner taking into account the abiotic conditions and spatial scales at which interactions occur. 


\section{ACKNOWLEDGEMENTS}

My thesis is dedicated to my parents and my sister.

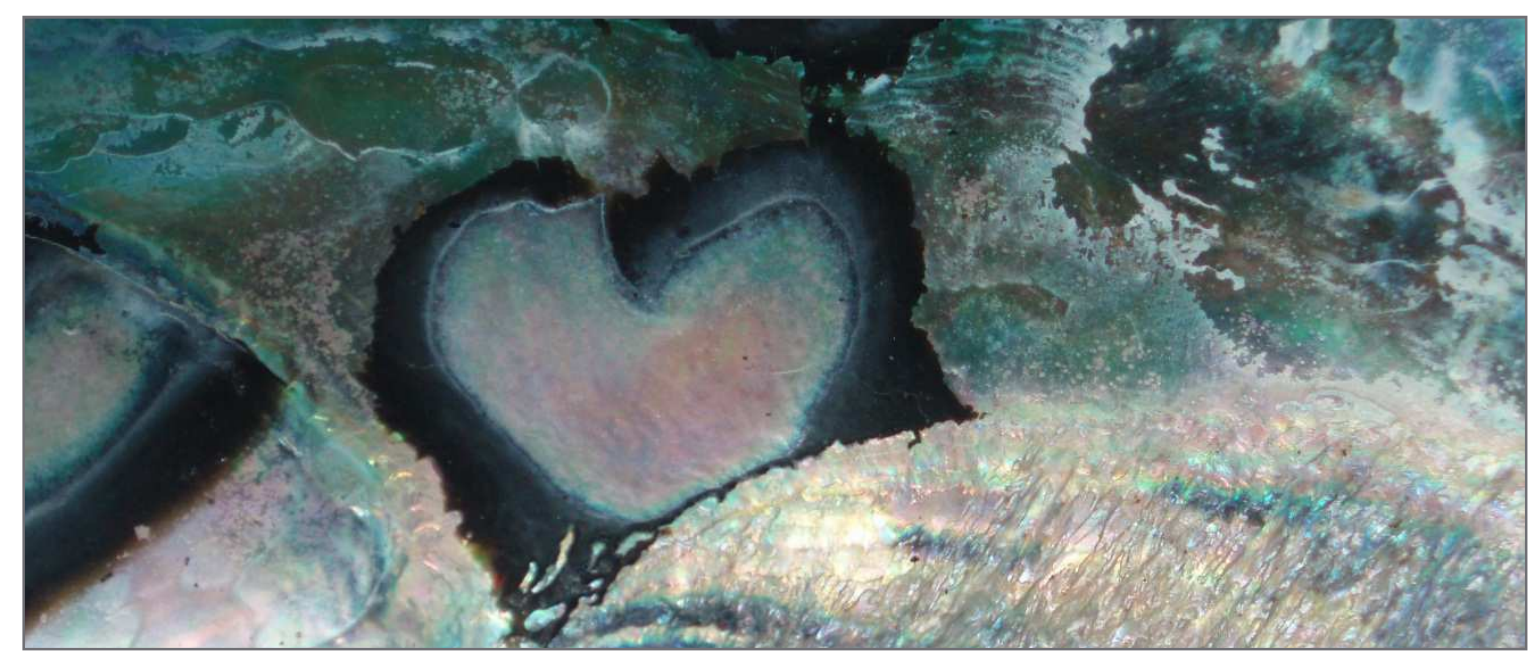

Paua-shell with heart-shaped pattern. 
$\mathrm{A} \mathrm{PhD} \mathrm{is} \mathrm{never} \mathrm{the} \mathrm{endeavour} \mathrm{of} \mathrm{just} \mathrm{the} \mathrm{PhD-student;} \mathrm{there} \mathrm{are} \mathrm{many} \mathrm{different}$ individuals and organisations involved to ensure the success of one's unexpected journey. Unfortunately, it is impossible to include everybody who supported me during my PhD. Therefore, I wish to ask for forgiveness to those who contributed, but are not named individually here; I still would like to thank you for your support.

I based my decision to become a PhD-student at Victoria University of Wellington on my good impression of my primary supervisor Dr Stephen Hartley, who throughout the course of my PhD has by far exceeded my expectations of a supervisor. I am greatly indebted to his continuous support of my research interests. My academic growth greatly benefitted from his vast knowledge of experimental design and his deep understanding of mathematics and statistics. I would like to thank you for your patience and your friendly guidance through this passage of my life. I consider myself lucky to have had the chance to be your PhD-student. I also would like to thank my secondary supervisor Dr David Bergin who shares my passion for coastal areas. He supported me with his extensive experience of dune restoration. I really appreciated your understanding of field work in these very dynamic areas. I very much treasured your encouragement after those stormy sandblasting days in the field and your continuous support of my thesis. I would also like to thank my third supervisor Dr Jon Sullivan for his support with my Senecio spp.-projects. Your knowledge about the taxonomy of Senecio spp. and their herbivores were the foundation for developing my projects. Your enthusiasm for Senecio spp. is admirable and infective.

Before thanking all those brave people who followed me into the field regardless of the weather I would like to thank those who made my PhD financially possible: The NZIDRS which paid for my living costs and my study fees as well as covering part of my conference travel was the foundation of my PhD. I am very thankful that I got awarded this prestigious scholarship for my PhD. Furthermore, I wish to thank Victoria University of Wellington for financial support with the Faculty Strategic Travel Grant and support for my PhD. My experiments would not have been possible without the financial support from the CBRE, the Department of Conservation in Wanganui, the Dunes Trust, Forest and Bird, Quinovic, the Wellington Botanical Society, and the anonymous donor who 
contributed to the plant costs. I would like to thank the Ngati Apa and Ngati Rauruu for their support and allowing me to conduct my experiment on their land. Rob Cross was crucial for getting all the plants for my experiment last minute and therefore I thank him.

My experiments required field work in every kind of weather and included hard manual labour - I wish to thank all my field assistants and all those who helped me with plants in the greenhouse. I especially would like to thank Jim Campbell for allocating his DOC staff to support my project and for his field site suggestions. Without your support and enthusiasm for my dune experiment this project would not have happened. Tai did a great job when he sprayed the marram grass according to my experimental design and I will always remember the fun we shared riding those quad bikes to the sites. I also want to thank Hannah Rainforth who was very dedicated and helpful in the field and without her hard work we probably would have never been able to get all those plants distributed to their final locations. Daniel Hurley was great at providing logistical support. Furthermore, I want to thank Adele Meyer for her help with volunteers and the Wanganui Tramping Club for their great work at Whitiau. I would like to thank Zoé Casini who has been a great help for both projects and has become a good friend. Regardless of the weather she always had a smile on her face and motivated everybody else. You were absolutely awesome in the field and I wish to thank you for all the laughs we shared! I also want to thank Aya Hozumi, Bridget Johnson, Clara Malouines, Clare, Daniel Wehnert, Ellen, Fabian Westermann, Guyo Gufo, Habteab Habtom, Jan Szydlowski, Jordie Mc Donald, Joy Lynn, Laura Kelly, Leighton Thomas, Mikey Wilcox, Mitch, Odis, Peter Kuhnt, Petra, Rafael Barbieri, Rudi Schnitzler, and Sam. I am thankful for the ArcGIS maps provided by Kristina Pettersson. I thank Duncan Wright for comments on my thesis drafts. I thank Fabian Westermann for his help with formatting my thesis.

The Top10 Holiday Park in Wanganui was a great place to come to after a hard day of field work and I thank Andre and Marti for their great hospitality. They made this campground a home away from home and always were up to a little chat with me.

Equipment is a crucial aspect of any research and therefore I wish to thank the producers of my little Olympus camera which despite sandstorms, rain and heat always 
came back to life - Sometimes with a crunchy zoom but in the end it was always good again. What a brave little camera, that has surpassed many others along its journey so far. And it is still going strong!

The staff at the School of Biological Sciences at Victoria University of Wellington has enriched my PhD-experience: I thank Patricia Stein for her great help as administrator and listener to all sorts of queries, Mary Murray for having always a smile and an awesome and helpful attitude, Sandra Taylor and Mark Stephen for doing a great job on a daily basis as well as Paul Marsden who always was helpful when it came to reimbursements etc.. Alan Hovard and Adrian Pike were crucial people to talk to when I needed equipment and their kiwi-engineering helped my experiments greatly. I am also thankful for all the helpful comments on my work by members of the legendary Bug Club.

I also want to thank all my friends, on this and the other side of the globe. Thanks to Sunita Singh Boparoy, Linda Luong, Lilja Sautter, Sharada Paudel, Kristina Pettersson and Helen Taylor for their support within New Zealand and my great friends at home who were always there for me despite the distance: Pia Sternisek and Miriam Pretot for their awesome friendship - Some friendships cannot be parted by physical distance. I also want to thank Kathleen Ehrbar and Lorenz Ehrbar as well as Nicole A. Schneider for their continuous friendship and support.

No acknowledgements are complete without thanking those closest to one: Family. I love my parents and my sister endlessly. I could not ask for better parents. Despite missing me and being scared of letting me go to the other side of the world my parents have unreservedly supported my PhD. I can never make up for all that you have done for me during this journey. You always were there for me, regardless of the time of the day. My sister is one of my closest friends and I thank her for her constant moral support. I therefore dedicate my PhD-thesis to my parents and my sister. 


\section{CONTENTS}

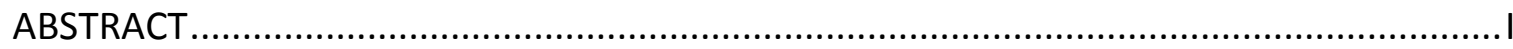

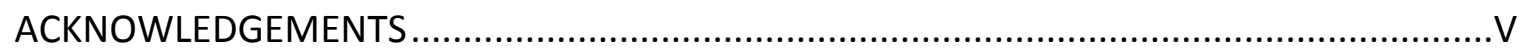

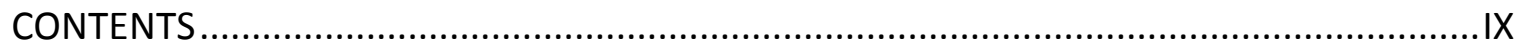

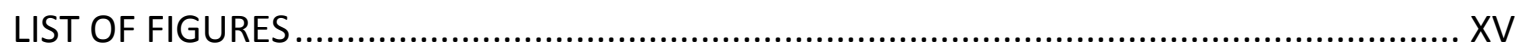

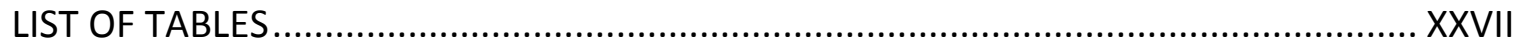

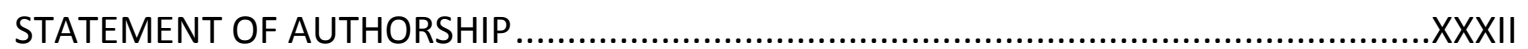

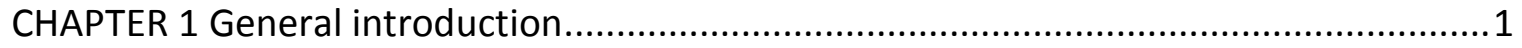

1.1 Competition as a force structuring communities .................................................

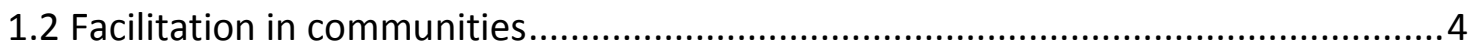

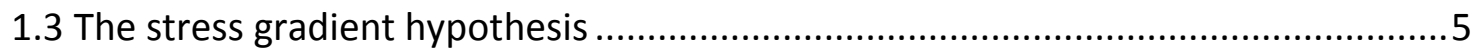

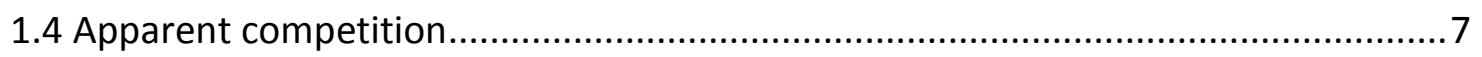

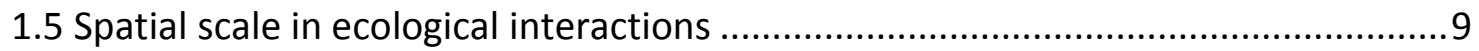

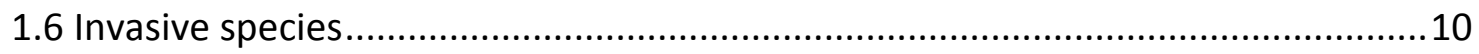

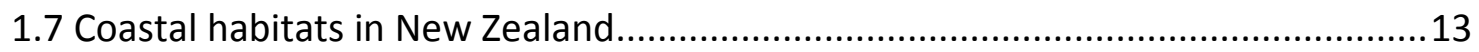

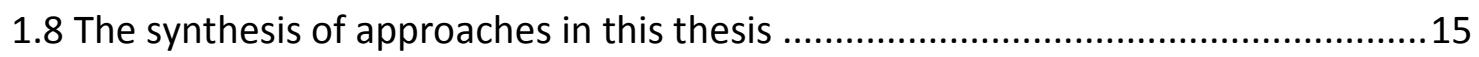

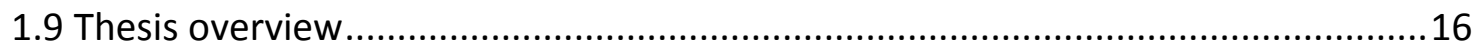

1.9.1 Direct competition versus facilitation along a stress gradient .......................16 
1.9.3 Overall discussion of the PhD-thesis.

1.9.4 Additional chapter .19

CHAPTER 2 The effect of dead and live marram (Ammophila arenaria) on spinifex (Spinifex sericeus) restoration plantings: a test of the stress gradient hypothesis. 21

2.1 Introduction

2.2 Materials and Methods.

2.2.1 Study species.

2.2.2 Field sites 30

2.2.3 Experimental setup 35

2.2.4 Data analysis

2.3 Results .46

2.3.1 Stress gradient measurements

2.3.2 Spinifex measurements .54

2.4 Discussion.

2.4.1 Stress gradient .69

2.4.2 Spinifex measurements

2.4.3 Spinifex growth and the influence of pre-existing marram grass cover .73

2.4.4 Practical relervance for conservation 
CHAPTER 3 Species abundances of self-colonizing native and introduced plants and the role of the stress gradient hypothesis in coastal dune systems.

3.1 Introduction .78

3.2 Materials and Methods.

3.2.1 Study species.

3.2.2 Field sites

3.2.3 Experimental setup

3.2.4 Statistical analysis

3.3 Results .88

3.3.1 Species diversity .88

3.3.2 Species composition .88

3.3.3 Changes in species abundance along an abiotic gradient and in response to existing vegetation structure

3.3.4 Cover changes of functional groups 101

3.3.5 Overview across species and functional groups 107

3.4 Discussion 108

3.5 Conclusions

CHAPTER 4 Senecio spp. food webs in New Zealand 115

4.1 Introduction .116

4.2 Methods 122 
4.2.1 Data collection

4.2.2 Data analysis

4.3 Results .125

4.4 Discussion

4.5 Conclusions 136

CHAPTER 5 The importance of plant morphology and different spatial scales of plant density for plant-insect herbivore host choice and interaction strengths.

5.1 Introduction 138

5.2 Materials and Methods.

5.2.1 Study species.

5.2.2 Study site.

5.2.3 Data collection

5.2.4 Data analysis

5.5 Results 158

5.5.1 Survey of naturally occurring populations.....

5.5.2 Plant density experiment 175

5.5.3 Plant size, plant density and insect herbivore host plant choice 184

5.5.4 Other plant densities and insect herbivore host plant choice 187

5.6. Discussion. 
6.1 Outline of thesis. .198

6.2 Direct competition-vs- facilitation and the stress gradient hypothesis .198

6.3 Indirect competition and the resource dilution hypothesis. 200

6.5 Contribution to current knowledge .204

6.6 Implications for conservation and dune management .205

6.7 Concluding remarks 209

APPENDIX I ADDITIONAL CHAPTER 7. Tri-trophic interactions and the minimal effect of host microsite, plant properties and plant density on parasitism of Sphenella fascigera (Diptera)

Abstract

7.1 Introduction

7.2 Methods and materials

7.4 Results

7.5 Discussion

APPENDIX II 226

APPENDIX III 230

APPENDIX IV 234

APPENDIX V.

REFERENCES .249 


\section{LIST OF FIGURES}

Figure 1.1: Hypothetical apparent competition is shown for two congeneric plants: Plant A has a positive influence (solid pink arrow) on the insect herbivore $(C)$, which has minor negative influences on $A$ as its host, but shows strong negative impacts (solid blue arrow) on B, and thus $B$ is indirectly negatively impacted by $A$ (blue-dotted arrow) and consequently facilitates indirectly (dotted pink arrow) A.

Figure 2.1: Dense stand with flowering marram.

Figure 2.2: Profiles of different sand dunes: $a=$ marram dune, $b=$ spinifex dune, $c=$ pingao dune (Esler 1970), adapted by (Jamieson 2010).

Figure 2.3: Spinifex seedheads and spinifex plants (photo by Stephen Hartley).

Figure 2.4: Both field sites are in relatively close proximity to Wanganui along the south western coast of NZ. Five transects were placed at Tapuarau and six at Whitiau. Data sourced from LINZ, Crown Copyright Reserved. 31

Figure 2.5: Transects $(=\mathrm{T})$ and stations $(=\mathrm{S})$ are displaced for Tapuarau. Sourced from LINZ. Crown Copyright Reserved.

Figure 2.6: Transects (=T) and stations (=S) at Whitiau. Sourced from LINZ Crown Copyright Reserved..... 33

Figure 2.7: Tapuarau: fore dune dominated by marram.

Figure 2.8: Whitiau: mid dune dominated by marram with occassional pingao.......

Figure 2.9: The stress gradient hypothesis is shown within the context of my field experiment setup: "+" indicates an increase in environmental stress (also emphasized by an increasingly red colour). Consequently, "-"indicates lesser stress and would therefore be associated with more competition, if the SGH is true for coastal dunes in New Zealand. The stations displayed represent the stations that were chosen for representing the expected environmental abiotic stress gradient, which is closely tied with the vegetation present as shown in the pictures.

Figure 2.10: Schematic drawing showing one $3 \times 3 \mathrm{~m}$ quadrat plot with the inner $2 \times 2 \mathrm{~m}$ quadrat with 25 plants. 
Figure 2.11: Planting examples at fore dune plots for all treatments at the time of planting in late

September 2011. 37

Figure 2.12: Mean monthly rainfall, minimum and maximum temperature for Wanganui. Graph based on statistics provided by NIWA (2013).

Figure 2.13: Difference between size measurements (width shown as height at the end of the experiment did not vary much due to the species height constraints). With size, plants with few leaves could achieve similar size dimensions as plants with the same width but a lot more leaves. Circumference measured at the bottom of the plants takes this into consideration as well as stolon growth.

Figure 2.14: Dune profiles of transect 1, 3, 4 and 5 at Tapuarau and transect 6, 7, 8 and 10. Red dots above dune profiles indicate approximate station locations.

Figure 2.15: Conductivity $(\mu \mathrm{S} / \mathrm{m})$ as a function of station (from fore dune to back dune) and vegetation cover treatment (Marram or Bare sand). $\mathrm{N}=24$ plots per treatment combination combined across both field sites for marram and bare plots.

Figure 2.16: Organic matter from sand samples from bare sand plots (left graph) and from marram plots (right graph) per station (station 1 = closest to the sea, station 2 = intermediate distance to the sea, station 3 = furthest away from the sea). Samples are split up by field site (upper graph Tapuarau, lower graph Whitiau). Note the difference in scale for the $y$-axis

Figure 2.17: Sand movement for station 1, 2, 3 (from left to right) for each treatment ( $B$ = bare sand, $M=$ marram, S = Sprayed marram) for plots at Tapuarau (upper graph) and Whitiau (lower graph) between February 2012 and November 2012. Movement change is given in \% and comprises planted and unplanted plots.

Figure 2.18: Slope in $\mathrm{cm} / \mathrm{m}$ from the sand plot per station in Nov/Dec 2012 (station 1 = closest to the sea, station 2 = intermediate distance to the sea, station 3 = furthest away from the sea). Samples are split up by field site (upper graph Tapuarau, lower graph Whitiau).

Figure 2.19: Slope in cm/m from the sand plot per station in Nov/Dec 2012 for marram and sprayed plots relative to bare sand. Station 1 = closest to sea, station $2=$ intermediate, station 3 = furthest away from the sea). Slope measurements are from Nov/Dec 2012. Errorbars are +/-SE.

Figure 2.20: Erosion at Whitiau. Picture A shows the first station of transect 6 at Whitiau before winter 2012 and picture B shows the same location after the winter storms in December 2012. Picture C and D show the cliff face of the eroded first station at transect 6 . Picture $E$ and $F$ show a public sign, which was at 
the time of construction clearly above the sand layer. The sand blocking the sign is from a nearby eroding cliff. ........ 53

Figure 2.21: Survival out of the nine inner plants is shown for Tapuarau one month after planting (October 2011), five months after planting (February 2012), nine months after planting (June 2012) and thirteen months after planting (November 2013). The boxplots are split up between the different treatments ( $B=$ bare sand, $M=$ live marram, $\mathrm{S}=$ sprayed marram). Station 1 is closest to the sea (fore dune), station 2 = intermediate distance to the sea (mid-dunes) and station 3 is furthest away from the sea (back-dune)....55

Figure 2.22: Survival out of the nine inner plants is shown for Whitiau one month after planting (October 2011), six months after planting (March 2012), nine months after planting (June 2012) and 14 months after planting (December 2013). The boxplots are split up between the different treatments $(B=$ bare sand, $M=$ live marram, $S=$ sprayed marram). Station 1 is closest to the sea (fore dune), station $2=$ intermediate distance to the sea (mid-dunes) and station 3 is furthest away from the sea (back-dune)....56

Figure 2.23: Shows inner plant survival (out of 9) for live marram and sprayed dead marram plots relative to bare sand. Error bars indicate + /- SE. Station refers to the location in reference to the sea (Station $1=$ closest to sea, station 2 = intermediate, station $3=$ furthest away from the sea). Plant counts are from June 2012, 9 months after planting... 56

Figure 2.24: Photos of typical plots along the three different stations along a transect. First row shows plantings in bare sand (BP), in live marram (MP) and in sprayed marram (SP). The same order of plot treatment is shown for the second station in the second row and the third station in the third row respectively.

Figure 2.25: Log-transformed plant size is shown per station (station 1 = closest to the sea, station $2=$ intermediate distance to the sea, station 3 = furthest away from the sea) for both field sites split up by treatment $(B=$ bare sand, $M=$ live marram, $S=$ sprayed marram).

Figure 2.26: Plant size is shown for marram and sprayed plots relative to bare sand. Station $1=$ closest to sea, station 2 = intermediate, station 3 = furthest away from the sea). Plant size measurements are from November 2012. Error bars indicate + /- SE.

Figure 2.27: Log-circumference of spinifex plants is shown for Tapuarau in (a) February 2012 , (b) November 2012, (c) Whitiau in March 2012 and (d) December 2012 for bare sand, marram and sprayed plots across all stations. Station 1 = closest to sea, station $2=$ intermediate, station 3 = furthest away from sea. 
Figure 2.28: Relative difference for growth (circumference) is plotted for planted marram and planted sprayed plots versus planted bare plots. Error bars show +/- SE. Station 1 = closest to sea, station $2=$ intermediate, station 3 = furthest away from sea.

Figure 2.29: Log-stransformed circumference of spinifex plants in November is shown against initial marram cover in April (when plots were chosen). Graph a) shows values for Tapuarau and b) for Whitiau. All plots are shown.

Figure 2.30: Log (circumference) of planted spinifex versus pre-existing marram grass (April 2011). Spinifex circumference was measured in Nov/Dec 2012 and marram cover in April 2011. Graph a) shows live marram plots for Tapuarau and b) for Whitiau while sprayed marram is shown for Tapuarau in graph c) and Whitiau in graph $\mathrm{d}$ ).

Figure 2.32: Square root transformed counts of stolons of spinifex plants per station is shown for the different treatments (i.e. $B=$ bare sand, $M=$ marram and $S=$ sprayed marram) seperately for Tapuarau (upper graph) and Whitiau (lower graph).

Figure 2.32: Dieback scores ranging from 1 - 3 ( 1 = present, $2=$ medium, $3=$ high $)$ are shown per field site ( $a=$ Tapuarau in Nov'12 and $b=$ Whitiau in Dec'12) per station and treatment $(B=$ bare sand, $M=$ marram, $\mathrm{S}=$ sprayed). 66

Figure 2.33: Relative dieback scores in comparison to bare plots. Graph c shows relative dieback scores +/SE for Tapuarau Nov'12. Graph d shows relative dieback scores +/- SE for Whitiau Dec'12. 66

Figure 3.1: Graph shows principal coordinate analysis of all plants of all plots classified by station (1= closest to the sea, 2 = intermediate distance and 3 = furthest away from the sea) at a) Tapuarau and b) Whitiau.

Figure 3.2: Boxplots show individual counts of Calystegia soldanella (Con sol) for all treatments ( $\mathrm{B}=$ bare sand, $M=$ live marram, $S=$ sprayed marram) for both field sites. Treatments are split up by station (1 = closest to sea, 2 = intermediate and 3 = furthest away).

Figure 3.3: Mean values for relative counts of Calystegia soldanella (Con sol) compared to bare sand (dotted line) are displayed for live marram and sprayed marram plots for both sites. Errorbars = +- SE. ... 89

Figure 3.4: Boxplots show individual counts of $\mathrm{S}$. oleraceus in Nov/Dec 2012 for all treatments $(B=$ bare sand, $M=$ live marram, $S=$ sprayed marram) split up by unplanted plots (only treatment without spinifex plantings upper graph) and planted plots (i.e. planted with spinifex = lower graph). Treatments are split up by station ( 1 = closest to sea, 2 = intermediate and $3=$ furthest away). 91 
Figure 3.5: Mean values for relative counts of $S$. oleraceus compared to bare sand (dotted line) are displayed for live marram and sprayed marram plots for unplanted plots (i.e. no spinifex planted = upper right graph) and planted plots (i.e. planted with spinifex = lower rightgraph. Errorbars = +- SE.

Figure 3.6: Boxplots show individual counts of S. elegans in Nov/Dec 2012 for all treatments $(B=$ bare sand, $M=$ live marram, $S=$ sprayed marram) split up by unplanted plots (only treatment without spinifex plantings left graphs) and planted plots (i.e. planted with spinifex = right graphs). Treatments are split up by station ( $1=$ closest to sea, 2 = intermediate and $3=$ furthest away).

Figure 3.7: Mean values for relative counts of S. elegans compared to bare sand (dotted line) are displayed for marram and sprayed marram plots for Tapuarau (upper graphs) and Whitiau (lower graphs) respectively. Left hand site graphs show plots planted with spinifex and right hand side plots show unplanted plots. Treatments are also split up by station (with $1=$ closest to sea, $2=$ intermediate and $3=$ furthest away). Errorbars $=+-\mathrm{SE}$

Figure 3.8: Boxplots show individual counts of Lagurus ovatus in Nov/Dec 2012 for both field sites for all treatments $(B=$ bare sand, $M=$ live marram, $S=$ sprayed marram). Treatments are split up by station $(1=$ closest to sea, 2 = intermediate and 3 = furthest away).

Figure 3.9: Mean values for relative counts of Lagurus ovatus compared to bare sand (dotted line) are displayed for marram and sprayed marram plots both field sites. Treatments are also split up by station (with 1 = closest to sea, 2 = intermediate and 3 = furthest away). Errorbars = +- SE. 95

Figure 3.10: Boxplots show individual counts of $O$. minor in Nov/Dec 2012 for Whitiau for all treatments (B = bare sand, $\mathrm{M}=$ live marram, $\mathrm{S}=$ sprayed marram). Treatments are split up by station ( 1 = closest to sea, $2=$ intermediate and 3 = furthest away) and whether they are planted or not (lower and upper graph respectively).

Figure 3.11: Mean values for relative counts of $O$. minor compared to bare sand (dotted line) are displayed for marram and sprayed marram plots for Whitiau (right graph) respectively. The upper graph shows unplanted plots, while the lower graph shows planted plots. Errorbars = +- SE.

Figure 3.12: Boxplots show individual counts of C. canadensis in November 2012 both sites for all treatments $(B=$ bare sand, $M=$ live marram, $S=$ sprayed marram). Treatments are split up by station $(1=$ closest to sea, 2 = intermediate and $3=$ furthest away).

Figure 3.13: Mean values for relative counts of $C$. canadensis compared to bare sand (dotted line) are displayed for marram and sprayed marram plots for Whitiau (right graph) respectively. Treatments are also split up by station (with 1 = closest to sea, 2 = intermediate and $3=$ furthest away). Errorbars = +- SE. 
Figure 3.14: Boxplots show individual counts of dandelions in November 2012 for both sites for all treatments $(B=$ bare sand, $M=$ live marram, $S=$ sprayed marram). Treatments are split up by station ( $1=$ closest to sea, 2 = intermediate and 3 = furthest away).

Figure 3.15: Mean values for relative counts of dandelions compared to bare sand (dotted line) are displayed for marram and sprayed marram plots for both sites respectively. Errorbars = +- SE. .99

Figure 3.16: Boxplots show individual counts of legumes in November 2012 for both sites for all treatments $(B=$ bare sand, $M=$ live marram, $S=$ sprayed marram). Treatments are split up by station ( $1=$ closest to sea, 2 = intermediate and 3 = furthest away). The upper graph shows uplanted and planted plots and the lower shows only planted plots.

Figure 3.17: Mean values for relative counts of legumes compared to bare sand (dotted line) are displayed for marram and sprayed marram plots for both sites. Errorbars = +- SE. 101

Figure 3.18: Boxplots show cover in \% for monocots in November 2012 for Tapuarau and Whitiau for all treatments $(B=$ bare sand, $M=$ live marram, $S=$ sprayed marram). Treatments are split up by station ( $1=$ closest to sea, 2 = intermediate and 3 = furthest away).

Figure 3.19: Mean values for relative cover in \% for monocots compared to bare sand (dotted line) are displayed for marram and sprayed marram plots at Tapuarau and Whitiau. Errorbars = +- SE. 103

Figure 3.20: Boxplots show cover in \% for herbs in November 2012 for Tapuarau and Whitiau for all treatments $(B=$ bare sand, $M=$ live marram, $S=$ sprayed marram). Treatments are split up by station ( $1=$ closest to sea, 2 = intermediate and 3 = furthest away). 104

Figure 3.21: Mean values for relative cover in \% for herbs compared to bare sand (dotted line) are displayed for marram and sprayed marram plots for Tapuarau and Whitiau respectively. Errorbars $=+$ +- SE.

Figure 3.22: Boxplots show cover in \% for woody plants in December 2012 for Whitiau for all treatments ( $B$ = bare sand, $M=$ live marram, $S=$ sprayed marram). Treatments are split up by station $(1=$ closest to sea, 2 = intermediate and 3 = furthest away). 106

Figure 3.23: Mean values for relative cover in \% for woody plants compared to bare sand (dotted line) are displayed for marram and sprayed marram plots for Whitiau (right graph) respectively. Treatments are also split up by station (with 1 = closest to sea, 2 = intermediate and 3 = furthest away). 106

Figure 4.1: Single species associations are shown for plant species vs. insect herbivores. Digits after species names indicate plant status: $1=$ endemic, $2=$ native, $3=$ introduced. Where no digit is given, status was 
unclear. Insect herbivores are grouped by order (black box). Associations highlighted with red are based on my own records.

Figure 4.2: Species interactions between Senecio spp. and insect herbivores are shown. Each connection represents a herbivore-Senecio spp association.

Figure 4.3: Frequency of Senecio spp. biostatus for which insects were reported. Each record represents a unique host plant-insect herbivore association. NA = Associations where the Senecio spp. was not identified to species level. 128

Figure 4.4: Frequency of host specificity for which insects were reported: Each record refers to one specific host plant-insect herbivore association.

Figure 4.5: Number of host plants for the top five insect herbivores with more than two host plant Senecio spp. in New Zealand. Herbivore status is given via colour coding: White= endemic and black= exotic. .... 129

Figure 4.6: Number of associations per insect herbivore order reported: Coleoptera, Diptera, Hemiptera, Hymenoptera, Lepidoptera and Nematocera.

Figure 4.7: Frequency of trophic guilds for insect herbivores on Senecio spp.-hosts. Each record represents a unique feeding association.

Figure 5.1: Focal Senecio spp. of this chapter: Senecio sterquilinus, S. lautus, S. skirrhodon, S. elegans, S. vulgaris and S. glastifolius.

Figure 5.2: Map shows field sites for the survey of natural populations around Wellington. Red points = field site. 146

Figure 5.3: Field site location for Senecio spp. experiment. Red= field site area. 147

Figure 5.4: Map shows transect locations of the field experiment. $T=$ transect. Red lines = transects with $S$. lautus versus S. elegans, green lines = transects with S. elegans versus $S$. skirrhodon and blue lines = transects with S. lautus versus S. skirrhodon.

Figure 5.5: Nested quadrat design is shown with the small $2 \mathrm{~m}$ quadrat where 9 plants were selected and Senecio spp. density within a $50 \mathrm{~cm}$ radius circle $\left(\right.$ area $=0.8 \mathrm{~m}^{2}$ ) was measured. The black big quadrat represents the $6 \mathrm{~m}$ quadrat (area of the annulus $=32 \mathrm{~m}^{2}$ ) in which Senecio spp.-plants were only counted but not further measured. 151

Figure 5.6: Subsampling design within a single $2 \times 2 \mathrm{~m}$ quadrat. Letters show $50 \mathrm{~cm}$ subquadrats. Numbers show idealised locations for all nine focal plants and green dots show hypothetical plants of varying sizes. 
Black lines indicate which plant would be a surveyed plant. The red circle shows the $50 \mathrm{~cm}$ radius circle in which all plants were counted $\left(\right.$ area $\left.=0.8 \mathrm{~m}^{2}\right)$.

Figure 5.7: Schematic experimental setup of one transect. Each small yellow square represents one $S$. lautus pot plant, each purple square represents one S. elegans pot plant. A minimum distance of $20 \mathrm{~m}$ was kept between transects. A-F = units of the transect.

Figure 5.8: Quantitative food web of the main insect herbivores found during the survey of natural populations. Each connection line between an herbivore and the Senecio spp. represents the association between the two. The thickness of the line (grey) and the plant species bar (black) are proportional to the number of specimens. The naming of insect herbivores goes from left to the right. Due to space restriction they are placed at varying heights to be included in the graph...

Figure 5.9: Species interaction linkage strengths part 1: (SE $=$ S. elegans with $n=124, \mathrm{SS}=$ S. skirrhodon with $\mathrm{n}=80, \mathrm{SL}=S$. lautus with $\mathrm{n}=618$ and $\mathrm{ST}=S$. sterquilinus with $\mathrm{n}=54)$. X-axis displays the investigated Senecio species, $y$-axis displays the squareroot transformed counts of the insect herbivore per plant unless otherwise given (clockwise: flowers with S. fascigera, stems with S. fascigera, leaves infested with Chromatomyia syngenesiae and leaf roller (lepidopteran larvae)). Blue diamonds = mean values \pm SE....163

Figure 5.10: Species interaction linkage strengths part 2: $\mathrm{x}$-axis displays the investigated Senecio species (SE $=$ S. elegans with $\mathrm{n}=124, \mathrm{SS}=$ S. skirrhodon with $\mathrm{n}=80, \mathrm{SL}=\mathrm{S}$. lautus with $\mathrm{n}=618$ and $\mathrm{ST}=\mathrm{S}$. sterquilinus with $\mathrm{n}=54), \mathrm{y}$-axis displays the squareroot transformed individual counts of the insect herbivore (clockwise: Cecidomyiid larvae, lepidopteran larvae, stems with Patagonoides farinaria (Lepidoptera), and all other larvae). Blue diamonds $=$ mean values $\pm \mathrm{SE}$.

Figure 5.11: Sphenella fascigera infestations are shown for: (a) Senecio lautus flowers,(b) S. elegans flowers,(c) S. lautus stems and (d) S. elegans stems against log transformed plant size. Data points have been "jittered" to reduce overlap and improve visualisation of the trend...... 167

Figure 5.12: Sphenella fascigera infestations on stems and flower heads of $S$. lautus with S. lautus densities within $50 \mathrm{~cm}$ (area $=0.8 \mathrm{~m}^{2}$ ) and $6 \mathrm{~m}\left(\right.$ area $=32 \mathrm{~m}^{2}$ ) around the focal plant. The fitted line shows the simple linear model of S. fascigera as the response variable with the associated density count as the only predictor. Solid lines show a significant relationship in the simple linear model, dashed lines show that the predictor was not significant. 169

Figure 5.13: Sphenella fascigera infestations on stems and flower heads of S. elegans with S. elegans densities within $50 \mathrm{~cm}\left(\right.$ area $\left.=0.8 \mathrm{~m}^{2}\right)$ and $6 \mathrm{~m}\left(\right.$ area $\left.=32 \mathrm{~m}^{2}\right)$ around the focal plant. The fitted line shows the simple linear model of S. fascigera as the response variable with neighbourhood density counts as the only predictor. 170 
Figure 5.14: Incidence of Sphenella fascigera in stems and flower heads of S. lautus, as a function of S. elegans density at two different scales. Fine scale $=$ number of plants within $50 \mathrm{~cm}\left(\right.$ area $\left.=0.8 \mathrm{~m}^{2}\right)$, coarsescale $=$ number of plants within $6 \mathrm{~m}$ around the focal plant $\left(\right.$ area $\left.=32 \mathrm{~m}^{2}\right)$. The fitted line shows the simple linear model of S. fascigera as the response variable with the associated density count as the only predictor. Lines show a significant relationship in the simple linear model, dashed lines show that the predictor was not significant. 171

Figure 5.15: Incidence of Sphenella fascigera in stems and flower heads of S. elegans, as a function of S. lautus density at two different scales. Fine scale = number of plants within $50 \mathrm{~cm}\left(\right.$ area $\left.=0.8 \mathrm{~m}^{2}\right)$, coarsescale $=$ number of plants within $6 \mathrm{~m}$ around the focal plant $\left(\right.$ area $\left.=32 \mathrm{~m}^{2}\right)$. The fitted line shows the simple linear model of S. fascigera as response variable with the associated density count as the only predictor. Lines show a significant relationship in the simple linear model, dashed lines show that the predictor was not significant.

Figure 5.16: Patagoniodes farinaria counts per S. lautus plant and the interaction with fine scale conspecific $\left(\mathrm{SL}=\right.$ S. lautus) and heterospecific (SE $=$ S. elegans) plant counts on fine $\left(\mathrm{area}=0.8 \mathrm{~m}^{2}\right)$ and coarse scale $\left(\right.$ area $\left.=32 \mathrm{~m}^{2}\right)$. Lines show a significant relationship in the simple linear model.

Figure 5.17: Quantitative food web showing the observed interactions of both monitoring rounds of the experiment. 176

Figure 5.18: Species interaction linkage strengths: $x$-axis displays first monitoring round on Senecio spp.transects ( $\mathrm{SE}=\mathrm{S}$. elegans, $\mathrm{SS}=\mathrm{S}$. skirrhodon, $\mathrm{SL}=\mathrm{S}$. lautus), $\mathrm{y}$-axis displays the squareroot transformed individual counts of the insect herbivore (clockwise: Chromatomyia syngenesiae, leaf rollers, lepidopteran larvae and aphids. Blue diamonds = mean values \pm SE). 178

Figure 5.19: Species interaction linkage strengths: $x$-axis displays second monitoring round on Senecio spp.-transects ( $\mathrm{S} E=S$. elegans, $\mathrm{SS}=\mathrm{S}$. skirrhodon, $\mathrm{SL}=\mathrm{S}$. lautus), $\mathrm{y}$-axis displays the sqrt-transformed individual counts of the insect herbivore (clockwise: Chromatomyia syngenesiae, leaf rollers, lepidopteran, aphids, flowers with S. fascigera and stems with S. fascigera. Blue diamonds = mean values $\pm \mathrm{SE}$ ).

Figure 5.20a-c: Chromatogmyia syngenesiae (sqrt-transformed) and plant size (log-transformed) from the first monitoring round (one month after planting). The fitted line shows the simple linear model of Chromatogmyia syngenesiae as the response variable with the associated density count as the only predictor. Solid lines show a significant relationship in the simple linear model, dashed lines show that the predictor was not significant.

Figure 5.21 a-c: Second repetition (monitoring after 2months): Sphenella fascigera in flowers and plant size of S. lautus, S. elegans and S. skirrhodon. The fitted line shows the simple linear model of Sphenella fascigera in flowers as the response variable with the associated density count as the only predictor. Solid 
lines show a significant relationship in the simple linear model, dashed lines show that the predictor was not significant.

Figure 5.22: Feeding damage (upper graph), plant stress (discolouration of leaves) and leaves with fungi out of 10 leaves are shown per Senecio species.

Figure 5.23a-c: C. syngenesiae in flowers and plant counts of S. lautus, S. elegans and S. skirrhodon for dataset one month after planting. The fitted line shows the simple linear model of $C$. syngenesiae as the response variable with the associated conspecific and congeneric (= heterospecific) density (includes all other Senecio spp. other than focal plant count as the only predictor). Solid lines show a significant relationship in the simple linear model, dashed lines show that the predictor was not significant. 185

Figure 5.24: Second repetition (monitoring after 2 months): Sphenella fascigera in flowers of S. lautus and conspecific density of S. lautus (left) and congeneric density of S. elegans (right). The fitted line shows the simple linear model of Sphenella fascigera in flowers as the response variable with the associated density count as the only predictor. Solid lines show a significant relationship in the simple linear model, dashed lines show that the predictor was not significant. 186

Figure 5.25 a-c: $C$. syngenesiae in flowers and plant counts of S. lautus for the first repetition. The fitted line shows the simple linear model of $C$. syngenesiae as the response variable with the associated density of small Asteraceae, large Asteraceae, small other plants and large other plants. Solide lines show a significant relationship in the simple linear model, dashed lines show that the predictor was not significant.

Figure 5.26 a-c: Sphenella fascigera in flowers and plant counts of S. lautus for the second repetition. The fitted line shows the simple linear model of $S$. fascigera as the response variable with the associated density of small Asteraceae, large Asteraceae, small other plants and large other plants. Solid lines show a significant relationship in the simple linear model, dashed lines show that the predictor was not significant.

Figure 5.27: Possible direct competition between S. elegans (bottom left, middle and upper right) and $S$. lautus (only middle).

Figure 6.1: Interactions of my research: Blue arrows = negative direct interaction, red arrows = positive direct interaction, blue dashed arrow = indirect negative interaction, red dashed arrow = indirect positive interaction. Interactions that were not researched, but are assumed are not shown in the graph. Other abiotic factors were not incorporated in my study (except for browsing monitoring), but are probably exhibiting both direct and indirect effects on coastal sand dune communities. 
Figure 6.2: Recommendations for spinifex restoration planting depending on local site conditions.

Based on Chapter $2 \& 3$ as well as on consultations with restoration stakeholders.

Fig. A I.1: Map showing the locations of the natural S. lautus populations sampled in this study (black points). Grey points mark urban areas. 218

Figure A II.1: Pingao at Tapuarau (Photo by Stephen Hartley). 226

Figure A II.2: Initial spinifex height in $\mathrm{cm}$ and the length of the longest leaf in $\mathrm{cm}$ are split up between different nurseries. Kitahii nursery plants are from the local iwi nursery and the Naturally Native nursery plants are grown commercially. T-test for height: $t=-17.9102, \mathrm{df}=16.927, \mathrm{p}$-value $=1.946 \mathrm{e}-12$. T-test for longest leaf: $t=-10.4604, d f=17.005, p$-value $=7.948 e-09$. 227

Figure A II.3: PCOA of conductivity, organic matter and sand movment at Whitiau (left graph) and Tapuarau (right graph).

Figure A V.5: Correlation between predictors of the LME: size (plant size), fine scale SL, fine scale SE, coarse scale SE and coarse scale SL are shown as correlation graphs. SL = Senecio lautus, $\mathrm{SE}=$ Senecio elegans.

Figure A V.1: Senecio elegans: a) typical plant, b) leaves = lobbed like S. lautus (hybrid?), c = flower in typical pink and in light purple, $d=$ unusual leaf, resembles more S. lautus than S. elegans, but flower (edge of photo) is purple, albeit a bit smaller than the average $S$. elegans flower, e= small flower of typical colouring and large flower in pale rose, almost white. .....

Figure A V.2: Senecio lautus: a) development of heteroblastic leaves, b) deeply lobbed leaves (origin Petone), c) rayless form, d) dissected flower head. 244

Figure A V.3: Senecio skirrhodon: a) unlobbed leaves, b) leaves = heteroblastic/lobbed, c = typical flower, $d$ = dissected flower head.

Figure A V.4: Senecio sterquilinus: a) S. sterquilinus on Matiu/Somes Island, b) deeply lobbed leaves (origin Petone), c) hybrid between S. sterquilinus and S. lautus (less than 20 rayflorets), d) Mature S. sterquilinus, finished flowering. 246

Figure A V.5: Insects: a) Melanagromyza senecionella, b) Cecimidoyiid larvae, c) Pteromalus sp., d) Nyctemera annulata caterpillar, e) Mating Sphenella fascigera, f) leafminer trace (Chromatomya syngenesiae) 


\section{LIST OF TABLES}

Table 2.1: List of plot-level treatments (six plots per station) and associated abbreviations.

Table 2.2: Monitoring schedule for Whitiau and Tapuarau. Monitoring times are given for spinifex plant survival, spinifex plant growth, sand burial, vegetation cover, plant counts, dune profiling, soil samples and wind measurements. $X$ = was measured, - = not measured.

Table 2.3: Models used in this chapter. LME= linear mixed effect model, GLMER= generalized linear mixedeffects Models. T and W indicate the field sites Tapuarau and Whitiau respectively where the models were used separately for each field site.

Table 2.4: Summary of a LME for conductivity (data from both field sites combined). The two levels of treatment were marram and bare sand. Transect was included as a random effect.

Table 2.5: Summary of LME for organic matter in \% (data separated by field site). Transect was included as a random effect.

Table 2.6: Summary of a LME with sand movement change in \% between February 2012 and November 2012. Transect was included as a random factor. Both planted and unplanted plots were used for this LME. Treatment had six levels (i.e. planted marram, unplanted marram, planted sprayed marram and unplanted sprayed marram, planted bare sand and unplanted bare sand).

Table 2.7: Summary of LME for slope in $\mathrm{cm}$ (data from both field sites combined). Transect was included as a random effect.

Table 2.8: Summary of LME for June inner plant survival (data from both field sites combined). Transect and plot ID were included as random effects.

Table 2.9: Summary of a GLMER for log-transformed plant size (data from both field sites combined). Transect and plot ID were included as random factors, and a poisson distribution of errors was assumed.

Table 2.10: ANOVA summary of a LME for log-transformed breadth in $\mathrm{cm}$ (data analysed separately per field site). Transect and plot ID were included as random effects.

Table 2.11: Summary of a LME for stolon counts Nov/Dec 2012. Transect and plot ID were included as random effects. 
Table 2.12: Summary of a LME for dieback scores in Nov/Dec 2012. Transect and plot ID were used as random effects 65

Table 2.13: Insect damage is shown with insect damage scores ( $1=$ present, 2 = medium, 3 =high) for both field sites (Tapuarau and Whitiau) separated by station and treatment.

Table 2.14: An overview of all model results used for stress gradient measurements.

Table 2.15: An overview of all model results used for spinifex measurements. Table 2.3 on page 50 shows the detailed model terms.

Table 3.1: Overview over all LMEs applied.

Table 3.2: Summary of a linear mixed effect model for abundance of Calystegia soldanella (data from both field sites combined). Transect was included as a random effect.

Table 3.3: Summary of a linear mixed effect model for abundance of Sonchus oleraceus (data from both field sites combined). Transect was included as a random effect.

Table 3.4: Summary of a linear mixed effect model for abundance of Senecio elegans (data were analysed separately per field site). Transect was included as a random effect.

Table 3.5: Summary of a linear mixed effect model for abundance of Lagurus ovatus (data from both field sites combined). Transect was included as a random effect.

Table 3.6: Linear mixed effect model anova values for $O$. minor at Whitiau. Transect was included as random effect.

Table 3.7: Linear mixed effect model for Conyza canadensis (data from both sites is combined) Transect was included as random effect.

Table 3.8: Linear mixed effect model summary for dandelion individual counts (data from both field sites was combined). Transect was included as a random effect.

Table 3.9: Linear mixed effect summary for legumes (data from both sites was combined). Transect was included as a random effect.

Table 3.10: Linear mixed effect model summary for monocot cover (data from each field site was analysed separately). Transect was included as a random effect. 
Table 3.11: Linear mixed effect model anova values for herb cover in \% as response variable and field site, planted as well as treatment, station the interaction between planted and station and the interaction between treatment and station were used as predictors. The dataset from each field site was used separately as field site was a significant factor in the selection model. Transect was used as random effect.

Table 3.12: Linear mixed effect model anova values for woody plant cover at Whitiau in \% as response variable and planted (i.e. planted or unplanted with spinifex) as well as treatment, station the interaction between planted and station and the interaction between treatment and station were used as predictors. Transect was used as random effect. 106

Table 3.13: Overview over LMEs per response variable. Significance values: $+=0.1>P>0.05, *=p<0.05$, $* *=p<0.01, * * *=p<0.001, n s=$ non-significant $(P>0.1), N A=$ not applciable as field sites tested separately. 107

Table 4.1: Databases searched for records of insect feeding associations with Senecio species in New Zealand.

Table 4.1: Cross tabulation of associations for plant status and feeding type of insect herbivore. Rows represent Senecio spp. biogeographic status and columns the specificity of the insect herbivore feeding relationships. Fisher's exact test: $\mathrm{p}=0.861$.

Table 4.2: Frequency of records between plants and insect herbivores in relation to their biogeographic status. Fisher's exact test:p-value $=0.391$.

Table 5.1: Plant combinations of units.

Table 5.2: Explanation of variables used in the linear models. All variables are continuous. Insect herbivore (IH) was used as dependent variable. .156

Table 5.3: Model variables used for LMEs of the experiment. First repetition = one month after planting, second monitoring was two months after planting. Insect herbivore was the dependent variable.

Table 5.4: Associations between insect herbivores and occasional incidental records of insect herbivore parasitoids are shown for all Senecio spp. investigated $(\mathrm{SL}=$ S. lautus, ST=S. sterquilinus, $\mathrm{SE}=$ S. elegans, SS $=S$. skirrhodon, SV = S. vulgaris). Senecio glastifolius is not extra listed, but only $N$. annulata specimens were found on it during the survey of natural populations. For S. angulatus only plant hoppers were recorded (Hemiptera). Numbers indicate relative abundance $(0=$ not found, $1=$ occasionally found, $2=$ common, 3 = abundant). If there was only one record per insect herbivore this is noted with $x$. Question marks were used to indicate that there is no information available for this species in that cell. 
Table 5.5: Results of a Kruskal-Wallis rank sum test, testing the null hypothesis that insect herbivores are equally prevalent across the four Senecio species. 162

Table 5.6: Anova summary for the complete LME for S. fascigera (sqrt-transformed) as response variable in flower heads of S. lautus (SL). Site, quadrat and subquadrat were included as nested random effects.168

Table 5.7: Anova summary for the complete LME for S. fascigera (sqrt-transformed) as response variable in stems of S. lautus (SL). Site, quadrat and subquadrat were included as nested random effects. 168

Table 5.7: Anova summary for the complete LME for S. fascigera (sqrt-transformed) as response variable in stems of S. lautus. Site, quadrat and subquadrat were included as nested random effects. 174

Table 5.8: Kruskal-Wallis rank sum test for numbers of insect herbivores vs. Senecio species on the first monitoring round (one month after planting).

Table 5.9: Kruskal-Wallis rank sum test for insect herbivores vs. Senecio species on the second monitoring round in January.

Table 5.10: Kruskal Wallis rank sum test for feeding damage, health stress and fungi infestation out of 10 leaves.

Table 5.11: Anova summary for the complete LME for $C$. syngenesiae (doublesqrt-transformed) as the response variable in stems of $S$. elegans. Transect and units were included as nested random effects. Congeneric density refers to S. skirrhodon and S. lautus counts (log-transformed). 184

Table A I.1: Summary statistics of fly and parasitoid incidence by site.

Table A I.2: Rate of parasitism depending on the location of the pupa in the stem or flowerhead of the plant.

Table A I.3: Results of a multi-variable (stepwise deletion) minimum adequate model and single-variable linear models for parasitism rate of $S$. fascigera by Pteromalus sp. NA = single value beta coefficients are not applicable for multi-level factors. NS = not significant, $\cdot=$ marginal significance when: $0.05<\mathrm{P}$-value $<$ 0.1 .

Table A III.1: Plant species used for the PcoA for Whitiau and Tapuarau. Only presence and absence data was used in the PcoA (yes=present, no=absent). 
Table A III.2: Complete species list of all plants recorded at Whitiau and Tapuarau. * $=$ rare, $1=$ station 1,2 = station 2, $3=$ station 3 .

Table A IV.1a: Senecio spp. and their biostatus; origin; year of introduction or first record; geographic range within NZ, and habitat. Introduced species are marked with an asterisk and natives are emphasised with bold font.

Table A IV.1b: Senecio spp. and their biostatus; origin; year of introduction or first record; geographic range within NZ, and habitat. Introduced species are marked with an asterisk and natives are emphasised with bold font.

Table A IV.1c: Senecio spp. and their biostatus; origin; year of introduction or first record; geographic range within NZ, and habitat. Introduced species are marked with an asterisk and natives are emphasised with bold font.

Table A V.1: Correlation coefficients of predictors used in the LME for Sphenella fascigera in stems and flower heads. 242 


\section{STATEMENT OF AUTHORSHIP}

I hereby declare that this thesis is my own work and that to the best of my knowledge and belief, it neither contains material previously published or written by another person nor material which to a substantial extent has been accepted for the award of any other degree or diploma of the university or other institutes of higher learning, except where due to acknowledgement it has been made clear in the text.

Clara Malouines, a summer intern conducted the field work for the additional Chapter 7 in the Appendix under Stephen Hartley's and my supervision. However, I have written Chapter 7. It is intended as a manuscript for submission to a journal. Clara will be a coauthor for that paper. Therefore Chapter 7 is written in the first person plural.

Susanne Krejcek 


\title{
CHAPTER 1
}

\author{
General introduction
}

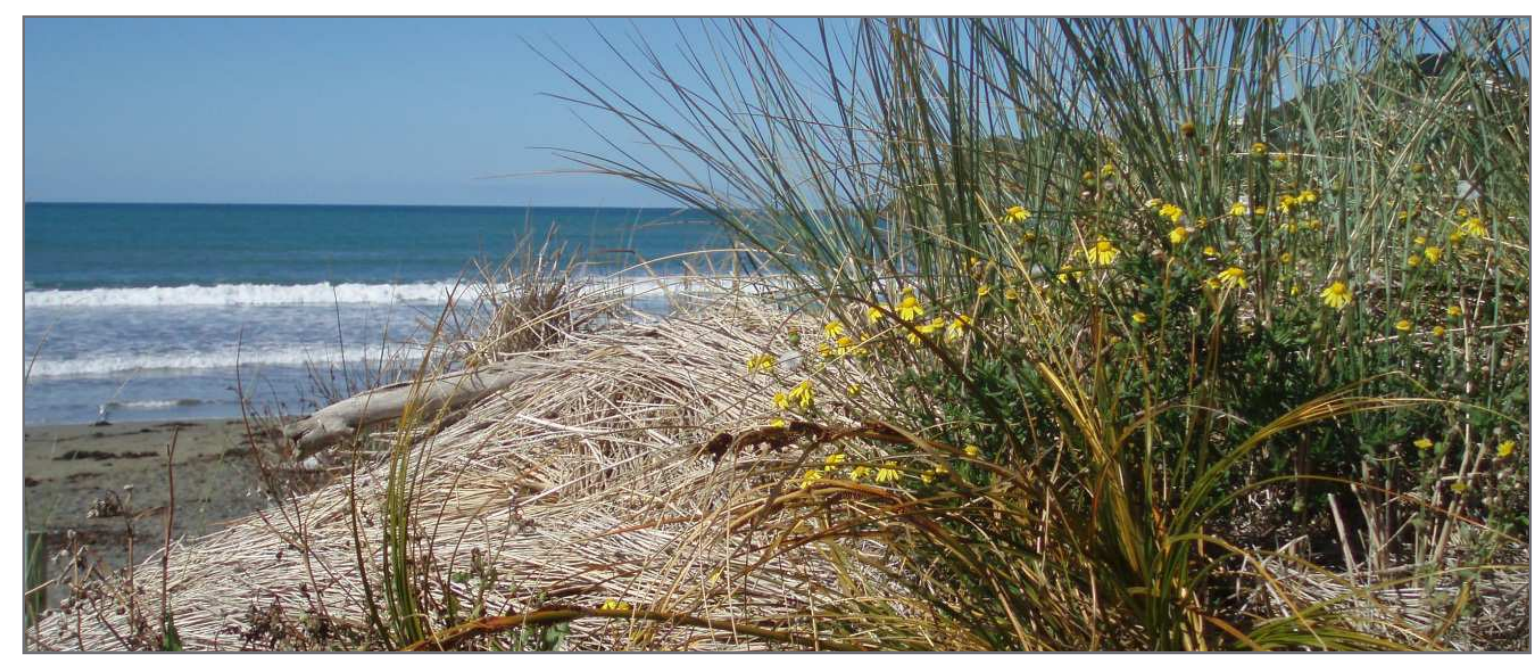

Dead and live marram grass as well as pingao and Senecio skirrhodon at Lyall Bay/Wellington. 


\subsection{Competition as a force structuring communities}

One of the major goals within ecology is to identify and understand how members of a community are structured and interact, more specifically to identify and explain the occurring patterns. Darwin recognized the importance of competition when he wrote the 'Origin of species' and 'the survival of the fittest' (Darwin 1859). Competition is probably the most important structuring force in nature that we know of, driving adaptation by competitive exclusion and ultimately evolution within and between species (Martin and Harding 1981).

Ecological theory acknowledges several different types of competition. Competition can be divided by species identity and then further by the mechanism of competition. Individuals can compete with each others of their own species (intraspecific competition) or against individuals of other species (interspecific competition). Intraspecific competition includes for example, paternal plants that compete with their offspring for resources as is the case for forest trees with low dispersal rates (Duncan 1991); individuals that compete for mates such as male deer defending territory for females (Clutton-Brock et al. 1988); chicks within the nest competing for food from their parents (Kacelnik et al. 1995); and where there is a limited food source within a defined territory (Assem 1967). Examples of interspecific competition include for example, competition for the same food source as e.g. Hawaiian forest birds compete for insects (Mountainspring and Scott 1985) and competition between blue tits (Parus caeruleus) and great tits (Parus major) (Minot 1981). This interspecific competitive interaction is particularly common between native and introduced species (Mountainspring and Scott 1985).

My thesis focusses on competition between species, i.e. interspecific competition. Directly competing species contest with one another for resources. Examples of resource competition are evident in all ecosystems and can be further separated into exploitative competition for resources and interference competition. Exploitative competitions is defined as a type of competition where one individual has a negative effect on the fitness of another individual because it exploits or depletes a resource that the other individual would otherwise use: e.g. plants compete for light with prominent examples such as trees growing to enormous heights (50 m or more) to be the first to 
intercept light allowing this plant to increase photosynthesis rates due crowns exposed to sunlight above the surrounding forest canopy (e.g. in New Zealand emergent trees such as the indigenous rimu (Dacrydium cupressinum) (Norton et al. 1988) and kauri (Agathis australis) (Ahmed and Ogden 1987)). However, Jones and Callaway (2007) stated that they believe that competition between plants for abiotic resources cannot be called direct competition as no material or information is directly transferred from one species to the other. Instead competition for abiotic resources between plants is to them the sum of direct effects of the target species on to the resource pool. Exploitation competition (Brown et al. 1979) may occur without two individuals ever coming into direct physical contact with one another, because it is mediated via access to a common resource pool.

In contrast to exploitation competition, active involvement of one competitor is required for interference competition. For plants this may occur via plant volatiles or via allolopathy where one plant species has a negative effect over another species due to its chemical warfare. Walnut trees (Juglans spp.) are a typical example: growth underneath walnut trees is very sparse compared to undergrowth under different tree species, hence shading is only a partial explanation. Walnut trees produce juglone, a chemical compound stored in the leaves but released and activated via soil organisms which prevents seedling establishment in the vicinity of the parent tree (Terzi 2008). Centaurea maculosa, (spotted knapweed) releases toxins that stunt plant growth in close proximity. The allelochemicals ((-)-catechin) of spotted knapweed gives it a competitive advantage over native plants in its introduced ranges (e.g. North America), while as in its home ranges some neighbouring species developed an immunity and unlike unadapted plants they do not suffer from acidification of their cytoplasma due to the knapweeds' chemical warfare (Weir et al. 2003). Interference competition can be expressed via behavioural competition in animals, (e.g. fights). Similar to plants, animals also compete for space e.g. for territories: predators defend territories as the first step toward ensuring access to more ultimate resources such as prey (e.g. Short-eared owls (Asio flammeus) and wolves (Canus vulpus) (Rich et al. 2012)). Competition between animals for food can be dependent on hunting behaviour but also on physical features such as body size - Cheetahs are very successful hunters, but due to their light weight, (an 
adaptation for high-speed running), they lose some of their prey to lions and other bigger predators as they are inferior competitors in a direct fight with them (Hayward et al. 2006). Competition for shelter follows a similar pattern as competition for territory e.g. the introduced North American crayfish (Pacifastacus leniusculus) competes with native crayfish (Astacus astacus) and (Austropotamobius pallipes) in Europe (Vorburger and Ribi 1999). Nguyen-Ngoc et al. (2012) showed that plants which have an equal amount of chemical warfare and adaptation to their environment often succeed over the competing species via their dispersal mechanism (e.g. the species with better dispersal rates is able to colonize a free space quicker and more comprehensively and therefore is able to secure this spot). The various types of competition are the drivers of niche theory, where different competitive abilities of a species define its ecological niche (Case and Gilpin 1974).

\subsection{Facilitation in communities}

Competitive interactions between organisms can vary according to a range of factors such as availability of resources and type of environment (Davis 2011). In favourable environments, competition between and within species can be a major driving force (Brooker 2006, Eränen and Kozlov 2008). However, in physically stressful environments, the presence of one individual may in fact be beneficial to at least one if not all other participants, referred to as facilitation (Bertness and Callaway 1994). In contrast to the negative interactions of competition, facilitation focusses on the positive interactions of species (Bruno et al. 2003). Facilitation has received less attention in the scientific literature than competition (McIntire and Fajardo 2013).

Stressful environments can only be colonised by pioneer species which are fully adapted and/or tolerant to the harsh conditions of that particular habitat (Parolin et al. 2002). Often the first colonizers ameliorate local site factors such as providing shelter on exposed sites to allow other species to become established (Franks 2003). The classic 'nurse plant effect' was first recognized by Shreve (1931), who found evidence for large desert trees supporting the establishment of small seedlings of other species, nearby. Another example occurs in intertidal zones where Spartina alterniflora alters habitat 
conditions so that other species can establish (Bruno 2000). In New Zealand, pioneer species such as manuka (Leptospermum scoparium) and kanuka (Kunzea ericoides) provide shade and shelter for a host of later successional tree species such as as kauri, rimu, tawa and kohekohe that benefit from shelter provided on open sites (Allen and Partridge 1992). There are even cases where introduced species such as gorse (Ulex europaeus) which are a major plant pest in many areas of New Zealand (Hill et al. 2000), can be effective nurse covers for eventual establishment of indigenous forest species, albeit the species composition differs compared to native facilitators (Sullivan et al. 2007). Hence, where stress is most severe, facilitative interactions are more common than competitive interactions.

\subsection{The stress gradient hypothesis}

The idea that the environment can determine the balance between competition verses facilitation was first identified by Bertness and Callaway (1994) who consequently formulated the 'stress gradient hypothesis' (SGH hereafter). Their hypothesis predicts that along an abiotic stress gradient facilitative interactions will be most common where stress is severe and more competitive interactions will occur where abiotic stress lessens. The SGH has been tested for a range of different ecosystems: e.g. Armas et al. (2011) found support for the SGH in arid areas of the Iberian Peninsula for facilitation by the shrub Retama sphaerocarpa, Eränen and Kozlov (2008) for Betula pubescens subsp. czerepanovii on the Kola Peninsula in north-western Russia and Poulter et al. (2008) found support for the hypothesis in examining the interaction between sawgrass (Cladium jamaicense) and coastal trees in Japan. Although the SGH has been supported by a range of studies, evidence in its favour is not universal, and debate is on-going about what species should be included and what general conclusions can be drawn (Maestre et al. 2005, 2006, 2009, Lortie and Callaway 2006, Brooker et al. 2007).

One of the practical questions within plant-community research is: How should competition be measured? Is it survival? Early authors believed that competing species will either eventually adapt to the situation or one will die out (Jaeger 1970). Maestre et al. (2009) refined the SGH by proposing that the situation is likely to be more complex 
when the stronger competitor (under "good" conditions) is kept below full dominance where stress is severe, thus allowing for a positive interaction that is only existing because of the stress. Depending on species identity and adaptation to the abiotic conditions along a stress gradient, survival might not be a good indicator, as plants may persist, but are not necessarily thriving compared to other species. Hence, biomass (to account for growth) has been suggested as a better indicator of plant performance (Maltez-Mouro et al. 2010). Plant size as the result of growth has also been acknowledged as an important result of competitive ability (Picoli et al. 2012). In addition, the importance of specific species' traits (i.e. their adaptation to a certain stressor) can be important factors when evaluating the interactions between different community members (van Veen et al. 2006). Furthermore, it has been argued that facilitative interactions might only occur where stress is not above a certain species specific threshold and thus at the most stressful ends of the stress gradient growth may not be possible at all and hence facilitation will also be absent (Malkinson and Tielbörger 2010). When studying the SGH it is recommended to research community interactions along the full extent of the stress gradient (Maestre et al. 2009, Maltez-Mouro et al. 2010).

Recent studies have examined the influence of specific species and their ability to cope with altered abiotic conditions especially in combination with invading species. Mason et al. (2012) researched the competitive effects of native plant species versus the introduced bitou (Chrysanthemoides monilifera subsp. rotundata) in the face of water shortage in a coastal ecosystem in New South Wales, Australia, and found evidence for increased competitive ability of the invader under stressful situations. Santoro et al. (2012) were able to show that invasive species can skew patterns of zonation predicted by the SGH and a random distribution can occur if the ecosystem is altered too fundamentally as natural zonation is changed and species occur random. The measured spatial extent of the abiotic stress gradient determines whether or not the species identity dependent interactions are identified (Forey et al. 2009, Maltez-Mouro et al. 2010). 


\subsection{Apparent competition}

While direct competition is widely acknowledged, apparent competition is a less documented phenomenon (Menge 1995). Apparent competition is indirect competition between two species on the same trophic level that is mediated by interactions with a shared host or enemy on a different trophic level (Holt 1977). For example, the presence of the plant A might increase the abundance of the insect herbivore (C) which spills over and has a detrimental effect on the plant species B as shown in Fig. 1.1:

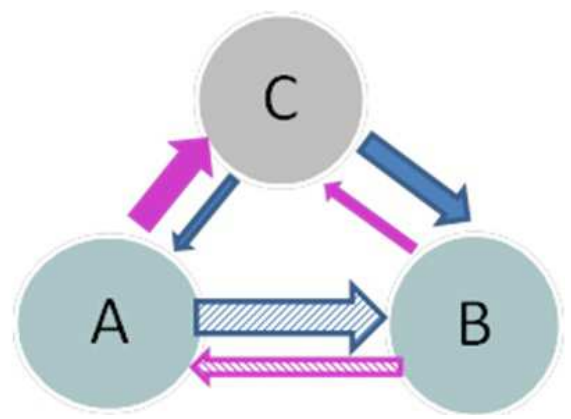

Figure 1.1: Hypothetical apparent competition is shown for two congeneric plants: Plant A has a positive influence (solid pink arrow) on the insect herbivore (C), which has minor negative influences on $A$ as its host, but shows strong negative impacts (solid blue arrow) on B, and thus $B$ is indirectly negatively impacted by A (blue-dotted arrow) and consequently facilitates indirectly (dotted pink arrow) A.

Albeit still underrepresented in current research, apparent competition has been widely accepted as a mechanism in nature (e.g. Noonburg and Byers 2005) and has been demonstrated for different ecosystems (e.g. Settle and Wilson 1990). For example, Morris et al. (2004) describe how competition between different types of leafhoppers are mediated via a shared parasitoid. In another example, the endangered lupin (Lupinus tidestromii) in California experiences more seed predation by the native rodent Peromyscus maniculatus when growing in close proximity to the exotic marram grass (Ammophila arenaria) and thus apparent competition is escalating its extinction in coastal dune systems (Dangremond et al. 2010). Orrock et al. (2008) were able to find evidence for the importance of spatial scale for apparent competition when researching the impact of small native mammals that were attracted to the exotic Brassica nigra and exhibited increasing negative indirect effects on native Nassella pulchra populations near B. nigra in a study in California. The native Lotus wrangelianus in California was indirectly negatively impacted by the introduced Medicago polymorpha which increased 
densities of exotic Egyptian alfalfa weevil (Hypera bruneeipennis) on Lotus wrangelianus (Lau and Strauss 2005).

Apparent competition is also influenced by the resources available to the species which are competing indirectly: The resource concentration hypothesis $(\mathrm{RCH})$, which was first posed by Root (1973) is an important hypothesis. It predicts larger quantities of insect herbivores in areas with high host plant concentrations. Despite the general recognition of this principle, some studies showed contrasting effects with less insect herbivores per plant in concentrated areas (Thompson 1978, Price 1997), whereas in areas with low host plant density insects were more abundant on isolated plants (Karban and Courtney 1987). In contrast to the $\mathrm{RCH}$, the resource dilution hypothesis (Otway et al. 2005), predicts that isolated plants experience a higher insect herbivore load than plants within dense patches. More examples from the literature are given in Chapter 5.

Despite its recognition, apparent competition is an important, often unpredictable force when an organism is introduced to an established food web (Dangremond et al. 2010). In order to understand and predict the consequences of species introduction, more research is needed. The identification of food web-interactions is a crucial step towards recognizing patterns of apparent competition between species. For insect herbivores this includes identifying the degree of host specificity that is exhibited by the herbivore and how it chooses its host (Price et al. 1980).

Some basic ecological questions on how a host is chosen remain. Indirect facilitative effects i.e. 'apparent facilitation' are a possible outcome, when two species, not directly interacting, are positively influenced by a third species. For instance, two plant species are visited by a shared pollinator, an increase in the abundance of one plant can increase the population of the pollinator and thereby increase fitness of the other plant, as the case for lizards being attracted by Pandanus plants to pollinate nearby threatened Trochetia blackburniana in Mauritius (Hansen et al. 2007). Helms and Vinson (2003) provide an example of an invasive mealybug indirectly facilitated by the invasive ant species Solenopsis invicta that uses native mealybugs in the USA. 


\subsection{Spatial scale in ecological interactions}

The integration of different spatial scales into ecological research is a relatively new phenomenon which has resulted in a new branch of ecology - spatial ecology - which together with landscape ecology uses a multi-scale perspective to explain food web dynamics (Tilman and Kareiva 1997). Hence, the spatial scales (of grain and extent) chosen for a study are an important consideration for most ecological questions including sampling of vegetation. The size of the sampling unit, for example, is an expression of spatial grain. For mapping moss a $10 \times 10 \mathrm{~cm}$ quadrat might have the appropriate scale (grain), for grasses most ecologists recommend at least a $1 \times 1$ metre quadrat, and in forests a standard size is at least $10 \times 10$ metres $(20 \times 20 \mathrm{~m}$ in high forest) (Allen et al. 1951, Peet et al. 1998). Quadrat sizes, and their dispersion in space, will effect perceptions of alpha, beta and gamma diversity (Kwiatkowska and Symonides 1986).

The relation between extent (the entire study area), grain size (sampling unit) and lag (the distance between the sampling unit) determines the appropriateness of data collection for a given hypothesis (Wiens 1989). Wrong conclusions can be drawn if assumptions are made beyond the investigated scales as patterns and processes are rarely uniform across scales (Turner et al. 1989b, 1989a). Nevertheless understanding relationships between fine and coarse scale processes could help to improve the accuracy of predictions across scales (Kunin et al. 2000, Gao et al. 2001, Thuiller et al. 2003). If grain is increased in size, the heterogeneity evident in smaller grain is lost and incorporated in the sampling unit and lost for detection. Depending on the mapping techniques of species, a change of grain also changes the perception of rare species (depending on coverage thresholds and the natural aggregation of species). If the extent is increased and grain held constant, more vegetation types are covered and heterogeneous samples are the result. However, if the distance (i.e. lag) between the sampling unit is changed, the perceived aggregation is also changed as terms such as 'isolated' or 'concentrated' change in their meaning.

Edge effects ( e.g. species adapted better to more sunexposure at forest edges (Matlack 1994) and predators having better access at river riparian planting edges and corridors (Haegen and Degraaf 1996), are effects that take place at different spatial scales. Stream 
water quality and even shore water quality is dependent on processes further upstream and runoff on farms far away might still influence the food webs further downstream (Alexander et al. 2007). Depending on the interactive processes within a community the local scale is either very dominant (i.e. for interactive communities) or the community might be more influenced by regional recruitment processes (Lawton 2000). Additionally to spatial scales, historical land use has been identified as a structuring factor for today's species assemblages as shown for remnants of traditionally managed semi natural grasslands in Sweden (Lindborg and Eriksson 2004). Whether or not an equilibrium of species is identified is largely depend on the size of the mapping unit - smaller units will identify more different patches such as forest clearings and other forms of disturbance despite being embedded into a larger unit that appears to be relatively homogenous (Crawley and Harral 2001).

The importance of spatial scales has also impacted on statistical methods available: with modern hierarchical linear models (HLMs) or also referred to as linear mixed effect models (LMEs) it is possible to account for nestedness of data (Raudenbush and Bryk 2002). For example, if samples were taken from several beaches and samples from each beach were at two different scales such as a large block with smaller quadrats within, then quadrats within the same block would be less independent than quadrats from separate blocks. However, all quadrats on one beach would also have some characteristics in common as they are situated at the same field site which most likely differentiates them from quadrats at another beach (Zuur et al. 2009).

\subsection{Invasive species}

Human-induced modification of habitat through the introduction of exotic species (both flora and fauna) is considered by many as the number one threat to global biodiversity (e.g. Pimm et al. 1995, Didham et al. 2007). The management of invasive species is a very costly enterprise when economic losses and control measures are taken into account. In New Zealand alone pest animal and plant management amounts to over $\$ 840$ Million NZD (Pimentel 2002, Pimentel et al. 2005). The flora and fauna of New Zealand has been dramatically altered with human settlement over the last nearly 1000 
years (e.g. McGlone (1989). Although food webs were altered permanently with the arrival of Maori (e.g. the extinction of the moa (McGlone 1989)), large scale modification started with the arrival of European settlers about 160 years ago (Quinn 2000). Native vegetation was regarded as wilderness that needed 'taming' and acclimatisation societies intentionally introduced European species and contaminated seeds unintentionally brought more alien species (Green 1997). Birds such as blackbirds were introduced to modify the bird song chorus to remind people of their European homes (Green 1997). More than $60 \%$ of New Zealand's land area has been modified for purely economic reasons in the creation ofpastures, farmland, forestry and settlements (Glasby 1991). The original indigenous vegetation cover on lowlands in most regions especially has been substantially reduced by human habitation and use (McGlone 1989). Consequently, most of the least modified wilderness areas within New Zealand today are in upland regions. Introduced species can have various consequences for the native communities and one of the major challenges for conservation management is to predict the consequences of pest introduction and spread on local biodiversity. An introduced plant can alter the native communities by directly or indirectly competing with native species for resources or facilitating some species but not others.

Invasive exotic species can alter the balance of competition and facilitation mechanisms within indigenous habitats including the relationships between species along environmental stress gradients. Introduced plants can also alter food webs and the abundance of a competing species indirectly through a second trophic level via a shared herbivore inapparent competition (Orrock et al. 2008). Introduced species can severely impact native species by hybridising with them, and therefore leading to major changes in native genetic pools (Huxel 1999). Additionally there is potential to affect indirectly without a direct trophic link other community members as shown by Watling et al. (2011) for American tadpoles (Anaxyrus americanus) found developing in close proximity to an invasive shrub (Lonicera maackii).

The spatial scale at which processes occur can be altered with the introduction of species as shown for the interactions between plants and native as well as introduced pollinators in temperate understory forests (Sugiura and Taki 2012). Additionally to 
altering the spatial scale of ecological processes, certain invasive plants are impacting human health as is the case with the invasive ragwort (Ambrosia artemisiifolia), which is believed to be a trigger for allergies such as hay fever (Ziska and Caulfield 2000). Trophic cascades and invasion meltdowns are feared consequences of introduced species, as shown for example by the introduction of yellow crazy ants (Anoplolepis gracilipes) to Christmas Island resulting in the depletion of the island's rich fauna, including, but not limited to, red crabs (Gecarcoidea natalis) (O'Dowd et al. 2003).

The success of an introduced species is dependent on its adaptation to its new home range. An introduced species needs to reach a critical population size to be successful, therefore several (independent) introduction events might be necessary for a species to establish (Wilson et al. 2009). There have been numerous studies aimed at identifying the factors that result in introduced species becoming invasive such as the spread of wilding pines in the high country of the South Island of New Zealand (Rejmanek and Richardson 1996), or Bellingham et al. (2004), who found no evidence for a predictability of invasiveness by seedling growth rate and survival of naturalized woody plants in New Zealand. However, it is often difficult to determine the key factors that make species invasive (Alpert et al. 2000) and triggers the rapid expansion of such species in various landscapes and habitats. There may often be a time-lag between when an introduced species is present, sometimes for many decades, before it rapidly expands and causes problems to native species. The reasons for this are the subject of much continued debate (Richardson and Pyšek 2006). Some authors have argued that species, which are adapted to disturbance regimes (pioneer species) are more likely to establish and become invasive, especially if they have sufficient dispersal capabilities (Daehler 2003). Furthermore, the way species were introduced is a crucial factor for invasion success (reviewed by Wilson et al. 2009). 


\subsection{Coastal habitats in New Zealand}

Coastal areas are no exception to the permanent alteration of landscapes and are now regarded as one of the most threatened habitats in New Zealand (Konlechner and Hilton 2010). About $60 \%$ of the world's population live in coastal areas (Vitousek et al. 1997). In New Zealand the top three cities which already account for $50 \%$ of the population are located on the coast (Cousins 2004) and a large proportion of New Zealanders live within $10 \mathrm{~km}$ of the coast (Hesp 2002, Spence et al. 2007). The demand for properties in proximity to the sea led to major modification of natural dunes for residential properties. The introduction of grazing and browsing animals over a century ago increased the occurrence of bare sand areas (Gadgil 2006a). Newly de-vegetated dunes and naturally highly dynamic dune fields were regarded as a threat to residential properties, forestry and farmland so effective methods for stabilisation of mobile sand dunes were sought (Cockayne 1911). New Zealand's native major sand-binding species spinifex (Spinifex sericeus) and pingao (Ficinia spiralis) were particularly vulnerable to these human-induced pressures.

The European settlers were familiar with marram grass (Ammophila arenaria) as a very effective sand binder (Gadgil 2006a). Marram grass has been introduced on a large scale to many countries. In the United States of America for example, it developed invasive characteristics and suppressed native plant growth directly and indirectly (Dangremond et al. 2010). In New Zealand, marram grass was introduced to stabilize the sand to allow for pine plantations; making marram grass an important step for forestry development (Gadgil and Ede 1998, Hilton et al. 2000). Therefore marram grass was systematically distributed with heavy machinery and a lot of manpower and promoted extensively as the solution to migrating sand. Extensive cover of marram grass and dune development altered natural geomorphological sand relocation processes in New Zealand (Hilton et al. $2005,2006)$. For instance, in some areas, seaward facing fore dune slopes were changed from gently sloping spinifex and pingao dunes to taller steeper marram grass-dominated fore dunes (Hilton et al. 2005). Early surveys of Cockayne (1911) compared with recent surveys show a total loss of over $70 \%$ of former dune areas (Hilton et al. 2000, 2006). The changes in habitat quality for native biota are unaccounted for within this figure. 
However, marram grass was not the only alien plant that was extensively planted in coastal dune areas and developed invasive properties: yellow tree lupin (Lupinus arboreus) was used for back dune stabilisation to support forestry (McQueen 1993) - as legume it can fix nitrogen and permanently change soil properties (Fowler et al. 2000). The intentionally planted alien species further promoted plant growth of accidently introduced garden and farmland weeds.

Over the last two decades, there has been increasing interest in restoration of sand dunes with a focus on restoration of indigenous plant and animal communities. This has involved local communities, in particular Coast Care groups, working in collaboration with regional, district and city councils, and the Department of Conservation throughout New Zealand (Bergin and FitzSimons 1997, Bergin and Herbert 1997, Bergin and Kimberley 1999). The impetus for dune restoration has increased over the last decade with the predicted impacts of climate change including likely sea level rise and increased severity of storms (Dahm et al. 2005). Substantial applied research and technology transfer has been carried out over this period and is currently underway by councils, tertiary institutes and by the Dune Restoration Trust of New Zealand (e.g. Spence et al. 2007, Bergin 2008). However, there is more research needed to identify the best restoration options for different local conditions. Unfortunately, the majority of restoration projects were not monitored, leaving impressions of what worked and what did not very subjective.

More research is needed to further reduce the detrimental impacts of introduced marram grass on native sand binders such as spinifex and pingao. Restoration aims to be more effective at restoring dunes dominated by non-native species - which is important for coastal protection, especially in the face of climate change and rising sea levels.

Another area that has not been researched intensively is apparent competition in coastal areas. There is scope for more research, especially where introduced congeners are growing in close proximity to natives. Little is known about the original food web interactions in native dunes prior to human settlement in New Zealand. Plant-insect interactions, in particular, remain largely unknown, as well as the interactions of other 
invertebrate species. More knowledge about these food web interactions could be very beneficial for restoration as they would help to predict the risk posed by introduced species, as well as to provide a better picture of historical food webs.

\subsection{The synthesis of approaches in this thesis}

The overall aim of my thesis was to identify and quantify the major impacts and driving forces of species interactions within coastal habitats. I choose to look at both direct and indirect interactions between plants. To investigate direct interactions (both positive and negative) I studied the key architectural plant species which form the physical habitat (the dunes) and how direct competition structures the species growth and diversity of naturally colonizing species. More specifically, I chose to look at the interactions between exotic marram grass (Ammophila arenaria) and native spinifex (Spinifex sericeus). As an applied goal I was interested in investigating the best restoration options to restore alien marram grass-dominated dunes back to native spinifex-dominated dunes. The stress gradient hypothesis (SGH) was in the centre of this research as I considered different distances from the sea (the stressor) to my experimental plots and researched how that affected colonization and competitive interactions represented by species cover and by species numbers (Direct competition and research concerning the SGH are represented in Chapters 2 and 3).

Indirect interactions (mediated by herbivores) are more likely to occur between closely related species; therefore I was interested in investigating the influences of different spatial scales and plant densities between closely related native and introduced species and their associated insect herbivores. For this study I chose coastal Senecio spp. as a focal plant genus as there are native and introduced species growing in close proximity to each other in either shingle beaches but also in sand dunes. I investigated the strength and direction of interaction between the insect herbivores and their plant hosts. Chapter 4 sets the scene by reviewing the current literature and knowledge about senecio food webs within the New Zealand context and comparing them with others elsewhere, before displaying results of my own field surveys that were conducted to detect natural patterns of interactions and backed up with a manipulative field experiment in Chapter 5. 
Chapter 6 is intended as an overall discussion where all chapters are discussed and a general synopsis is made. Chapters are written as mostly independent papers - Hence there is some overlap in the introductions. Further information is displayed in the appendix additionally to an extra data chapter which examines the interaction between a parasitoid wasp and its tephretid host on Senecio spp.

\subsection{Thesis overview}

\subsubsection{Direct competition versus facilitation along a stress gradient}

\section{Chapter 2:}

The effect of dead and live marram (Ammophila arenaria) on spinifex (Spinifex sericeus) restoration plantings: a test of the stress gradient hypothesis.

This chapter aims to investigate how direct competition versus facilitation structures the plant community that builds the dunes as physical structures for a whole food web. I examined the interaction between the introduced marram grass and the native spinifex along a stress gradient running from the seaward to landward zones of the dune system. Moreover, as there is intense interest in ecological restoration of marram-dominated dunes back to a more natural condition dominated by native species, I also investigated whether dead Marram stems and roots (the result of herbicide spraying) act as a physical impediment or facilitator to new plantings. I anticipated the research outcomes on this interaction to give direct conservation management recommendations to improve survival of costly native plantings by testing if:

i) Is the survival/growth of spinifex (i.e. native sand binder) facilitated by dead marram grass structures (i.e. introduced sand binder) compared to plantings in bare sand as traditionally used for restoration?

ii) Does the balance between facilitation and competition change along an abiotic stress gradient?

iii) Is live marram is a better facilitator than dead marram grass in dune systems?

iv) Does the surrounding type of plant cover change spinifex plant survival and/or growth? 
I researched these research questions by conducting a large scale field experiment close to Wanganui (lower South-West North Island of New Zealand).

\section{Chapter 3: Species abundances of self-colonizing native and introduced plants and the role of the stress gradient hypothesis in coastal dune systems}

This chapter focusses on all plants naturally occurring at the field sites used for research in chapter 2. Similarly to chapter 2 the stress gradient hypothesis is also in the focus of my research aims. My research here focuses on the interactions between the occurring assemblage of introduced and native plants and how they may impact restoration attempts in coastal dunes. Thereby, I particularly focused on wide-spread weeds within the dune system to test these hypotheses:

i. Bare sand is more likely to be colonized by plants than plots of live marram or plots of recently dead (herbicide-sprayed) marram.

ii. Live marram is a less effective facilitator of self-colonizing plants compared to dead (herbicide-sprayed) marram.

iii. Planted spinifex will reduce the number of self-colonizing plants in herbicidesprayed marram plots compared to unplanted plots

\subsubsection{Indirect competition}

The second part of my PhD focuses on researching indirect competition between coastal Senecio spp.(i.e. Senecio lautus, S. elegans, S. skirrhodon, S. sterquilinus). I choose Senecio spp.as they are one of the largest genera within the Asteracea (Jeffrey et al. 1977). Furthermore, New Zealand's shores show a mixture of beaches with some exclusively inhabited by the native $S$.lautus while others are only inhabited by alien Senecio spp., and others harbour both, which allows for good research opportunities as there is still a controversy on how closely related introduced congenerics respond to the food web interactions in their new range. I was particularly interested in identifying the species of the food web and quantifying the interactions with regards to spatial scale and species identity. 
Chapter 4: Review of the current knowledge about Senecio spp. food webs in New

\section{Zealand}

The aim of this chapter is to review the current knowledge about Senecio spp.-food webs in New Zealand. A reasonable amount of information has begun to be accumulated, but it is dispersed across many disparate sources, including much "grey literature" not immediately accessible to interested parties. My aim therefore was to bring the current information together in one place and review general trends in host specificity, feeding guilds, host overlap and the degree of food web integration between native and introduced species as a preliminary step towards a better understanding of the direct and indirect effects of introduced species (both plants and insects). Therefore I compared the trends found for food web interactions between New Zealand's Senecio spp. and their associated insect herbivores to trends for feeding guilds and species relatedness to other studies elsewhere.

Chapter 5: The importance of plant morphology and different spatial scales of plant density for plant- insect herbivore host choice and interaction strengths

The densities of resources as well as the importance of scale and size of resource units and their interaction with resource consumers are the focus of this chapter. More specifically, I researched the influence of plant density (of introduced and native coastal senecios) as well as plant properties and other insects on insect herbivore density to quantify species linkage strengths. The tephretid stemborer and seed head fly Sphenella fascigera was my main focal insect herbivore. I conducted natural surveys of native and introduced coastal Senecio spp. in Wellington and additionally set up a manipulative field experiment to verify the research outcomes from our natural surveys. I was particularly interested in the effects of close congeners on insect distributions. I expected more native insects 'spilling over' to introduced plants when native Senecio spp. where in larger abundances. 


\subsubsection{Overall discussion of the PhD-thesis}

\section{Chapter 6: Discussion}

The final chapter of my PhD-thesis brings all results together and discusses them collectively in the wider research context and relates back to my original aims and the research literature displayed in the introductory chapter. I particularly aimed to relate my research back to the questions evolving around invasive species and competitive ability along a stress gradient. Furthermore I aimed to discuss apparent competition and facilitation between closely related native and introduced plant species and their associated insect herbivores, which relates back to my research questions for Chapters 4 and 5. For the latter research approach I researched the importance of spatial scale which will be discussed in the overall discussion with respect to the current literature.

\subsubsection{Additional chapter}

Chapter 7: Tri-trophic interactions and the minimal effect of host microsite, plant properties and plant density on parasitism of Sphenella fascigera (Diptera)

Throughout rearing flies for Chapter 5 I found evidence for a parasitoid wasp-insect herbivore relationship for which previously only a single record existed (Sullivan, pers. comm, 2010). Together with the help of a summer intern Clara Maloines, we were able to collect a robust data set about Pteromalus spp., an undescribed parasitoid wasp that parasitizes Sphenella fascigera. We were interested in the effects of plant density and $S$. fascigera densities on parasitation at different spatial scales $(50 \mathrm{~cm}, 2 \mathrm{~m}$ and $6 \mathrm{~m})$. Furthermore, we were especially interested in determining whether or not a distinctive host search strategy was apparent in Pteromalus spp. Since a different approach was used for data collection here and the questions are diverting from the core PhD-thesis hypothesis and research questions I have placed this chapter into the appendix. 
CHAPTER 1 


\section{CHAPTER 2}

The effect of dead and live marram (Ammophila arenaria) on spinifex (Spinifex sericeus) restoration plantings: a test of the stress gradient hypothesis.

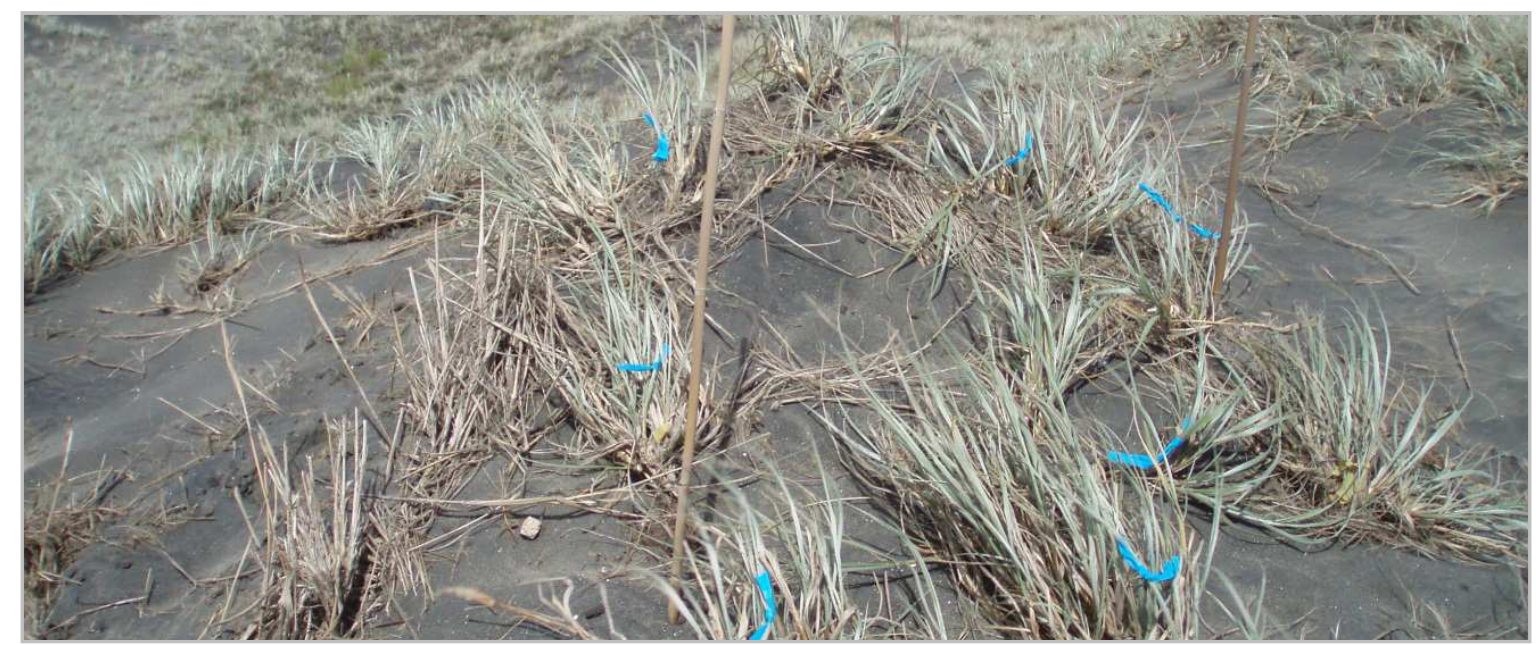

A plot of herbicide-treated marram grass (mostly dead and dispersed) planted with spinifex (tagged with blue flagging tape). Photo taken 9 months after planting. 


\subsection{Introduction}

Coastal habitats are highly dynamic ecosystems, both spatially and temporally (Koch et al. 2009). Despite a high rate of natural disturbance caused by repeating cycles of erosion and reclamation of dunes, plant communities have distinct zonation of spatially defined species assemblages (Sykes and Wilson 1991). However, invasive species can displace native species through pre-emption of space (Sakai et al. 2001), and can alter the spatial structure of coastal plant communities (Santoro et al. 2012).

Invasive species are considered one of the major threats to biodiversity and are also economically costly. For example invasive species cost the US economy in excess of $\$$ 120 billion annually (Pimentel et al. 2005). Introduced species can impact native communities via altering food web linkages and linkage strengths: alien plants are predicted to lower insect productivity by $67 \%$ on the Azores (Heleno et al. 2009) and on Christmas Island the introduction of yellow crazy ants altered several trophic levels (O’Dowd et al. 2003). The potentially far-reaching consequences of invasive species on native communities are still not entirely understood and conservation managers are struggling to mitigate the impacts of invasive species, especially when the native ecosystem engineers are replaced by invaders.

In coastal dunes, survival rates of planted native sand-binders are relatively low, around $40 \%$, as opposed to $80 \%$ or more in forest ecosystems (Otsamo et al. 1997), which exhibit a more stable environment in comparison. Often it is necessary to eradicate the invasive species to restore ecosystem services with native species. Native species are often less competitive than introduced species, and thus more research is needed to overcome this challenge (Pywell et al. 2003). Invasive pest plants can exhibit a higher stress tolerance compared to native species due to their population biology (Sakai et al. 2001).

Plantings at the coast are exposed to a stressful environment: wind that desiccates plants and mobile sand (potentially leading to lethal sand burial of photosynthetic structures or exposure of roots). There are high salinity levels, and low levels of soil development (Wilson and Sykes 1999). Additionally, (introduced) herbivores threaten plant survival. Planting trials on several New Zealand dune sites indicate native sand 
binders fertilised with slow release fertilizer tablets have improved establishment compared to non-fertilised plants (Bergin and Kimberley 1999).

The stress gradient hypothesis (SGH hereafter), first formulated by Bertness \& Callaway, (1994) predicts that along an abiotic stress gradient facilitative plant-plant interactions will occur where environmental stress is severe, but more competitive interactions will occur where environmental stress lessens. The SGH has been tested for a range of habitats, including some examples from salt marshes and coastal dune systems (e.g. salt marshes in Spain (Alvarez-Rogel et al. 2006) and sand dunes in west Portugal (MaltezMouro et al. 2010). However, results have been mixed. Some studies found support, as shown for coastal trees and their interaction with sawgrass (Cladium jamaicense) in Japan (Poulter et al. 2008) and for native and introduced plants in northern Italy (Santoro et al. 2012). However, others did not find conclusive evidence supporting the SGH and thus the debate is on-going (Maestre et al. 2005, 2006, 2009, Lortie and Callaway 2006). Recently, there is growing interest investigating whether the SGH distinguishes the type of stress experienced by a plant community. Two types of abiotic stress can be distinguished, which can occur simultaneously, but not necessarily in the same direction (Emery et al. 2001):

1) Resource stress - this stressor affects the access of community members to biomass-increasing resources such as nutrient, water and light (Maestre et al. 2009, Mason et al. 2012) and;

2) Non-resource related stress posed by e.g. altered temperature, salinity, wind exposure and soil structure (Grime 1977, Maestre et al. 2009).

In their refinement of the SGH, Maestre et al. (2009) pointed out the importance of identifying potentially annihilating mechanisms in stressful environments. Consequently, it was recommended (Emery et al. 2001, Maestre et al. 2009) to take into consideration the plant species' adaptations to stress and its relative position on the stress gradient when testing the SGH where it has been previously rejected.

The classic facilitative effect of nurse plants, which describes facilitation by a mature plant of one species on establishing plants of another species, was the foundation for the SGH. Nurse plant facilitation has been demonstrated for a wide range of habitats and plant communities: e.g. the facilitation of Agave deserti seedlings under Hilaria 
rigida canopies (Franco and Nobel 1988); facilitation of a range of species under Bolax gummifera cushion plants in the Chilean Patagonian Andes (Cavieres et al. 2002); and the facilitation of Quercus douglasii seedlings by shrubs (Callaway 1992). Moreover, facilitation of plants can have widespread consequences: plants can expand their range which leads to an increase in species diversity in habitats that would otherwise be unsuitable for the facilitated species (Hacker and Gaines 1997). Plant-plant interactions are thought to be able to mitigate or escalate impacts (facilitation of invasive species) of environmental change and be one of the drivers of successional processes and evolutionary selection (review in Brooker, 2006). They are thought to act at different spatial scales (Forey et al. 2008). Plant-plant interactions play an important role in conservation and restoration: e.g. a meta-analysis of forest restoration with the help of shrubs as nurse plants (Gómez-Aparicio and Zamora 2004); and the use of the moss Polytrichum strictum as nurse plant to facilitate sphagnum moss in peat land restoration (Rochefort et al. 2007).

Stress is an important driver for plant strategies and one of the structuring forces of the CSR triangle. The CSR triangle distinguishes between plants with adaptations to tolerate stress over long periods of time (S), ruderal selected species (R) and plants which evolved strong competitive abilities in relatively undisturbed conditions (C) (Grime 1977). Competition is expected to dominate where stress lessens (Bertness and Callaway 1994). Competition can be separated into types of competition either via species involved (i.e. interspecific competition and intraspecific competition) (Kaplan and Denno 2007, Rich et al. 2012) or by mechanisms; i.e. interference competition (Case and Gilpin 1974, Human and Gordon 1996, Allstadt et al. 2012), exploitative competition (Brown et al. 1979) where species indirectly compete through a limiting resource, or apparent competition (Holt 1977), where another higher trophic level mitigates survival and/or growth of two otherwise not directly competing species. A typical example of apparent competition is the mitigation of fitness/growth of two plants by a shared enemy. Apparent competition is the focus of the third experimental chapter of my PhD-thesis (Chapter 5).

To my knowledge interactions used for restoration have been mostly investigated between two or more live species, albeit there are some rare examples of documented 
benefits of dead plants for insects in coastal dune systems (Cereto et al. 2011). The management of competitively superior invasive species to facilitate native plant recovery often results in dead invasive plants at the site of restoration and there is little knowledge if those dead structures can be used to a restoration advantage e.g. by providing shelter from sand burial and salt spray. Invasive species management is a very costly operation and options can include mechanical removal, biological control, chemical eradication or a combination of these methods ( $D$ 'Antonio and Meyerson 2002). Chemical treatment leaves dead plant structures at the site of restoration for at least a short period of time, unless mechanical removal follows.

Coastal habitats rank as one of the most threatened habitats within New Zealand (Sykes and Wilson 1991, Konlechner and Hilton 2010). More recently, the ecosystem services provided by coastal sand dunes such as protection from storm surges, has received some attention (Koch et al. 2009). A detailed knowledge of the species and local condition is crucial to appropriately manage the ecosystem services, as well as for restoration purposes (see appendix with detailed species description).

A substantial proportion of New Zealand's dunes are dominated by introduced species (e.g. Gadgil and Ede 1998 and personal observation). Little remains of the original species compositions and vegetation sequences, as the introduction of marram grass (Ammophila arenaria) was very comprehensive and changed the dune landscape dramatically (Hilton et al. 2000). Gently sloping dunes with native sand binding grass spinifex (Spinifex sericeus) and pingao (Ficinia spiralis) that had become degraded by early human use and exploitation (e.g. grazing), were replaced by large scale exotic forestry plantations. This involved the planting of marram grass aimed at stabilising vast areas of mobile dunes systems in many regions (Gadgil 1983).

The aim of this chapter is to investigate whether it is possible to use the remaining dead plant structures of invasive marram grass, to assist in restoration of the native sand binding species, spinifex. The herbicide sprayed plant structures of marram grass are expected to persist for a limited time due to the high rate of sand movement and breakdown of plant material on such exposed dune sites. The exact period of time that dead material will persist is dependent on the initial cover thickness, rates of natural disturbance as well as the chemical formulation used. Coast care groups report longer 
breakdown times for plants killed with the broad spectrum herbicide glyphosate (e.g. Roundup $^{\odot}$ ) as opposed to the grass-specific herbicide haloxyfop (e.g. Gallant ${ }^{\odot}$ ) $($ Harley Spence, Dune Restoration Trust of NZ, pers comm.). Comparing spinifex planted within the live marram, with spinifex planted within dead plant structures of marram (i.e. killed by spraying with haloxyfop) will provide the opportunity to distinguish between competition and facilitation along an environmental stress gradient from fore dunes to back dunes. It will also provide the opportunity to test the prediction of the stress gradient hypothesis which states along an abiotic stress gradient facilitative plant-plant interactions will occur where environmental stress is severe, but more competitive interactions will occur where environmental stress lessens (Bertness and Callaway 1994).

\section{More specifically, I asked the following questions:}

I. Is the survival/growth of spinifex facilitated by dead marram grass structures when compared to plantings in bare sand which are traditionally used for restoration?

II. Is live marram a facilitator or competitor of spinifex plantings?

III. Does the balance between facilitation and competition change along an abiotic stress gradient?

IV. Does the surrounding type of plant cover change spinifex plant survival and/or growth? 


\subsection{Materials and Methods}

\subsubsection{Study species}

\section{Marram grass (Ammophila arenaria)}

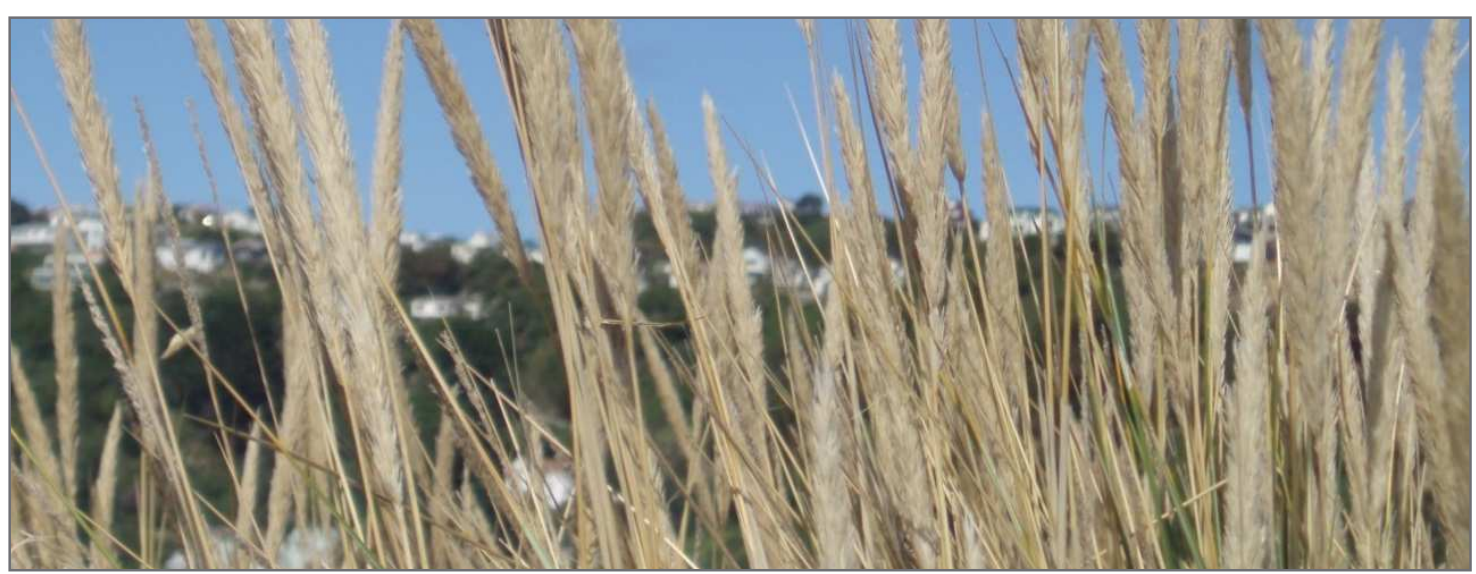

Figure 2.1: Dense stand with flowering marram.

Profile of:
a. Marram dune
b. Spinifex dune
c. Pīngao dune

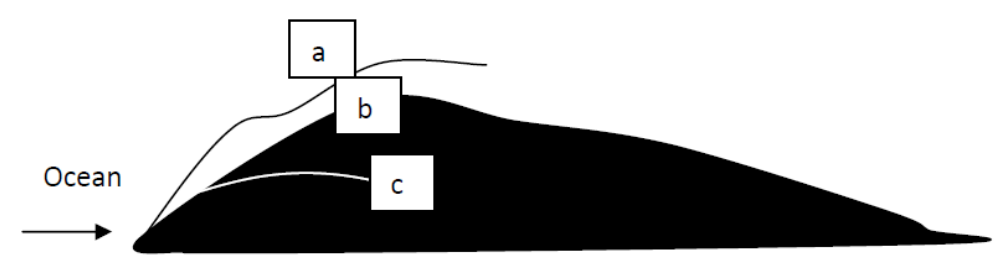

Figure 2.2: Profiles of different sand dunes: $a=$ marram dune, $b=$ spinifex dune, $c=$ pingao dune (Esler 1970), adapted by (Jamieson 2010).

Marram (Fig. 2.1) was deliberately introduced to New Zealand where it was used extensively to stabilise substantial areas of eroding sand dunes in many regions (Gadgil 2006a). In fact, one of New Zealand's foremost botanists, Leonard Cockayne, advocated the use of marram grass to control drifting sands particularly along the dynamic parts of the west coast of the North Island (Cockayne 1911). While erosion of sand dunes is often natural and can be on a large scale, such as the transgressive dune fields of the Manawatu (Hesp 2001) and parts of the western coast of Stewart Island (Hart et al. 
2012), human-induced factors such as pre-European burning of dune vegetation and the introduction of rabbits and grazing by early settlers, has resulted in significant loss of natural dune form and function and loss of indigenous biodiversity wherever marram grass has become established (see Appendix II). The pros and cons of the use of marram grass on New Zealand dunes has been reviewed by Gadgil (2006a).

Marram grass inhabits both the fore dunes and back dunes of many dune systems in New Zealand (Gadgil 2006b). It is often the dominant sand binding species in the cooler regions from the middle North Island southwards, but it also persists as substantial stands on more dynamic coastlines along the west coast of the North Island where there are persisting onshore winds and a ready supply of sand (Bergin and FitzSimons 1997). Tall marram grass-induced fore dunes (Fig. 2.2) can be erosion prone and collapse depending on the local conditions and thus hinder native back dune development. Marram grass is known to form effective seed banks on Stewart Island (Konlechner and Hilton 2010). Furthermore, there is evidence that some marram stands can prevail for several decades (pers. communication, with DoC-staff in Christchurch). These stands are hard to control for conservation purposes, as densities are often too high, preventing spray from reaching all rhizomes when applied once. Hence a continuous management approach is necessary (Konlechner and Hilton 2010).

Ecological management and conversion of marram-dominated dunes typically consists of the following: entire dunes can be reshaped with bulldozers - depending on the degradation of the coastal habitat. Thereby, the upper soil-containing layer is either so deeply buried that re-sprouting of alien species is prevented or it is completely removed, to allow plantings to grow in fresh, seed-free sand. The former method is a mechanical removal method. However, a very widely used method amongst land managers is to spray marram grass with herbicides. Two herbicides are commonly used for this management approach: Gallant (haloxyfop) (Dow AgroSciences 2000), which is a grassspecific herbicide and can be advantageous if managing a pingao dune where marram grass has encroached, (pingao is a sedge and will not be affected). In contrast, Roundup (glyphosate) (Nufarm 2013), is a broad-spectrum herbicide that kills a wider range of plants, including most dicotyledonous plants. Anecdotally, the speed of breakdown of marram grass plant tissues after spraying can vary depending on which herbicide is used. 
Spence (2011 pers. comm.) reported a longer period for marram grass tissue to breakdown when Gallant is used. He compared Gallant to Roundup when he used marram grass plantings to stabilize a mobile sand area on Great Barrier Island to allow later planting of spinifex on the dune that had been semi-stabilised by marram grass. For a few restoration areas around the Wellington South Coast, marram grass was sprayed and the dead structures were subsequently removed (i.e. chopped and left to wind deportation). To my knowledge, spraying and planting into sprayed marram grass has only been used for small experimental trials, but was not quantified before this experiment.

\section{Spinifex (Spinifex sericeus)}

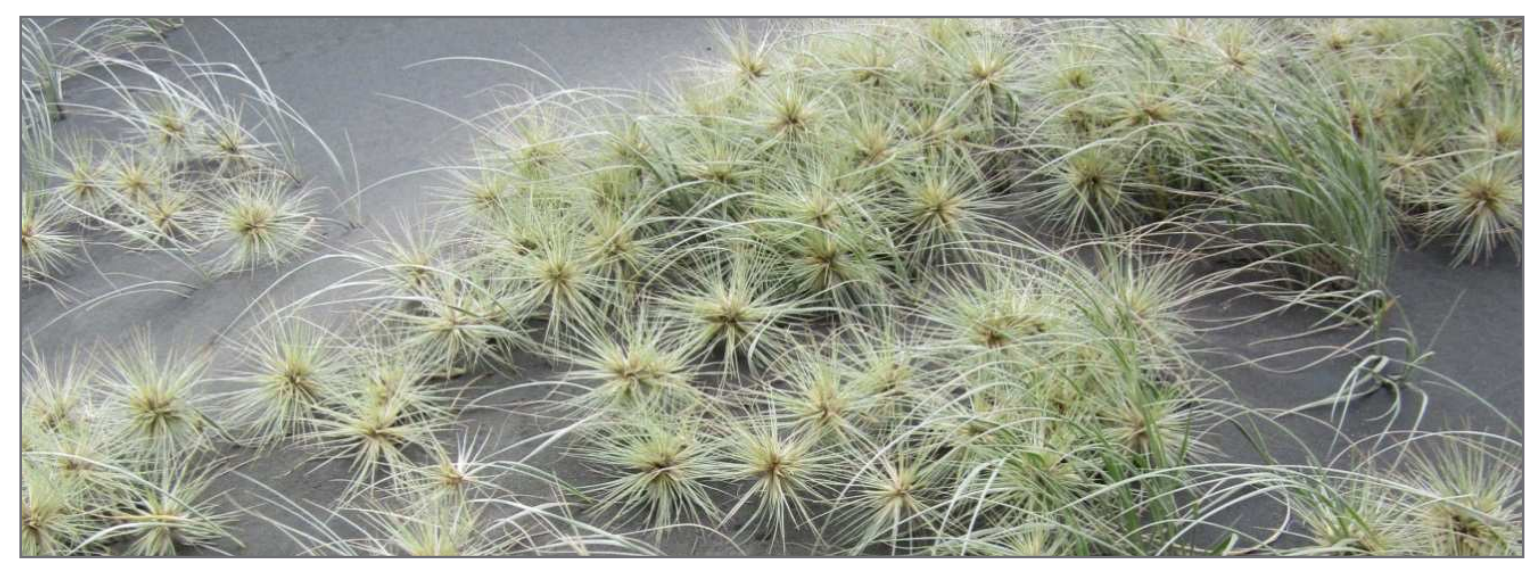

Figure 2.3: Spinifex seedheads and spinifex plants (photo by Stephen Hartley).

Spinifex is a sand-binder native to New Zealand and Australia (Fig. 2.3). In New Zealand the distribution is limited by temperature as spinifex does not tolerate frost very well (Bergin 2008b). Hence, natural distribution of spinifex only extends southward to Christchurch (Simpson 1974). Spinifex is more salt tolerant than marram grass, allowing it to grow closer to the sea (Esler 1970). It reproduces sexually, with separate male and female plants, and vegetatively via stolons. Unlike marram rhizomes, spinifex stolons are better at repairing front dune faces by outreaching stolons. Although yet to be researched, spinifex may have local varieties which are especially adapted to local conditions. Therefore nurseries try to source seeds locally. In the past one of the reasons why marram grass was chosen over spinifex is the latter's tendency to grow less quickly (Wendelken 1974). Spinifex is also more vulnerable to human-induced disturbance than 
marram grass. This includes browsing by pest animals such as rabbits, grazing and trampling by domestic stock, disturbance from both pedestrian and beach users, and competition from aggressive exotic species (Bergin 2011). Spinifex dunes are intermediate in height when compared to marram and pingao dunes (Esler 1970). Occasionally, land managers face problems in areas where only one sex of the plant is present (pers. comm. with DOC-staff and Coast Care Groups). To my knowledge the reason for this sex bias remains unknown.

\subsubsection{Field sites}

The large manipulative field experiment comprised a total of 11 transects across two field sites (Fig. 2.4) on the West Coast of the North Island, New Zealand. At both field sites, a mixture of introduced marram grass (Ammophila arenaria), the native sand binding grass spinifex (Spinifex sericeus) and the endemic sedge pingao (Ficinia spiralis) form the dune landscape. Both sites are of special value for conservation due to their inland nature and their specialised dune slack flora. Comprehensive monitoring data is not available for either of the two field sites. Different land use schemes have resulted in different weed pressures for both sites: Tapuarau (Fig. 2.5) has similar weed species as Whitiau, but with lower abundance, since all hinterland areas are actively managed by the owners of an adjacent dairy farm.while Whitiau (Fig. 2.6) is relatively weedy with Senecio elegans and acacias (Acacia longifolia) as problem species. This is due to large seed sources from the forest understory and logged areas that are currently out of use for forestry. Senecio glastifolius is a potential invader of the Whitiau dunes due to massive stands further inland. However, there are working bees to remove S. glastifolius at Whitiau to mitigate this invasion risk.

Tapuraus' beach is accreting while Whitiau has an eroding coastline (pers. comm. Campell, 2012). Both sites are exposed to strong south-westerly winds, but in comparison to Whitiau, Tapuarau is slightly more exposed to wind and has more and larger bare sand areas between vegetated dunes. 


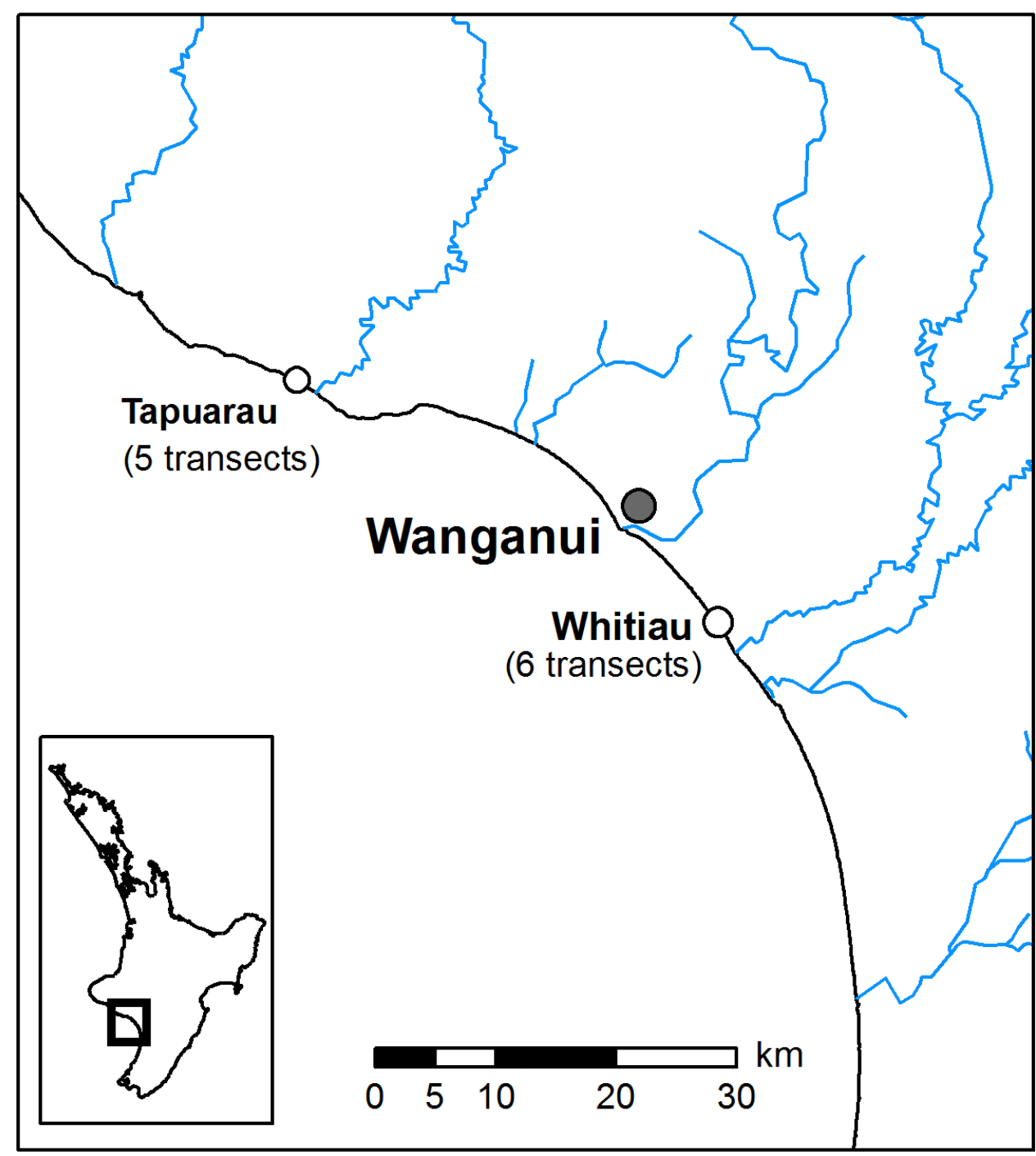

Figure 2.4: Both field sites are in relatively close proximity to Wanganui along the south western coast of NZ. Five transects were placed at Tapuarau and six at Whitiau. Data sourced from LINZ, Crown Copyright Reserved. 


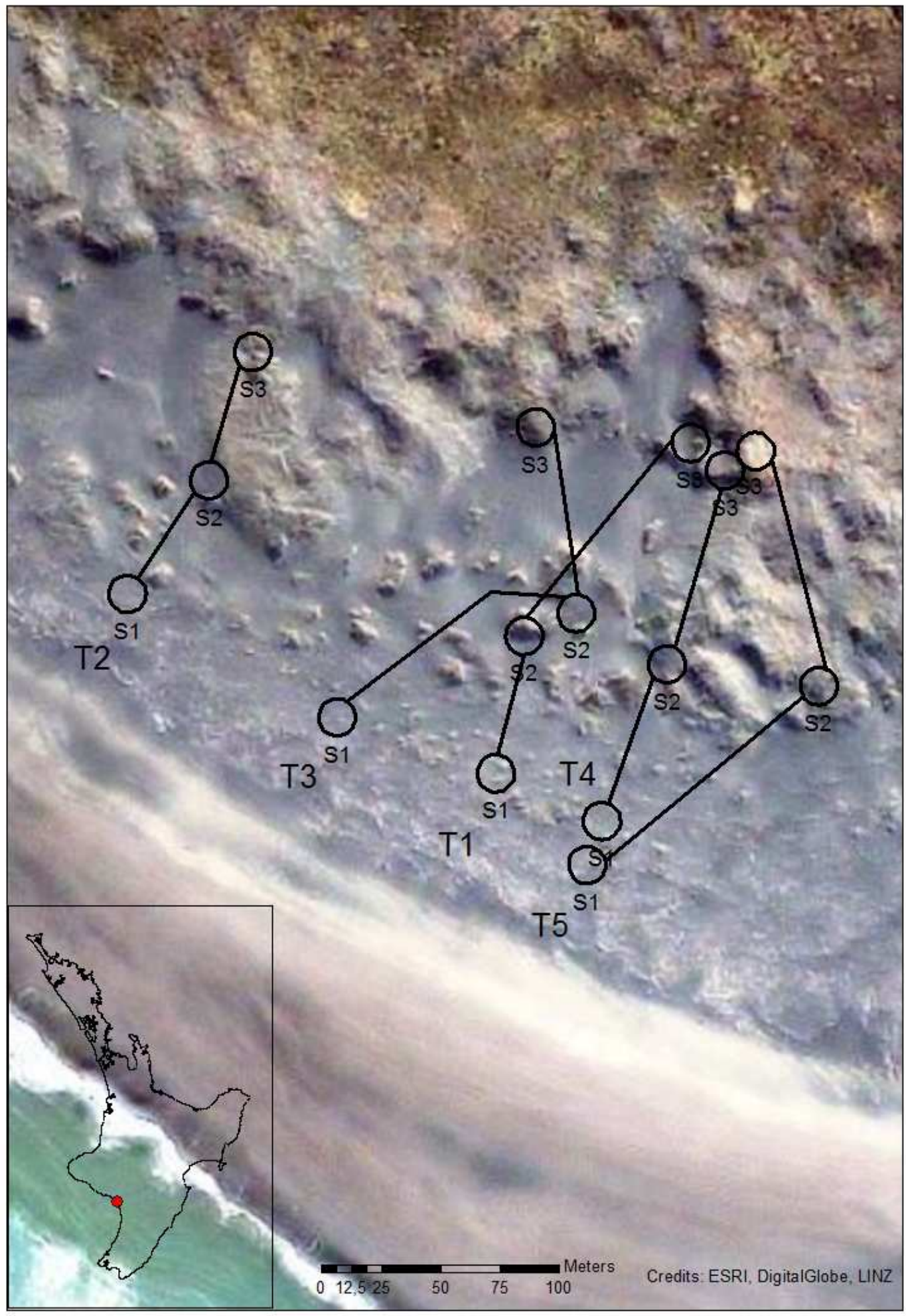

Figure 2.5: Transects (=T) and stations (=S) are displaced for Tapuarau. Sourced from LINZ. Crown Copyright Reserved. 


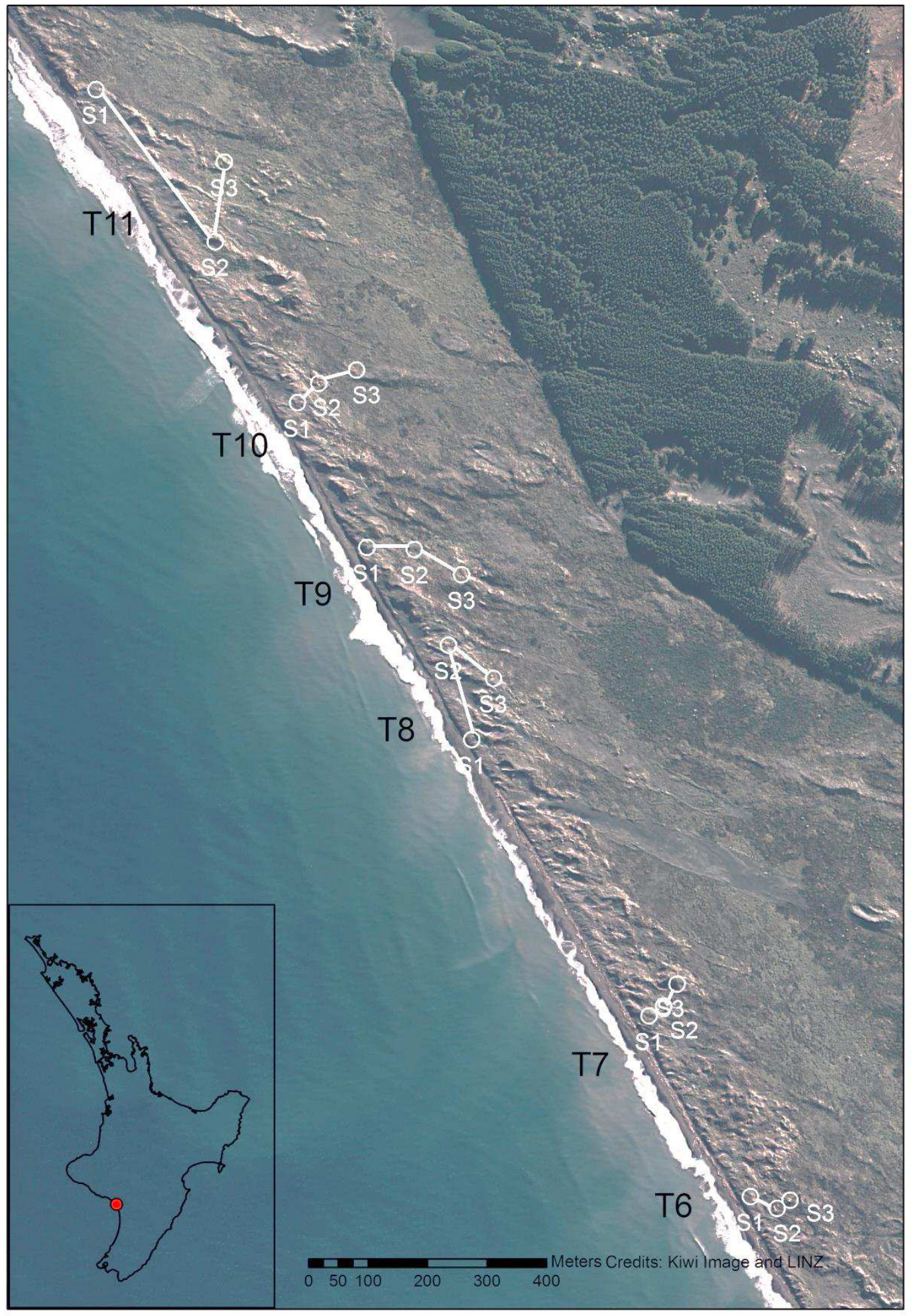

Figure 2.6: Transects (=T) and stations (=S) at Whitiau. Sourced from LINZ Crown Copyright Reserved. 


\section{Dune classification used for this study:}

Fore dunes are defined as the first prominent dunes (hence also referred to as first dune) coming from the intertidal section of the beach going inland. Within the context of this experiment I refer to fore dunes as 'station 1 '. Fore dunes are typically speciespoor in comparison to dunes further landward. Fore dunes (station 1) are typically vegetated with a mixture of marram grass, spinifex and pingao and the occasional sand convolvulus (Calystegia soldanella). Contrasting to Tapuarau some areas at Whitiau also have herbaceous weeds such as S. elegans and dandelions at fore dunes (station 1), which typically appear on the second big dune (station 2) at Tapuarau. This difference in species occurrence is likely due to Whitiau's eroding coast line. Mid dunes (also referred to as 'station 2' within this thesis), are defined as the second major dunes after the fore dunes. Second dunes are covered in a mixture of marram, spinifex, pingao and herbaceous weeds such as S. elegans, dandelions (Crepis capillaris, Leontodon taraxacoides and Taraxacum officinale), Sonchus oleraceus, Conyza canadensis), Fabacea spp. and rarely woody species at low densities. Occasionally, mid dunes at Tapuarau and Whitiau are lower than the fore dune (station 1) and third dune (back dune (= station 3)). Back dunes at Whitiau and Tapuarau are defined as third dunes (= station 3) and typically vegetated with a mixture of marram grass, herbaceous species, other grasses and the first woody species including, but not limited to, species such as Muehlenbeckia complexa and Ozothamnus leptophyllus. Both field sites (Fig. 2.7 and Fig. 2.8) have prominent fore/mid and back dunes. Further details of the biotic and abiotic environment are presented in the Results (and Chapter 3 with regards to plant community composition). 


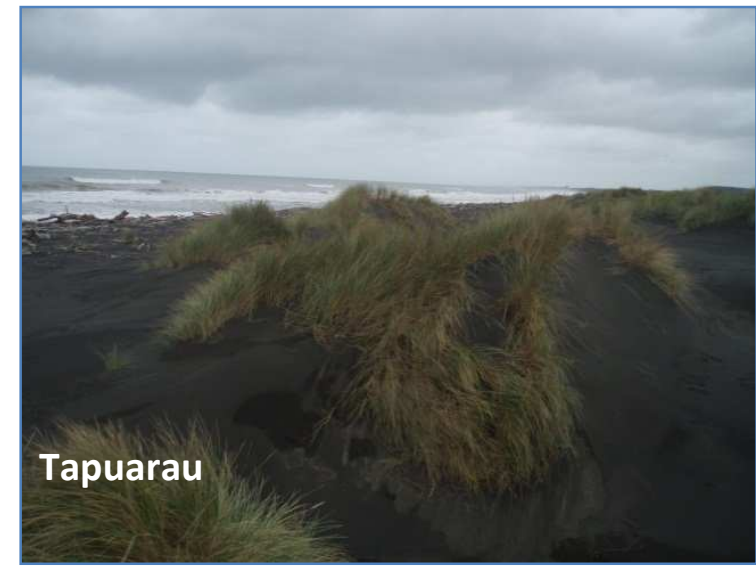

Figure 2.7: Tapuarau: fore dune dominated by marram

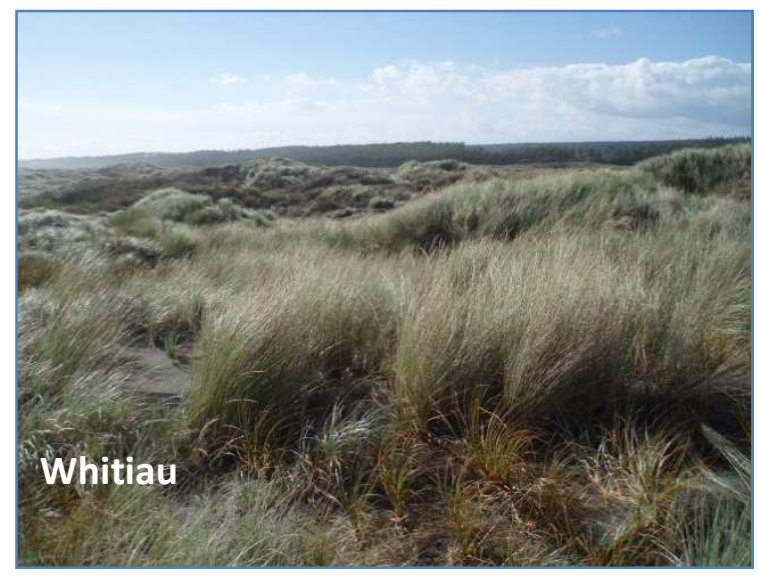

Figure 2.8: Whitiau: mid dune dominated by marram with occassional pingao

\subsubsection{Experimental setup}

Eleven transects were established along exposed dune fields near Wanganui's west coast, lower North Island/New Zealand (six transects at Whitiau (Fig. 2.5) and five at Tapuarau (Fig. 2.6)). Each transect (Fig. 2.9) consisted of three stations (located on the first, second and third major dunes respectively). At each station six plots were established: three to receive spinifex plantings and three as unplanted controls - two of the three plots in each set were located within existing stands of marram while the third plot was located in bare sand $(<10 \%$ vegetation cover). One of the marram-dominated plots was sprayed with the herbicide Gallant in late April/May 2011 while the other was left untreated (Table 2.1). Subsequently half of the plots were planted in late September 2011 with 25 spinifex plants each (in total 2475 spinifex plants across 99 plots) (Fig. 2.10 and Fig. 2.11). The distance between stations was set in an adaptive manner dependent on dune geomorphology and vegetation.

Each plot consisted of a $3 \times 3 \mathrm{~m}$ square $\left(9 \mathrm{~m}^{2}\right)$, but only a $2 \times 2 \mathrm{~m}\left(4 \mathrm{~m}^{2}\right)$ quadrat nested within the plot was planted and used for the vegetation surveys, leaving a $50 \mathrm{~cm}$ buffer to minimize any possible edge effects as vegetation patches varied in size. The size of $2 \times 2 \mathrm{~m}$ is commonly used to estimate cover in dune habitats (e.g. Pemadasa et al.1974) and was therefore deemed appropriate for this experiment, especially given that even at the third station shrubs consisted of smaller specimens and thus no larger plot size was needed. 
Spinifex plants used for planting were sourced from two different nurseries (Kii Tahi Nursery and Naturally Native). Although there appeared to be some initial differences in size of the plants from the two different nurseries, these differences were insignificant at the time of first monitoring (5-6 months after planting, see Appendix II). As a further precaution, the plants of one nursery were concentrated in the central nine planting positions to allow for a sufficient sample size in case differences between nurseries had persisted and plants on the outside would have not survived. Those from the other nursery were planted in the outer 16 , so that each quadrat received the same ratio of plants ( \pm 1 plant) from the two different nurseries. Most measurements were aggregated across the quadrat prior to analysis. One slow release fertilizer tablet was buried with each plant for all 25 plantings for each plot, as is standard practice in New Zealand (Bergin and Kimberley 1999).

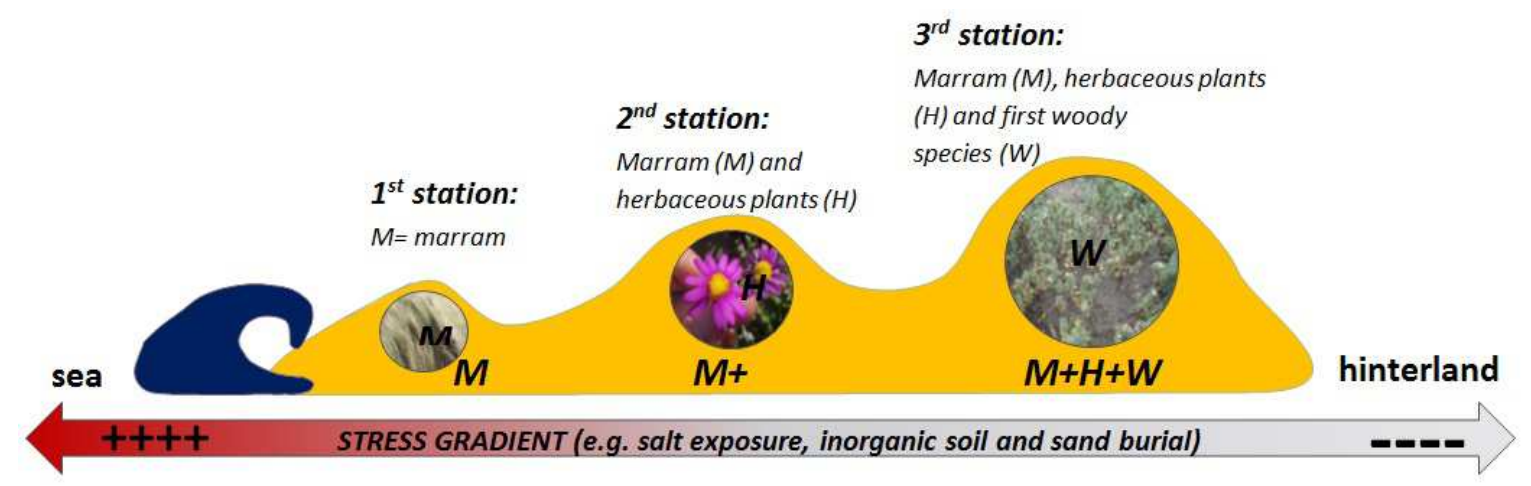

Figure 2.9: The stress gradient hypothesis is shown within the context of my field experiment setup: "+" indicates an increase in environmental stress (also emphasized by an increasingly red colour). Consequently, "-"indicates lesser stress and would therefore be associated with more competition, if the SGH is true for coastal dunes in New Zealand. The stations displayed represent the stations that were chosen for representing the expected environmental abiotic stress gradient, which is closely tied with the vegetation present as shown in the pictures. 
Table 2.1: List of plot-level treatments (six plots per station) and associated abbreviations.

\begin{tabular}{llc}
\hline Bare sand (B) & Live marram (M) & Sprayed marram (S) \\
\hline Control (no plantings) (BN) & Control (no spraying \& no plantings) (MN) & Control (no plantings) (SN) \\
Spinifex plantings (BP) & Spinifex plantings (MP) & Spinifex plantings (SP) \\
\hline
\end{tabular}

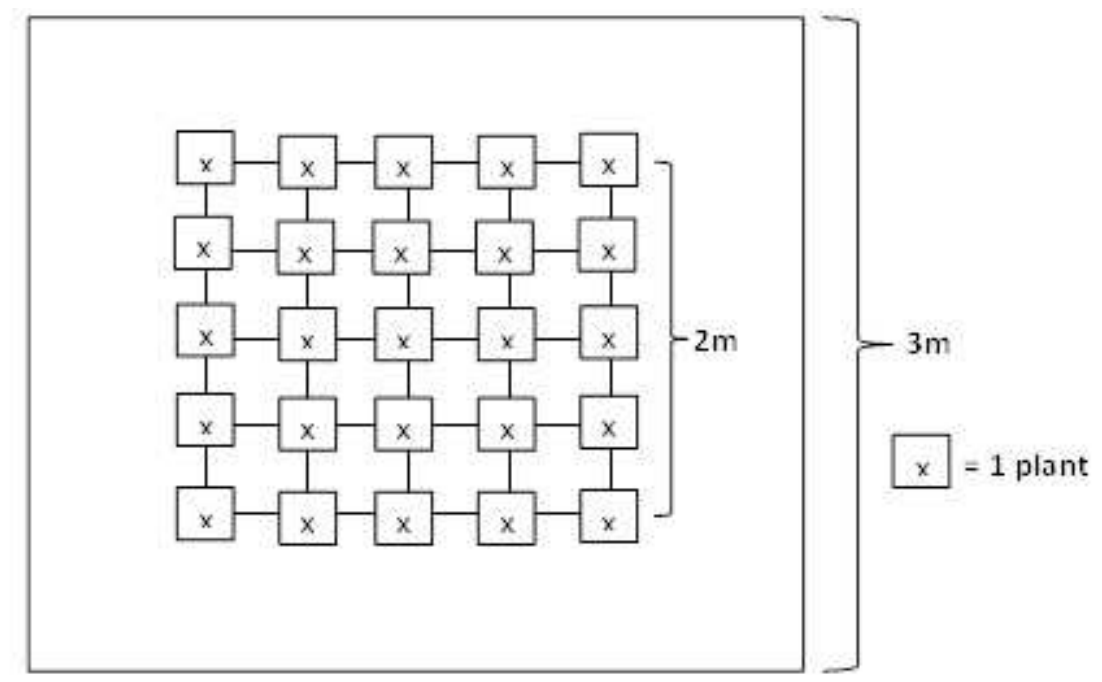

Figure 2.10: Schematic drawing showing one $3 \times 3$ m quadrat plot with the inner $2 \times 2$ m quadrat with 25 plants.

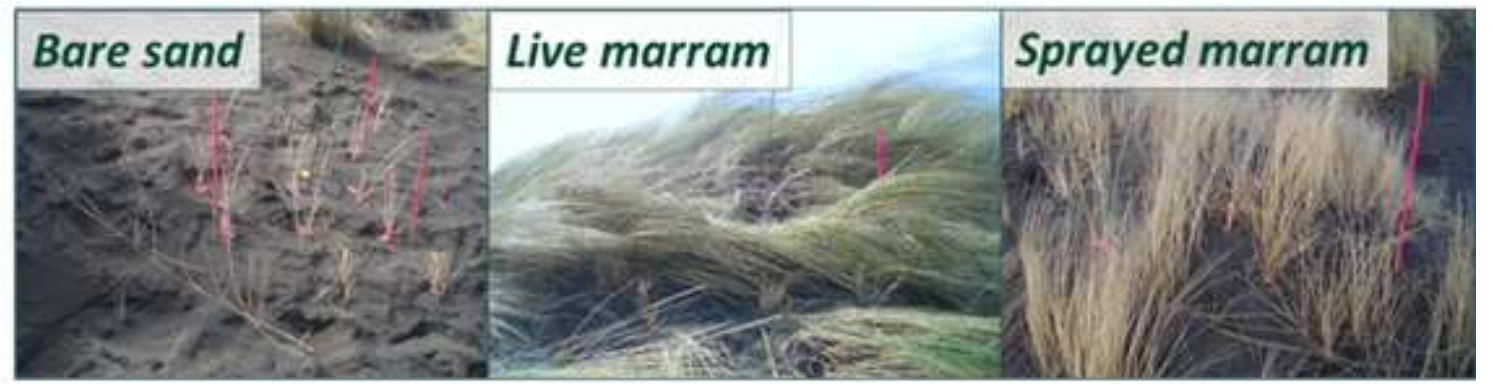

Figure 2.11: Planting examples at fore dune plots for all treatments at the time of planting in late September 2011. 


\section{Environmental gradients}

\section{Climate}

Both field sites experience a similar climate and are exposed to strong winds, especially in winter, where storms can reshape the dunes significantly over short time periods (Fig. 2.11 for monthly rainfall and min and max temperature averages ).

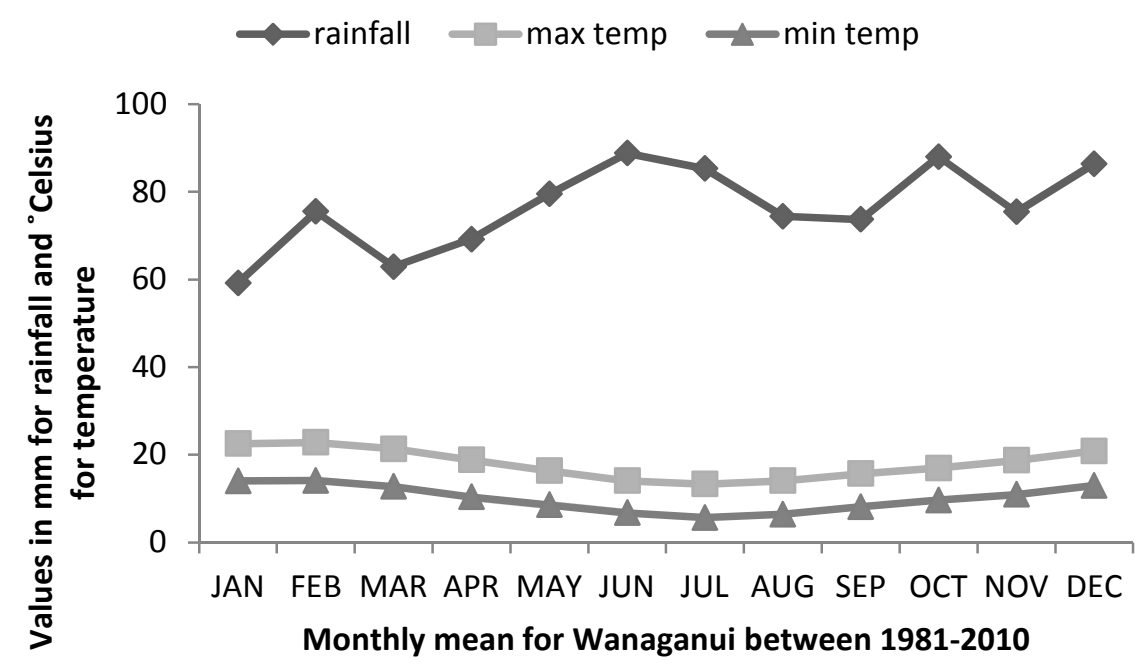

Figure 2.12: Mean monthly rainfall, minimum and maximum temperature for Wanganui. Graph based on statistics provided by NIWA (2013).

\section{Soil measurements}

Sand samples were collected from four out of five transects at Tapuarau from $10 \mathrm{~cm}$ depth for bare sand and for marram grass covered areas at each station. Samples were taken three times, but only the last dataset was used in the analysis due to a failure of the first conductivity meter that was used. Samples were taken from live marram, not sprayed marram plots. These samples were used for conductivity and organic matter determination. I used $20 \mathrm{~g}$ of soil and filled the volume of a $70 \mathrm{ml}$ pottle (small container) up with distilled water, stirring the contents with a spatula for 30 seconds prior to measuring conductivity (conductivity meter model ilQ350, SIEMENS).

The percent of organic matter in the soil was estimated by the combustion method, comparing dry weights of samples before and after combustion in a muffle oven for 24 hours at 400 degree Celsius. 
Sand movement (burial and erosion) was measured with bamboo sticks. The bamboo sticks were used to mark experimental plots. The height of the sticks was measured when the plots were established. It was re-measured to determine sand burial regularly. For a monitoring schedule see Table 2.2.

Topography:

Dune profiles reflect the wind and sand dynamics of a beach, and the interactive effects of vegetation and geomorphological processes (Baas 2002). I was interested in relating my 'station' to the overall dune profiles and thus recorded the dune profiles with differential GPS from Trimble along several transects.

Slope and orientation of plots could potentially influence plant growth due to different exposure to salt spray and wind. Therefore I chose plots facing the same direction (seaward). The slope however, varies and is naturally lower at bare plots due to sand movements (personal observation). Therefore the slope was measured in each plot at the steepest point and in the middle of the plot, and the average was used for the analysis.

\section{Assessment of vegetation:}

Spinifex plantings:

Vegetation cover percentages were estimated for all plots before planting at the time of planting. Spinifex plants were planted in the last week of September 2011, 4-5 months after spraying of marram plots. Spinifex plants were randomly allocated to transects and stations. A more detailed vegetation survey was conducted for all plots at at Whitiau shortly after planting. For transect No 6 at Whitiau all planted spinifex plants were measured to provide an exemplary sample. The measures were: vigour (a subjective health score ranging from $1-5$, with 1 = plant barely alive and $5=$ plant in perfect health), number of leaves, height (only up to live parts of leaves) and the number of stems. These were recorded to determine the characteristics of the plantings as a base line for determining growth. There were no significant differences between treatments at the time of planting. Survival checks of plantings were first conducted in early November 
2011, about a month after planting. In late February 2012 the five transects at Tapuarau were monitored and the six transects at Whitiau in March 2012.

Survival was recorded by counting all plants with at least one partially green leaf out of 25. Photos were taken of each plot. The number of surviving spinifex plants was counted for all planted plots, and measurements of individual plants were taken for up to 10 spinifex plants per planted plot (less only if fewer than 10 plants out of 25 survived). For the statistical analysis the data set from June 2012 was used as it was the oldest data set available prior to the large destructive winter storm which eroded the front stations of a couple of transects at Whitiau.

Survival is not always a sensitive measure of stress (Maestre et al. 2005), hence growth measurements were also incorporated in the research design: plant height, minimum and maximum width, presence/absence of stolons, stolon length (if present) and stolon direction. For each plant I estimated the number of leaves by counting bunches of approximately 10 leaves. If the plant showed dieback, browsing or insect attacks this was also noted and distinguished in three different units of severity from being present, medium and high. The basal circumference (also referred to as breadth interchangeably) of the plant stems and leaves above sand cover was recorded using a measuring string. I incorporated this measure of growth as as I felt it gave a more reliable representation of plant size compared to breadth higher up the plant (Fig 2.13). Plant circumference included stolons which were rooted.

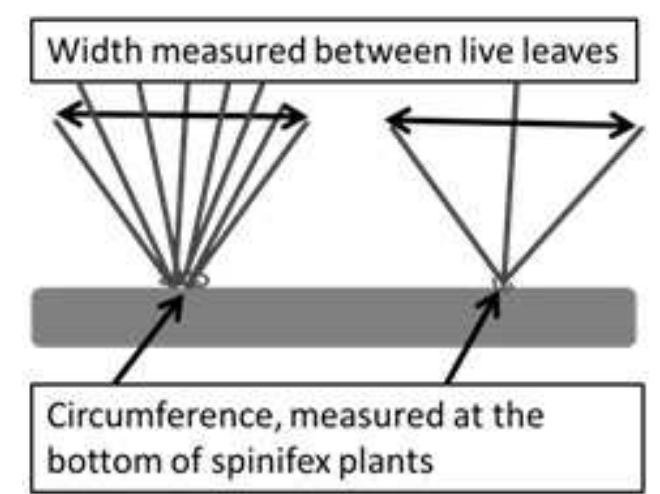

Figure 2.13: Difference between size measurements (width shown as height at the end of the experiment did not vary much due to the species height constraints). With size, plants with few leaves could achieve similar size dimensions as plants with the same width but a lot more leaves. Circumference measured at the bottom of the plants takes this into consideration as well as stolon growth. 
Survival, vegetation cover and sand burial were monitored in June. The last comprehensive monitoring trip (wind, survival, vegetation cover and plant counts, sand burial, dune profiles) was conducted in November 2012 (Tapuarau) and December 2012 (Whitiau). An overview of the monitoring times and what was monitored is given in Table 2.2 . 
Table 2.2: Monitoring schedule for Whitiau and Tapuarau. Monitoring times are given for spinifex plant survival, spinifex plant growth, sand burial, vegetation cover, plant counts, dune profiling, soil samples and wind measurements. $X=$ was measured, $-=$ not measured.

\begin{tabular}{|c|c|c|c|c|c|c|c|c|}
\hline Field site & Date & Survival & Growth & $\begin{array}{l}\text { Sand } \\
\text { burial }\end{array}$ & $\begin{array}{l}\text { Vegetation } \\
\text { cover }\end{array}$ & $\begin{array}{l}\text { Plant } \\
\text { counts }\end{array}$ & $\begin{array}{l}\text { Dune } \\
\text { profiles }\end{array}$ & $\begin{array}{l}\text { Soil } \\
\text { samples }\end{array}$ \\
\hline \multirow[t]{6}{*}{ Tapuarau } & Apr '11 & NA & NA & $x$ & $x$ & - & - & - \\
\hline & Sep '11 & NA & NA & $x$ & $x$ & - & - & - \\
\hline & Nov '11 & $x$ & - & $x$ & - & - & - & - \\
\hline & Feb '12 & $x$ & $x$ & $x$ & $x$ & $x$ & - & $x$ \\
\hline & Jun '12 & $x$ & - & $x$ & $x$ & - & - & - \\
\hline & Nov '12 & $x$ & $x$ & $x$ & $x$ & $x$ & $x$ & $x$ \\
\hline \multirow[t]{6}{*}{ Whitiau } & Apr'11 & NA & NA & $x$ & $x$ & - & - & - \\
\hline & Sep '11 & NA & NA & $x$ & $x$ & - & - & - \\
\hline & Nov '11 & $x$ & - & $x$ & - & - & - & - \\
\hline & Mar '12 & $x$ & $x$ & $x$ & $x$ & $x$ & - & $x$ \\
\hline & Jun '12 & $x$ & - & $x$ & $x$ & - & - & $x$ \\
\hline & Dec '12 & $x$ & $x$ & $x$ & $x$ & $x$ & $x$ & $x$ \\
\hline
\end{tabular}

\section{Vegetation surveys:}

In order to avoid variation due to observer biases, I estimated vegetation cover for all plants on all plots (rounding to the nearest $5 \%$ ) and counted the individuals for each species where possible (excluding rhizome reproducing species such as grasses). I used $5 \%$ as a lower bound i.e. if there was one specimen, it would account for five per cent cover even if the actual cover was presumably less than $5 \%$. Due to time constraints in the field and a lack of reproductive traits for identification, it was not always possible to identify taxa to species level. Hence vegetation was estimated for the dandelion/hawkbeard species collectively as well as for introduced legumes. For those species groups, relative dominance of the different contributing taxa was estimated for each field site. 


\subsubsection{Data analysis}

I used ordination via Principal Coordinate Analysis (PcoA), also known as metric multidimensional scaling (Zuur et al. 2007) to illustrate differences for transects and stations regarding the stress gradient abiotic measurements. The field experiment was carried out over two field sites, resulting in transects at one field sites being more closely related than their counterparts at the other field site. Therefore, a modeling approach that takes spatial nestedness into consideration was necessary for each transect. Hierachical linear models (HLMs), also called mixed effects models, were used to examine the effects of the treatments and the effects of the assumed stress gradient represented by the three stations. I used the functions 'Ime' and 'Imer' from the Rpackages "nlme" (Pinheiro et al., 2012) and "Ime4" (Bates et al., 2012) respectively, which were used for modeling the results. LMEs assume a near normal distribution of residuals for valid inference (Zuur et al. 2009). Therefore, original data were tested for normal distribution split by factor levels. Where data were non-normal a 'square root transformation' was used for counts, the arcsin-squareroot transformation for percent cover estimates and a log transformation for other measured variables (Osborne 2002). Where data after transformation still failed to meet criteria of normal distribution the model was still applied, and residuals were tested for normality with the Shapiro-Wilk test. If another distribution could be recognized graphically, models were built using the 'Imer' function (GLMER), where it is possible to incorporate a non-normal distribution of data and residuals by choosing the distribution family accordingly. However, some models failed to show a normal distribution despite transformation. Nevertheless, linear models are known to be relatively robust to deviations from normal distribution and minor deviations from normality are frequently ignored in research (Sengupta 2012).Thus the models were still used if the departure from normality was not considered severe. I used June 2012 survival for the LME, as I lost entire stations later on in a winter storm. The storm caused erosion which was well beyond normal erosion and therefore would have skewed the data unreasonably. I illustrate survival over the course of the experiment to give some indication of how plants developed in the different treatments. Plant size was calculated using a volume-based size formula converted back to a linear dimension and log-transformed to normalise the values: 


$$
\left(\log \left(\text { height } *((\min w i d t h+\max w i d t h) / 2)^{2}\right)^{1 / 3}\right)
$$

Initial models were applied to test for an interaction between the predictors and field site. If any of the interaction terms with field site were significant, the two field sites were analysed separately. If none of the interaction terms were significant, data from both field sites were analysed together in a single model, with field site as a main effect only. In theory "site" could have been used as a random factor, but it would not have saved any degrees of freedom and would have added to the complexity of the nested random factors already included - which can create problems in model fitting when three or more levels are being fitted. A complete overview of all final LMEs is shown in Table 2.3. Models were fitted using maximum likelihood and F-ratios examined to determine the significance of each predictor variable. The amount of live pre-existing marram grass cover and other vegetative cover were used as covariates. My a priori interest was a test of the stress gradient hypothesis (SGH) and for that to be proven I require a significant interaction between station and treatment. Underwood (2000) commented on the necessity carefully constructed a priori tests of null hypotheses opposed to solely relying on statistical tests only. Underwood (1997) also emphasized the need to use logic when interpreting ANOVA results. For the SGH this means if significance of the interaction is found, examination of graphs is then sufficient to tell whether or not the pattern is in accordance with the SGH. While post hoc tests can increase the understanding of significant main effects their use for exploring significant interaction effects is considered controversial and highly context dependent (Martinez 2013). My experiments exhibit a level of complexity in the interaction of treatments (e.g. nine interaction combinations for Chapter 2) which make the use of newly developed post hoc tests for LMEs inadequate.

All statistical analyses was performed using the open source program 'R 2.15.1' (R Core Team, 2012). Where boxplots were used, boxes and whiskers are by $R$ default (boxes encompass the interquartile range (IQR). Whiskers extend to the end of the range except for the outliers (>1.5 times the range). A user defined function was applied to create graphs comparing the treatments relative to bare sand (see Appendix II). 
Table 2.3: Models used in this chapter. $L M E=$ linear mixed effect model, GLMER= generalized linear mixed-effects Models. $T$ and $W$ indicate the field sites Tapuarau and Whitiau respectively where the models were used separately for each field site.

\begin{tabular}{|c|c|c|c|c|c|}
\hline Field sites & model & response variable & unit & predictors & random factors \\
\hline & & & change in & & \\
\hline $\mathrm{T}, \mathrm{W}$ & LME & sand movement & $\%$ & treatment*station & transect \\
\hline$T, W$ & LME & conductivity & $\mathrm{m} / \mathrm{Si}$ & treatment*station & transect \\
\hline $\mathrm{T}, \mathrm{W}$ & LME & $\begin{array}{l}\text { June inner plant } \\
\text { survival }\end{array}$ & counts & treatment*station & transect \plotID \\
\hline $\mathrm{T}, \mathrm{W}$ & LME & $\begin{array}{l}\text { June outer plant } \\
\text { survival }\end{array}$ & counts & treatment*station & transect \plotID \\
\hline $\mathrm{T}, \mathrm{W}$ & LME & $\begin{array}{l}\text { November outer } \\
\text { plant survival }\end{array}$ & counts & treatment*station & transect \plotID \\
\hline$T, W$ & LME & $\begin{array}{l}\text { Nov inner plant } \\
\text { survival }\end{array}$ & counts & treatment*station & transect \plotID \\
\hline $\mathrm{T}, \mathrm{W}$ & GLMER & June plant size & $\mathrm{cm}$ & treatment*station & transect $\backslash$ plotID \\
\hline both & GLMER & Nov plant size & $\mathrm{cm}$ & treatment*station & transect\plotID \\
\hline $\mathrm{T}, \mathrm{W}$ & LME & Feb circumference & $\mathrm{cm}$ & treatment*station & transect\plotID \\
\hline $\mathrm{T}, \mathrm{W}$ & LME & Nov circumference & $\mathrm{cm}$ & treatment*station & transect\plotID \\
\hline $\mathrm{T}, \mathrm{W}$ & LME & Nov stolons & counts & treatment*station & transect \plotID \\
\hline & LME & Nov circumference & $\mathrm{cm}$ & treatment*station & transect\plotID \\
\hline$T, W$ & & & & $\begin{array}{l}\text { covariable: Marram } \\
\text { grass from April } \\
\text { (\%cover estimates) }\end{array}$ & \\
\hline
\end{tabular}




\subsection{Results}

\section{Dune profiles}

Dune profiles are displayed in Figure 2.14. Profiles for Whitiau typically started on top of the front cliff (Transect 6 - 10).
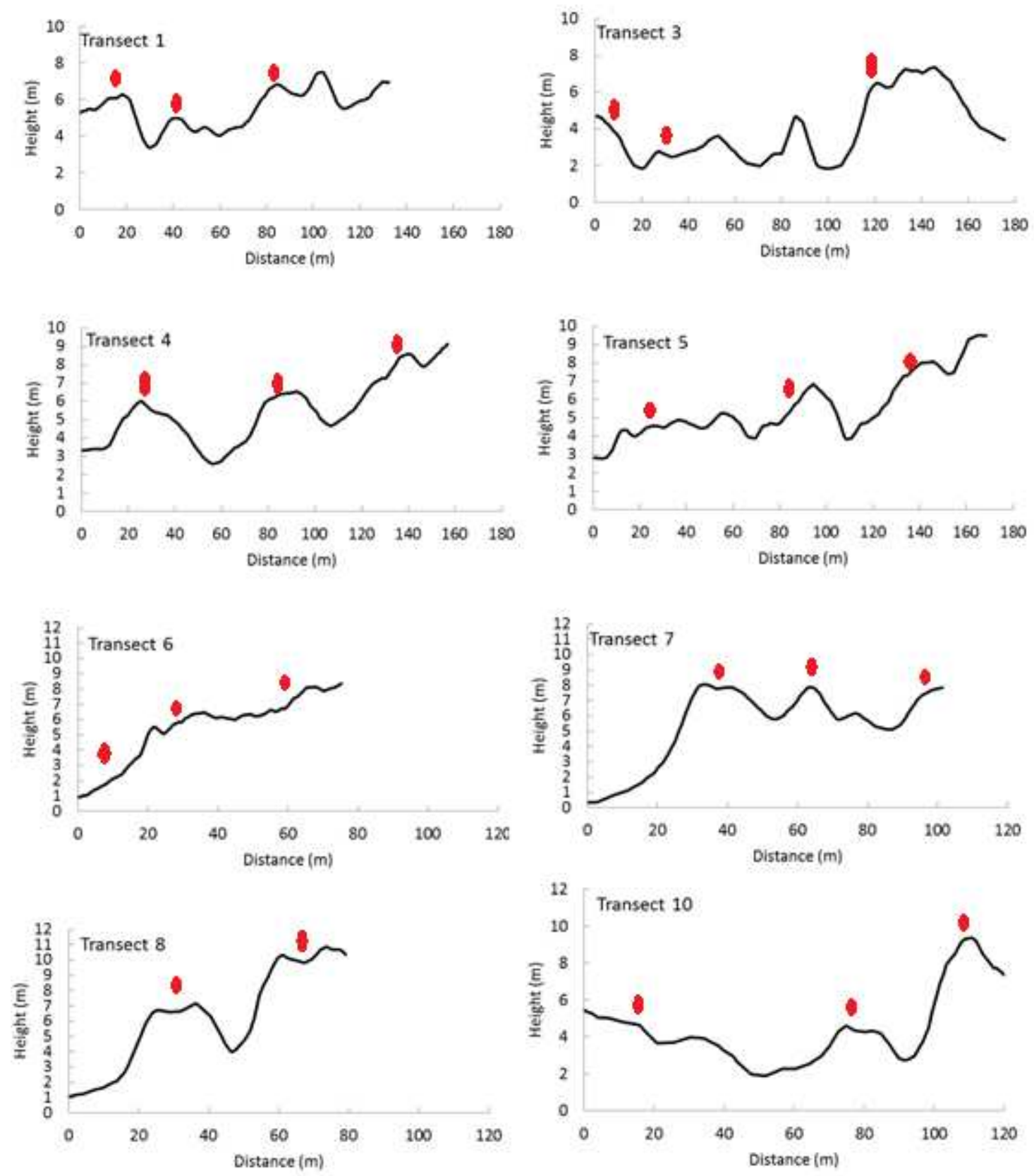

Figure 2.14: Dune profiles of transect $1,3,4$ and 5 at Tapuarau and transect $6,7,8$ and 10. Red dots above dune profiles indicate approximate station locations. 


\section{Differences between spinifex nurseries}

At the time of the first monitoring there were no significant differences for height and largest leaf between the nurseries. Therefore nursery origin was not included as a factor in subsequent models.

\subsubsection{Stress gradient measurements}

A PCoA of conductivity, sand movement and organic matter showed differences between stations (Appendix, Fig. A 11.3).

Sand movement and organic matter showed significant interactions between field site and a covariate and therefore both response variables were analysed separately per field site. Both sites were analysed together for conductivity and slope as these did not show any interaction between field site and any of the predictors.

\section{Conductivity}

Conductivity was significantly different between stations (Table 2.4, Figure 2.15) but did not differ significantly between treatments, field sites nor the interaction between treatment and station.

Table 2.4: Summary of a LME for conductivity (data from both field sites combined). The two levels of treatment were marram and bare sand. Transect was included as a random effect.

\begin{tabular}{llrrrr}
\hline Response variable & Predictor & numDF & denDF & F-value & p-value \\
\hline conductivity $(\mu \mathrm{S} / \mathrm{m})$ & field site & 1 & 5 & 5.123 & 0.073 \\
& treatment & 1 & 32 & 0.372 & 0.547 \\
& station & 1 & 32 & 8.885 & 0.006 \\
& treatment:station & 1 & 32 & 0.185 & 0.670 \\
\hline
\end{tabular}




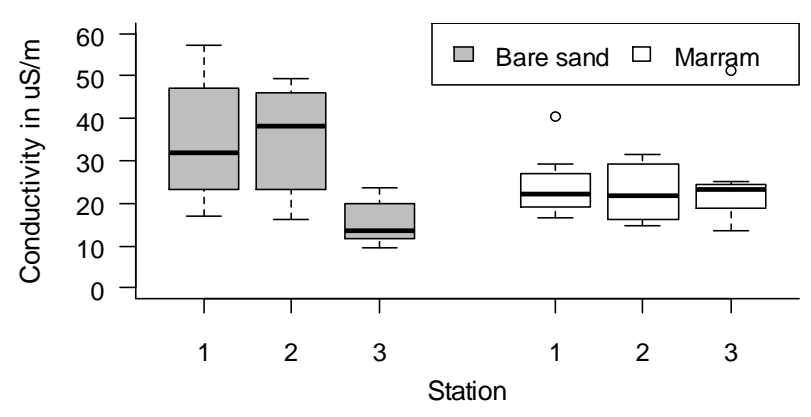

Figure 2.15: Conductivity $(\mu \mathrm{S} / \mathrm{m})$ as a function of station (from fore dune to back dune) and vegetation cover treatment (Marram or Bare sand). $\mathbf{N}=\mathbf{2 4}$ plots per treatment combination combined across both field sites for marram and bare plots. Whiskers extend to the end of the range except when there are outliers (where outliers are values $>1.5$ times the IQR beyond the box).

\section{Organic matter}

Distance to the sea (station) was a significant predictor of organic matter at Whitiau (Table 2.5). Organic matter increased with distance to the sea (Fig 2.16, Table 2.5).

Table 2.5: Summary of LME for organic matter in \% (data separated by field site). Transect was included as a random effect.

\begin{tabular}{|c|c|c|c|c|c|c|}
\hline Field site & Response variable & Predictor & numDF & denDF & F-value & p-value \\
\hline \multirow[t]{3}{*}{ Tapuarau } & organic matter & treatment & 1 & 17 & 1.424 & 0.249 \\
\hline & $(\%)$ & station & 1 & 17 & 0.856 & 0.368 \\
\hline & & treatment:station & 1 & 17 & 1.078 & 0.314 \\
\hline \multirow[t]{3}{*}{ Whitiau } & & treatment & 1 & 17 & 0.206 & 0.656 \\
\hline & & station & 1 & 17 & 15.717 & 0.001 \\
\hline & & treatment:station & 1 & 17 & 0.994 & 0.333 \\
\hline
\end{tabular}

A similar trend (non-significant) was also evident across the bare plots at Tapuarau, but not among the marram plots (Figure 2.16 and Table 2.5). 

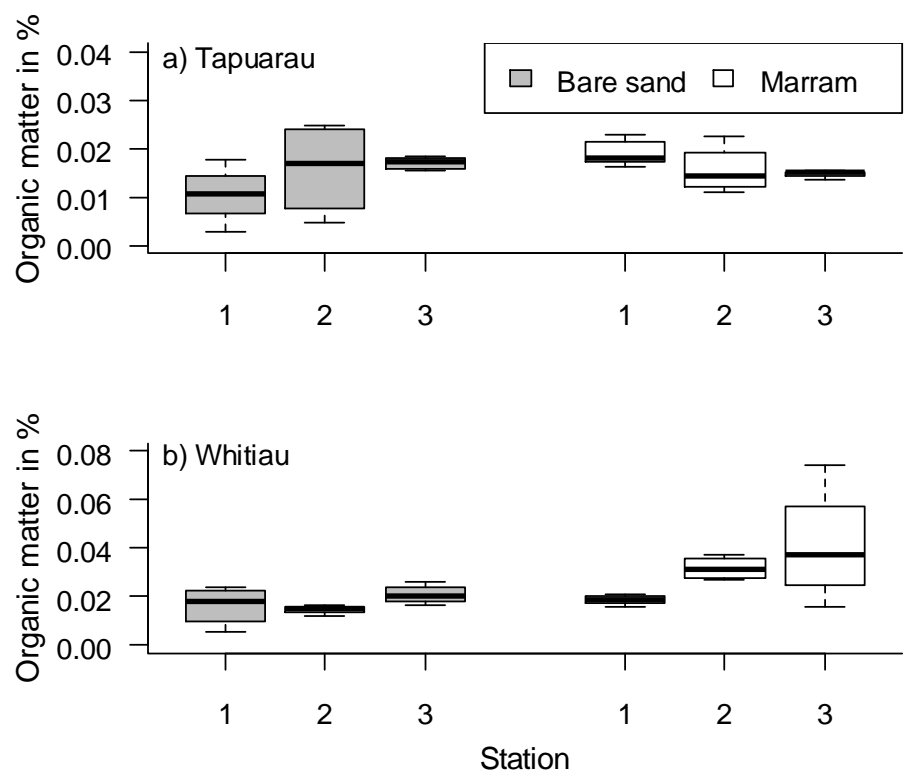

Figure 2.16: Organic matter from sand samples from bare sand plots (left graph) and from marram plots (right graph) per station (station 1 = closest to the sea, station 2 = intermediate distance to the sea, station $\mathbf{3}$ = furthest away from the sea). Samples are split up by field site (upper graph Tapuarau, lower graph Whitiau). Note the difference in scale for the y-axis. 


\section{Sand movement}

\section{Tapuarau}

Sand movement at Tapuarau showed significant effects of the predictor variables 'treatment' and 'station' (Table 2.6) but not for the interaction between both (Table 2.6). Sand movement varied between field sites: for Tapuarau sand movements were most variable at second sprayed plots, followed by first bare plots (Fig. 2.17).

\section{Whitiau}

No significant effects of 'treatment' or 'station' were found for sand movement at Whitiau.

Table 2.6: Summary of a LME with sand movement change in \% between February 2012 and November 2012. Transect was included as a random factor. Both planted and unplanted plots were used for this LME. Treatment had six levels (i.e. planted marram, unplanted marram, planted sprayed marram and unplanted sprayed marram, planted bare sand and unplanted bare sand).

\begin{tabular}{|c|c|c|c|c|c|c|}
\hline Field site & response variable & predictor & numDF & denDF & F-value & p-value \\
\hline \multirow[t]{3}{*}{ Tapuarau } & sand change in \% & treatment & 5 & 64 & 3.202 & 0.012 \\
\hline & & station & 1 & 64 & 4.689 & 0.034 \\
\hline & & treatment $\times$ station & 5 & 64 & 1.357 & 0.252 \\
\hline \multirow[t]{3}{*}{ Whitiau } & sand change in \% & treatment & 5 & 40 & 1.039 & 0.408 \\
\hline & & station & 1 & 40 & 2.142 & 0.151 \\
\hline & & treatment:station & 5 & 40 & 0.370 & 0.866 \\
\hline
\end{tabular}



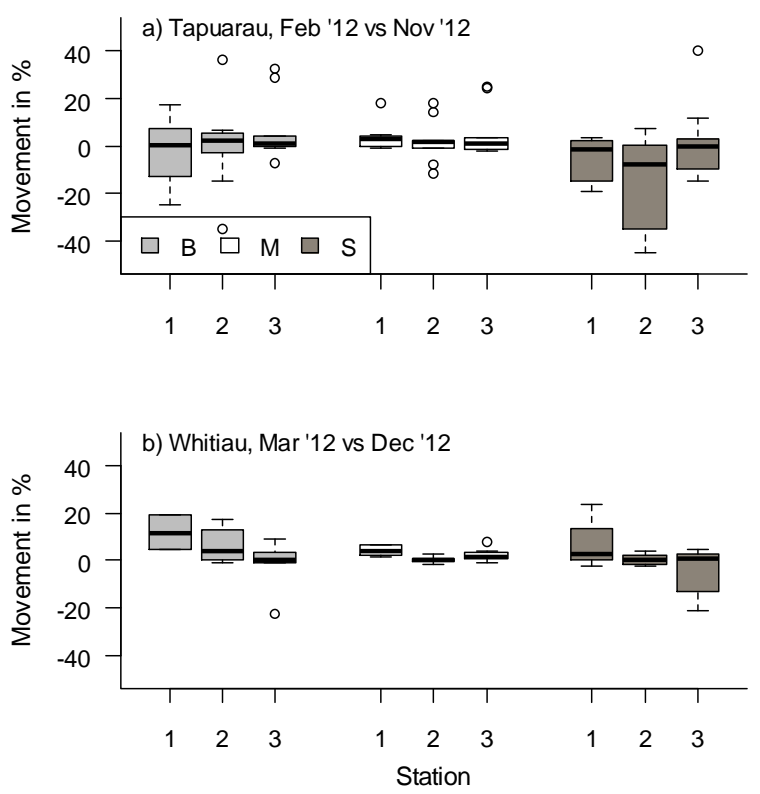

Figure 2.17: Sand movement for station 1, 2, 3 (from left to right) for each treatment ( $B$ = bare sand, $M=$ marram, $\mathbf{S}=$ Sprayed marram) for plots at Tapuarau (upper graph) and Whitiau (lower graph) between February 2012 and November 2012. Movement change is given in \% and comprises planted and unplanted plots.

\section{Slope}

Slope was significantly predicted by the location of the plot (station), the type of treatment and the interaction between the two. (Table 2.7). There was no significant effect of field sites (Table 2.7).

Table 2.7: Summary of LME for slope in $\mathrm{cm}$ (data from both field sites combined). Transect was included as a random effect.

\begin{tabular}{llrrrr}
\hline Response variable & predictor & numDF & denDF & F-value & p-value \\
\hline Slope in cm & field site & 1 & 9 & 2.437 & 0.153 \\
& treatment & 2 & 931 & 188.360 & $<0.001$ \\
& station & 1 & 931 & 151.045 & $<0.001$ \\
& treatment:station & 2 & 931 & 22.062 & $<0.001$ \\
\hline
\end{tabular}

Dune slope varied greatly among plots (Fig. 2.18 and Fig. 2.19). The steepest slopes were measured on live marram plots, in particular at the front station (i.e. station 1). The second steepest slopes were measured on sprayed marram plots followed by bare plots (Fig. 2.19). 


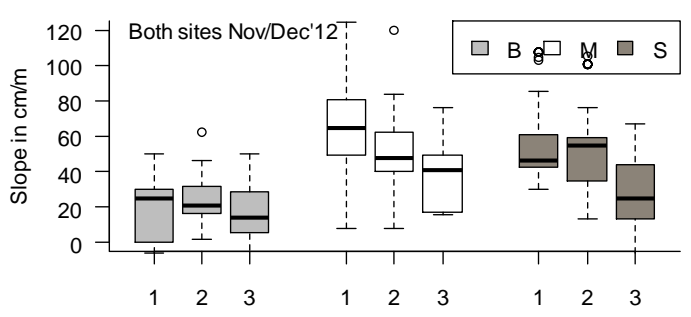

Figure 2.18: Slope in $\mathrm{cm} / \mathrm{m}$ from the sand plot per station in Nov/Dec 2012 (station 1 = closest to the sea, station 2 = intermediate distance to the sea, station $\mathbf{3}$ = furthest away from the sea).

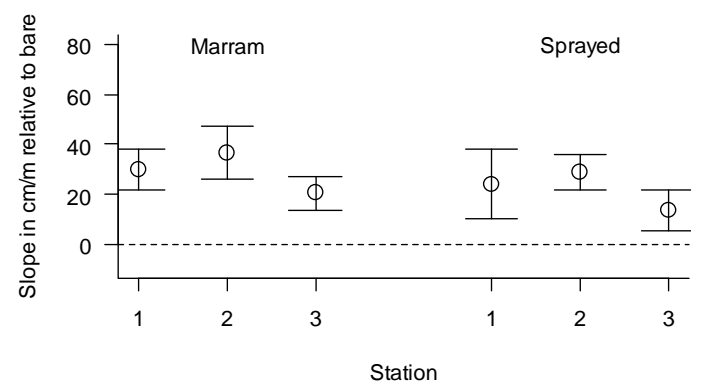

Figure 2.19: Slope in $\mathrm{cm} / \mathrm{m}$ from the sand plot per station in Nov/Dec 2012 for marram and sprayed plots relative to bare sand. Station 1 = closest to sea, station 2 = intermediate, station $\mathbf{3}=$ furthest away from the sea). Errorbars are +/-SE. 


\section{Erosion and accretion}

Signs of erosion and accretion were visible throughout the experiment at Whitiau and Tapuarau respectively (Fig. 2.20). While the accretion was not very visible on photos, Figure 2.20 shows the erosion of a cliff of station one (transect 6) at Whitiau and the gradual burial of one public sign (E-F).

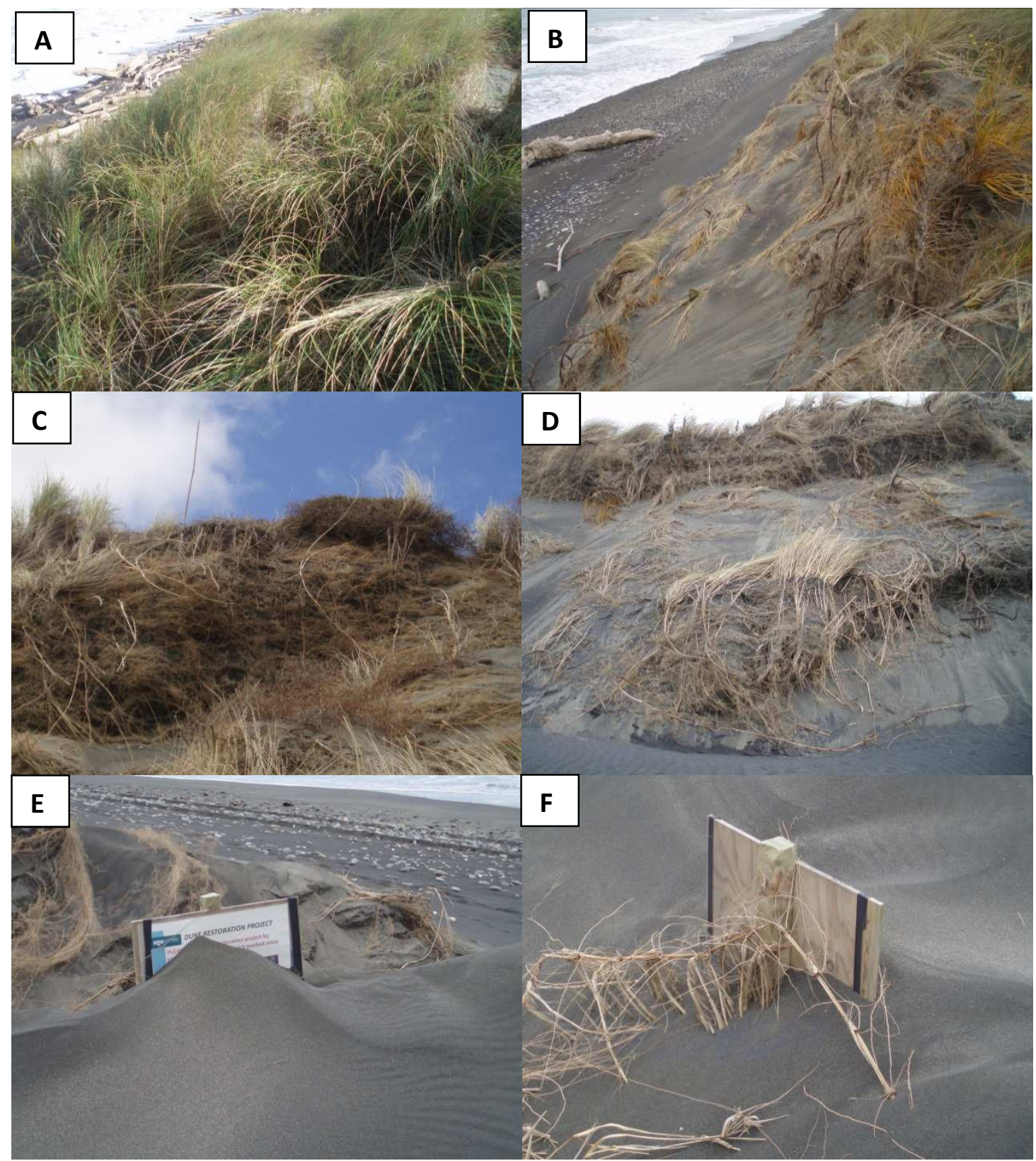

Figure 2.20: Erosion at Whitiau. Picture A shows the first station of transect 6 at Whitiau before winter 2012 and picture $B$ shows the same location after the winter storms in December 2012. Picture C and D show the cliff face of the eroded first station at transect 6 . Picture $E$ and $F$ show a public sign, which was at the time of construction clearly above the sand layer. The sand blocking the sign is from a nearby eroding cliff. 


\subsubsection{Spinifex measurements}

In the following analyses there are only three levels of 'treatment' (planting of spinifex into (i) herbicide-sprayed, dead marram (ii) live marram and (iii) bare sand). For obvious reasons, spinifex survival and growth could not be measured in plots that did not receive spinifex plantings.

\section{Spinifex survival}

Spinifex survival differed significantly between the two field sites and with the location of the plot within each field site. However 'treatment' had no significant effect on survival and none of the interaction terms were significant (Table 2.8). Sites were combined for analysis (as there was no significant interaction between site and the other variables) but have been plotted separately because there is a main effect of site survival results for Tapuarau and Whitiau respectively (Fig. 2.21, Fig. 2.22 and Fig. 2.23).

Table 2.8: Summary of LME for June inner plant survival (data from both field sites combined). Transect and plot ID were included as random effects.

\begin{tabular}{llllll}
\hline Response variable & Predictor & numDF & denDF & F-value & p-value \\
\hline Survival & Fieldsite & 1 & 9 & 8.9947 & 0.015 \\
(out of 9) & treatment & 2 & 71 & 0.2238 & 0.8 \\
& station & 1 & 71 & 6.7032 & 0.0117 \\
& treatment:station & 2 & 71 & 0.8115 & 0.4483 \\
\hline
\end{tabular}

Survival decreased over time (Fig. 2.21, Fig. 2.22 and Fig. 2.23) and was generally higher at stations further away from the sea. 

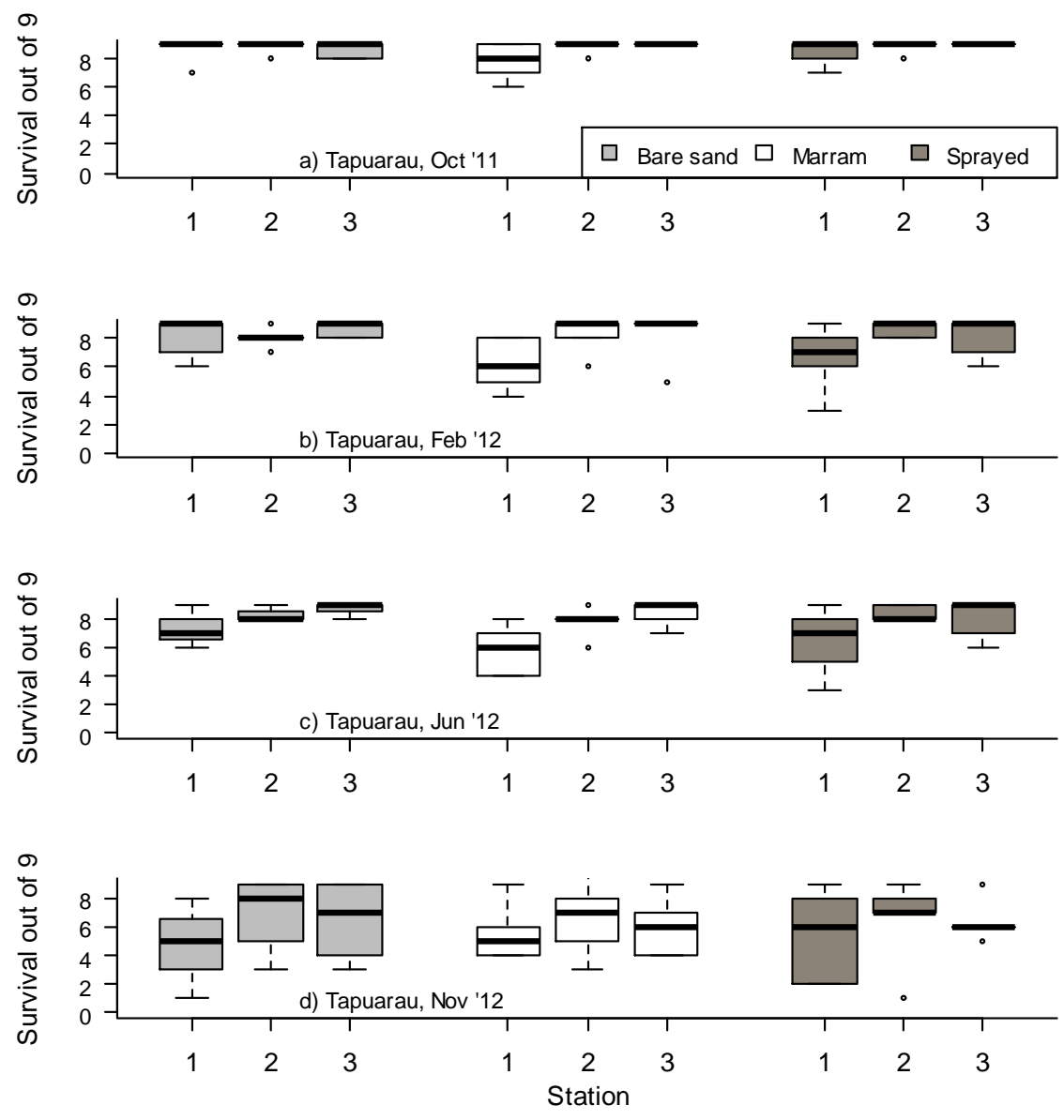

Figure 2.21: Survival out of the nine inner plants is shown for Tapuarau one month after planting (October 2011), five months after planting (February 2012), nine months after planting (June 2012) and thirteen months after planting (November 2013). The boxplots are split up between the different treatments $(B=$ bare sand, $M=$ live marram, $S=$ sprayed marram). Station 1 is closest to the sea (fore dune), station $\mathbf{2}$ = intermediate distance to the sea (mid-dunes) and station 3 is furthest away from the sea (back-dune). 

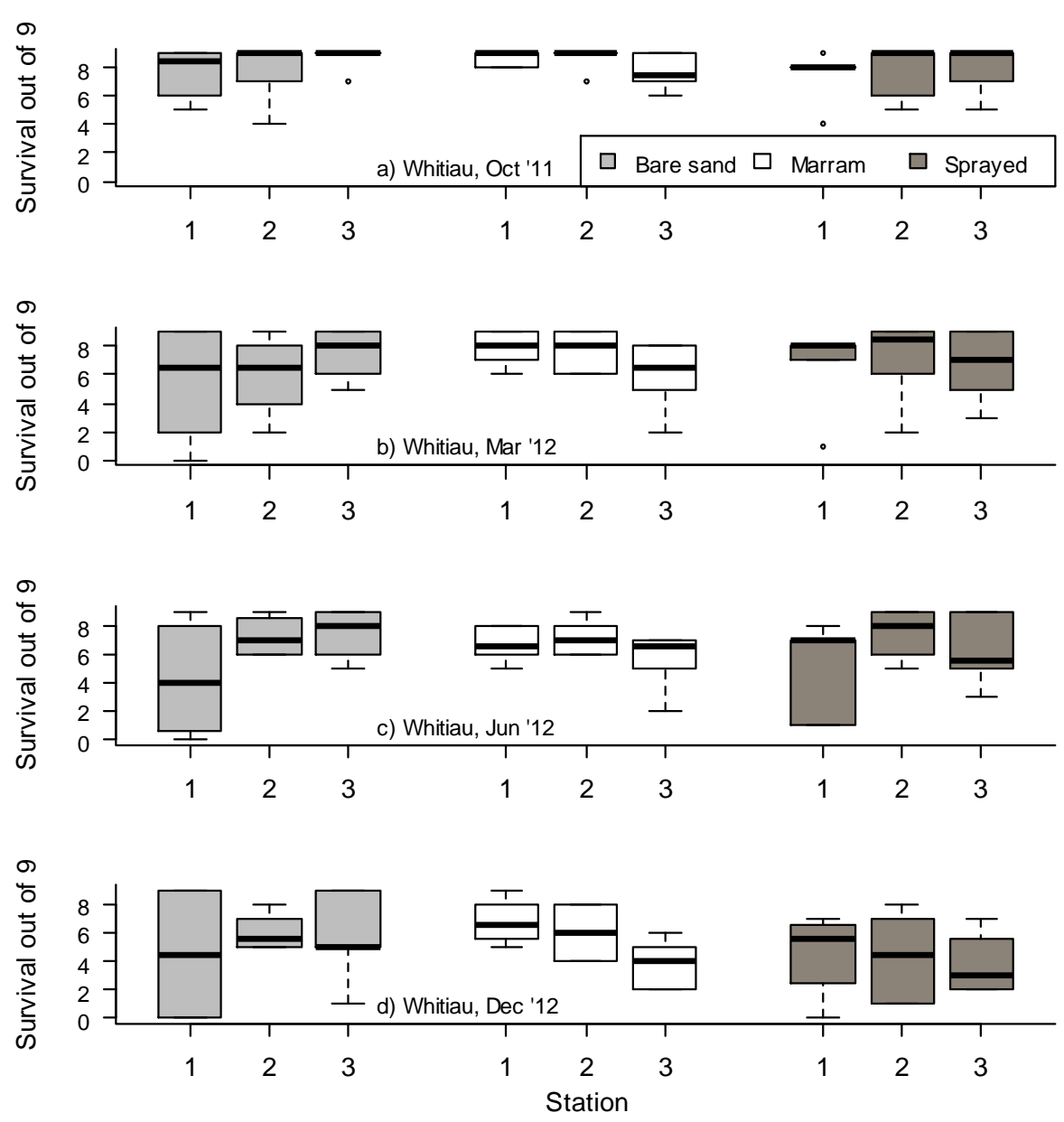

Figure 2.22: Survival out of the nine inner plants is shown for Whitiau one month after planting (October 2011), six months after planting (March 2012), nine months after planting (June 2012) and 14 months after planting (December 2013). The boxplots are split up between the different treatments ( $B=$ bare sand, $\mathbf{M}$ = live marram, $\mathbf{S}=$ sprayed marram). Station 1 is closest to the sea (fore dune), station $\mathbf{2}=$ intermediate distance to the sea (mid-dunes) and station 3 is furthest away from the sea (back-dune).

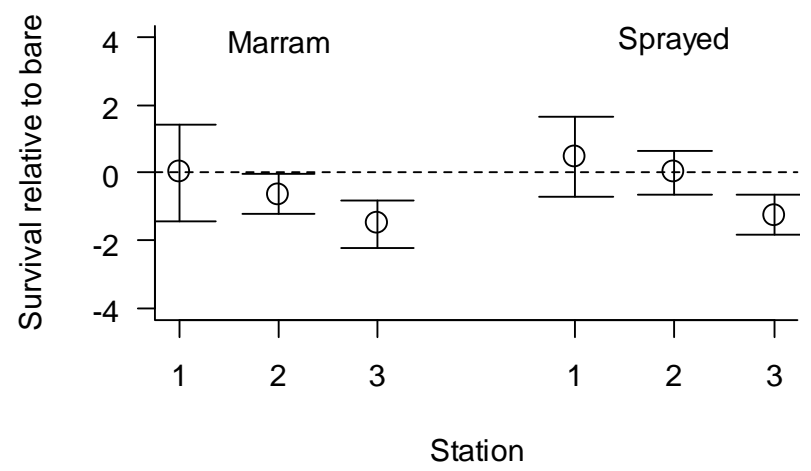

Figure 2.23: Shows inner plant survival (out of 9) for live marram and sprayed dead marram plots relative to bare sand. Error bars indicate $+/$ - SE. Station refers to the location in reference to the sea (Station 1 = closest to sea, station 2 = intermediate, station 3 = furthest away from the sea). Plant counts are from June 2012, 9 months after planting. 


\section{Spinifex growth}

Examples of spinifex growth are shown in Figure 2.24.

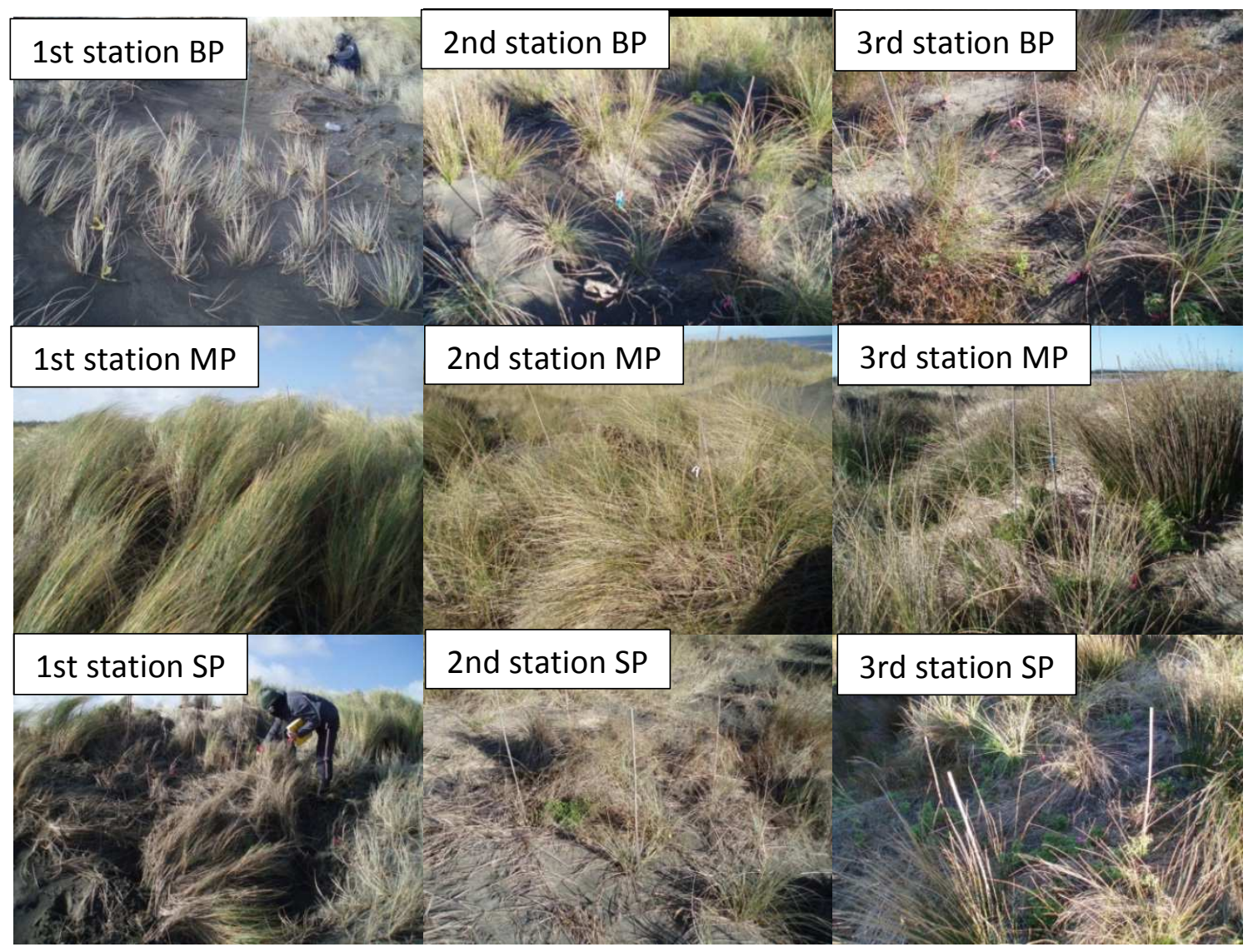

Figure 2.24: Photos of typical plots along the three different stations along a transect. First row shows plantings in bare sand (BP), in live marram (MP) and in sprayed marram (SP). The same order of plot treatment is shown for the second station in the second row and the third station in the third row respectively. 


\section{Size comparison within and among stations}

Plant size showed a poisson distribution therefore, a GLMER was used as a model instead of a LME. The Nov/Dec dataset showed treatment as the only significant predictors for spinifex plant size (Table2.9). Station showed a trend, but it was not significant (Table 2.9).

Table 2.9: Summary of a GLMER for log-transformed plant size (data from both field sites combined). Transect and plot ID were included as random factors, and a poisson distribution of errors was assumed.

\begin{tabular}{llllc}
\hline Response variable & Predictor & Chisq & Df & $\operatorname{Pr}(>$ Chisq $)$ \\
\hline Plant size & treatment & 10.268 & 2 & 0.006 \\
November & station & 2.821 & 1 & 0.093 \\
& treatment:station & 0.631 & 2 & 0.729 \\
\hline
\end{tabular}

Plant size differed significantly between treatments: in general growth was greater in bare sand than in live or dead marram. Growth was also generally greater closer to the sea (Fig. 2.25 and Fig. 2.26).

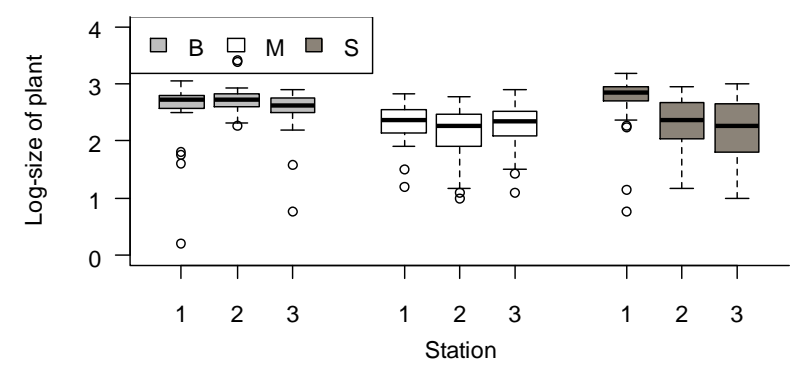

Figure 2.25: Log-transformed plant size is shown per station (station 1 = closest to the sea, station 2 = intermediate distance to the sea, station $3=$ furthest away from the sea) for both field sites split up by treatment ( $B=$ bare sand, $M$ = live marram, $\mathbf{S}=$ sprayed marram).

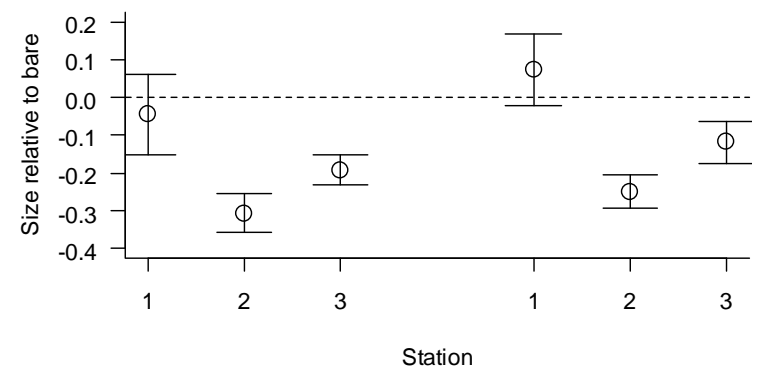

Figure 2.26: Plant size is shown for marram and sprayed plots relative to bare sand. Station 1 = closest to sea, station $\mathbf{2}$ = intermediate, station $\mathbf{3}$ = furthest away from the sea). Plant size measurements are from November 2012. Error bars indicate +/- SE. 


\section{Spinifex growth and the influence of pre-existing marram grass cover}

LME model results:

Spinifex growth, also referred to as breadth (as measured by log-basal circumference 12 months after planting), was significantly affected by the interaction of treatment with station and pre-existing marram grass cover for both field sites. At Tapuarau all tested explanatory variables were significant apart from station were a trend was evident with $p<0.1$ (Table 2.10). The interaction between pre-exisiting marram grass cover and station was significant (Table 2.10). 'Slope' did not improve the overall model where spinifex growth and survival parameters were accounted for. Hence it was deleted from the model.

Table 2.10: ANOVA summary of a LME for log-transformed breadth in $\mathrm{cm}$ (data analysed separately per field site). Transect and plot ID were included as random effects.

\begin{tabular}{|c|c|c|c|c|c|c|}
\hline Field site & $\begin{array}{l}\text { Response } \\
\text { variable }\end{array}$ & Predictor & numDF & denDF & F-value & $\begin{array}{c}\mathrm{p}- \\
\text { value }\end{array}$ \\
\hline \multirow[t]{5}{*}{ Tapuarau } & breadth & initial marram cover & 1 & 29 & 26.023 & $<.0001$ \\
\hline & $\log$ & treatment & 2 & 29 & 6.208 & 0.006 \\
\hline & transformed & station & 1 & 29 & 3.477 & 0.072 \\
\hline & $\mathrm{Cm}$ & initial marram cover:station & 1 & 29 & 5.556 & 0.025 \\
\hline & & treatment:station & 2 & 29 & 3.804 & 0.034 \\
\hline \multirow[t]{5}{*}{ Whitiau } & " " & initial marram cover & 1 & 27 & 34.904 & $<.0001$ \\
\hline & & treatment & 2 & 27 & 12.887 & 0.000 \\
\hline & & station & 1 & 27 & 0.887 & 0.355 \\
\hline & & initial marram cover:station & 1 & 27 & 2.135 & 0.156 \\
\hline & & treatment:station & 2 & 27 & 6.152 & 0.006 \\
\hline
\end{tabular}




\section{Tapuarau}

The sprayed planted plots at the first station showed the highest overall circumference values for Tapuarau and the lowest for first and second station marram plots (Fig. 2.27). Bare sand plots showed higher absolute values for the November measurements compared to the February monitoring results. In both monitoring rounds, plants in bare sand in first and second station plots had similar circumferences (Fig 2.27 and Fig 2.28).

\section{Whitiau}

Spinifex plants in the bare sand second station plots had the largest circumference values compared to all other treatments and stations in both monitoring rounds (March and December 2012) (Fig. 2.27). Values for the bare sand planted plots remained similar between monitoring rounds except that the number of plots available for the first station bare sand plots dropped due to erosion and thus some planted plots were lost (Fig. 2.27). While marram planted plots showed the lowest circumference values for both monitoring rounds compared to the other treatments, they were relatively homogenous between station during the March 2012 monitoring (Fig. 2.27). Sprayed planted plots showed no significant differences between stations for March and values for first station sprayed plots were lower than second and third station circumferences in Nov/Dec2012. The third station showed the highest values for sprayed planted plots in December.

\section{Relative log circumference differences compared to bare plots}

Only first station sprayed plots showed higher relative mean values compared to bare sand plots for circumference in February/March 2012 (Fig. 2.28). All marram plots regardless of the station showed lower values compared to sprayed plots. However, the pattern was different in November/December 2012: sprayed first stations showed higher values than bare plots. Second sprayed and marram plots showed similar low values for circumference in comparison to bare sand (Fig. 2.28).

All marram and sprayed plots at Whitiau showed lower mean values for circumference of spinifex plants compared to bare sand regardless of the station in March 2012 (Fig. 2.28). All marram circumference means were lower compared to bare sand. Sprayed plots showed lower values for breadth in comparison to bare sand (Figure 2.28). 

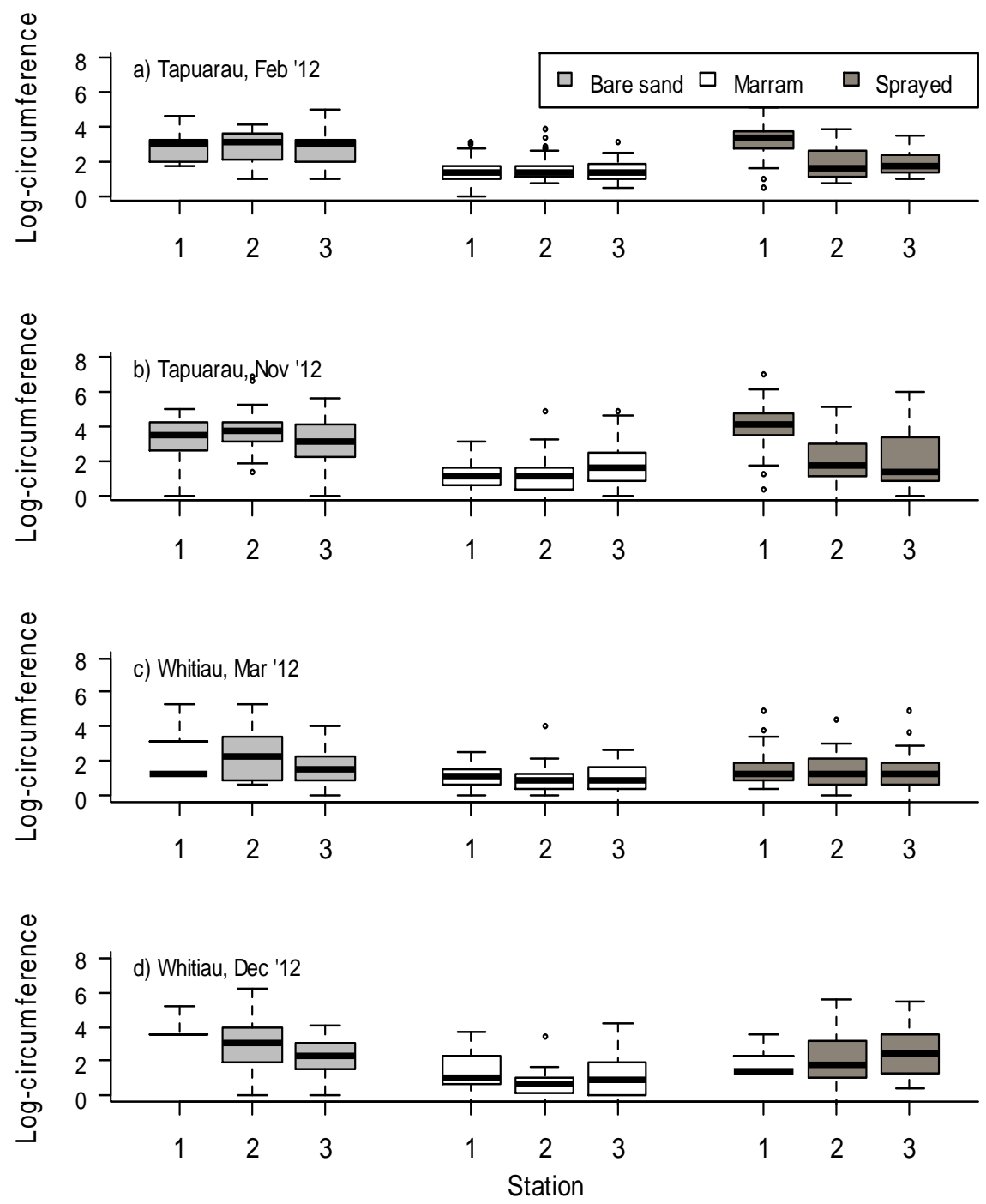

Figure 2.27: Log-circumference of spinifex plants is shown for Tapuarau in (a) February 2012 , (b) November 2012, (c) Whitiau in March 2012 and (d) December 2012 for bare sand, marram and sprayed plots across all stations. Station 1 = closest to sea, station 2 = intermediate, station $\mathbf{3}=$ furthest away from sea. 
a) Tapuarau, Feb'12

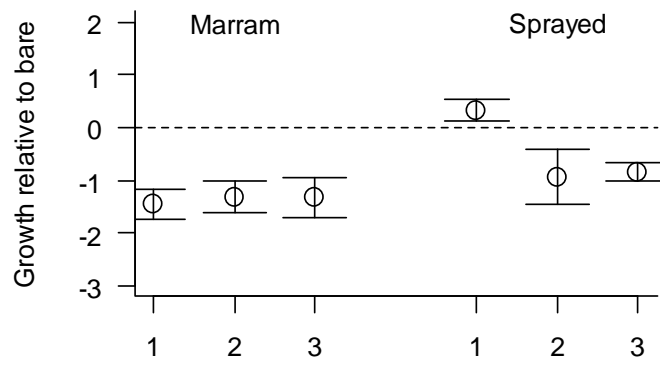

b) Whitiau, Mar'12 Station

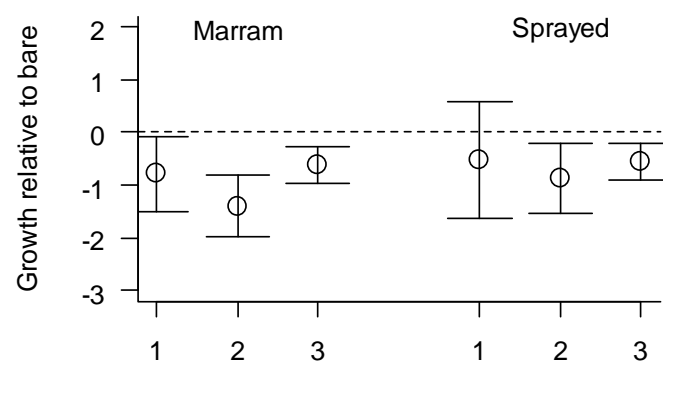

Station c) Tapuarau, Nov'12

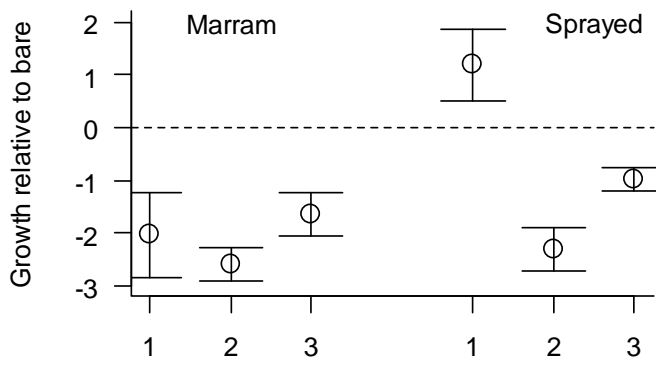

d) Whitiau, Dec'12

Station

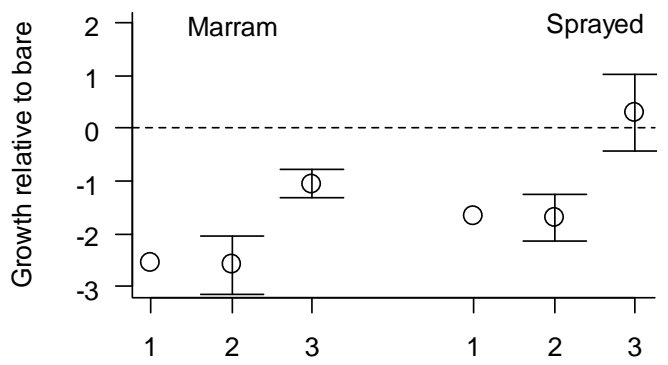

Station

Figure 2.28: Relative difference for growth (circumference) is plotted for planted marram and planted sprayed plots versus planted bare plots. Error bars show +/- SE. Station 1 = closest to sea, station 2 = intermediate, station $\mathbf{3}$ = furthest away from sea.

Spinifex circumference and the correlation with pre-existing marram grass cover was examined: a negative correlation was found for all treatments at Tapuarau and Whitiau (Fig. 2.29).

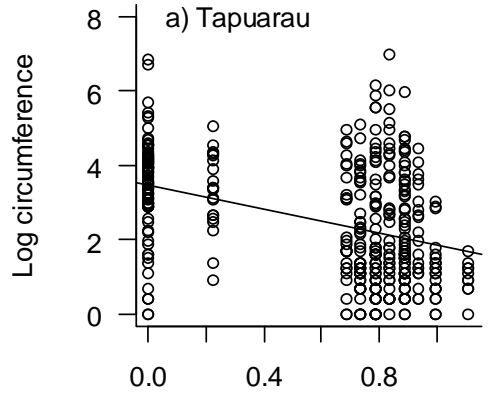

Arcsine sqrt transformed marram

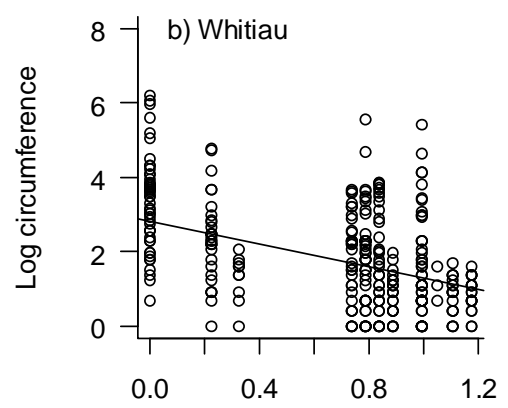

Arcsine sqrt transformed marram

Figure 2.29: Log-stransformed circumference of spinifex plants in November is shown against initial marram cover in April (when plots were chosen). Graph a) shows values for Tapuarau and b) for Whitiau. All plots are shown. 
The relationship between log-transformed circumference and pre-existing marram grass cover (transformed with the arcsine square root fuction) was further split up between live and sprayed marram grass (Fig. 2.30). The negative correlation between between log-transformed circumference and pre-existing marram grass cover (transformed with the arcsine square root fuction) was stronger at Tapuarau compared to Whitiau (Fig. 2.30). For sprayed marram grass as the treatment the LM-curve was steeper compared to live marram: higher values for log circumference were found (Fig. 2.30) for lower arcsine transformed marram but also remained higher for highest marram values at Tapuarau compared to data collected at Whitiau (Fig 2.30).

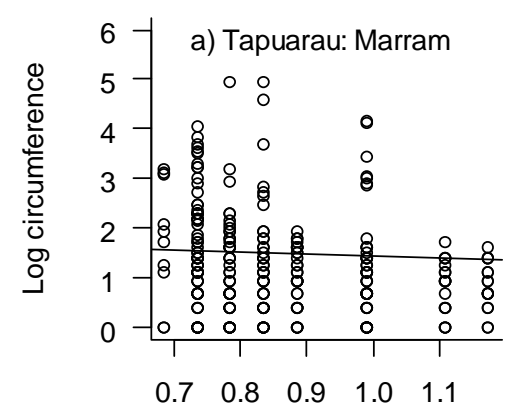

Arcsine sqrt transformed marram

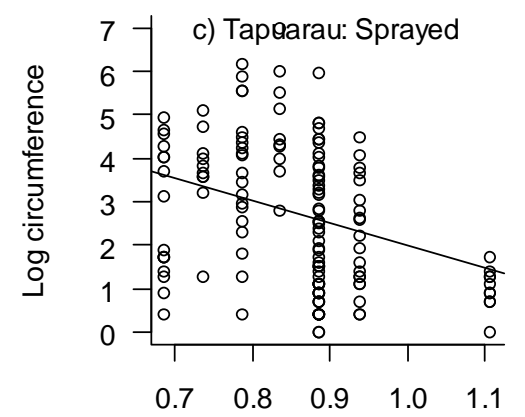

Arcsine sqrt transformed marram

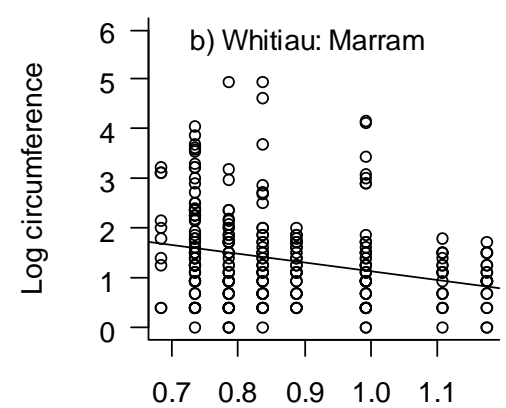

Arcsine sqrt transformed marram

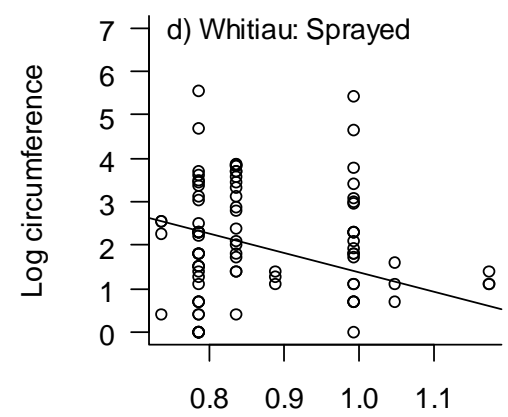

Arcsine sqrt transformed marram

Figure 2.30: Log (circumference) of planted spinifex versus pre-existing marram grass (April 2011). Spinifex circumference was measured in Nov/Dec 2012 and marram cover in April 2011. Graph a) shows live marram plots for Tapuarau and b) for Whitiau while sprayed marram is shown for Tapuarau in graph c) and Whitiau in graph d). 


\section{Other growth and health records of spinifex plantings}

The number of stolons showed differing response patterns for each field site and was thus analysed separately. The LME showed no significant effects of station or the interaction between treatment and station for stolon counts. However, the effect of treatment was extremely close to statistical significance and may warrant further investigation (Table 2.11 and Figure 2.31). In general, the number of stolons was higher in sprayed marram and bare sand plots compared to live marram plots (Figure 2.31).

Table 2.11: Summary of a LME for stolon counts Nov/Dec 2012. Transect and plot ID were included as random effects.

\begin{tabular}{|c|c|c|c|c|c|c|}
\hline Field site & Response variable & predictor & numDF & denDF & F-value & p-value \\
\hline \multirow[t]{3}{*}{ Tapuarau } & stolon counts & treatment & 2 & 28 & 3.335 & 0.050 \\
\hline & Nov/Dec'12 & station & 2 & 28 & 1.845 & 0.177 \\
\hline & & treatment:station & 4 & 28 & 0.856 & 0.502 \\
\hline \multirow[t]{3}{*}{ Whitiau } & & treatment & 2 & 27 & 3.256 & 0.054 \\
\hline & & station & 2 & 27 & 1.596 & 0.221 \\
\hline & & treatment:station & 4 & 27 & 1.938 & 0.133 \\
\hline
\end{tabular}
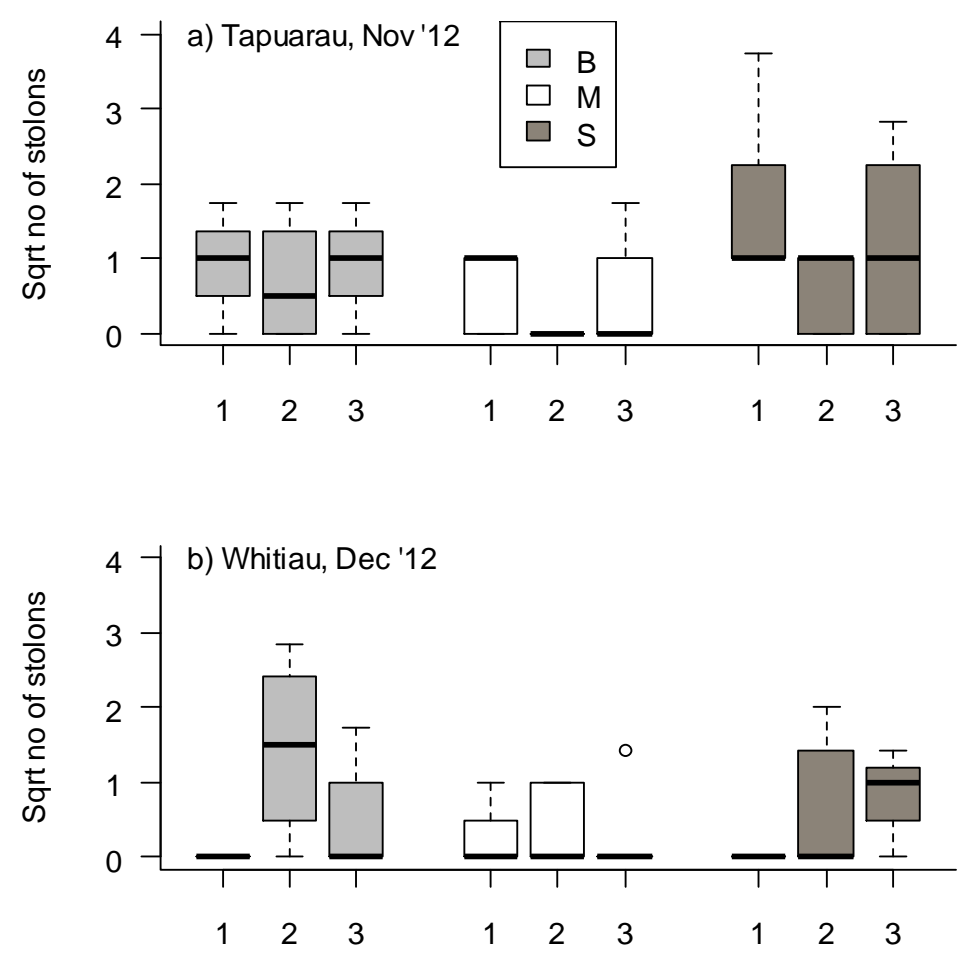

Figure 2.31: Square root transformed counts of stolons of spinifex plants per station is shown for the different treatments (i.e. $B=$ bare sand, $M=$ marram and $S=$ sprayed marram) seperately for Tapuarau (upper graph) and Whitiau (lower graph). 
The stolon length data was too sparse for parametric testing. The longest stolons had grown 3-5 metres in 12 months, but for those it was not possible to distinguish between plant specimens anymore. No stolons were recorded for spinifex planted among live marram.

\subsubsection{Spinifex flowers}

Only a few flowers were found across treatments across field sites. Most flowers (highest single value was 18 flowers per plot) were recorded for second bare stations at Tapuarau. All other stations and treatments at Whitiau only showed a few outliers.

\subsubsection{Browsing, dieback and insect damage}

\section{Browsing}

Browsing was only observed at Whitiau and only twice at second station sprayed plots with medium browsing score.

\section{Dieback}

Spinifex plant dieback showed a significant effect for station, with no significant interaction between the two in the LME (Table 2.12).

Table 2.12: Summary of a LME for dieback scores in Nov/Dec 2012. Transect and plot ID were used as random effects.

\begin{tabular}{llrrrr}
\hline Response variable & predictor & numDF & denDF & F-value & p-value \\
\hline Dieback & Field site & 1 & 9 & 0.768 & 0.404 \\
score & treatment & 2 & 63 & 3.084 & 0.053 \\
& station & 2 & 63 & 5.877 & 0.005 \\
& treatment:station & 4 & 63 & 0.844 & 0.503 \\
\hline
\end{tabular}

Dieback medians were generally higher at back stations (Fig. 2.32). Dieback varied across field sites and between stations (Fig. 2.32 and 2.33): Dieback was higher among live and sprayed marram grass compared to bare sand (Fig. 2.33 and Table 2.12). 

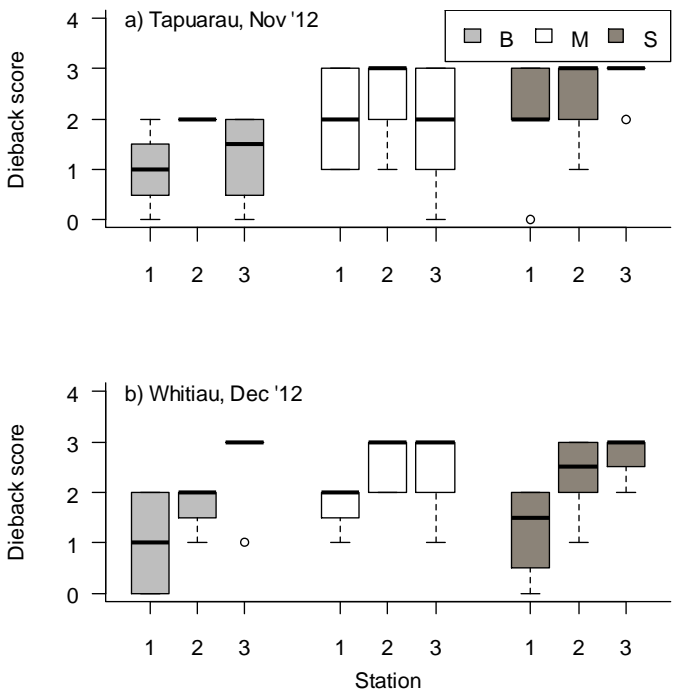

Figure 2.32: Dieback scores ranging from 1 - 3 (1 = present, $\mathbf{2}=$ medium, $\mathbf{3}=$ high) are shown per field site ( $a=$ Tapuarau in Nov'12 and $b=$ Whitiau in Dec'12) per station and treatment ( $B=$ bare sand, $M=$ marram, $\mathbf{S}=$ sprayed).
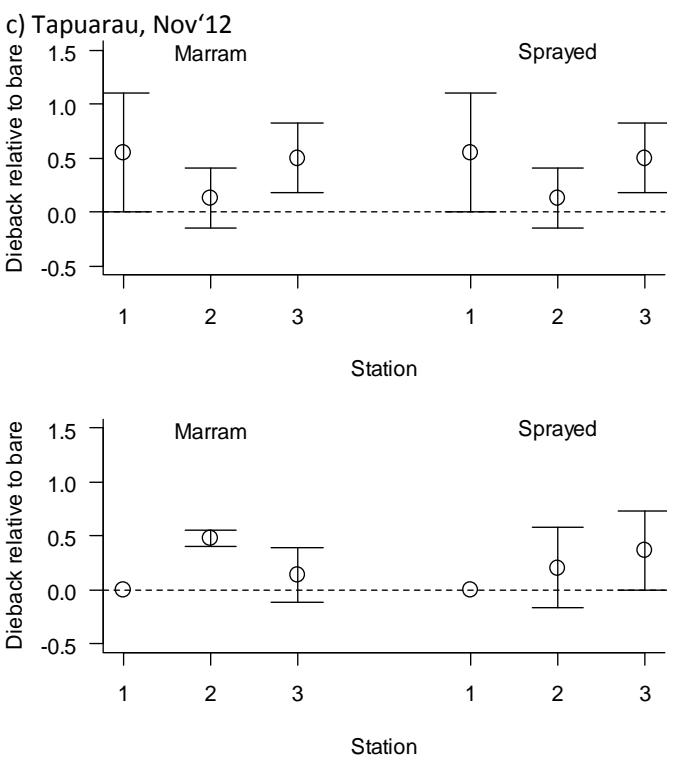

Figure 2.33: Relative dieback scores in comparison to bare plots. Graph c shows relative dieback scores +/- SE for Tapuarau Nov'12. Graph d shows relative dieback scores +/- SE for Whitiau Dec'12. 


\section{Insect damage}

There was hardly any insect damage on plots at either field site (Table 2.13).

Table 2.13: Insect damage is shown with insect damage scores (1= present, 2 = medium, 3 =high) for both field sites (Tapuarau and Whitiau) separated by station and treatment.

\begin{tabular}{lrrr}
\hline Location and treatment & Station $\mathbf{1}$ & Station 2 & Station 3 \\
\hline Tapuarau & 0 & 0 & 0 \\
Bare & 1 & 0 & 0 \\
Marram & 0 & 0 & 0 \\
Sprayed & 2 & $2 \times 1$ & 2 \\
\hline Whitiau & & & \\
\hline Bare & 0 & 0 & 1 \\
Marram & 1 & 0 & 0 \\
Sprayed & 0 & 1 & 0 \\
\hline
\end{tabular}

\section{Overview of all LMEs and GLMERS}

Despite some significant results of either treatment or station only a few models showed significant results for the interaction between treatment and station: Slope***; breadth* (Table 2.14 and Table 2.15).

Table 2.14: An overview of all model results used for stress gradient measurements.

\begin{tabular}{|c|c|c|c|c|c|c|}
\hline Model & Response variable & $\begin{array}{l}\text { field site } \\
\text { in model }\end{array}$ & $\begin{array}{c}\text { field } \\
\text { site }\end{array}$ & treatment & station & treatment*station \\
\hline LME & sand change in $\%$ & Tapuarau & NA & $*$ & $*$ & ns \\
\hline$"$ & $"$ & Whitiau & NA & ns & ns & ns \\
\hline LME & conductivity $\mu / S$ & both & $<0.1$ & $* *$ & ns & ns \\
\hline LME & organic matter in \% & Tapuarau & NA & ns & ns & ns \\
\hline$"$ & $"$ & Whitiau & NA & ns & $* *$ & ns \\
\hline LME & slope in $\mathrm{cm}$ & both & ns & $* * *$ & $* * *$ & $* * *$ \\
\hline
\end{tabular}


Table 2.15: An overview of all model results used for spinifex measurements. Table 2.3 on page 50 shows the detailed model terms.

\begin{tabular}{|c|c|c|c|c|c|c|c|}
\hline Model & $\begin{array}{c}\text { Response } \\
\text { variable }\end{array}$ & $\begin{array}{l}\text { field site } \\
\text { in model }\end{array}$ & $\begin{array}{l}\text { field } \\
\text { site }\end{array}$ & treatment & station & treatment*station & $\begin{array}{c}\text { pre- } \\
\text { existing } \\
\text { marram }\end{array}$ \\
\hline LME & $\begin{array}{c}\text { June inner } \\
\text { survival }\end{array}$ & both & $*$ & ns & $* *$ & ns & NA \\
\hline LME & $\begin{array}{c}\text { Nov inner } \\
\text { survival }\end{array}$ & both & ns & ns & ns & ns & ns \\
\hline GLMER & $\begin{array}{c}\text { plant size } \\
\text { Nov/Dec'12 }\end{array}$ & & ns & $* *$ & ns & ns & NA \\
\hline LME & $\begin{array}{l}\text { breadth log- } \\
\text { transformed }\end{array}$ & Tapuarau & NA & $* *$ & $*$ & $*$ & $*$ \\
\hline$"$ & " & Whitiau & NA & $* * *$ & ns & $*$ & ns \\
\hline LME & $\begin{array}{l}\text { dieback } \\
\text { scores }\end{array}$ & both & ns & $<0.1$ & $* *$ & ns & NA \\
\hline
\end{tabular}




\subsection{Discussion}

This chapter investigated the interactions between native and introduced dune-building grasses along an environmental stress gradient. The results showed that growth (including circumference, number of stolons and plant size) was dependent on plant treatment and frequently showed higher values for sprayed plots compared to; live marram plots at all stations and bare marram plots at first stations. Measurements of plant growth showed greater sensitivity to treatment effects than did survival. Spinifex planted into bare sand plots tended to have better growth rates further away from the sea, while spinifex planted in sprayed plots close to the sea showed better growth compared to sprayed plots further back. More plots were lost due to erosion at Whitiau compared to Tapuarau. The pre-existing cover of marram grass was shown to have a great influence on the interaction between dead marram grass and spinifex plantings and the magnitude of the effect altered with distance from the sea. This was in line with predictions of the SGH i.e. growth was more likely to be facilitated by the presence of marram in stations close to the sea and more likely to be inhibited by the presence of marram further from the sea. High initial marram grass cover exhibited a negative influence on spinifex growth at all stations.

\subsubsection{Stress gradient}

Dune profiles display a momentary state of the height of dunes, which can change overnight with a large storm event (Edelman 1972). However, the general pattern with highest disturbance at the seaside, more soil development further inland and fluctuating values for second stations depending on relative dune height in comparison to station 1 , was confirmed with the dune profiles. Therefore a reasonable level of confidence seems justified for assuming the stress gradient measurements are indeed following a gradient. The stress gradient measurements are important for providing for the context as to why the SGH might be relevant to dune plants. Moreover, from a conservation perspective the stress gradient is one of the major challenges for survival of planting during restoration (Bergin and Kimberley 1999). 
Dune profiling with a differential GPS, as well as personal observations, suggests the middle dunes to be the smallest dune most often (out of the three dunes where we placed the three stations). Frequently the back dune (i.e. oldest dune), which is also furthest away from the sea was significantly higher than all the other dunes (fore and mid-dunes). There was no opportunity to mitigate for this effect, it is a natural development that reflects the dune succession on New Zealand's West Coast of the lower North Island (personal observation). Dunes within New Zealand have been shown to be very dynamic. Historically New Zealand had a significant proportion of very mobile sand dunes (Gadgil and Ede 1998). Blowouts have been shown to alter dune dynamics in terms of the remaining soil and the vegetation patterns in close proximity (Jungerius and Meulen 1988). Consequently, I avoided selecting dunes that were in a direct line with a big blowout, so that wind funnels would not impact on the comparability of the transects. According to Department of Conservation staff the prevailing wind direction for storms in winter is often North to South, which is not directly from the sea going inland. Wind patterns have been shown to be the major force in stabilizing or mobilizing dunes along with vegetation cover (Baas 2002, Yizhaq et al. 2007).

The sand movement largely follows the expectations of higher movements seaward compared to landward plots. However, the graphs of sand movement do not reflect the loss/build up of sand at the cliff/the very edge of vegetation towards the seaside. Some of the cliff-faces have eroded to an extend that an entire first station was lost at transect no 8 and another first station at transect no 6 was almost completely lost with parts of the first station at transect 7 also missing. These are processes which are only partly reflected by the sand-bamboo stick measurement. However, the stress gradient was reflected by the selected 'stations' at fore, mid and back dunes as only fore dunes eroded and or collapsed.

Plants at fore and mid dunes experienced higher salinity concentrations within the rootsoil zone than their conspecifics in the back dunes. The pattern of conductivity is in accordance with sand burial measurements, which was expected, since the main distribution of sea spray and therefore of salt is via wind, which is reflected by sand movements. The figures illustrate that there was a strong difference between fore dunes (first station plots) and the other two stations (i.e. mid and back dunes). Consequently, 
plants at fore dunes experienced higher salinity concentration within the root-soil zone than their conspecifics further back.

Salinity and hence salt exposure is one of the main stressors in the coastal environment (Wilson and Sykes 1999) - allowing only specially adapted plants to grow. Many plants have evolved salt secreting mechanisms such as storing salt in their leaves and shedding them (i.e. Suaeda maritima), secreting salt, thick succulent cuticules, special closing mechanisms to avoid desiccation (e.g. Greenway \& Munns, 1980). The zonation of plants is therefore determined by their adaptation to salt exposure in areas where this is the main stressor (Crain et al. 2004). The zonation of plants in accordance to their special adaptation to localised conditions is widely acknowledged (Olff et al. 1993, Poulter et al. 2008).

The build-up of organic matter in the soil is a much slower progress in comparison to salinity increases and sand movements involving several different stages of (mostly) plant material break down (Sollins et al. 1996). Since the majority of higher terrestrial plants are dependent on nutrient uptake from the soil (excluding e.g. parasitic plants and epiphytes), the paucity of organic matter does represent a stressor in the coastal environment. The absolute values for organic matter differed between the two field sites (Whitiau had higher rates of organic matter compared to Tapuarau), which is likely to be a result of the eroding coastline at Whitiau: Areas that are 'older' in direct comparison to the ones at Tapuarau are closer to the sea. The development of soils from pure sand is strongly related to colonisation patch age (Berendse et al. 1998) .

\subsubsection{Spinifex measurements}

Spinifex survival differed significantly according to the distance from the sea, but not between different treatments of marram and thus did not provide support for the SGH. The later survival counts at Whitiau were impacted by the loss of several plots due to massive erosion removing the most seaward plots. The kind of erosion that these plots experienced was too severe for any type of restoration planting and thus represent losses due to the force of nature but not due to the restoration planting techniques which were employed. In contrast, at Tapuarau, mortality of spinifex tended to increase 
when moving inland, perhaps reflecting a more competitive interaction and dominance of other species as expected by the stress gradient hypothesis (Bertness and Callaway 1994). The refined definition of SGH by Maestre et al. (2009) emphasized that survival responses are dependant on the relative strength of the stressor and consequently survival responses might not differ between species, as could be the case for the interaction between marram and spinifex at seaward stations. Spinifex and marram grass, which were the focus of the interaction, are both Poaceae that are especially adapted to coastal conditions and function as clonal dune-engineering keystone species. Therefore, it seems justified to assume they compete in a similar manner for resourses. Moreover, it was proposed that such 'treatment' changes might be soley recognizable for more sensitive parameters such as growth (Maestre et al. 2009). Especially for architecturally important clonal plants, growth has been suggested as one of the major traits responsible for maintaining plant diversity and competitive ability (Wildová et al. 2012).

Usually growth measurements and/or estimates of plant cover in the field are surrogates for estimating biomass if direct biomass measurements are not possible (Montès 2009). Despite due consideration it was deemed impractical to attempt measuring a gain in biomass directly. Spinifex is known to be able to grow up to several meters a year with extensive root and stolon development and trap large masses of sand. Occasionally it was not even possible to distinguish between individual plants due to intensive growth and cover was used for those plots. However, a range of different spinifex growth parameters (i.e. number of leaves, circumference, size dimensions) and indicators of plant performance (health, damage due to dieback, insects and browsing as well as reproductive development, stolon presence and length) were measured. Spinifex size was included as it is a common surrogate for growth. Similar measurements such as plant spread have been used to assess spinifex performance i.e. square root of plant length $\mathrm{x}$ width (Bergin and Kimberley 1999). However, the error for smaller plants seemed relatively high and thus basal circumference seemed to be a more reliable representation of plant growth and biomass compared to size determined from aerial measurements. 
The number of stolons showed a trend towards higher counts at sprayed plots compared to the other treatments, thus showing facilitated growth but not dependent or following the stress gradient as expected. Stolons are crucial for stabilizing dunes and hence their growth is one of the restoration goals to enhance plant capability to repair storm damage on fore dunes (Bergin 2011).

\subsubsection{Spinifex growth and the influence of pre-existing marram grass cover}

Spinifex survival did not provide support for the SGH and neither did plant size, but plant circumference, which was the growth measurement which was found to be most accurate, showed some support: together with initial marram grass cover as a covariate an interaction between the treatment and station was evident. At Tapuarau the observed pattern supported the SGH and showed more faciliatation at high stress front dunes. At Whitiau the pattern was different and showed higher facilitation at back sprayed marram plots compared to bare sand.

Additionally, pre-existing marram cover and spinifex growth showed a strong negative correlation. Consequently, the LMEs with spinifex circumference as response variable and the interaction between treatment and station and pre-existing marram cover (April 2011 when plots were chosen) as predictors, were most appropriate to explain the interactions between treatments and location of plantings. Data shows that a preexisting marram cover over $70 \%$ impedes spinifex growth significantly once the marram grass is killed via spraying. Interestingly, this interaction is not so strong when marram grass is still alive. This seems to be because a cover of complete marram grass cover is equally "bad" for spinifex whether it is dead or alive, but at at lower, intermediate levels of initial marram cover spinifex did significantly better compared to live marram.

It is believed that spinifex and (live) marram can co-exist at the first seaward dunes where spinifex is more salt tolerant than marram and thus competitive interactions counteract (Esler 1970). It is possible however, that within our experiment the plots were already too far away from the very edge, since at least two metres were left between a plot and the most seaward vegetation to allow for potential erosion. Another possible reason could be the choice of plots: marram plots with less than $40 \%$ cover 
were not chosen. Hence this cover threshold might already be above the cover where spinifex and live marram can co-exist. My research found only limited support for the $\mathrm{SGH}$. However, it is possible that some of the variables that might have had an important influence were not measured and hence some of the underlying gradients might not have been observed. Additionally, Santoro et al. (2012) found that invaded coastal plant communities showed an altered distribution compared to uninvaded communities. Therefore it could be possible, that the modern day native and non-native plant communities in New Zealand behave in a different way. The debate over whether or not invaded plants should be included in research regarding the SGH is controversial: Lortie \& Callaway (2006) criticised Maestre et al. (2005) for including introduced species in their meta-analysis. However, Maestre et al. (2006) argued that in an earlier study, Bertness \& Callaway (1994) did not confine the SGH in their initial proposal to a species geographic origin and thus concluded exotic species should be included in SGH-testing. My study is a step towards closing this gap in current knowledge.

In comparison to other studies, my research also considered the influence of a dead invader, which is not widely considered in current literature. But as my results for 'treatment' and facilitation of spinifex plantings show facilitation, in the form of providing shelter by dead invaders, can be supportive of restoration plantings.

\subsubsection{Practical relervance for conservation}

The results have shown that survival was not significantly higher in sprayed vs. live marram grass and bare sand. However, the results have also shown that the likelihood of losing entire plots is higher on bare sand compared to within live marram and sprayed marram. Furthermore my results suggest that restoration managers should carefully assess the local conditions, especially pre-existing marram cover and consider planting into dead marram only if intermediate cover of marram is present initially.

As a consequence careful consideration has to be given to the nature of the restoration site, as the extra effort of planting (volunteers claimed it was a lot harder to plant within dead marram vs. bare sand) might not be worth the effort unless it is a very exposed site, where plant growth is a critical variable in keeping sand stabilized. 
At steeper plots with high vertical erosion the newly planted spinifex were not able to halt the erosion process, but they probably slowed it down, as not all plantings were lost, as the case for bare plots in a similar scenario. Only spinifex was planted at our field sites, as it is the major sand binding grass within New Zealand. However, in areas with high marram-reinvasion potential, several consecutive sprayings, potentially over a period of around 5 years might be necessary to ensure marram grass eradication on a long-term basis (Konlechner and Hilton 2010). A time intensive, and therefore only practical for small areas solution, would be to spot-spray reinvading and/or surviving marram plants, which allows for spinifex plantings to survive herbicide application. One possibility in larger areas with high re-invasion potential or difficulties in eradicating thick marram covers, could be the planting of the endemic sedge pingao (Ficinus spiralis), as it is not affected by gallant spraying.

\subsection{Conclusions}

The dependance of interactions between species on a stress gradient (i.e. salt exposure, wind, sand movement) was the focus of this chapter. Hence, concerning my research aims, the experiment showed:

i) Spinifex growth was facilitated by dead marram grass structures. Treatment was however not a significant predictor of survival.

ii) The interaction between station and treatment was significant for circumference of spinifex, which was found to be the most accurate measurement of plant growth compared to more conventional methods as explained in the methods, and thus provided some support for the SGH.

iii) Live marram was frequently a poorer facilitator of spinifex plantings than was live marram.

iv) Pre-existing marram grass cover exhibited a significant influence on planting growth performance - if cover was above $70 \%$ sprayed marram did not break down quickly enough to allow for optimal spinifex growth.

v) A careful evaluation of the local conditions, including pre-existing cover, is necessary for adequate management decisions. 
CHAPTER 2 


\section{CHAPTER 3}

Species abundances of self-colonizing native and introduced plants and the role of the stress gradient hypothesis in coastal dune systems

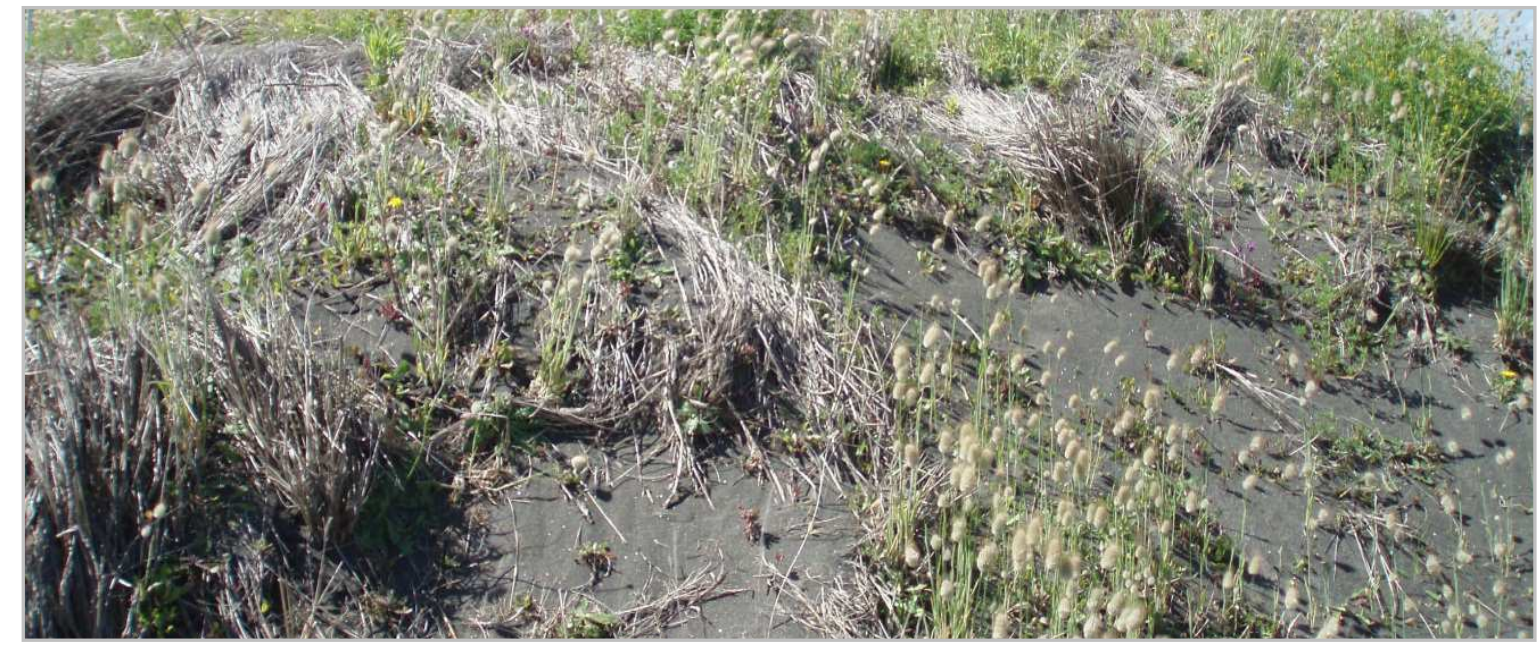

Self-colonizing plants in a sprayed marram plot. 


\subsection{Introduction}

Births, deaths, immigration and emigration are the four fundamental processes structuring population dynamics, local abundance and ultimately multi-species ecological patterns. Individual members of a community are constantly replaced and new habitat patches, as well as the patches where parental plants are located at the time of seed dispersal, are colonized (Howe and Smallwood 1982). Colonization by seed is often linked to disturbance, and therefore frequently disturbed sites are especially prone to invasion by introduced plants (Daehler 2003). Metapopulation theory predicts the re-colonization of patches with suitable habitat if there is sufficient connectivity for individuals to reach the habitat patches were extinction occurred (Opdam 1991, Hanski 2001). If other species of plants or animals are able to occupy the space of the locally extinct specimen, they exhibit a competitive advantage (a priority effect) over the recolonizing species that might arrive later (Bolker and Pacala 1999, Seabloom et al. 2003). Local soil disturbance promotes the establishment of therophytes (i.e. annual plants, including some facultative perennial plants which survive unfavourable conditions as seeds) compared to other life forms(Mclntyre et al. 1995). Annual plants in temperate regions die off during the winter months and their space is partly taken by their offspring or biennial plants where they are able to germinate and flower (Werner 1977). Local interactions between species or individuals sharing the same "patch" can be both positive (facilitative) and negative (competitive). Where dispersal is not limiting, these interactions may play a more predictable role than with dispersal restrictions in the assembly of plant communities. After a long history of studies investigating competition (e.g (Bleasdale 1960, McGilchrist and Trenbath 1971), the facilitation of plants has now become the focus of numerous studies and is thought to be a key foundation for community structure (Bruno et al. 2003).

Current research acknowledges several different aspects of facilitation, which apply for colonizing plants as to where their survival likelihood is greatest: 
1. The classic nurse plant effect (Turner et al. 1966, Franco et al. 1989) describes facilitation between one plant and another; e.g. the natural facilitation of the cactus Neobuxbaumia tetetzo by the nurse plant Mimosa luisana (ValienteBanuet and Ezcurra 1991). Instances of plants facilitating each other occur not only in nature but the concept is also used in applied commercial horticulture, e.g. the facilitation of Juglans nigra by Elaeagnus umbellata (Funk et al. 1979) and for habitat restoration (e.g. reviewed by (Padilla and Pugnaire 2006).

2. The patchy distribution of plants in harsh environments is sometimes attributed to facilitative effects. The nucleation hypothesis predicts an accumulation of more seeds and consequently more plants after the first seedling's establishment (Franks 2003). According to this hypothesis, colonization radiates from the first plant establishment, resulting in a clumped distribution versus a random distribution.

3. The interactions around facilitation and competition are thought to be complex, and not based on a singular mechanism such as resource (Kawai and Tokeshi 2007). Additionally benefactor size and life stage play an important role (Callaway and Walker 1997). Hence, the stress gradient hypothesis (SGH) (Bertness and Callaway 1994) predicts the facilitative interaction between plants similar to the classic nurse-plant-effect, but which vary along an abiotic stress gradient. The interactions would be more facilitative at stressful habitat locations, and become more competitive when stress reduces.

The stress gradient hypothesis has been tested in a number of habitats. Support for the SGH was found along an aridity gradient on the Iberian Peninsula where Retama sphaerocarpa was found to facilitate shrubs and increased species diversity at the arid end of a gradient (Armas et al. 2011) and in a subarctic forest (Eränen and Kozlov 2008). Direct facilitative effects were found in a New England salt marsh for increasing species composition (Hacker and Gaines 1997) as well as for a salt marsh experiment under laboratory settings (La Peyre et al. 2001). In French coastal dunes sand burial was identified as the main stress regulating community composition at local scales, with plants facilitating each other were stress prevails (Forey et al. 2008). Examples for and against the SGH have been studied in different ecosystems with differences in the 
number of species included in the study as well as the abiotic stress surrogates measured on varying stress gradient lengths (see reviews in Brooker et al. 2007, Eränen and Kozlov 2008, Martinez and Garcia-Frankco 2008, Maltez-Mouro et al. 2010).

Due to differing results, the SGH was modified by Maestre et al. (2009) who pointed out that a careful consideration of the habitat requirements of the species in the study system is crucial to untie the net-effects of facilitation and competition which occur simultaneously. They proposed the benefits of recording growth, rather than only survival and emphasised the advantages of experimental settings.

The validity of the stress gradient hypothesis has been the subject of on-going debate: Maestre, Valladares, \& Reynolds (2005) conducted a meta-analysis that included studies testing the hypothesis in arid habitats to test the predictability of the SGH and found no support for it in arid environments. Lortie \& Callaway (2006) criticised Maestre et al.'s approach, finding that the study inclusion criteria were not strict enough, included nonpeer reviewed studies, studies that did not identify/quantify a stress gradient and some that included invasive species. Maestre et al. (2006) replied that the SGH does not include any restrictions on a species geographic origin, but they did agree that when testing of the stress gradient including a sufficient stress gradient length is necessary for appropriate conclusions. More recently, research has emphasized temporal aspects for facilitation and competition, as facilitation is more frequently found in early stages of plant interactions, which with increased plant age leads to more competitive interactions (Malkinson and Tielbörger 2010). Moreover, the latter authors showed that despite the expectation of a linear relationship between stress and facilitation/competition, the relationship could be curved due to infrequent interactions at extreme stress levels and the minimum survival requirements of specific species curtailing their distributions (Malkinson and Tielbörger 2010). It has been argued that the severity interaction relationship, stress on one end of the spectrum and little stress on the other, is unimodal (le Roux and McGeoch 2010). Several authors (e.g. (Kawai and Tokeshi 2007, Eränen and Kozlov 2008) have noted the need for more studies considering multiple species along multiple stress gradients.

Restoration efforts are most likely to succeed if they understand and accommodate the interactions along abiotic stress gradients (Padilla and Pugnaire 2006) and one important 
step for the management of modern day communities is the inclusion of introduced species in these studies. This is not in contradiction of the assumptions of the SGH (Maestre et al. 2006), as the original SGH (Bertness and Callaway 1994) does not make any restrictions regarding a species geographic origin.

Coastal habitats are highly dynamic habitats, with erosion and reclamation of dunes taking place in re-occurring cycles and constantly providing disturbed bare patches for colonization of native and introduced species. Research into the coastal habitats of New Zealand is a priority as these are amongst the most threatened habitats in the country (Lange et al. 1999, Department of Conservation 2010), with the main threats being habitat loss and encroachment by invasive species such as marram (Ammophila arenaria). Native and introduced plants on coastal dunes are exposed to multiple stressors that lessen with distance from the sea: salt exposure, thought to be the most influential stressor in New Zealand, sand burial and wind (Wilson and Sykes 1999). In the more recent past, a call for more research involving multiple species while investigating the SGH has been made (Brooker et al. 2007, Maestre et al. 2009).

Marram and spinifex are the major structural components on sand dunes and represent potential competitors or facilitators for the colonisation and growth of other species. The stress gradient hypothesis predicts an interaction between the factors relating to the presence of structural plants (marram or spinifex) and location along the environmental stress gradient, with abundance greater in marram-occupied plots relative to bare plots closer to the sea (especially in dead sprayed marram plot), and abundance greater in bare plots relative to marram-occupied plots further inland. Similarly, the stress gradient hypothesis predicts facilitation of self-colonizing species in spinifex- planted plots closer to the sea relative to planted plots further inland.

The research focus of this chapter is on the interactions between the assemblage of exotic and native coastal plants and how they may impact the restoration of coastal dunes while testing whether self-colonizing plants in this dune system follow the predictions of the SGH. In particular I focused on widespread weeds within the dune system and their response to different management techniques involving the two most 
common grasses: (exotic) marram grass (Ammophila arenaria) and the native spinifex (Spinifex sericeus).

\section{More specifically I hypothesized:}

In accordance with the SGH the balance of interactions between plant species changes from net facilitation toward net competition along an abiotic stress gradient (i.e. species less sensitive to salt exposure, wind and thus sand movements) when stress lessens (i.e. further away from the sea). Within the context of the experimental design, I specifically tested whether:

I. Self-colonizing plants follow the predictions of the SGH and are therefore more likely to be facilitated in stressful environments close to the sea.

II. Live marram is a worse facilitator of self-colonizing plants compared to dead (herbicide-sprayed) marram.

III. Planted spinifex will reduce the number of self-colonizing plants in herbicidesprayed marram plots compared to unplanted plots. 


\subsection{Materials and Methods}

\subsubsection{Study species}

A detailed description of the focal study species including background information on conservation issues can be found in Appendix III (and photos of S. elegans in Appendix V (Fig. A V.1)).

Changes in local abundance (i.e. end result of seed dispersal in the face of colonization vs. extinction as well as competition vs. facilitation) were measured by individual plant counts and plant cover estimates.

\subsubsection{Field sites}

To test my research hypotheses, the same field sites from Chapter 2 were used (i.e. Tapuarau, close to Waitotera, and Whitiau, close to Whanganui, both on the North Island of New Zealand (see Fig. 2.4-2.6 in Chapter 2 for location maps and station locations). Both are relatively rare examples of well-established dunes with a large backdune area with high value for conservation (pers. comm. La Cock and Campell, 2011).

\subsubsection{Experimental setup}

I began a large scale field experiment involving 198 plots over two field sites (Whitiau and Tapuarau) in late September 2011 Each plot was $3 \times 3 \mathrm{~m}$ in size, with measurements taken from the central $2 \times 2 \mathrm{~m}$ zone. Three different management treatments were applied (bare sand, live marram and herbicide-sprayed dead marram) with one replicate per treatment per station planted with 25 spinifex plants paired with one unplanted replicate. The plots with dead marram were sprayed approximately five months prior to planting. The plots were distributed over three locations from the sea going inland (station 1, station 2 and station 3, respectively). This was done to capture the expected stress gradient, with the station closest to the sea expected to exert the greatest environmental stress due to salt spray exposure, wind, (including sand burial), and poor soil nutrients (sand with very little organic matter). A detailed account of the experiment 
setup and environmental measurements (i.e. wind speed measurements, slope, sand burial, and organic matter and conductivity), can be found in the previous chapter. For this chapter both spinifex-planted and unplanted plots $(n=198)$ were considered for analysis.

Vegetation cover was estimated for each plant species. I applied a $5 \%$ threshold for all vegetation cover estimates; i.e. if a plant existed in a plot it automatically reached $5 \%$ cover even though the specimen might have covered less. Therefore vegetation cover estimates summed across species could occasionally exceed $100 \%$ per plot. Vegetation was assessed looking at the plot from above, hence multiple layers were not accounted for separately. Vegetation height was always below chest height (i.e. $<1.35 \mathrm{~m}$ above ground).

To assess species abundances, individuals of each species were counted and frequently occurring species were used in the analysis; i.e. Sonchus oleraceus, Senecio elegans, Conyza canadensis, Orobranche minor and Lagurus ovatus (for species descriptions see Appendix 1). It was often not possible to identify specimens to species level when they lacked reproductive traits, therefore it was necessary to group these species. The grouped species comprised included Leontodon taraxacoides, Taraxacum officinale, Hypochaeris radicata and Crepis capillaris which were thereafter referred to as 'dandelions and hawksbeards'. For the latter species each rosette of leaves was counted as an individual plant.

Similarly, it was not always possible to distinguish between individuals for grasses with stoloniferous growth and (creeping) legumes (such as Lotus pedunculatus, Trifolium repens, Trifolium pratense and Trifolium arvense), therefore these species were removed from the individual analysis and/or grouped for the vegetation cover estimates and are consequently referred to as "legumes" from here onwards. For Lagurus ovatus (hares tail) the number of flowers was used as a surrogate for counting individuals to give an estimate of plant density. 


\subsubsection{Statistical analysis}

I used ordination via Principal Coordinate Analysis (PcoA), also known as metric multidimensional scaling (Zuur et al. 2007) to compare species composition between stations for each field site respectively to confirm differences in species composition along the abiotic stress gradient. All empty plots and species with a rare occurrence (less than 5 plots with the species) and outliers were removed from the analysis prior to applying the PcoA. I calculated a dissimilarity (distance) matrix using presence/absence data and the Bray-Curtis distance measure and then plotted the proportion of variance explained by the first two dimensions (or eigenvectors). I used the R-packages "labdsv" (Roberts, 2012) and "ape" (Paradis et al., 2004) to apply and visualize the PcoA.

For each species or taxonomic group tested I used boxplots of abundance (counts or percent cover) to show the differences per treatment split by location along the stress gradient (with station 1 most exposed, station 2 intermediate and station 3 least exposed). Where boxplots were used, boxes and whiskers are by $\mathrm{R}$ default (boxes encompass the interquartile range (IQR). Whiskers extend to the end of the range except for the outliers ( $>1.5$ times the range).Alongside boxplots, graphs of the difference in plant counts/cover between the average level in a marram plot (live marram and sprayed marram) and its corresponding bare sand plot are displayed for ease of comparison. I generated graphs from a user-defined $\mathrm{R}$ function for calculating and plotting mean values and their standard errors (Appendix II). I used linear mixed effects (LME) models (also known as hierachical linear models) to test for effects of marram management, spinifex planting and environment upon the next season's abundance of other plant species or taxa. Marram management had three "treatment" levels (presence of live marram, herbicide-sprayed dead marram, or no marram i.e. bare sand), spinifex "planting" had two levels (planted or not) and "environment" was a continuous variable sampled at three locations (stations) along a transect as it was assumed that the three stations represent locations of decreasing stress along an abiotic stress gradient.

The eleven transects used in this study were split across two field sites. Although the sites are conceptually considered to be coarse-scale replicates, they have a number of differences in their history, exposure and geomorphology that might lead one to expect 
different responses at each site. Therefore as a preliminary step I added a term for "site" to each LME as well as sitextreatment, sitexplanting and sitexenvironment terms. If any of the interactions of field site were significant, a model including both field sites was rejected and data were analyzed separately for each field site. If there were no significant interactions with site the data were not split per field site, but 'site' was was included in the single two-site model as a fixed effect. Transect was included as a random effect in all models.

Where significant interactions were detected in the LME, I elucidated the nature of the interaction by examing the aforementioned boxplots and graphs of relative growth.

I measured population dynamics by counting individual plants in each permanently marked quadrat with repeated measures over time (5-6 months after planting, 8-9 months after planting and 13-14 months after planting). The data set with the most pronounced differences between treatments (which had developed slowly over time) was from the last monitoring trip in November and December 2012 and this was used for the analysis. I used the recommended squareroot transformation to improve the normality of residuals for counts where they did not initially meet criteria of normal distribution (Osborne 2002). For some variables a log transformation or fourth-root (double-squareroot) transformation proved to be more effective. The recommended arcsine transformation for proportional data (Osborne 2002) was used for percentage cover estimates. If the residuals departed more than acceptable (i.e. clear gaps between distribution gaps or unidentifiable type of distribution, very strong skewness and departing kurtosis) from normal distribution after visual inspection of the residual histogram the model was rejected and consequently only the field site displayed where data assumptions were adequately met. Table 3.1 shows an overview over all applied models. LME models were fitted using maximum likelihood (ML). I used the statistical program R for all statistical analysis and graphs (R-core Team, 2012). 
Table 3.1: Overview over all LMEs applied.

\begin{tabular}{|c|c|c|c|c|}
\hline Response variable & field site in LME & $\begin{array}{l}\text { field site as } \\
\text { predictor }\end{array}$ & predictors & $\begin{array}{l}\text { random } \\
\text { factors }\end{array}$ \\
\hline Calystegia. soldanella & Both & yes & $\begin{array}{l}\text { station, treatment, } \\
\text { planted, } \\
\text { treatment*station, } \\
\text { planted*station }\end{array}$ & transect \\
\hline Sonchus. oleraceus & Both & yes & "'" & "" \\
\hline Senecio elegans & Whitiau & NA & "'" & "" \\
\hline "" & Tapuarau & NA & "'" & "'" \\
\hline Lagurus. ovatus & Both & yes & "'" & "" \\
\hline Orobranche minor & Whitiau & NA & "'" & "" \\
\hline Conyza. canadensis & Both & yes & "" & "'" \\
\hline dandelions & Both & yes & "'" & "" \\
\hline legumes & Both & yes & "'" & "" \\
\hline grass cover & Whitiau & NA & "" & "" \\
\hline "" & Tapuarau & NA & "'" & "" \\
\hline herb cover & Whitiau & NA & "'" & "" \\
\hline "" & Tapuarau & NA & "'" & "" \\
\hline woody plant cover & Whitiau & NA & "'" & "'" \\
\hline
\end{tabular}




\subsection{Results}

\subsubsection{Species diversity}

A total of 32 species were recorded from 13 families. Refer to Appendix III (Fig. A III.2) for a complete species list with information on species occurrence according to station and treatment for both field sites.

\subsubsection{Species composition}

At Tapuarau the PCoA ordination demonstrated a gradation in community composition moving from station 1 to 2 to 3 . The community compositions recorded across station 3 appear to be a subset of those found across station 2 whereas there is much less overlap in composition between first and second station plots (Fig. 3.1a). The pattern was less distinct at Whitiau, where an overlap between all stations was visible (Fig. 3.1 b). Species occurring for all stations at both field sites included dandelions, S. elegans and $S$. oleraceus. A list of the species considered in the PcoA can be found in the Appendix III (Table A III.1).

a) PCoA on plants for all plots at Tapuarau

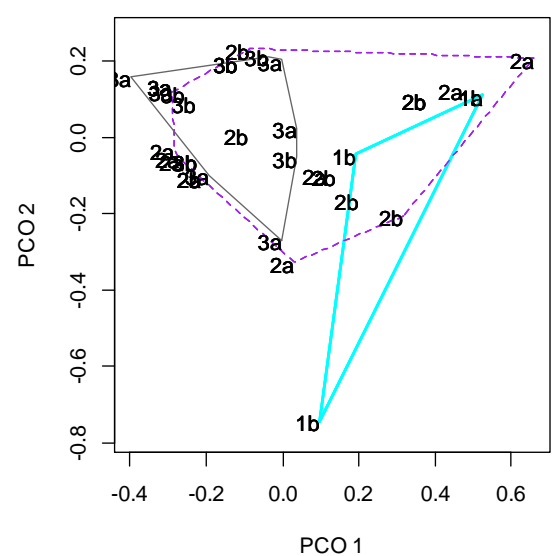

b) PCoA on plants for all plots at Whitiau

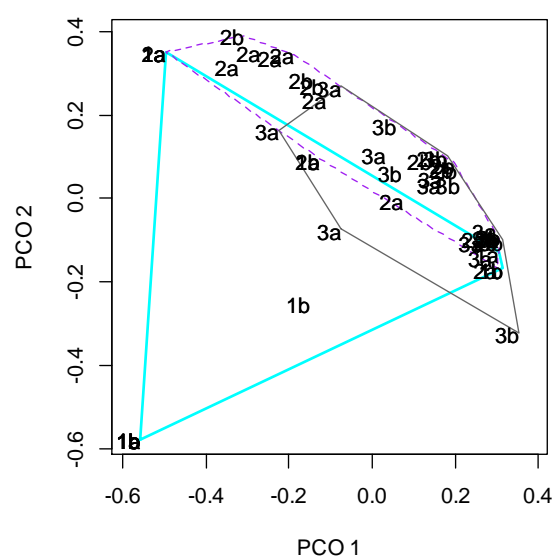

Figure 3.1: Graph shows principal coordinate analysis of all plants of all plots classified by station (1= closest to the sea, 2 = intermediate distance and 3 = furthest away from the sea) at a) Tapuarau and b) Whitiau. 


\subsubsection{Changes in species abundance along an abiotic gradient and in response to}

\section{existing vegetation structure}

Calystegia soldanella (sand convolulus) native

Counts of C. soldanella showed significant differences between sites and highly significant differences across stations, but no effect of marram treatment or spinifex planting (Table 3.2). Overall abundances were higher at Tapuarau compared to Whitiau. Counts were lowest at the first station regardless of the treatment, and generally increased towards the back dune (station 3) (Fig. 3.2 and Fig. 3.3).

Table 3.2: Summary of a linear mixed effect model for abundance of Calystegia soldanella (data from both field sites combined). Transect was included as a random effect.

\begin{tabular}{llrrrr}
\hline Response variable & Predictor & numDF & denDF & F-value & p-value \\
\hline Calystegia soldanella & field site & 1 & 8 & 7.051 & 0.029 \\
(individual counts) & spinifex planting & 1 & 150 & 0.156 & 0.694 \\
& marram treatment & 2 & 150 & 1.029 & 0.360 \\
& station & 1 & 150 & 15.306 & $<0.001$ \\
& planting×station & 1 & 150 & 0.662 & 0.417 \\
& treatment×station & 2 & 150 & 0.006 & 0.994 \\
\hline
\end{tabular}

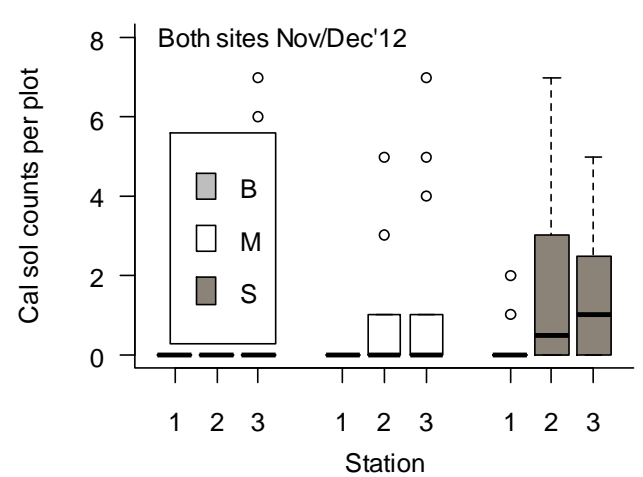

Figure 3.2: Boxplots show individual counts of Calystegia soldanella (Con sol) for all treatments ( $B$ = bare sand, $M=$ live marram, $S$ = sprayed marram) for both field sites. Treatments are split up by station ( 1 = closest to sea, 2 = intermediate and 3 = furthest away).

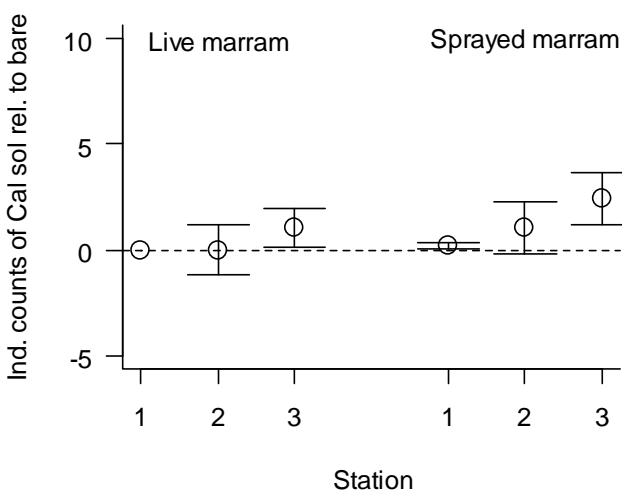

Figure 3.3: Mean values for relative counts of Calystegia soldanella (Con sol) compared to bare sand (dotted line) are displayed for live marram and sprayed marram plots for both sites. Errorbars = +- SE. 
Sonchus oleraceus (Puha) introduced

The initial model selection showed no significant effect of interactions between field site and any of the predictors. Therefore both sites were used for the analysis and field site employed as a predictor. Counts for S. oleraceus showed significant differences across stations and between field sites, but no significant effect of marram treatment or spinifex planting (Table 3.3). Nonetheless, plots planted with spinifex showed slightly higher counts of $S$. oleraceus $(P=0.051)$ and better facilitation by marram (dead and alive) at the second station. Lowest overall counts were evident for first station plots (Fig. 3.4 and Fig. 3.5). At the third station, presence of marram (dead and alive) appeared to inhibit abundance of S. oleraceus relative to the abundances achieved through colonisation of bare sand. This hump-backed response to the treatmentxenvironment (station) interaction may not have been picked-up as significant by the LME in which station was treated as a continuous variable without any quadratic terms included in the model (Table 3.3).

Table 3.3: Summary of a linear mixed effect model for abundance of Sonchus oleraceus (data from both field sites combined). Transect was included as a random effect.

\begin{tabular}{llrrrr}
\hline Response variable & Predictor & numDF & denDF & F-value & p-value \\
\hline Sonchus oleraceus & field site & 1 & 8 & 9.847 & 0.014 \\
(individual counts) & spinifex planting & 1 & 149 & 3.857 & 0.051 \\
& marram treatment & 2 & 149 & 2.377 & 0.096 \\
& station & 1 & 149 & 6.514 & 0.012 \\
& planted×station & 1 & 149 & 0.111 & 0.739 \\
& treatment×station & 2 & 149 & 1.475 & 0.232 \\
\hline
\end{tabular}



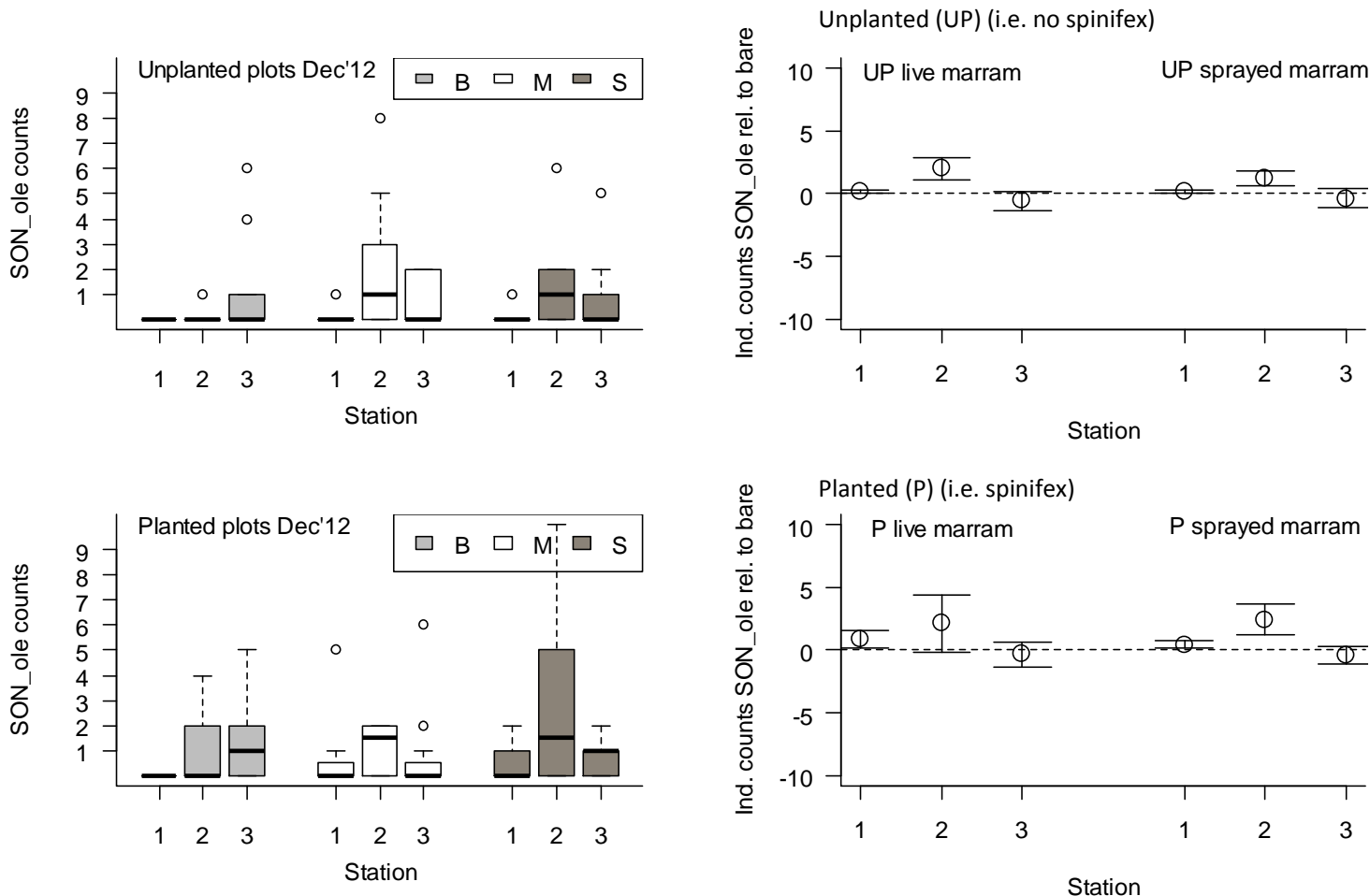

Figure 3.4: Boxplots show individual counts of S. Figure 3.5: Mean values for relative counts of $S$. oleraceus in Nov/Dec 2012 for all treatments (B = oleraceus compared to bare sand (dotted line) bare sand, $M=$ live marram, $S=$ sprayed marram) are displayed for live marram and sprayed split up by unplanted plots (only treatment without spinifex plantings upper graph) and planted plots (i.e. planted with spinifex = lower graph). Treatments are split up by station $(1=$ closest to marram plots for unplanted plots (i.e. no spinifex planted = upper right graph) and planted plots (i.e. planted with spinifex $=$ lower rightgraph. sea, 2 = intermediate and 3 = furthest away). 
Senecio elegans (purple groundsel)

"Treatment" was a significant predictor of S. elegans counts at Tapuarau, with highest counts in sprayed marram plots compared to the other treatments (upper graph Fig. 3.7). At Taparuau, the treatment $\times$ station interaction was not significant $(P=0.25)$. The effect of planting spinifex only had a significant effect on S. elegans at Whitiau (Fig. 3.6 and Fig. 3.7, Table 3.4).

Table 3.4: Summary of a linear mixed effect model for abundance of Senecio elegans (data were analysed separately per field site). Transect was included as a random effect.

\begin{tabular}{|c|c|c|c|c|c|c|}
\hline Field site & Response variable & Predictor & numDF & denDF & F-value & p-value \\
\hline \multirow[t]{6}{*}{ Whitiau } & Senecio elegans & & & & & \\
\hline & (individual counts) & planted & 1 & 66 & 5.393 & 0.023 \\
\hline & & treatment & 2 & 66 & 2.934 & 0.060 \\
\hline & & station & 1 & 66 & 11.361 & 0.001 \\
\hline & & planted ×station & 1 & 66 & 0.002 & 0.963 \\
\hline & & treatment×station & 2 & 66 & 3.892 & 0.025 \\
\hline \multirow[t]{5}{*}{ Tapuarau } & & planted & 1 & 76 & 0.034 & 0.854 \\
\hline & & treatment & 2 & 76 & 10.123 & $<0.001$ \\
\hline & & station & 1 & 76 & 39.759 & $<0.001$ \\
\hline & & planted ×station & 1 & 76 & 0.085 & 0.772 \\
\hline & & treatment $\times$ station & 2 & 76 & 1.412 & 0.250 \\
\hline
\end{tabular}


At both sites the abundance of $S$. elegans was strongly linked to station and increased towards the back dune (Fig. 3.6). At Whitiau there was a significant interaction between 'station', and "treatment", where the presence of marram (dead or alive) was facilitative at the first station and inhibitory (or competitive) at the third station (Fig. 3.7). The highest counts of $S$. elegans, relative to bare sand plots, were observed at the second station amongst sprayed-dead marram on unplanted and planted plots at Tapuarau and on unplanted plots at Whitiau (Fig 3.7). 


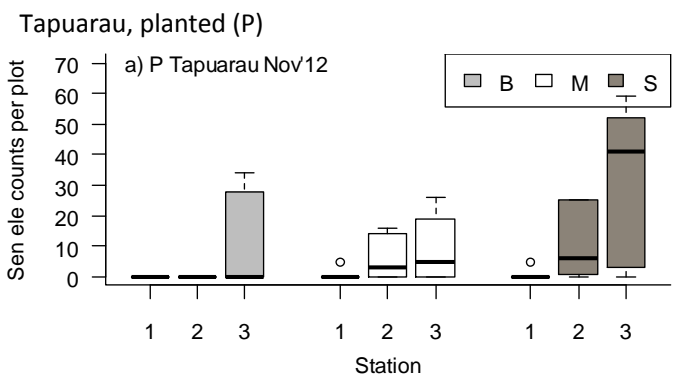

Whitiau, planted (P)

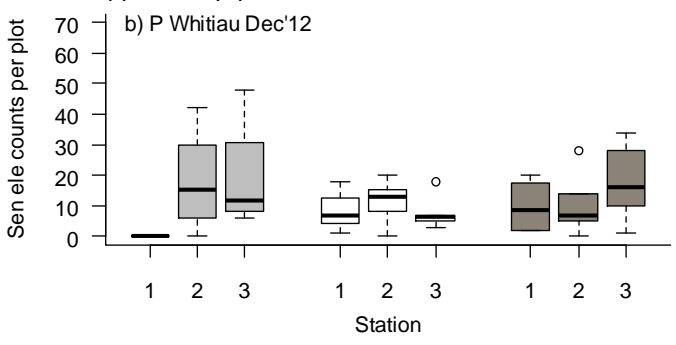

Tapuarau, unplanted (UP)

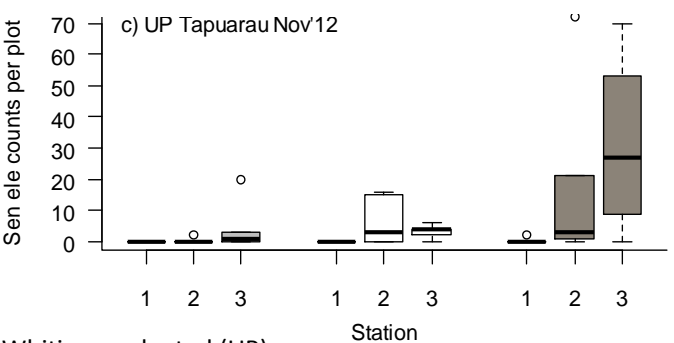

Whitiau unblanted (UP)

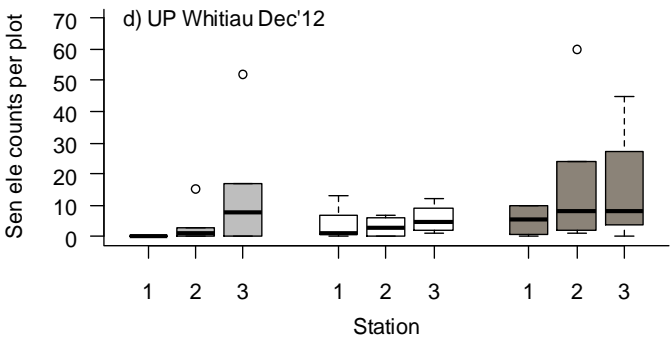

Figure 3.6: Boxplots show individual counts of $S$. elegans in Nov/Dec 2012 for all treatments (B = bare sand, $M$ = live marram, $S=$ sprayed marram) split up by unplanted plots (only treatment without spinifex plantings left graphs) and planted plots (i.e. planted with spinifex = right graphs). Treatments are split up by station ( $1=$ closest to sea, 2 = intermediate and $3=$ furthest away).
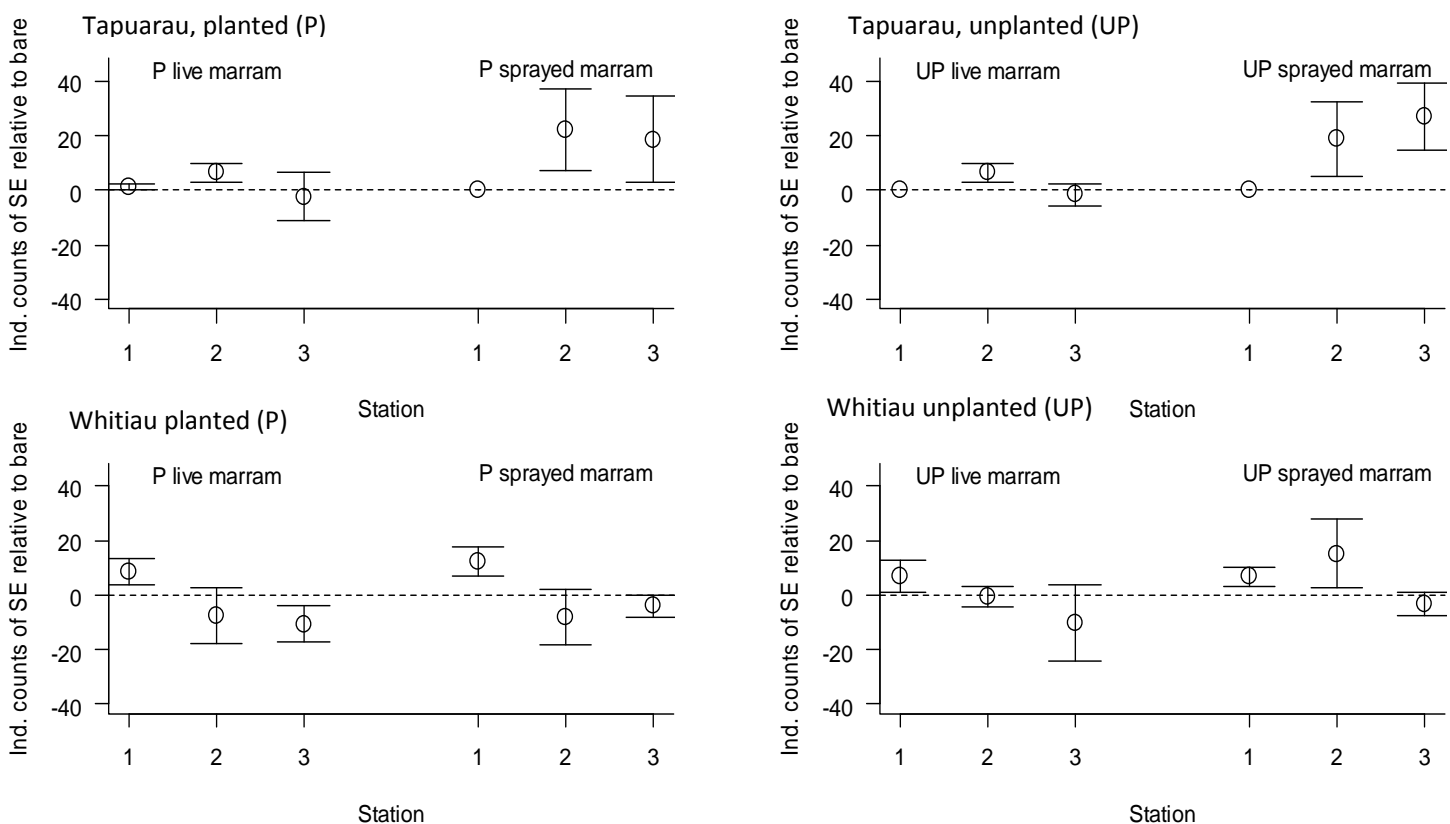

Figure 3.7: Mean values for relative counts of $S$. elegans compared to bare sand (dotted line) are displayed for marram and sprayed marram plots for Tapuarau (upper graphs) and Whitiau (lower graphs) respectively. Left hand site graphs show plots planted with spinifex and right hand side plots show unplanted plots. Treatments are also split up by station (with $\mathbf{1}=$ closest to sea, $\mathbf{2}=$ intermediate and 3 = furthest away). Errorbars = +- SE. 
Lagurus ovatus (hares tail)

Initial model selection showed no significant effect of the interaction between 'field site' and any of the other predictors (i.e. 'station', 'treatment' and 'planted') (Table 3.5). Hence, both sites were analysed together. Plant counts varied significantly between stations (Table 3.5): no specimens were recorded at first stations, a few at second station plots but the majority of recorded plants were counted at third station plots (Fig. 3.8 and Fig. 3.9).

Table 3.5: Summary of a linear mixed effect model for abundance of Lagurus ovatus (data from both field sites combined). Transect was included as a random effect.

\begin{tabular}{lllrrrr}
\hline Field site & Response variable & Predictor & numDF & denDF & F-value & p-value \\
\hline Both & Lagurus ovatus & & & & & \\
& (individual counts) & field site & 1 & 8 & 0.035 & 0.857 \\
& & spinifex planting & 1 & 149 & 1.892 & 0.171 \\
& marram treatment & 2 & 149 & 0.198 & 0.821 \\
& & 1 & 149 & 62.300 & $<.001$ \\
& station & 1 & 149 & 0.431 & 0.512 \\
& planted:station & 2 & 149 & 0.225 & 0.799 \\
\hline
\end{tabular}

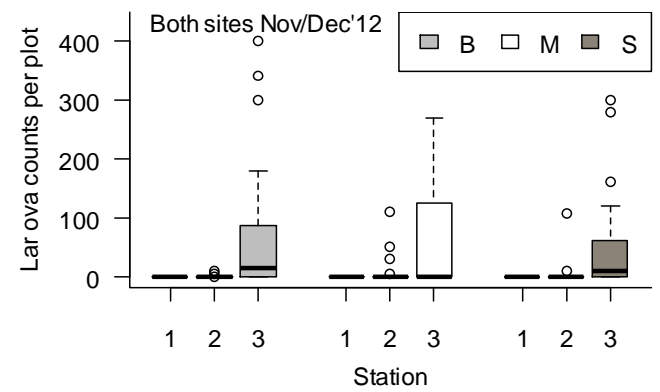

Figure 3.8: Boxplots show individual counts of Lagurus ovatus in Nov/Dec 2012 for both field sites for all treatments $(B=$ bare sand, $M=$ live marram, $S=$ sprayed marram). Treatments are split up by station ( $1=$ closest to sea, 2 = intermediate and 3 = furthest away).

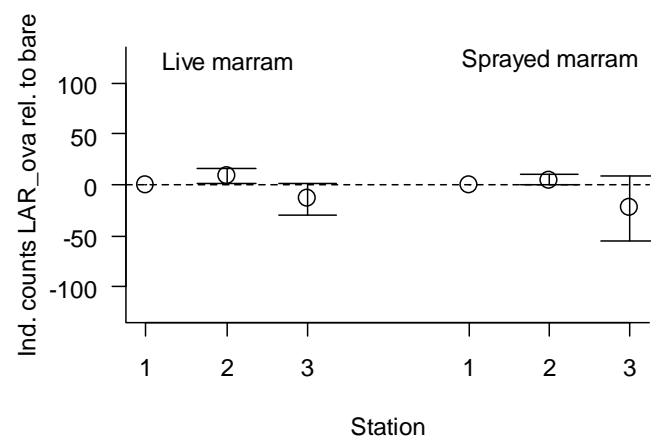

Figure 3.9: Mean values for relative counts of Lagurus ovatus compared to bare sand (dotted line) are displayed for marram and sprayed marram plots both field sites. Treatments are also split up by station (with 1 = closest to sea, $\mathbf{2}$ = intermediate and 3 = furthest away). Errorbars = +- SE. 
Orobranche minor (broomrape) exotic hemiparasite

The interaction between 'planted' and station was the only significant predictorinteraction of $O$. minor counts (Table 3.6). Plots planted with spinifex usually showed higher counts of $O$. minor, though this varied with station, hence the significant intreaction between "planted" and "station". Whether or not a plot was planted with spinifex, and station (the location) were both significant predictors on their own in the LME (Table 3.6).

Table 3.6: Linear mixed effect model anova values for 0 . minor at Whitiau. Transect was included as random effect.

\begin{tabular}{lllrrrr}
\hline Field site & Response variable & Predictor & numDF & denDF & F-value & p-value \\
\hline Whitiau & Orobranche minor & & & & & \\
& (individual counts) & spinifex planting & 1 & 66 & 5.787 & 0.019 \\
& & marram treatment & 2 & 66 & 2.071 & 0.134 \\
& & station & 1 & 66 & 6.567 & 0.013 \\
& & plantedxstation & 1 & 66 & 6.287 & 0.015 \\
& & treatment×station & 2 & 66 & 1.158 & 0.321 \\
\hline
\end{tabular}

At Whitiau the abundance of $O$. minor was strongly linked to station and increased towards the back dune (Fig. 3.10 and Fig. 3.11). No individuals were counted on unplanted bare plots (Fig. 3.10). 

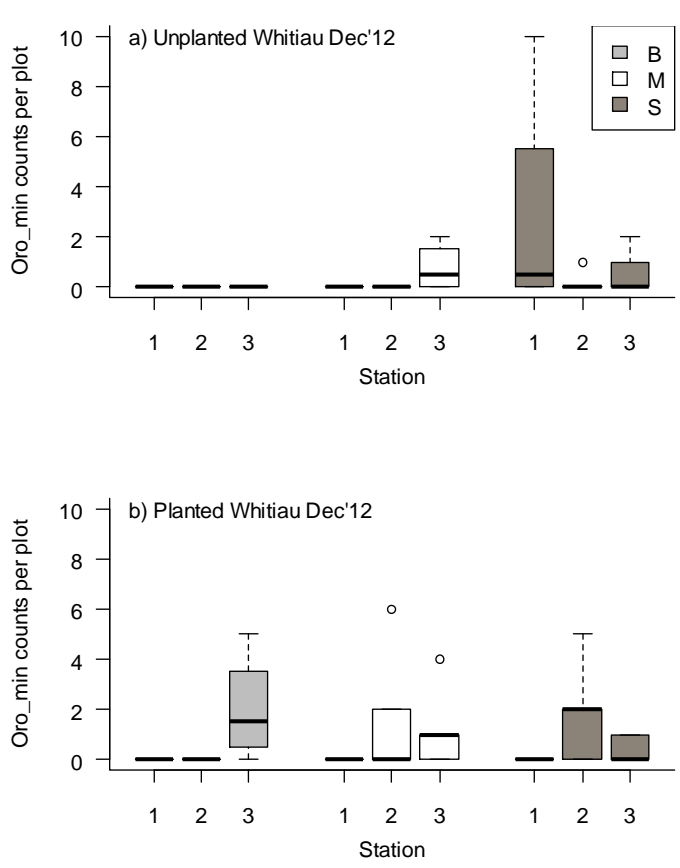

Figure 3.10: Boxplots show individual counts of $O$ minor in Nov/Dec 2012 for Whitiau for all treatments ( $B=$ bare sand, $M=$ live marram, $\mathbf{S}=$ sprayed marram). Treatments are split up by station (1 = closest to sea, $\mathbf{2}$ = intermediate and $\mathbf{3}$ = furthest away) and whether they are planted or not (lower and upper graph respectively).
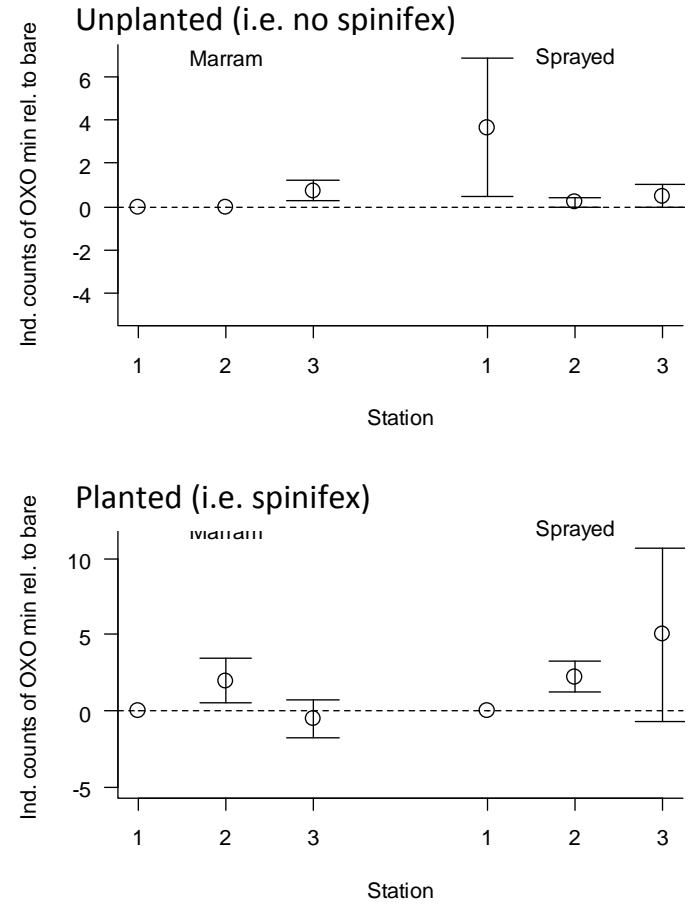

Figure 3.11: Mean values for relative counts of $\boldsymbol{O}$. minor compared to bare sand (dotted line) are displayed for marram and sprayed marram plots for Whitiau (right graph) respectively. The upper graph shows unplanted plots, while the lower graph shows planted plots. Errorbars $=+-\mathrm{SE}$. 
Conyza canadensis (fleabean, exotic)

There was no significant interaction between 'planted' and 'station' and between 'treatment' and 'station' (Table 3.7 and Figure 3.12 and Figure 3.13). However, there was a trend for the interaction between 'treatment' and 'station'. The predictors 'marram treatment' as well as 'station'. were significant in the LME (Table 3.7 and Figure 3.12 and Figure 3.13). Overall abundances were higher at Whitiau compared to Tapuarau. Higher counts of $C$. canadensis were found in sprayed marram compared to all other treatments and third stations showed the highest abundances compared to station 1 and 2 (Figure 3.12 and Figure 3.13).

Occurrence on second and first stations was to low for errorbars for the relative comparison (Figure 3.13).

Table 3.7: Linear mixed effect model for Conyza canadensis (data from both sites is combined) Transect was included as random effect.

\begin{tabular}{lllrrrr}
\hline Field site & Response variable & Predictor & numDF & denDF & F-value & p-value \\
\hline Both sites & Conyza canadensis & & & & & \\
& (individual counts) & field site & 1 & 8 & 5.569 & 0.046 \\
& & spinifex planting & 1 & 149 & 0.983 & 0.323 \\
& & marram treatment & 2 & 149 & 11.200 & $<.001$ \\
& & station & 1 & 149 & 18.317 & $<.001$ \\
& & planted:station & 1 & 149 & 0.051 & 0.822 \\
& & treatment:station & 2 & 149 & 2.492 & 0.086 \\
\hline
\end{tabular}

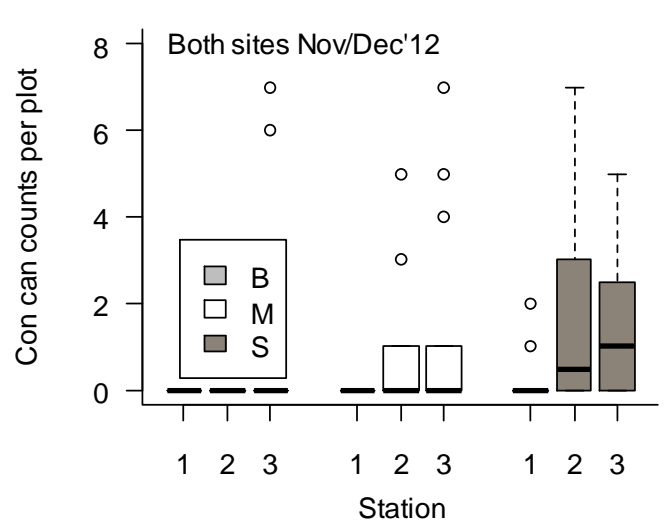

Figure 3.12: Boxplots show individual counts of $C$. canadensis in November 2012 both sites for all treatments $(B=$ bare sand, $M$ = live marram, $S=$ sprayed marram). Treatments are split up by station ( 1 = closest to sea, 2 = intermediate and 3= furthest away).

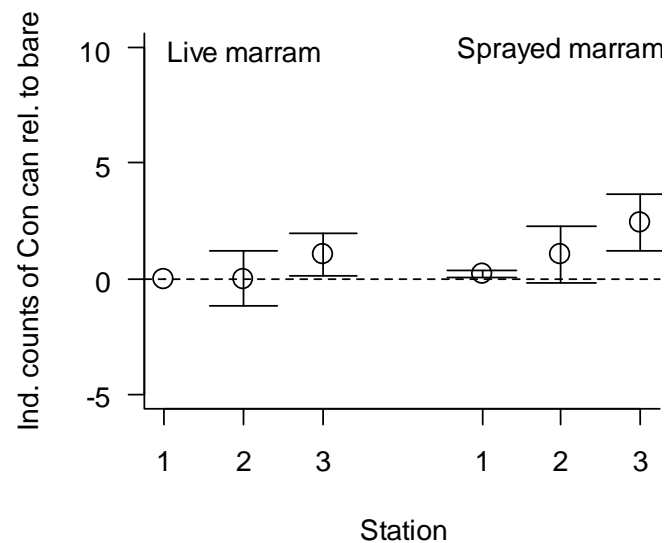

Figure 3.13: Mean values for relative counts of $C$. canadensis compared to bare sand (dotted line) are displayed for marram and sprayed marram plots for Whitiau (right graph) respectively. Treatments are also split up by station (with $1=$ closest to sea, $\mathbf{2}=$ intermediate and $\mathbf{3}=$ furthest away). Errorbars = +- SE. 
Dandelions

Both predictors treatment and station were significant in the LME, but not the interaction between them (Table 3.8). The planting of spinifex had no significant effect on densities of dandelion.

Table 3.8: Linear mixed effect model summary for dandelion individual counts (data from both field sites was combined). Transect was included as a random effect.

\begin{tabular}{lllrrrr}
\hline Field site & Response variable & Predictor & numDF & denDF & F-value & p-value \\
\hline Both & dandelions & & & & & \\
& (individual counts) & field site & 1 & 8 & 0.010 & 0.923 \\
& & spinifex planting & 1 & 149 & 0.071 & 0.790 \\
& marram treatment & 2 & 149 & 9.316 & $<.001$ \\
& station & 1 & 149 & 101.414 & $<.001$ \\
& spinifex & & & & \\
& planting:station & 1 & 149 & 0.066 & 0.798 \\
& marram & & & & \\
& treatment:station & 2 & 149 & 1.360 & 0.260 \\
\hline
\end{tabular}

Dandelions were rarely recorded on first station plots, intermediate counts were recorded on second station plots and highest overall counts were observed on third station plots (Fig 3.14). Sprayed and live marram grass were facilitators of dandelions compared to bare sand (Fig 3.15).

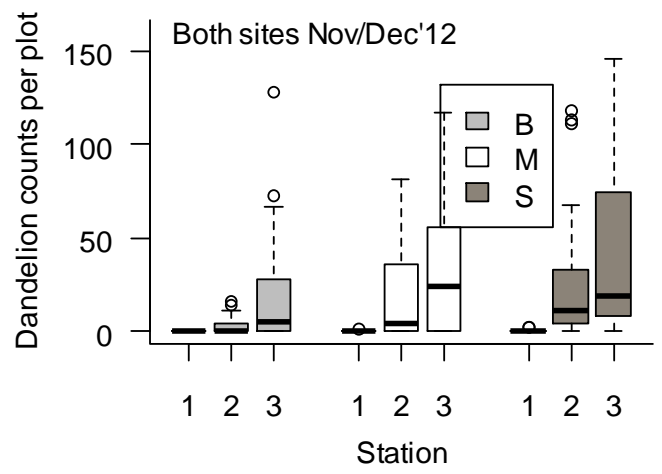

Figure 3.14: Boxplots show individual counts of dandelions in November $\mathbf{2 0 1 2}$ for both sites for all treatments ( $B=$ bare sand, $M=$ live marram, $\mathbf{S}=$ sprayed marram). Treatments are split up by station ( 1 = closest to sea, $\mathbf{2}=$ intermediate and $\mathbf{3}=$ furthest away).

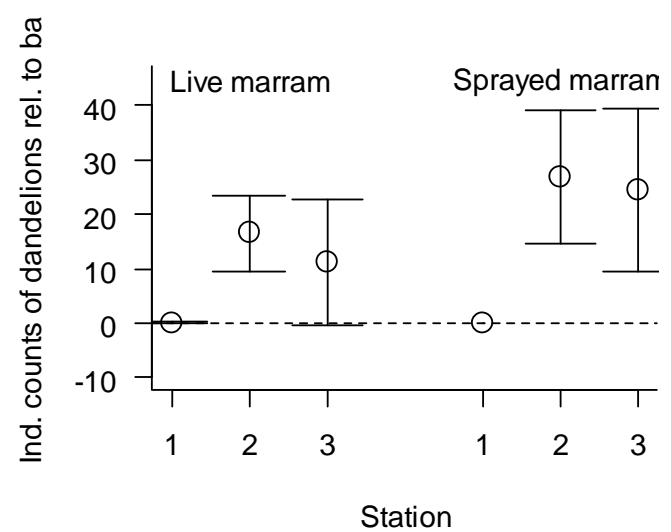

Figure 3.15: Mean values for relative counts of dandelions compared to bare sand (dotted line) are displayed for marram and sprayed marram plots for both sites respectively. Errorbars = +SE. 


\section{Legumes}

There was a significant interaction between station and whether or not a plot was planted, (Table 3.9), where third station sprayed marram plots showed highest overall counts of legumes (Fig 3.16 and Fig. 3.17). In the LME treatment and station were significant predictors (Table 3.9).Third station plots of sprayed marram that had been planted with spinifex facilitated the greatest growth of legumes relative to plots of bare sand (Fig. 3.17).

Live marram and herbicide-sprayed dead marram showed higher counts of legumes compared to bare sand (Fig 3.16 and Fig. 3.17). In plots planted with spinifex, sprayed marram had higher counts of legumes at second and third stations compared to the other two treatments (Fig 3.16 and Fig. 3.17). Counts of legumes were highest at third stations, followed by second and lowest on first stations regardless if planted or not (Fig 3.16 and Fig. 3.17).

Table 3.9: Linear mixed effect summary for legumes (data from both sites was combined). Transect was included as a random effect.

\begin{tabular}{lllrrrr}
\hline Field site & Response variable & \multicolumn{1}{c}{ Predictor } & numDF & denDF & F-value & p-value \\
\hline Both & Legumes & field site & 1 & 8 & 0.058 & 0.816 \\
& (counts) & spinifex planting & 1 & 149 & 1.930 & 0.167 \\
& & marram treatment & 2 & 149 & 3.392 & 0.036 \\
& & station & 1 & 149 & 71.876 & $<.001$ \\
& & spinifex planting:station & 1 & 149 & 8.777 & 0.004 \\
& & marram treatment:station & 2 & 149 & 1.142 & 0.322 \\
\hline
\end{tabular}



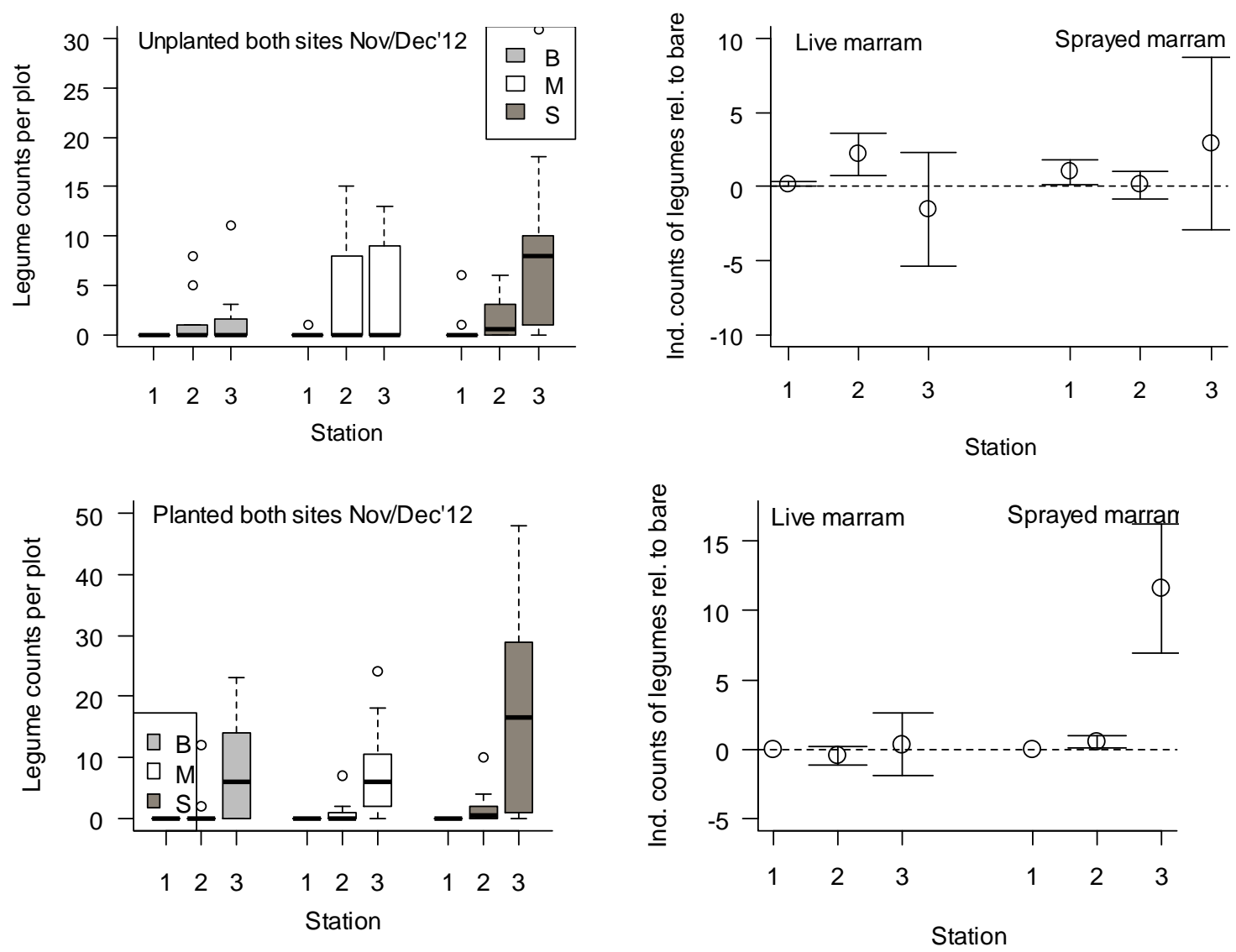

Figure 3.16: Boxplots show individual counts of Figure 3.17: Mean values for relative counts of legumes in November $\mathbf{2 0 1 2}$ for both sites for all legumes compared to bare sand (dotted line) treatments ( $B=$ bare sand, $M$ = live marram, $S=$ sprayed marram). Treatments are split up by station (1 = closest to sea, 2 = intermediate and 3 = furthest are displayed for marram and sprayed marram plots for both sites. Errorbars = +- SE.

away). The upper graph shows uplanted and planted plots and the lower shows only planted plots.

\subsubsection{Cover changes of functional groups}

Grasses, sedges and rushes (hereafter referred to as 'monocots')

The initial selection model showed significant effects for interactions between field site and the other predictors (i.e. station, treatment and planted), so I analysed both field sites separately.

Tapuarau

The interaction between treatment and station showed a non-significant trend $(P=$ 0.069) where facilitation by live marram increased with distance from the sea but with 
sprayed marram levels of competition increased with distance from the sea (Fig 3.19, Table 3.10).

Whitiau

Station (=distance for sea) was the only signficant predictor in the LME (Table 3.10).

Table 3.10: Linear mixed effect model summary for monocot cover (data from each field site was analysed separately). Transect was included as a random effect.

\begin{tabular}{|c|c|c|c|c|c|c|}
\hline Field site & Response variable & Predictor for monocot cover & numDF & denDF & F-value & p-value \\
\hline \multicolumn{7}{|l|}{ Tapuarau } \\
\hline & monocot & spinifex planting & 1 & 78 & 0.022 & 0.881 \\
\hline & cover in $\%$ & marram treatment & 2 & 78 & 3.817 & $<.001$ \\
\hline & & station & 1 & 78 & 13.491 & $<.001$ \\
\hline & & spinifex planting:station & 1 & 78 & 2.054 & 0.156 \\
\hline & & marram treatment:station & 2 & 78 & 2.771 & 0.069 \\
\hline \multirow[t]{5}{*}{ Whitiau } & & spinifex planting & 1 & 76 & 0.069 & 0.793 \\
\hline & monocot & marram treatment & 2 & 76 & 0.041 & 0.960 \\
\hline & cover in $\%$ & station & 1 & 76 & 50.498 & $<.001$ \\
\hline & & spinifex planting:station & 1 & 76 & 0.160 & 0.690 \\
\hline & & marram treatment:station & 2 & 76 & 0.349 & 0.707 \\
\hline
\end{tabular}

At the Tapuarau field site the highest monocot cover was recorded on marram plots, followed by bare plots, and was lowest on sprayed plots (Fig 3.18). Third station plots showed highest grass cover followed by second and first station plots (Fig. 3.18). 

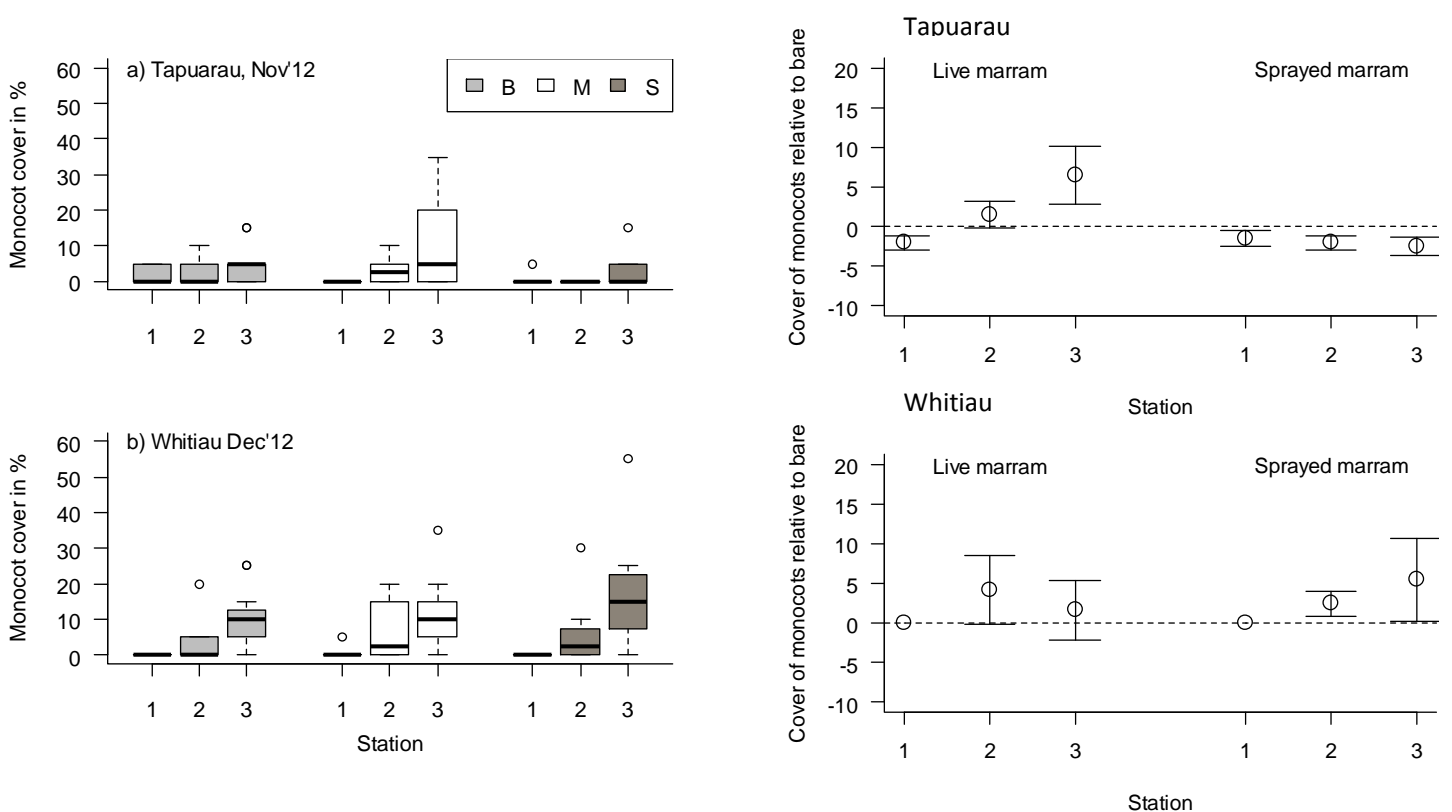

Figure 3.18: Boxplots show cover in \% for monocots in November 2012 for Tapuarau and Whitiau for all treatments ( $B=$ bare sand, $M=$ live marram, $S=$ sprayed marram). Treatments are split up by station ( $1=$ closest to sea, 2 = intermediate Figure 3.19: Mean values for relative cover in \% for monocots compared to bare sand (dotted line) are displayed for marram and sprayed marram plots at Tapuarau and Whitiau. Errorbars = +- SE. and 3 = furthest away).

At Whitiau, similar to Tapuarau, there was a clear significant increase for monocot cover across all treatments with increasing distance from the sea (Fig. 3.18 and Fig. 3.19).

Herbaceous plants

Tapuarau

Treatment and station separateley were significant predictors in the LME (Table 3.11) for herbaceoaus plant cover as response variable. The interactions beween planting and station and between treatment and station however, were not significant.

Whitiau

Treatment and station were significant predictors for the aboundance of herbaceous plants in the LME (Table 3.11). However, there was no significant interaction between these variables and no effect of planting Spinifex. 
Table 3.11: Linear mixed effect model anova values for herb cover in $\%$ as response variable and field site, planted as well as treatment, station the interaction between planted and station and the interaction between treatment and station were used as predictors. The dataset from each field site was used separately as field site was a significant factor in the selection model. Transect was used as random effect.

\begin{tabular}{lllrrrr}
\hline Field site & Response variable & Predictor for herb cover & numDF & denDF & F-value & p-value \\
\hline Tapuarau & Herbs & & & & & \\
\cline { 3 - 6 } & (cover in \%) & spinifex planting & 1 & 78 & 1.027 & 0.314 \\
& & marram treatment & 2 & 78 & 6.715 & 0.002 \\
& & station & 1 & 78 & 49.670 & $<.001$ \\
& & spinifex planting:station & 1 & 78 & 0.098 & 0.755 \\
Whitiau & & marram treatment:station & 2 & 78 & 0.110 & 0.896 \\
& & spinifex planting & 1 & 75 & 1.749 & 0.190 \\
& & marram treatment & 2 & 75 & 13.292 & $<.001$ \\
& & station & 1 & 75 & 54.783 & $<.001$ \\
& & spinifex planting:station & 1 & 75 & 0.183 & 0.670 \\
& & marram treatment:station & 2 & 75 & 1.073 & 0.347 \\
\hline
\end{tabular}

At Tapuarau, cover values for herbaceous plants were higher for both live and sprayed marram compared to bare sand (Fig 3.20 and Fig. 3.21). Highest overall cover values were recorded on second and third stations compared to first station plots.
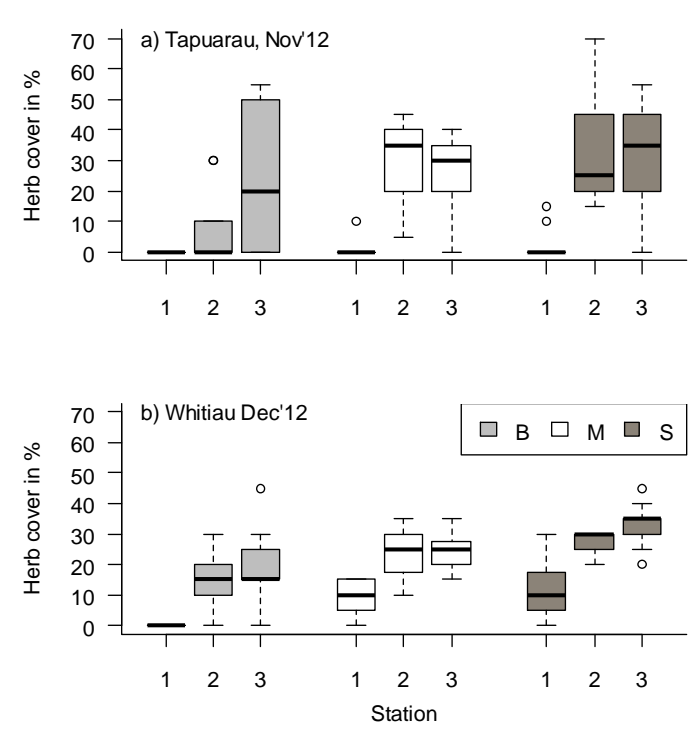

Figure 3.20: Boxplots show cover in \% for herbs in November 2012 for Tapuarau and Whitiau for all treatments $(B=$ bare sand, $M=$ live marram, $S=$ sprayed marram). Treatments are split up by station ( 1 = closest to sea, 2 = intermediate and $\mathbf{3}=$ furthest away).
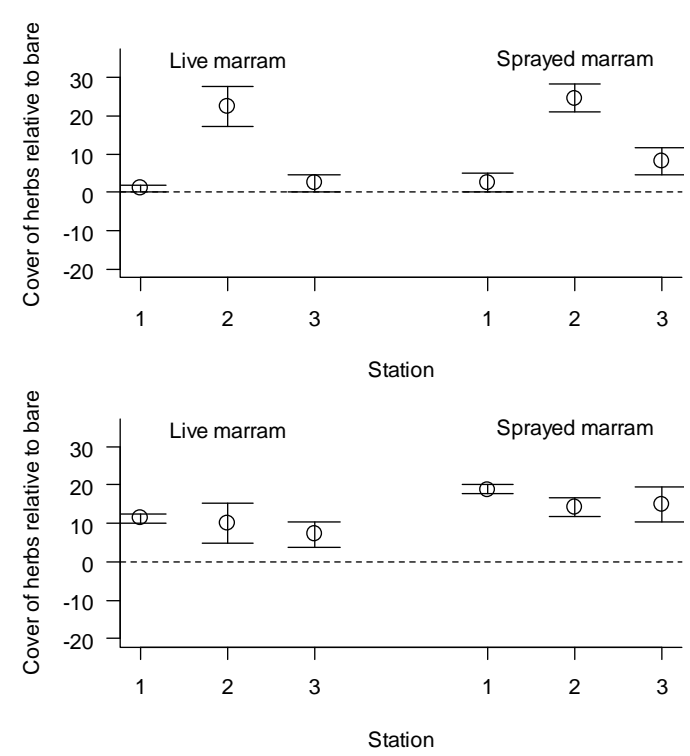

Figure 3.21: Mean values for relative cover in \% for herbs compared to bare sand (dotted line) are displayed for marram and sprayed marram plots for Tapuarau and Whitiau respectively. Errorbars = +- SE. 
Similar patterns were evident at Whitiau; higher herb cover values were recorded further from the sea and on live marram and sprayed marram plots compared to bare sand (Fig. 3.20 and Fig. 3.21). 
Woody plants

Only the dataset from Whitiau had enough records and is displayed (Fig 3.22 and Fig 3.23). Station significantly affected woody plant cover at Whitiau (Table 3.12). Planting of spinifex, treatment and their interaction with station was non-significant (Table 3.12).

Table 3.12: Linear mixed effect model anova values for woody plant cover at Whitiau in $\%$ as response variable and planted (i.e. planted or unplanted with spinifex) as well as treatment, station the interaction between planted and station and the interaction between treatment and station were used as predictors. Transect was used as random effect.

\begin{tabular}{|c|c|c|c|c|c|c|}
\hline Field site & $\begin{array}{l}\text { Response } \\
\text { variable }\end{array}$ & Predictor & numDF & denDF & F-value & p-value \\
\hline \multirow[t]{5}{*}{ Whitiau } & $\begin{array}{l}\text { Woody plant } \\
\text { cover }\end{array}$ & spinifex planting & 1 & 76 & $<0.001$ & 0.994 \\
\hline & in $\%$ & marram treatment & 2 & 76 & 0.658 & 0.521 \\
\hline & & Station & 1 & 76 & 11.735 & 0.001 \\
\hline & & spinifex planting:station & 1 & 76 & 0.134 & 0.716 \\
\hline & & marram treatment:station & 2 & 76 & 0.971 & 0.384 \\
\hline
\end{tabular}

Highest cover values were observed on third station plots compared to all other stations

(Fig. 3.22 and Fig. 3.23).

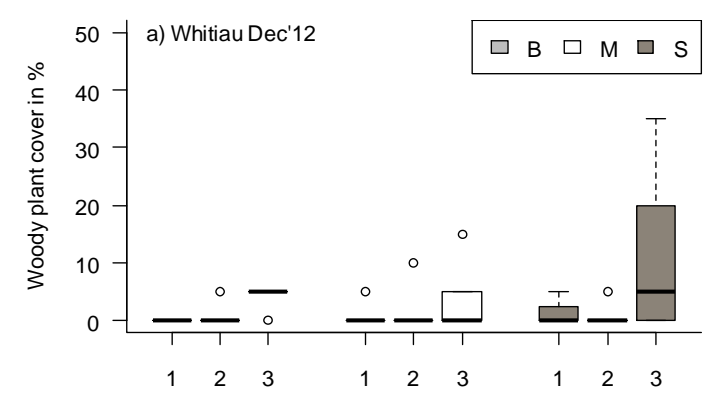

Figure 3.22: Boxplots show cover in \% for woody plants in December 2012 for Whitiau for all treatments $(B=$ bare sand, $M=$ live marram, $S=$ sprayed marram). Treatments are split up by station (1 = closest to sea, 2 = intermediate and 3 = furthest away).

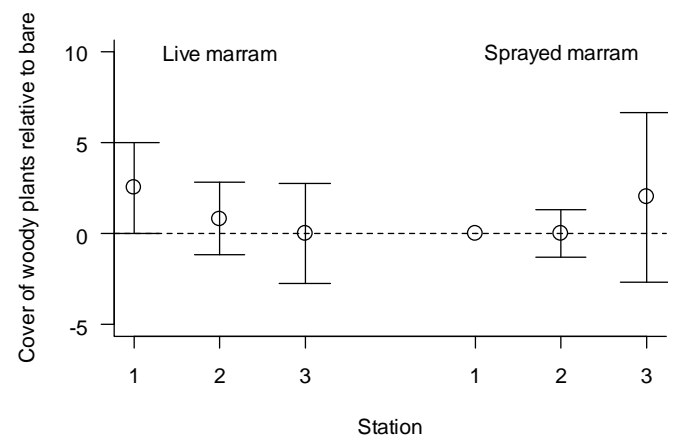

Figure 3.23: Mean values for relative cover in \% for woody plants compared to bare sand (dotted line) are displayed for marram and sprayed marram plots for Whitiau (right graph) respectively. Treatments are also split up by station (with 1 = closest to sea, 2 = intermediate and 3 = furthest away). 


\subsubsection{Overview across species and functional groups}

Despite frequent significance of either treatment or station or both of them as main effects, the interaction between treatment and station was only significant for S. elegans counts and close to significant $(0.1>\mathrm{P}>0.05)$ for $C$. canadensis and grass cover (Table 3.13). Planting spinifex only affected the abundance of a taxon in two of fourteen tests and the interaction between planting and station was significant for 0 . minor $(p=0.015)$ and for legume-cover $(p=0.004)$.

Table 3.13: Overview over LMEs per response variable. Significance values: $+=0.1>P>0.05, *=p$ $<0.05, * *=\mathrm{p}<0.01, * * *=\mathrm{p}<0.001, \mathrm{~ns}=$ non-significant $(\mathrm{P}>0.1), \mathrm{NA}=$ not applciable as field sites tested separately.

\begin{tabular}{llllllll}
\hline Response variable & $\begin{array}{l}\text { field site } \\
\text { in LME }\end{array}$ & $\begin{array}{l}\text { field } \\
\text { site }\end{array}$ & station & Treatment & planted & $\begin{array}{l}\text { treatment* } \\
\text { station }\end{array}$ & $\begin{array}{l}\text { planted } \\
\text { *station }\end{array}$ \\
\hline $\begin{array}{l}\text { Calystegia. soldanella } \\
\text { Sonchus oleraceus }\end{array}$ & Both & $*$ & $* *$ & $\mathrm{~ns}$ & $\mathrm{~ns}$ & $\mathrm{~ns}$ & $\mathrm{~ns}$ \\
Senecio elegans & Both & $*$ & $*$ & + & + & $\mathrm{ns}$ & $\mathrm{ns}$ \\
"'" & Whitiau & $\mathrm{NA}$ & $* *$ & + & $*$ & $*$ & $\mathrm{~ns}$ \\
Lagurus. ovatus & Tapuarau & $\mathrm{NA}$ & $* * *$ & $* * *$ & $\mathrm{~ns}$ & $\mathrm{~ns}$ & $\mathrm{~ns}$ \\
Orobranche minor & Both & $\mathrm{ns}$ & $* * *$ & $\mathrm{~ns}$ & $\mathrm{~ns}$ & $\mathrm{~ns}$ & $\mathrm{~ns}$ \\
Conyza canadensis & Whitiau & $\mathrm{NA}$ & $*$ & $\mathrm{~ns}$ & $*$ & $\mathrm{~ns}$ & $*$ \\
dandelions & Both & $*$ & $* * *$ & $* * *$ & $\mathrm{~ns}$ & + & $\mathrm{ns}$ \\
legumes & Both & $\mathrm{ns}$ & $* * *$ & $* * *$ & $\mathrm{~ns}$ & $\mathrm{~ns}$ & $\mathrm{~ns}$ \\
grass cover & Both & $\mathrm{ns}$ & $* * *$ & $*$ & $\mathrm{~ns}$ & $\mathrm{~ns}$ & $* * *$ \\
"'" & Whitiau & NA & $* * *$ & $* * *$ & $\mathrm{~ns}$ & + & $\mathrm{ns}$ \\
herb cover & Tapuarau & NA & $* * *$ & $\mathrm{~ns}$ & $\mathrm{~ns}$ & $\mathrm{~ns}$ & $\mathrm{~ns}$ \\
"'" & Whitiau & NA & $\mathrm{ns}$ & $* * *$ & $\mathrm{~ns}$ & $\mathrm{~ns}$ & $\mathrm{~ns}$ \\
woody plant cover & Tapuarau & NA & $* * *$ & $* * *$ & $\mathrm{~ns}$ & $\mathrm{~ns}$ & $\mathrm{~ns}$ \\
\hline
\end{tabular}




\subsection{Discussion}

This chapter examined the abundance and distribution of self-colonizing plants across three different treatments (i.e. bare plots, marram plots and sprayed marram plots) with or without planted spinifex at three different distances from the sea. Both field sites showed a differentiation for most species at the first station plots compared to the more landward second and third station plots. The interactions between the colonising species and marram changed depending on species identity, location and treatment. However, only one interaction was significant where there was higher facilitation by dead sprayed marram at front stations for S. elegans compared to landward stations. A trend for an interaction change with distance to the sea was evident for $C$. canadensis and monocot cover. The interaction between planting of spinifex (i.e. either planted or unplanted) and station was significant for $O$. minor, a hemiparasitic plantand for legumecover. Overall, results provide little support for the SGH from these data, especially as for two of the groups the effect was in the opposite direction as expected.

The results of the PCoA showed an overlap of species composition between stations which was focused around the second station, but infiltrated into the first and third station. As mentioned in the results, this overlap was due to a few species (i.e. dandelions mostly), which were able to persist occasionally at the first, but more prominently at the second and third stations. Therefore, the study indicates an apparent environmental gradient that is influencing species distribution and abundance and therefore zonation according to position with regards to the sea within the study sites. Poulter, Qian, \& Christensen, (2008) describe the interaction between sawgrass and pine regeneration along a salinity gradient. Similarly, the zonation in estuarine marshes was found to be related to salinity and the interactions among the neighbouring species (Crain et al. 2004). This has been shown for salt marshes (Alvarez-Rogel et al. 2006) and in the succession of sand dunes (Olff et al. 1993). Furthermore the zonation and plant distribution is also related to salinity and the neighbouring species (Moreno-Casasola 1984, 1988, Honrado et al. 2010). The importance of biotic interactions in addition to abiotic ones has been emphasized for biodiversity studies (Maestre et al. 2009, Tomasetto et al. 2013). While the effects of browsing and insect infestations were 
discussed in Chapter 2, other biotic effects of animals on self-colonizing species were not accounted for.

Most species showed either significant effects for 'station' (i.e. the location in reference to the sea); 'treatment' (i.e. whether planted in bare sand, live marram or sprayed marram) or 'planted' (i.e. whether additionally to the treatments mentioned before spinifex was planted or not). However, S. elegans counts at Whitiau, O. minor and legume cover were the exceptional species (groups) where the interaction between plants and treatment or whether a plot was planted or not with spinifex were significant. I expected higher facilitative (i.e. more positive) interactions where stress was most severe to support the SGH. Only S. elegans at Whitiau followed this pattern, showing better facilitation at the first station, then a decline at further distant stations ( 2 and 3 ) as the interactions presumably became more competitive and less facilitative (i.e. negative). In contrast, facilitation of $O$. minor was better at the back stations (i.e. station 2 and 3 ) compared to station 1 . This result is not suprising considering that this parasitic species is dependent on species which occurred more frequently at the back stations $(O$. minor favours Asteraceae, and Fabaceae, but is also able to survive on Poaceae, see appendix for a more comprehensive description). Similar to O. minor, facilitation of legumes was better at the back stations compared to the ones at the front. Legumes fix nitrogen through symbiotic nitrogen fixing bacteria in their root nodules (Crews 1999). Soil pathogens increase with soil development (which increases with distance from the sea) and can cause damage to early successional species (i.e. very salt and sand burial tolerant plants) (Putten 2003) and could hence influence species abundances.

Both support and no support have been shown for studies of coastal communitiesThese studies mostly looked at pairwise interactions (e.g. recent review in Callaway (2007). There has been a call for studies focussing on the entire community (Maestre et al. 2009, Honrado et al. 2010, Maltez-Mouro et al. 2010). I considered all species as far as it was possible to distinguish between them and as long as they exhibited sufficient counts for further analysis (see species list Appendix III (Fig. A III.2)) for all the other species that were encountered less frequently and thus did not provide enough data points for further analysis). My focus was on the colonisation of unplanted species. Therefore I counted/estimated percent covers for each species. Although my approach 
was to consider all species, the actual interaction (whether it was competitive or facilitative) was tested between the focal species and the eco-engineering species: i.e. the introduced, self-established marram and the planted native spinifex. Ecoengineering species are thought to exhibit both positive and negative impacts on other (facilitated) species, even though a general positive effect is expected on larger (i.e. regional) scales (Jones et al. 1997). Although the strongest interactive effects were expected between the eco-engineering species and self-colonizing plants, it is possible that some weaker, but yet potentially biologically and statistically significant interactions were not detected. However, for support of the SGH I would have expected significant interactions between species abundances and the location. There was only support for this assumption for the coastal Senecio elegans.

New Zealand's coastal sand dunes are one of the most threatened habitats within the country as they have been largely modified (Pegman and Rapson 2005). Intact native vegetation sequences on dunes are now rare (Sykes and Wilson 1991). Therefore an experiment that takes introduced species into consideration is the best model to reflect the current situation around beaches in New Zealand. Therefore experimental manipulation in this study involving herbicide spraying was restricted to the major exotic sand binding species marram to reflect the current situation around beaches in New Zealand. Using introduced species when testing the SGH has been controversial. For example Lortie \& Callaway (2006) criticised Maestre et al. (2005) for including introduced species in their meta-analysis. However, Maestre et al. (2006) argued that in an earlier study, Bertness \& Callaway (1994) did not confine the SGH in their initial proposal to a species' geographic origin and thus concluded exotic species should be included in SGH-testing. Santoro et al. (2012) showed that invaded communities are less likely to show zonation mirroring the stress gradient. Moreover, when coastal communites were invaded plant species showed a random distribution. Unfortunately, in my study there was no reference site for comparing a similar invaded and noninvaded site as the climatic conditions change along the latitudal gradient of New Zealand's coastline. Both Whitiau and Tapuarau are relatively rare dune systems (pers. comm. with DOC staff in Wanganui) along the West Coast of the lower North Island. 
There are few dune systems with an extensive inland dune complex remaining that have not been converted to productive pasture or pine forests.

One explanation for the variable pattern of species support for the SGH could be an underlying random distribution due to invasion patterns of exotic species. The differences in results between the two field sites could be based on their different levels of weediness. Whitiau was the weedier site largely due to substantial weed propagule sources on adjacent forestry wasteland while the backdunes of the Tapuarau site border a dairy farm where there is less weed propagule sources. Furthermore, physical dune proceses differ at each sites the dunes at Whitiau are eroding while the situation is opposite at Tapuarau, where the dunes are accreting. Consequently, the stations at Whitiau could be much older compared to the newly established ones at Tapuarau.

With the exception of the cosmopolitan native $C$. soldanella, all species considered for separate analysis of this chapter were introduced species. Most of the introduced species that were recorded at Whitiau and Tapuarau were facilitated by vegetation both live marram but to an even larger extent by sprayed, dead marram or by planted spinifex at stations further landward. This is opposed to the expected facilitation where stress is more severe closer to the sea. However, it has been argued that a species' ecological adaptations are crucial to identifying where the stress gradient is potentially affecting its abundance and establishment with or without facilitators (Maestre et al. 2009). The species considered here are mostly pasture weeds from Europe (e.g. dandelions and legumes, or associated with them (e.g. O. minor) and are not especially adapted to very exposed coastal conditions (see appendix for more detailed species descriptions and references therein). Consequently, the stressful conditions at their survival limit could be just starting at the second and third stations rather than at the first stations. Sonchus oleraceus and the herbaceous plants show a pattern which might be interpreted thus, i.e. unable to survive well at all at the first station, facilitated by marram and at the second station, and then more inhibited by marram at the third station. Monocots showed higher abundances on bare plots compared to live and sprayed marram. It is also possible that the spraying impaired the self colonizing monocots on sprayed plots. Several studies failed to provide support for facilitation in locations with very high stress levels (see discussions in Maestre et al., 2009; Malkinson 
\& Tielbörger, 2010). The latter authors argued that multiple stress gradients exist silmultaneously and thus are able to affect species differently according to species identity. They suggested measuring and identifying the different stressors as opposed to assuming a certain stress gradient is present. In chapter 2 I showed my results measuring the stress gradient. Some of the abiotic stress gradient measurements did not completely follow our expectations, which is most likely due to the shelter from wind provided by second dunes (where the second stations were located) compared to first or third stations. In a previous study, salinity and sand burial were identified as the most important structuring environmental forces in New Zealand's coastal dune systems (Wilson and Sykes 1999).

The summer of 2012/13 was a record summer with much lower precipitation than usual (Turner and Chapell 2013), even for the exposed west coast. This study did not directly consider a water availability gradient, but Mason, French, \& Russell (2012) showed a competitive advantage for the introduced bitou-bush over native plants in the presence of water shortage and argued this could yield conservation problems for future droughts as predicted with climate change.

\subsection{Conclusions}

As may be expected in a study of a range of exotic and native species that occur across a highly variable environmental gradient evident on the dunes sites studied here, support for the SGH varies depending on the species considered and the treatments and sites in proximity to the sea evaluated. Only S. elegans as a truly coastal species fitted the pattern described by the SGH with higher facilitation at the seaward stations compared to the landward sites and where marram had been sprayed. Most species (with $S$. oleraceus as an exception and dandelions at third stations) were better facilitated by sprayed marram grass compared to live marram grass regardless of station. Station was a significant effect and thus shows differences in stress levels.

Careful consideration must be given to the current vegetation composition at coastal dune sites prior to spraying marram grass and leaving it, as this also facilitates weeds. This scenario is especially relevant for sites where there is a major source of weed 
propagules (eg. seeds) nearby. For very weedy sites management strategies other than planting into sprayed (and thus killed) marram may be required. For instance, one option may be to completely reshape the dune, removing or burying the sprayed weed cover, and start with clean sand that does not have a vibrant seedbank of weedy species that can then be planted with appropriate coastal native species. This has been successfully carried out at several weedy sites in the Coromandel (Jim Dahm, Coastal Scientist, pers comm., 2013).

Further plant community studies that consider both invaded and uninvaded sites at stressful locations are needed to test the SGH and confirm whether exotic species influence natural zonation patterns as may have occurred in this study. 
CHAPTER 3 


\section{CHAPTER 4}

Senecio spp. food webs in New Zealand

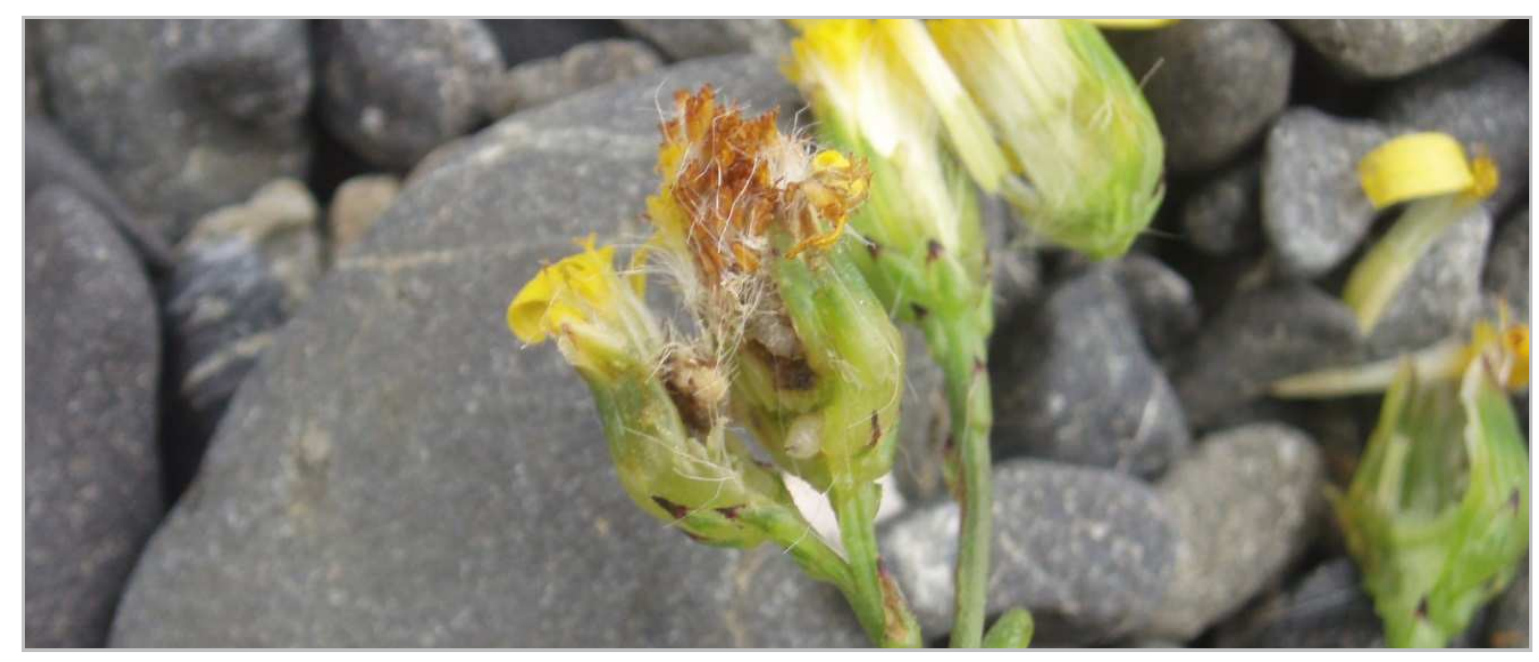

Larvae of Sphenella fascigera in a flower head of Senecio lautus. 


\subsection{Introduction}

Communities are spatially structured by the abiotic environment and their constituent populations interact via trophic connections (e.g. predation and herbivory) or via direct and indirect competition and facilitation if on the same trophic level (Dayton 1971, Menge and Sutherland 1987). To understand the ecological interactions within a community it is important to identify and quantify linkages between members of the community- the food web. Herbivorous insects are the most diverse terrestrial group and consequently influence food webs in various ways (reviewed in Schoonhoven et al. 2007). The evolution of host specificity among herbivorous insects is thought to be an important step in understanding processes towards species formation (Dethier 1954). Information on species host specificity is therefore crucial to identifying comprehensive linkages and potential interactions between species within a community (van Veen et al. 2006) and thus improve the understanding of food webs in general.

Modern day communities are often composed of sets of species that co-evolved over tens of thousands to tens of millions of years and species that were introduced more recently deliberately or unintentionally (Minor et al. 2009). As a consequence, the land use and the introduced species used for it often determines modern day food webs and the interactions between their members (Tylianakis et al. 2007, Didham et al. 2007, de Visser et al. 2011). When species are removed via extinction or added through invasions to food webs, the interactions are changed (Niemelä and Mattson 1996, Pearson and Callaway 2003, 2008); often with unpredictable consequences (e.g. McCann 2000). Evidence for different effects of introduced species has been demonstrated in previous studies: Results ranging from filling a previously unoccupied niche with an introduced invader to extinctions have been documented (Sakai et al. 2001, Drossel and McKane 2002, Yoshida 2008). Altered food webs especially illustrate the need to understand interactions among different species and trophic levels within a food web, raising questions such as: How do introduced species insert themselves into a food web? Are they more likely to be generalist rather than specialist feeders? Are external feeders more often successful in adapting to novel hosts compared to internal feeders? When considering the primary producer level, are plants that are closely related to host plants 
in the introduced species' home range more prone to become novel hosts? Are particular taxonomic orders of herbivores more successful in adapting to novel host plants? What are the consequences for the invaded food webs?

Understanding the impacts of introduced species both plants and herbivores on an invaded food web enhances the knowledge of species interactions in general it also benefits the management of introduced species through improved risk assessments and appropriate use of biocontrol agent. More effective management in turn will reduce the costs of biosecurity (Henneman and Memmott 2001). Currently invasive species are considered to be one of the highest risks to biodiversity, second only to habitat destruction and modification (Kareiva et al. 2008). Approximately $42 \%$ of all threatened species in the US are linked to invasive species (Pimentel et al. 2005) and the effects of invasive species on food webs carries important implications for restoration management and weed control.

Several types of general host specificity are acknowledged in ecological research:

i.) monophagous species, as defined where herbivores feed only on one species by Symons and Beccaloni 1999as shown for the sphingid Manduca quinquemaculata feeding on Nicotiana noctiflora (Cates 1980);

ii.) oligophagous species, where herbivores feed on species within one genus or plant family. This is often related to herbivore accumulation if plant volatiles for their own advantage as is the case for the lepidopteran Nyctemera annulata feeding on Senecio spp. and retaining their pyrrolizidine alkaloids (Benn et al. 1979), and

iii.) polyphagous species, where insect herbivores are known to feed on several genera across several plant families (Schoonhoven et al. 2007).

Depending on their host specialization and spatial abundance, a population of insect herbivores can potentially increase plant diversity (Pacala and Crawley 1992). Introduced insect herbivores can impact host plants' fitness directly as the case forAsian black twig borer (Xylosandrus compactus Eichhoff 1875) on native koa is (Acacia koa) on Hawaii (Daehler and Dudley 2002), or indirectly via apparent competition where two 
species are mediated indirectly via a higher trophic species (reviewedby Kenis et al. 2008). The way an insect herbivore feeds on its host plant can have an important influence on its impact on the host plant. Often seed-predating insect herbivores damage their host plants more compared to foliage feeders (McArt et al. 2012).

Phylogenetic distance of host plants was found to be one of the most important predictors of insect herbivore assemblage in a New Guinea rain forest with congeneric host plants being more likely to have a great overlap in herbivore composition (Weiblen et al. 2006). Current research is starting to explain the evolutionary origins of host plant use by specific insect groups as shown for leaf mining sawflies (Leppänen et al. 2012). Escape and radiation co-evolution can be one of the drivers of host expansion (Winkler et al. 2009). Similarly climate changes in the past are expected to have shaped long term host plant evolution over millennia (Winkler et al. 2009). While related host plants often share similar insect herbivores, related insect herbivores are often found on very different host plants as demonstrated for coleopterans in woodlands (Baker et al. 2012). Often it remains impossible to incorporate all taxa at the species level in food webs due to complex situations, especially within species rich communities (Williams and Martinez 2000).

Several types of food webs are acknowledged in the literature e.g. community webs, where a selected set of interacting species is considered (Drossel and McKane 2002), also often referred to as trophic food webs. The latter term is used when trophic levels are identified. Consequently trophic food webs are a type of hierarchical food web (Polis 1991, Power and Dietrich 2002). Hierarchical sink webs rely on keystone species identification (Jordán et al. 1999). In contrast to these hierarchical food webs, niche webs take all possible prey into consideration. Early niche webs were one dimensional which was revised later on to account for nested interactions (Allesina et al. 2008). There are many different food web reviews (e.g. Polis and Strong 1996, Polis et al. 1997, Dunne et al. 2002). However, the majority focus on specific habitat types or geographic regions, but less often on particular taxonomic groups. Example include Steinmetz et al. (2003) for aquatic food webs, Murakami and Nakano (2000) for bird functions in a forest-canopy food web, and Bruno and O'Connor (2005) for a marine food web. One 
example of research within one insect subfamily (Tephretidae) on Veronica spp. showed high specialization between the different phytophagous tephretids as well as a tendency for higher overlap of associated herbivore communities between closely related hosts (Prado and Lewinsohn 2004). The importance of phylogenetically closely related hosts was also emphasized in a recent review by Bertheau et al. (2010).

Senecio (Asteraceae) is one of the worlds' most species rich plant genera (Jeffrey et al. 1977, phylogeny review in Pelser et al. 2007. The approximately 1250-1500 species of Senecio (Pelser et al. 2007, Hamzaoğlu et al. 2009) are globally distributed and comprise several functional types including vines, trees and succulents (Webb et al. 1988) and are thus are a representative plant genus.The majority of Senecio spp., however, are shortlived herbaceous plants adapted to a range of different environments, particularly disturbed environments (Lawrence 1985). Senecio spp. range from weedy problem species such as Senecio inaquidens in Europe (Heger and Böhmer 2005) to critically endangered species such as S. scaberulus (NZPC Network, 2013). Senecio spp. pose a taxonomic challenge to researchers as they are known to hybridize amongst each other and taxonomic revisions such as the placement of J. vulgaris (formerly known as Senecio jacobaea) in the genus Jacobaea instead of Senecio spp. are not uncommon (Pelser et al. 2012). Hybridisation could be important for insect herbivore host plant choice as hybrids show different plant volatile combinations: Senecio vulgaris is known to hybridize with $S$. vernalis, resulting in intermediate alkaloid concentrations for hybrids (von Borstel et al. 1989).

The effects of introduced Senecio spp. on herbivore communities and congeneric plants remain largely unknown in New Zealand. Amongst the 2146 naturalized species in New Zealand (Diez et al. 2009) are S. vulgaris and S. glastifolius (Webb et al. 1988). Both are problematic weed species. Senecio glastifolius is spreading rapidly throughout New Zealand, it was introduced in 1969 from South Africa to Wellington,New Zealand (Webb et al. 1988, Williams et al. 1999) and current research is trying to predict its potential future distribution (pers. Comm. Beautrais, 2012). Particularly, S. vulgaris is a prominent example which has caused problems for farming elsewhere, even in Europe, its home range (Frantzen and Müller-Schärer 2006). Senecio spp. exhibit species specific profiles 
of plant volatiles, i.e. pyrrolizidine alkaloids, which can be toxic to lifestock (Meijden 1996, Scherber et al. 2003, Hol 2011).

Despite its placement in the genus Jacobaea, J. vulgaris (formerly known as Senecio jacobaea) is still considered to be a close relative to other Senecio spp. and has therefore been continued to be used as a model species for other Senecio spp. for insect herbivore research (Jacquemart et al. 2013). Within farming, J. vulgaris is known to be toxic to livestock and can cause hepatic failure and death. Similarly, S. vulgaris is also toxic to stock but usually not as problematic as J. vulgaris (Stegelmeier et al. 1999). Furthermore, J. vulgaris has been shown to compete with other pasture plants, facilitating some temporarily and decreasing growth of others (Wardle et al. 1995). Jacobaea vulgaris shows a great overlap with other Senecio spp. in terms of its well-studied insect herbivores (Jacquemart et al. 2013). According to Cameron (1935) a total of 75 insect herbivores from Europe are known to use J. vulgaris.

A study from Belgium showed that $S$. inaquidens was more prone to generalist herbivores in its introduced range compared to the related J. vulgaris, which was more susceptible to herbivory by specialist feeders (Jacquemart et al. 2013). Introduced plants are suggested to be able to exhibit adaptations for increased generalist defence compared to their native conspecifics as shown for J. vulgaris populations in their introduced range (i.e. USA, Australia and New Zealand) compared with their native relatives from Europe (Joshi and Vrieling 2005). Whether or not New Zealand's introduced Senecio spp are experiencing higher pressure from generalist feeders compared to their native congenerics is currently unknown.

Aim: My aim for this chapter is to review the current knowledge about Senecio spp.-food webs in New Zealand. A reasonable amount of information has begun to be accumulated but it is recorded across many disparate sources, including much "grey literature" that is not immediately accessible. Therefore my objectives were to

I. Bring the current information together in one place and review general trends in host specificity, feeding guilds, host overlap 
II. Investigate whether introduced species are more frequently encountered by generalist feeders compared to native ones.

III. Assess the degree of food web integration between native and introduced species as a preliminary step towards a better understanding and prediction of the potential direct and indirect effects of introduced species (both plants and insects) entering this food web. 


\subsection{Methods}

\subsubsection{Data collection}

For this chapter I searched the databases displayed in Table 4.1 additionally to a general web search which included Google Scholar. Furthermore I used my own field research involving Senecio spp. and their insect herbivores (Chapter 5 elaborates on the methods used to obtain association records).

Table 4.1: Databases searched for records of insect feeding associations with Senecio species in New Zealand.

\begin{tabular}{|c|c|}
\hline Database/sources & years covered \\
\hline \multicolumn{2}{|c|}{$\begin{array}{l}\text { ISI Web of Knowledge using CrossSearch including the } \\
\text { following data bases: }\end{array}$} \\
\hline ISI Web of Science & 1990-present \\
\hline \multicolumn{2}{|l|}{ Web of Knowledge } \\
\hline Science Direct - Agricultural and Biological Sciences & 1823-present \\
\hline \multicolumn{2}{|l|}{ JSTOR } \\
\hline \multicolumn{2}{|l|}{ AGRICOLA } \\
\hline Index to Theses & $1970-2003$ \\
\hline UMI ProQuest Digital Dissertations & $1950-2003$ \\
\hline \multicolumn{2}{|c|}{$\begin{array}{l}\text { COPAC - database of the } 24 \text { main British and Irish university } \\
\text { libraries and the British Library and National Library of } \\
\text { Scotland }\end{array}$} \\
\hline Natural History Museum Library & 1980-present $+80 \%$ prior \\
\hline \multicolumn{2}{|l|}{ Online Public Access Catalogue (books) } \\
\hline \multicolumn{2}{|l|}{ Journal Article Citation Index (journals) } \\
\hline \multicolumn{2}{|l|}{ SCIRUS - Scientific Search Engine } \\
\hline Crop and Food/Landcare Research data base & Martin 2013 \\
\hline Spiller and Wise & publication 1982 \\
\hline own field work & $2010-2013$ \\
\hline
\end{tabular}

Consequently, I evaluated all references and any reference that added to the knowledge about linkages between New Zealand's Senecio spp. and their insect herbivores was used for further analysis.

I classified Senecio spp. into different categories: endemic (only occurring naturally in New Zealand), native (non-endemic natives), and exotic (introduced and naturalized or cultivated but thought at risk of naturalizing). With the exception of S. sterquilinus, 
which is regarded as part of the Senecio lautus complex (Ornduff 1964, Webb 1988), only 20 species are represented here (i.e. Senecio angulatus, S. banksii, S. bipinnatisectus, S. biserratus, S. diaschides, S. elegans, S. esleri, S. glastifolius, S. glomeratus, S. hispidulus, S. lautus, S. minimus, S. quadridentatus, S. radiolatus, S. rufiglandulosus, S. skirrhodon, S. sterquilinus, S. sylvaticus, S. vulgaris and S. wairauensis, instead of the 33 species that Sullivan et al. (2008) mention. Senecio spp. without reported associations or revised taxonomy and/or subspecies status were not further considered and hence are not part of the species list $S$. aquaticus, S. cineraria, $S$. linearifolius, S. mikanioides, S. petatsitis, S. carnoosulus, S. dunedensis, S. glaucophyllus, S. hauwai, S. kermadecensis, S. marotiri and S. scaberulus,). Senecio sterquilinus was included solely from records based on my own surveys, as to my knowledge no other records exist about its food web associations. A detailed table of all Senecio spp. included can be found in Appendix IV.

I included only herbivores that were reared on a Senecio plant. Where it was unclear what Senecio sp. it was I distinguished those records from those with clear host species identification. Host specificity was classified according to the literature/database information. I identified insect herbivores, as monophagous, oliphagous, or polyphagous as defined earlier. Where other host plant species are known for the insect herbivore but no information was available in terms of its host specialization I used the term 'unknown'.

In order to compare the parts of the Senecio spp. that were used by the insect herbivore I distinguished between different feeding types: flower feeders, leaf miners, stem borers, nectar feeders, foliage feeders, insects that suck on plant sap, insect herbivores feeding on roots and leaves. Included were all records that showed evidence of rearing the insect herbivore on that particular plant or a Senecio sp within New Zealand in general (without species reference). 


\subsubsection{Data analysis}

All data obtained from the literature was consolidated into one data file for further analysis. The graphs displayed to compare the biostatus of the Senecio spp. host plant and the biostatus of insect herbivores may contain multiple species associations per species.

Fischer's exact tests were used to compare the distributions of various aspects of the associations between native, endemic and introduced herbivores, plants and their host specificity. Significance was assumed at $p<0.05$. For food web association graphs I used bipartite food web association graphs generated with the package bipartite (Dormann et al. 2008) using the statistical program R (R Core Team 2012). Where boxplots were used, boxes and whiskers are by $R$ default (boxes encompass the interquartile range (IQR). Whiskers extend to the end of the range except for the outliers ( $>1.5$ times the range). 


\subsection{Results}

A total of 97 unique Senecio-spp. insect herbivore associations was retrieved from the databases. Twenty-eight insect herbivore species were found on the 20 Senecio taxa investigated (See Fig. 4.1 and 4.2 for all associations). A detailed list with species descriptions of all Senecio spp considered in this study is available in Appendix IV with photos for coastal Senecio spp and some of the major insect herbivores (Fig. A V.1-6). The majority of reports for insect herbivores on Senecio spp. were for naturalized Senecio spp followed by non-endemic natives and endemics (Fig. 4.3). All records are either based on my own records which were validated against voucher specimens or are based on records with a reliability score that ensures that the herbivore was raised on the plant (higher than score "8"). 

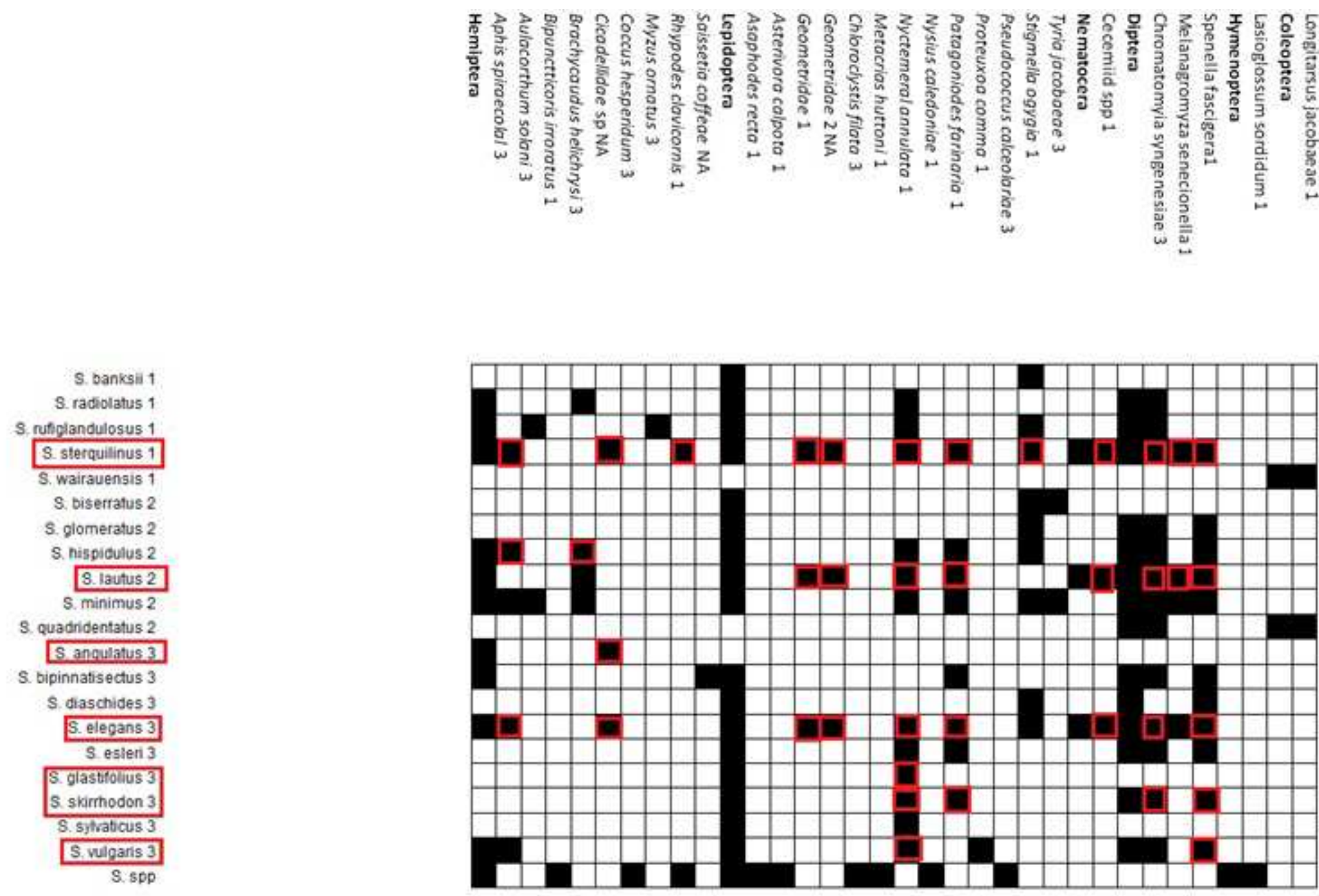

Figure 4.1: Single species associations are shown for plant species vs. insect herbivores. Digits after species names indicate plant status: 1= endemic, $2=$ native, $3=$ introduced. Where no digit is given, status was unclear. Insect herbivores are grouped by order (black box). Associations highlighted with red are based on my own records. 


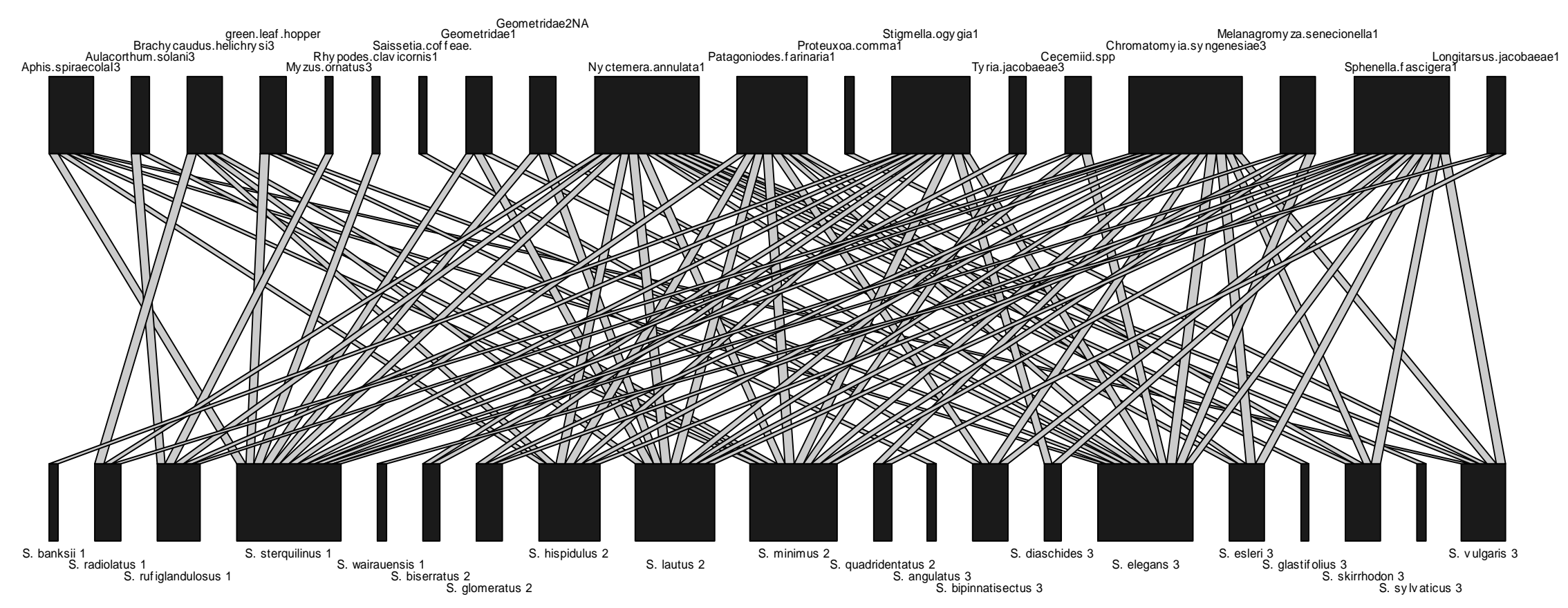




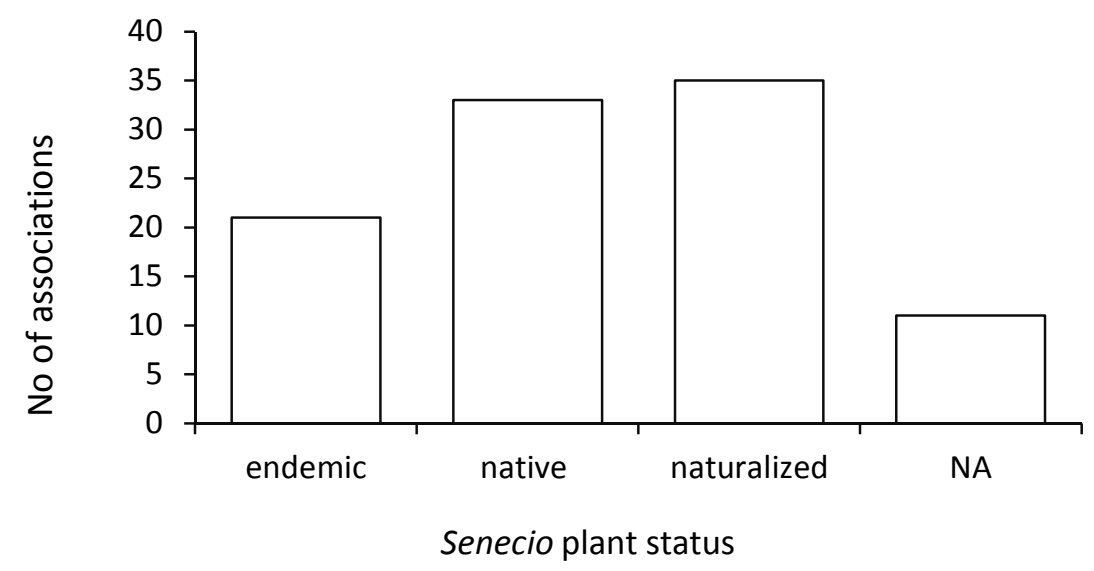

Figure 4.3: Frequency of Senecio spp. biostatus for which insects were reported. Each record represents a unique host plant-insect herbivore association. NA = Associations where the Senecio spp. was not identified to species level.

The frequency of host specificity of insect herbivores on Senecio spp. showed higher numbers for insect herbivores recorded which are known to only feed on Senecio spp. (Fig. 4.4) compared to oligophagous or polyphagous. However, the proportion of unknown host specificity was second highest.

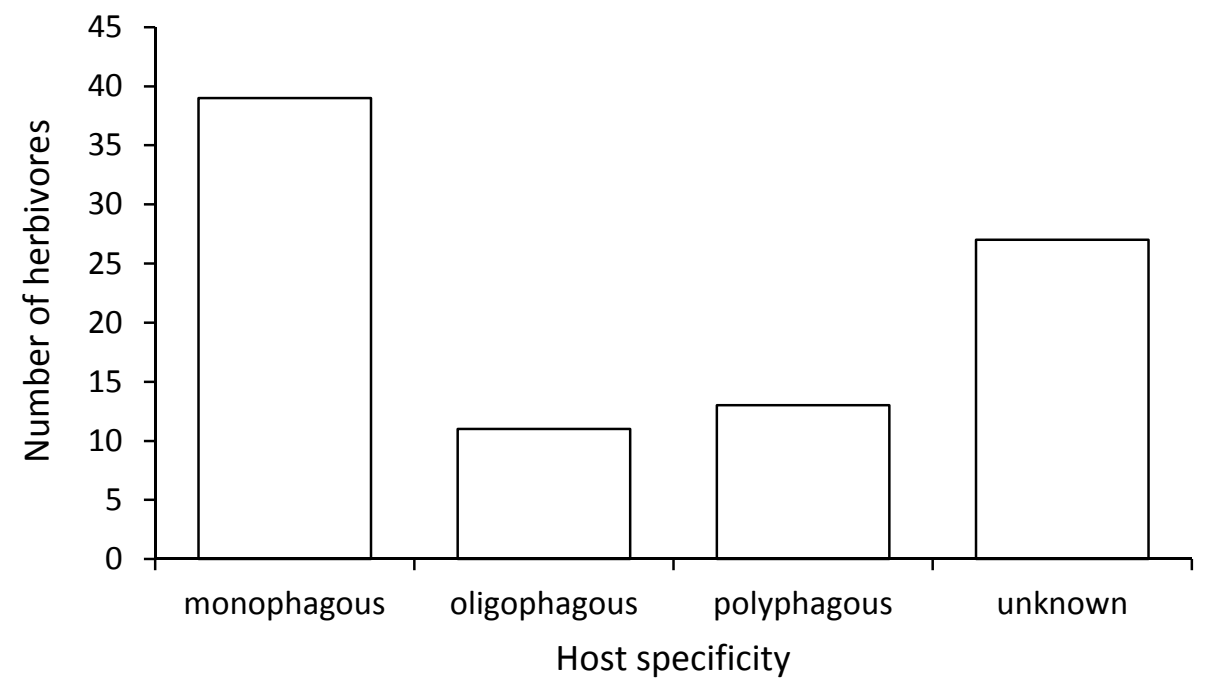

Figure 4.4: Frequency of host specificity for which insects were reported: Each record refers to one specific host plant-insect herbivore association. 
The top five insect herbivores are shown in Fig. 4.5. Naturalized Chromatomyia syngenesiae (Diptera: Agromyzidae) was the species with the most Senecio spp.-feeding associations, closely followed by the endemic Nyctemera annulata (Lepidoptera: Arctiidae).

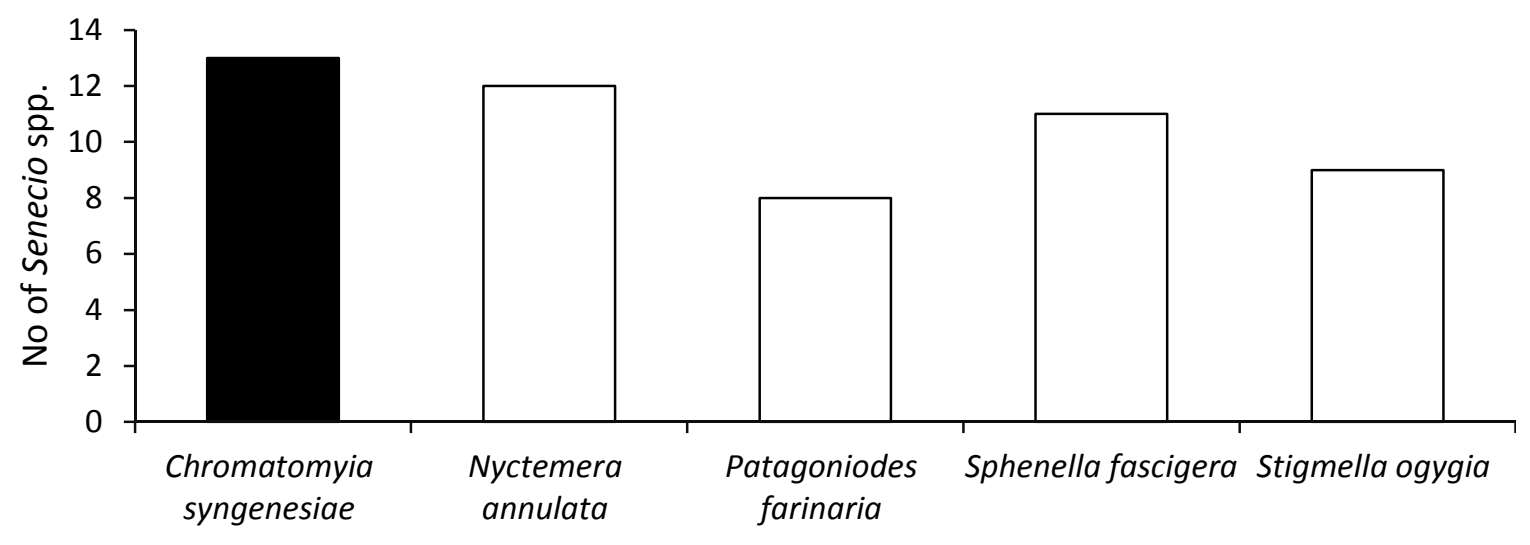

Insect herbivore

Figure 4.5: Number of host plants for the top five insect herbivores with more than two host plant Senecio spp. in New Zealand. Herbivore status is given via colour coding: White= endemic and black= exotic.

Lepidoptera were the most frequently reported (44 associations) order of insect herbivores on all Senecio spp., followed by Diptera (28 associations), Hemiptera (20 associations), Coleoptera, Hymenoptera and Nematocera, which had between one and two associations each (Fig. 4.6). 


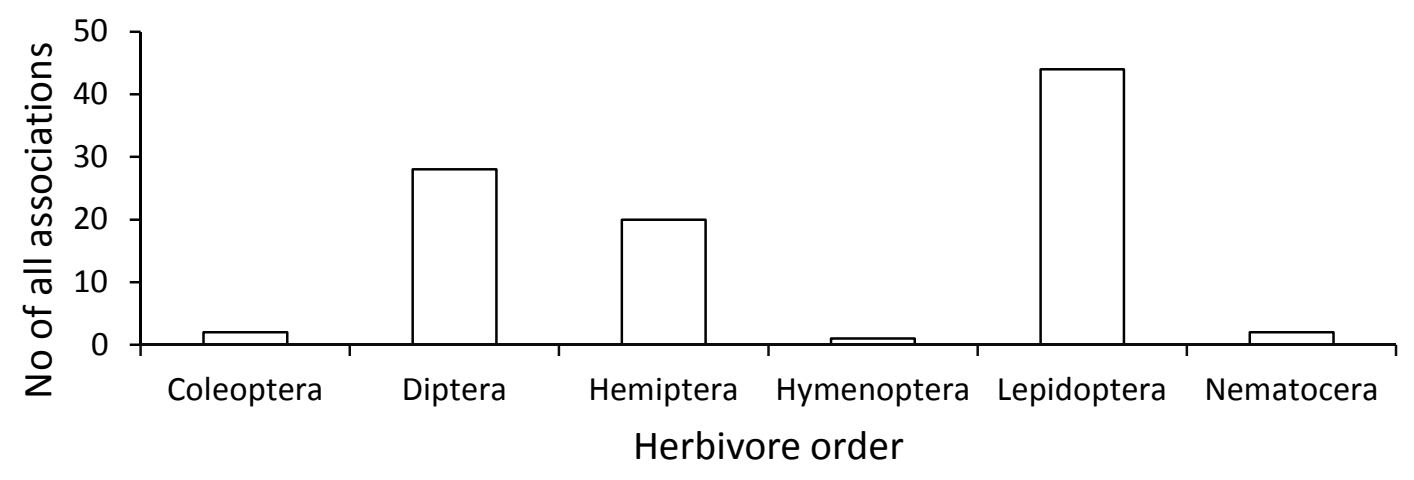

Figure 4.6: Number of associations per insect herbivore order reported: Coleoptera, Diptera, Hemiptera, Hymenoptera, Lepidoptera and Nematocera.

Fisher's exact test showed no significant differences between associations regarding their host specificity and geographic origin $(p=0.861)$ (Table 4.1). However, the number of associations between native Senecio spp. and Senecio spp.-specific insect herbivores was highest together with introduced Senecio spp. and Senecio spp. specific herbivores. Less than half the values as reported for the latter were found for all other combinations (Table 4.1).

Table 4.2: Cross tabulation of associations for plant status and feeding type of insect herbivore. Rows represent Senecio spp. biogeographic status and columns the specificity of the insect herbivore feeding relationships. Fisher's exact test: $p=0.861$.

\begin{tabular}{|c|c|c|c|c|c|}
\hline & monophagous & oligophagous & & polyphagous & total \\
\hline endemic & 10 & & 3 & 4 & 22 \\
\hline native & 19 & & 5 & 3 & 33 \\
\hline naturalized & 19 & & 5 & 4 & 33 \\
\hline
\end{tabular}

Fisher's exact test $(p$-value $=0.861)$ provided no evidence that non-native insects are more or less likely to associate with non-native plants. Naturalized plants and endemic herbivores showed the highest number of plant-insect feeding associations, followed by native plants and endemic insect herbivores. There were no records for native plants and native herbivores as well as for endemic plants and native herbivores. More than half of all feeding associations involved either naturalized plants or insects (Table 4.2). 
Table 4.3: Frequency of records between plants and insect herbivores in relation to their biogeographic status. Fisher's exact test:p-value $=0.391$.

\begin{tabular}{l|ll} 
& endemic herbivore & naturalized herbivore \\
\hline endemic plants (5 species) & 12 & 7 \\
native plants (6 species) & 18 & 13 \\
naturalized plants (9) & 21 & 7
\end{tabular}

The different feeding guilds were most frequently represented by foliage feeders and leaf miners followed by sucking insects, flower and stem feeders, shoot and root feeders, and insects feeding on roots and leaves (Fig. 4.7).

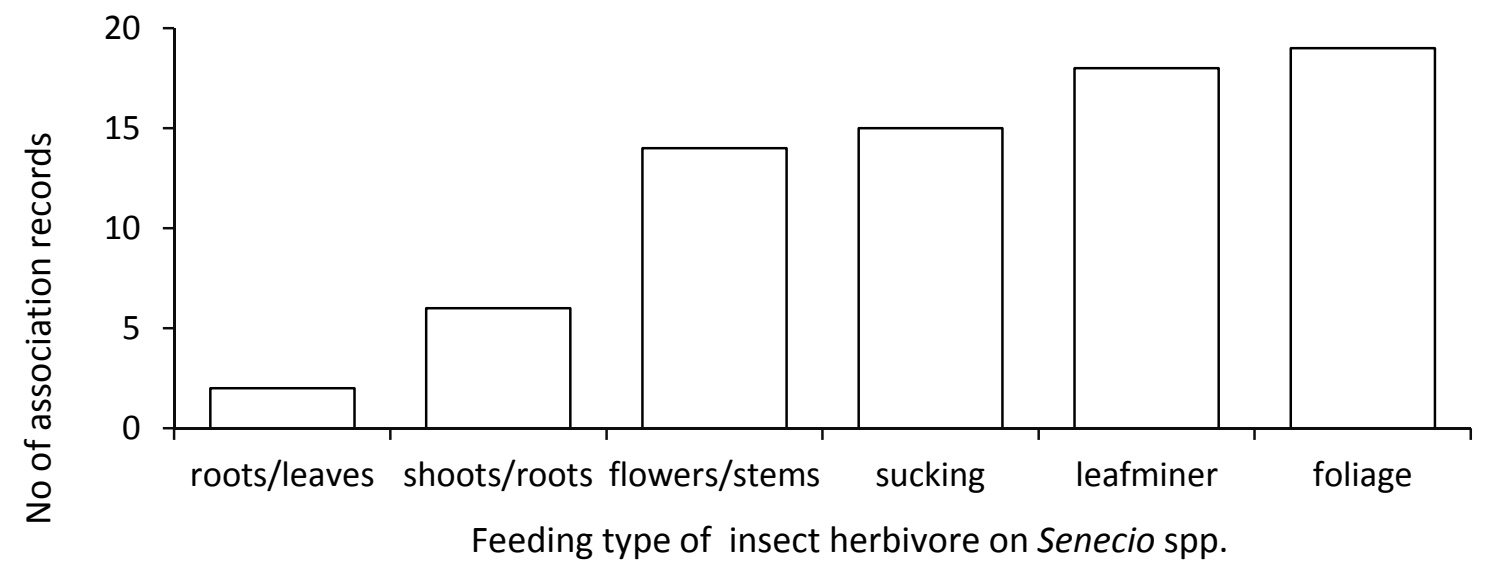

Figure 4.7: Frequency of trophic guilds for insect herbivores on Senecio spp.-hosts. Each record represents a unique feeding association. 


\subsection{Discussion}

This chapter collates current knowledge about New Zealand's Senecio spp.-food webs and reviews general trends in host specificity, feeding guilds, host overlap and the degree of food web integration between native and introduced species. The results showed more herbivore-plant associations for naturalized plants. However, the proportion of native plant records was high and herbivores were mostly monophagous (Senecio spp.-specific). Most associations were found for Lepidoptera and leaf miners (either Lepidoptera or Diptera).

Despite the economic importance of introduced Senecio spp. and closely related senicioids as weeds in New Zealand (e.g.J. vulgaris Wardle et al. 1995), there is surprisingly little knowledge about food webs of Senecio spp. plants and their food web interactions in New Zealand. More than half of the recorded plant-insect associations I found were for insect herbivores on exotic plants. Given the geographic distribution and the close proximity of introduced and native Senecio spp. within the New Zealand context this was to be expected: In particular, native and introduced Senecio spp. grow very close together in coastal habitats, possibly directly competing for resources (personal observation) or indirectly competing via shared enemies. According to the Enemy-release hypothesis (Maron and Vila 2001, Keane and Crawley 2002, Vilà et al. 2005) introduced plants escape their natural enemies in their introduced new home ranges. When comparing the seed predating insect herbivores of native and introduced Asteraceae in New Zealand and their British home range, only one record of the endemic Senecio spp.-specific tephretid fly Sphenella fascigera was found colonizing the introduced species in New Zealand (Fenner and Lee 2001), while up to $48 \%$ of Asteraceae were infested by seed head predators in the UK.

Typically, introduced plants are thought to be more readily colonized by generalist phytophagous insects compared to specialists (reviewed by Liu \& Stiling 2006). The results of this chapter do not support the assumption that introduced plants have fewer records of insect herbivores compared to natives. However, the proportion of native species records was high and despite the assumption that more polyphagous insects should be found on naturalized plants my results show that both native and naturalized 
Senecio spp. are dominated by records of Senecio spp.-specific insect herbivores. Senecio spp. are a chemically well defended plant genus with pyrrolizidine alkaloids as defence that possibly deter generalist herbivores, as these tend to focus on plants with lower chemical defence capability (Meijden 1996). However, Macel et al. (2005) showed that pyrrolizidine alkaloid mixtures can affect generalist herbivores while single compounds may not. It is possible that agriculturalists as well as scientists are biased and record more frequently insects feeding on economically important introduced weeds such as $J$. vulgaris compared to less conspicuous introduced and native Senecio spp. and thus these results could be skewed towards such species. Naturally uncommon or relict species such as Senecio sterquilinus had few or no known insect-herbivore plantassociations prior to my own field work (chapter 5). There is also the natural sampling effort of more common and widespread species being more likely to pick up enemies than rare and restricted species.

Tosh et al. (2011) argue that the phylogeny of host plants plays a crucial role in the development of novel host associations with introduced hosts: congeneric, closely related plants, as researched in this chapter, appear to have more similar insects compared to hosts of the same family (Novotny and Basset 2005). This dataset supports this research finding, as I found a great overlap in alien-plant-endemic herbivore and native/endemic plant-endemic herbivore associations. It has been hypothesized that insect herbivore richness on alien plants often reaches similar numbers to those on native/endemic plants (Yela and Lawton 1997).

However, species identity is only one criterion to describe insect -plant associations. Feeding guilds may differ between introduced and native congeneric plants as documented for the introduced Solidago altissima and the native S. virgaurea in Japan (Ando et al. 2010). They found a much higher proportion of introduced sap-feeding insect herbivores on the introduced plant compared to the native, suggesting that insect herbivores with less adaptations and shorter times to co-evolve with introduced plants are more likely to be external feeders. Depending on the feeding guild, leaf structure might be more important than plant nutrient levels in influencing which associations form (Peeters 2002). A few papers look at the distribution of feeding guilds on plants: It 
appears that feeding guilds are evenly distributed across continents but do differ between plant species (examples in Lewinsohn et al., 2005). In addition to a plant's geographic range, as well as its plant architecture, plant size was identified as important in determining the number of insect herbivores a plant can host (e.g. review in Lawton (1983)).

Nevertheless, Senecio spp. are well known for their pyrrolizidine alkaloids, which in their concentration and composition are species specific and thus could potentially determine insect distributions. This was shown for several generalist feeders by Macel et al. (2005). They demonstrated various responses: plant sucking species were susceptible to higher pyrrolizidine concentrations in the vital plant parts such as the young leaves or flower heads while caterpillars of very polyphagous species remained unaffected. According to Wilcox (2012) it is possible that even the geographic origin of plants of the same species could influence its alkaloid composition and concentration which in return might be influencing insect herbivore abundances. Apart from his thesis however, there is currently no further information available on New Zealand's Senecio spp. and their pyrrolizidine alkaloid concentrations and the influences on insect herbivores. Nevertheless, a phytochemical review by Hol (2011) emphasized the importance of pyrrolizidine alkaloid concentrations for senecio-insect herbivores. Apparently, alkaloid concentration is correlated with nutrient status of the host plant and thus varies within the season, allowing different herbivores to colonize at different times within the season as shown for nitrogen levels in J. vulgaris (Hol 2011). It was not clear from the references if plants were observed throughout all seasons- It seems more likely that records were single observations rather than detailed systematic studies across all seasons. Food quality for generalist insect herbivores can be impacted by the consumption of plant volatiles, but they might act as a defence against parasitoids and hence the trade-off between food quality and protection can be worthwhile as documented for Estigmene acrea caterpillar development with Senecio longilobus and Viguiera dentata as host plants (Singer et al. 2004).

The majority of insects on New Zealand's Senecio spp. were those with clear visual impacts to the host plants- such as leaf miners and foliage feeders and hence 
conspicuous to recording. Foliage feeding insects such as coleopterans (not very much represented in the Senecio spp. records displayed here) and lepidopterans are thought to comprise about two thirds of all known insect herbivores (Howe and Jander 2008). However, it is very possible that a range of Senecio spp.-insect interactions records in New Zealand are not formally recorded yet or remain undiscovered, especially given the numbers of insects that have been recorded elsewhere on closely related plants e.g. 75 herbivores are documented on J. vulgaris (Harrison and Thomas 1991). It was beyond the scope of this study to investigate latitudinal effects on insect herbivore assemblages, which can influence plant-insect associations as shown by Fagundes \& Fernandes (2011), which due to New Zealand's a range of different latitudes could potentially impact distributions via different climate conditions.

Except for the coastal Senecio spp. of my own field work ((see chapter 5); and Waring (2010) I was unable to find quantitative data on Senecio spp. food webs in the New Zealand context and thus unable to quantify linkage strengths. Higher trophic levels such as parasitoid wasps are also not very well recorded, as is often the case with parasitoids due to high sample sizes and other logistic challenges (Paynter et al. 2010). -Although there is some information about some of the species links, there was not enough information on parasitoid links to the plants of their insect herbivore hosts. How exotic plants impact native Senecio spp. food web associations is currently unclear, although some examples show that exotic Senecio spp. can increase insect herbivore overall abundances and indirectly impact native Senecio spp. via apparent competition (Waring 2010).

However, I suspect one of the most important difficulties with determining insect associations for Senecio spp. are taxonomic difficulties with the host plants, which make Senecio spp. a challenging study subject. Throughout my own food web research regarding coastal Senecio spp. I frequently encountered Coast Care Groups and residents who accidently mistook exotic S. skirrhodon for native S. lautus and only weeded for $S$. elegans, giving S. skirrhodon a competitive advantage over the more easily identified purple flowering S. elegans. The number of associations that were recorded for Senecio spp. without Senecio species identification further supports my opinion that taxonomy 
plays a vital role in the paucity of specific associations reported. Even for invaders, that have recently received some attention through to their expanding range and striking appearance such as S. glastifolius, information on food web linkages remain scarce and an accurate assessment of the impacts of such expanding exotics remains difficult to assess due to the lack of information. The feeding guilds of mostly generalist insect herbivores (and some very specialised species) make Senecio spp. very interesting focal species to assess the impacts of closely related invaders. Comparing the habitat-types of New Zealand Senecio spp. it is apparent that most species occur on wastelands or other disturbed sites such as riverbanks, coastal sites or forest margins/clearings. Therefore there is a high overlap of some introduced species and native species in these habitats, creating great opportunities to study the introduced-native-plant-insect interactions which will further enhance our understanding of how introduced species integrate themselves into established food webs.

\subsection{Conclusions}

My Senecio spp. food web review showed no significant effect of plant and insect herbivore bio status and the number of recorded associations. Most records were for Lepidoptera and leaf miners (regardless whether lepidopteron or dipteran), which were Senecio spp.-host specific. Furthermore, I found a similar number of insect herbivore records for naturalized and native Senecio spp., probably indicating a bias of recording. Consequently, more information on New Zealand's insect herbivores on food webs is required to construct quantitative food webs, as data were mostly based on nonquantitative records. 


\section{CHAPTER 5}

The importance of plant morphology and different spatial scales of plant density for plant-insect herbivore host choice and interaction strengths

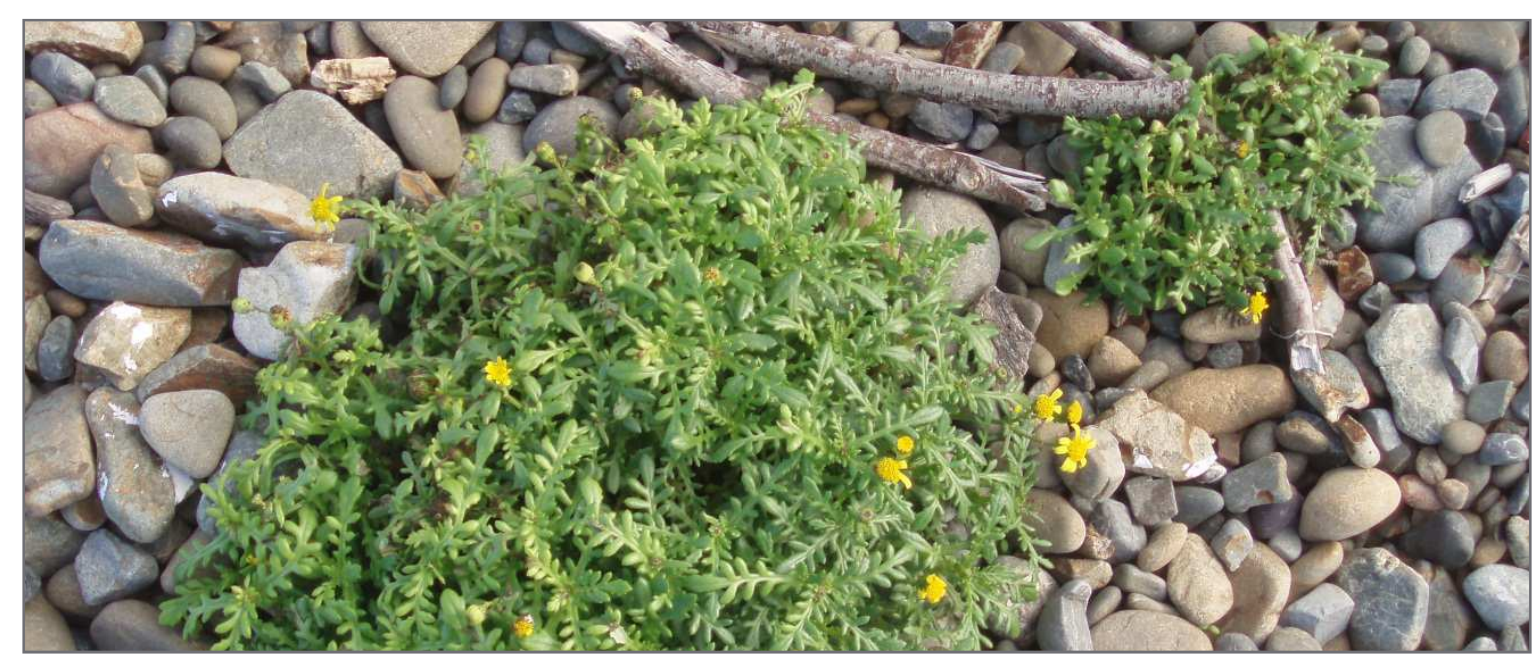

Two specimens of native Senecio lautus at shingle beach in Eastbourne/Wellington. 


\subsection{Introduction}

An important step towards understanding the dynamics of food webs is the understanding of interaction links between species; especially interactions between two trophic levels. However, the mechanisms that predict and determine host specificity are still not fully understood and some research questions remain. The interactions between native and introduced plants, and their associated insect herbivores are a particularly important area of research, because closely related plants are often similar in terms of their chemical profile (e.g. plant volatiles such as alkaloids) and morphology. Several types of host specificity are acknowledged in ecological research: i). monophagous species; herbivore feeds only on one species (Symons and Beccaloni 1999) ii). oligophagous species, i.e. herbivore feeds on species within one genus or plant family and iii). polyphagous species; where insect herbivores are known to feed on several genera across several plant families (Schoonhoven et al. 2007).

Ecological theory suggests one or more of the following influence host selection: i). morphological traits such as leaf size, flower head colour, shape and plant size (Prokopy and Owens 1983) ii). interspecific competition spill-over effects and apparent competition (Holt 1977, White et al. 2006, White 2008) and iii). phylogeny; which explains how closely two species are related and therefore share similar e.g. chemical traits as shown by Symons and Beccaloni (1999) and Briese and Walker (2002).

Host-parasite interactions cannot be seen completely separately from the community they are embedded in due to various types of interactions. Identifying interactions between members of a habitat community is crucial for the wider understanding of ecological processes.

Research on food webs is particularly important to predict the consequences for a community when a new species arrives in an established food web (Brockerhoff et al. 2010). When researching food webs, it is important to identify host specificity within the study system (Novotny and Basset 2005), in order to identify comprehensive linkages between species within a community. Furthermore it provides useful information for conservation; especially when species from a food web are removed via extinction or 
added through invasions which can lead to unpredictable consequences (McCann 2000). Different adaptations of food webs to introduced species have been demonstrated in previous studies and range from filling a previously unoccupied niche with an alien invader to extinctions (Drossel et al. 2000).

Insect herbivores are not evenly distributed across their host species specimens (Egan and Ott 2007). Therefore several different ecological hypotheses have been posed to explain spatial differences of insect herbivore loads: the enemy release hypothesis (ERH) assumes that native species are largely confined in their abundance by their native enemies (e.g. Keane and Crawley (2002)). However, introduced species do not generally have the same enemies which evolved with their host species and therefore have a competitive advantage (e.g. Clay, 2003; Wolfe, 2002). The resource concentration hypothesis (RCH), which was first posed by Root (1973), predicts larger quantities of insect herbivores in areas with high host plant density. Despite the general recognition of this principle, some studies showed contrasting effects with less insect herbivores in denser areas (Thompson 1978, Price 1997), and in areas with low host plant density insects were more abundant on isolated plants (Karban and Courtney 1987). The resource dilution hypothesis (Otway et al. 2005) predicts that isolated plants experience a higher insect herbivore load than plants within dense patches. The natural enemy hypothesis (NEH), first raised by Pimentel (1961), predicts that generalist natural enemies are more efficient in controlling pest populations in complex systems than in species poor systems (Russell 1989, Stiling et al. 2003). In addition to direct competition, indirect competition is an important interaction between two species on the same trophic level that is mediated by interactions with a shared host or enemy on a different trophic level (Levine 1976, Holt 1977, Bonsall and Hassell 1997). If the apparent interaction is positive and thus facilitative, it is referred to as apparent facilitation (Helms and Vinson 2003, Hansen et al. 2007, Pellissier et al. 2010) 


\section{Resource density within the landscape}

Resources are not evenly distributed within the landscape and therefore ecological interactions take place at different spatial scales (Wiens 1989). Resource dependencies also differ depending on the species and the topography of the landscape. In arid areas, water is the limiting resource that determines ecological processes at different spatial scales (Sponseller et al. 2013). For predators, the availability of their prey determines resource availability at different spatial scales (Červinka et al. 2013). Plant-insect interactions can operate at multiple scales: the smallest scale might be a leaf of a plant, at the next scale up insects may search for the plant itself as well as various other scales that need to be identified for each study. Typically, three different factors have to be taken into consideration when setting up a study: the overall area of the study, the size of the sampling units and the distance between the different sampling units (described as extent, grain and lag respectively in Turner et al. (1989) and O'Neill et al. (1996)). Depending on the hypothesis being tested, the scale necessary for the survey or experiment varies: for mapping moss a $10 \times 10 \mathrm{~cm}$ quadrat might have the appropriate scale (grain), for grasses most ecologists recommend at least a $1 \times 1$ metre quadrat, and in forests a standard size is at least $10 \times 10$ metres (20 $20 \mathrm{~m}$ in high forest) (Allen et al. 1951, Peet et al. 1998). Quadrat sizes, and their dispersion in space, will affect perceptions of alpha, beta and gamma diversity (Kwiatkowska and Symonides 1986).

Murray et al. (2002) examined the relationship between plant traits and commonness of rare plants at local, regional and geographical ranges as a first step towards a methodology of rarity studies. Often it is necessary to build up hierarchical nested data sets to create the best model to answer the questions around host choice.

I chose to investigate plant density as my main scale dependant factor for insect herbivore host choice. Several studies in the past have used plant density or biomass as measures for determining which of the two hypotheses is supported: the resource concentration or the resource dilution hypothesis (e.g. Bañuelos and Kollmann (2011), Stephens and Myers (2012)). These two hypotheses are also in the focus of my study as I compared different plant densities in terms of their insect herbivore infestations. In contrast to many of the previous studies, in my study system plants are not simply seen 
as either hosts or non-hosts as often is the case. I considered the plant densities as factors in my linear mixed effect models. Furthermore, I used a set of very closely related native and introduced Senecio spp. to research the effects of the potential introduced host. More specifically, I also wanted to know, if spill over effects (where insects accidently lay eggs on a non-host plant in close proximity to a host plant) occur (Holt 1977, White et al. 2006, White 2008). My study incorporates several different spatial scales to help identify the factors influencing host specificity and host choice. I chose coastal Senecio spp. and their insect herbivores as a study system as they include closely related introduced and native species within a relatively species poor community. I expected to clarify the effects of an introduced congener on the interactions between native plant-insect interactions as the species paucity gave the opportunity to manipulate the food web.

Coastal areas of New Zealand have undergone dramatic changes since the beginning of European settlements. Historically, New Zealand's active dunes were more sparsely vegetated than their European counterparts (Gadgil 2006a), as only a few species evolved here. European species adapted to grazing and anthropogenic influences now have a competitive advantage over those species which were native to New Zealand dunes (Norton et. al. 1997). Naturally dynamic active dune areas have been stabilized with introduced marram grass (Ammophila arenaria). The planting of marram grass changed species combinations and facilitated the growth of other introduced species such as Glaucium flavum, Senecio elegans, Senecio skirrhodon, introduced legumes and many others (Gadgil 2006a). A mixture of native S. lautus, relict S. sterquilinus (and hybrids of S. lautus $x$ S. sterquilinus) and closely related introduced Senecio spp. are part of today's coastal communities. Currently there is little information about New Zealand's coastal plant- insect communities. Despite a database for plant-insect herbivore linkages (Martin 2013) the interactions between coastal plants including Senecio spp. and insects, and interaction strengths remain largely unknown (see Chapter 4). With a survey of natural populations and a field experiment I aimed to identify important scales of plant densities and insect herbivore host plant choice. 


\section{Aims and research questions}

I. Quantify species linkage strengths between insect herbivores and host plants

II. Does plant density affect insect herbivore host plant choice and cause spill over effects from native to introduced plants? Are there differences when congeneric, heterogeneric plant densities are considered?

III. Is fine scale plant density more important for host plant choice than coarse scale density?

IV. Which plant properties (plant morphology) influence insect herbivore host choice? 


\subsection{Materials and Methods}

\subsubsection{Study species}

\section{Focal plants}

As focal study species I chose plants from the genus Senecio spp., which is the most species rich genera within Asteraceae (Jeffrey et al. 1977), which is an important plant family (Stebbins, 1981). Senecio spp. are widespread and many species are known to be weedy (Radford and Cousens 2000, Garcia-Serrano et al. 2005). Within the New Zealand context, ragwort (Jacobea vulgaris, formerly known as Senecio jacobaea) is known to have a profound ecological and economic influence on native and pastoral ecosystems and was consequently declared a pest plant (New Zealand Government, 2008). Senecio spp. contain pyrrolizidine alkaloids and terpenes as defence chemicals to deter insects, which are known to be toxic to stock if digested in high numbers. Differences in toxicity depend on species identity (e.g. J. vulgaris McLean (1970), Johnson et al. (1989)). However, some specialist insects are able to sequester alkaloids and use them for their own defence; these insects may use alkaloids as a positive cue for host-finding and acceptability (Macel 2011).

Within the Wellington region the following plant species have been previously recorded (including inland species): S. angulatus, S. biserratus, S. elegans, S. hispidulus, S. glastifolius, S. glomeratus, S. lautus, S. quadridentatus, S. skirrhodon, S. sterquilinus and S. vulgaris (Sullivan, pers. comm. 2010). I focused on S. lautus, S. skirrhodon, S. elegans and S. sterquilinus as they most frequently were found to grow in close proximity at exposed coastal shingle beaches. I only considered Senecio lautus (native), S. sterquilinus (relict endemic, associated with environmental conditions in the past, in this case bird guano), S. elegans (introduced) and S. skirrhodon (introduced) for my surveys and experiment, and occasional observations on S. glastifolius (introduced) and S. vulgaris (introduced) (Fig. 5.1). A detailed description of the study species can be found in Appendix V, and Figures A V.1-6. 

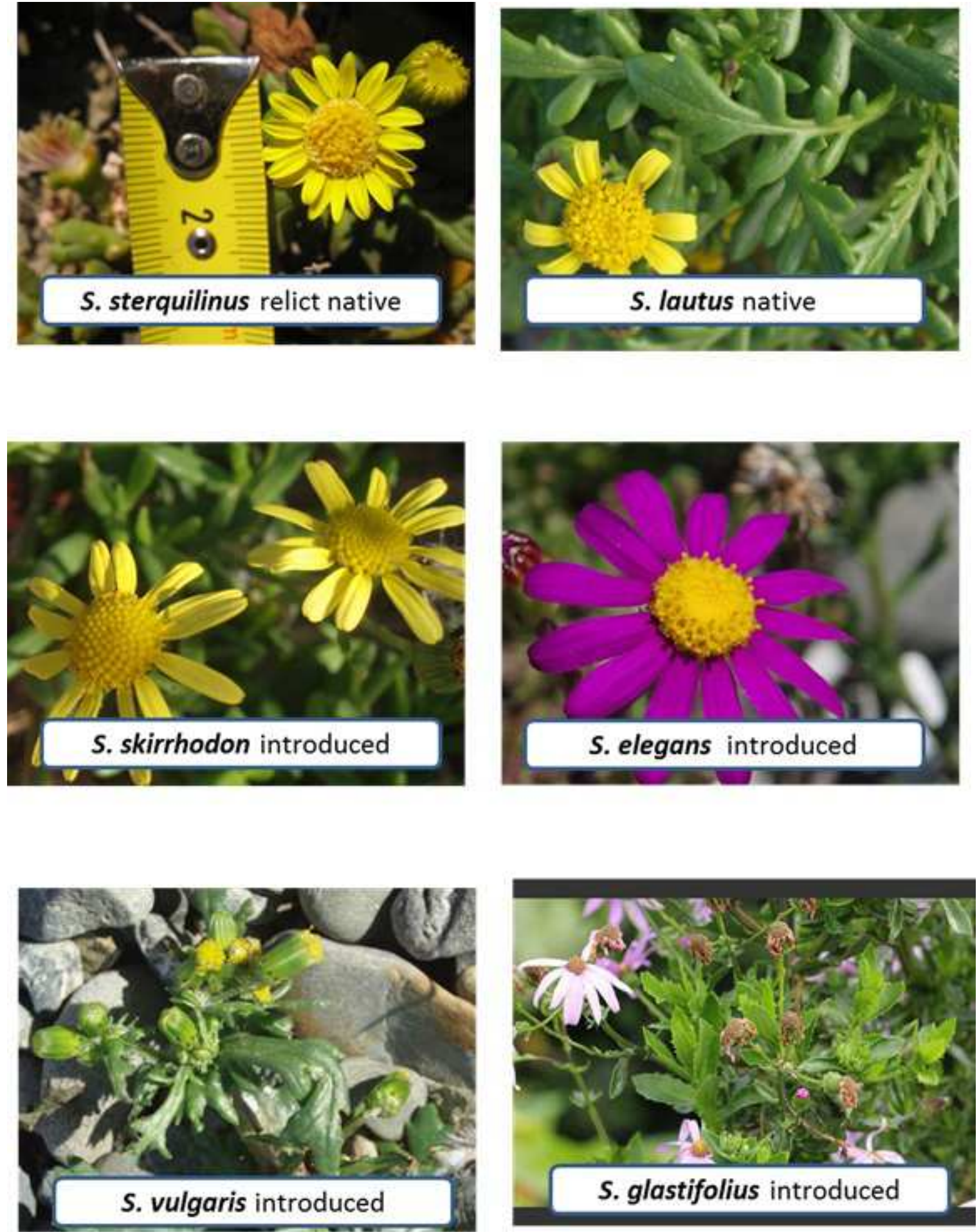

Figure 5.1: Focal Senecio spp. of this chapter: Senecio sterquilinus, S. lautus, S. skirrhodon, S. elegans, S. vulgaris and S. glastifolius. 


\section{Focal insect herbivores}

I chose leaf miners, stem borer, gallers, leaf roller, seed head predators and lepidopteran larvae as focal insect herbivores. My selection was based on the dependence of the insect herbivore on the Senecio spp. plant for reproduction, and the effort and accuracy required for sampling. Additionally, leaf miners and seed head predators in particular are known to be highly host specific (Schoonhoven et al. 2007, Bañuelos and Kollmann 2011, Ali and Agrawal 2012). Therefore they should be good study organisms for the community influences of a closely related alien plant within the community. The major species were: the seed head predator tephritid fly Sphenella fascigera (endemic), the blue stem borer moth Patagonoides farinaria, the endemic diurnal magpie moth Nyctemera annulata, and the introduced leaf miner fly Chromatomyia syngenesiae. For a detailed description of the insect herbivores and their previous records see Appendix V. Insects other than the focal insect herbivores were recorded if they were reproducing on the plants (e.g. Geometridae and other lepidopteran larvae as well as dipteran larvae).

\subsubsection{Study site}

\section{Survey of naturally occurring populations}

I surveyed five field sites within the Wellington region. The locations were Eastbourne, Petone, Makara Beach, Matiu/Somes Island and the Wellington South coast (Fig. 5.2). Long stretches of Eastbourne's shingle beach have abundant S. elegans and S. skirrhodon populations, which seems to be a species combination which is widely distributed around New Zealand's coast (personal observation). An approx. $150 \mathrm{~m}$ long stretch of shingle beach at the southern end of Eastbourne (latitude, longitude: -41.30751, 174.8844), however is mainly inhabited by S. lautus (with only a few scattered individuals of S. elegans and S. skirrhodon). Only S. lautus is present at Makara beach. Senecio sterquilinus, S. lautus and possibly their hybrids are sharing the beaches on Matiu/Somes Island. Along the small bays of the South coast only S. lautus are nested 
within stretches of S. elegans and mixtures of S. elegans and S. skirrhodon. Wellington is very windy with an average of 173 days per year with winds greater than $60 \mathrm{~km} / \mathrm{h}$ (Turner and Chapell 2013). Average daily temperatures range $16.5^{\circ} \mathrm{C}$ (summer) to $9.3^{\circ} \mathrm{C}$ (winter) and annual precipitation is around 1185 mm (NIWA 2013).

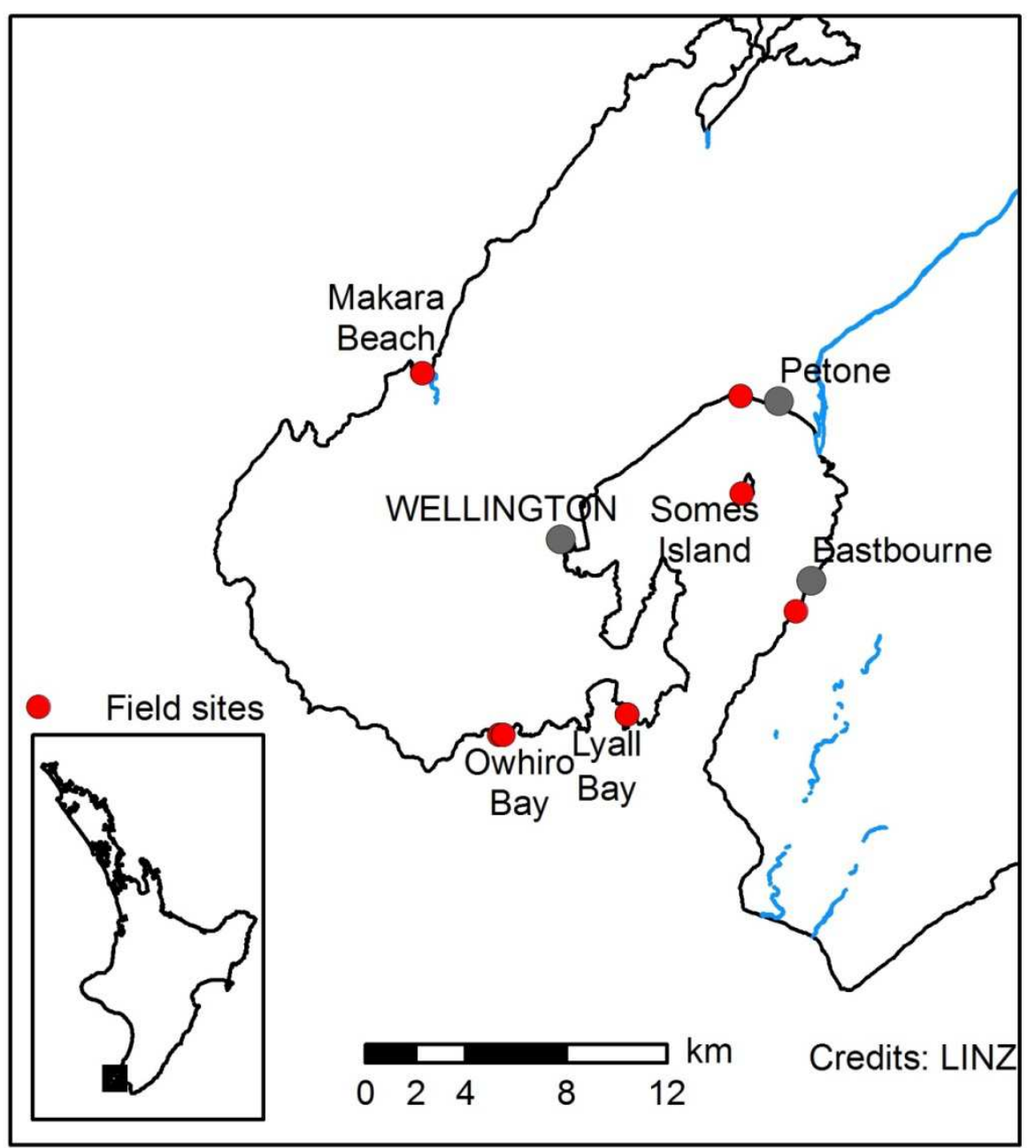

Figure 5.2: Map shows field sites for the survey of natural populations around Wellington. Red points = field site. 


\section{Experiment field site}

I chose the shingle beach at Eastbourne for this experiment (Fig. 5.3 and Fig. 5.4), as the field site consists of a long continuous stretch of similar vegetation with naturally occurring Senecio spp. (see Fig. 5.3 for field site location and Fig. 5.4 for transect locations). Plant species present at the field site include: Coprosma repens, Senecio skirrhodon, S. elegans, S. lautus, S. vulgaris, Anagallis arvensis, Glaucium flavum, Gazania rigens, Chrysanthemoides monilifera subsp. monilifera, Sonchus oleraceus, Lobularia maritima, Crepis capillaris, Hypochaeris sp., Taraxacum officinale, Atriplex prostrata and Galium spp. The vegetation typically occurs in bands parallel to the tideline and topographic undulations further inland, presumably reflecting differences in microclimate and substrate conditions. Often coastal Senecio spp. root in debris from the tideline (pers. observation).

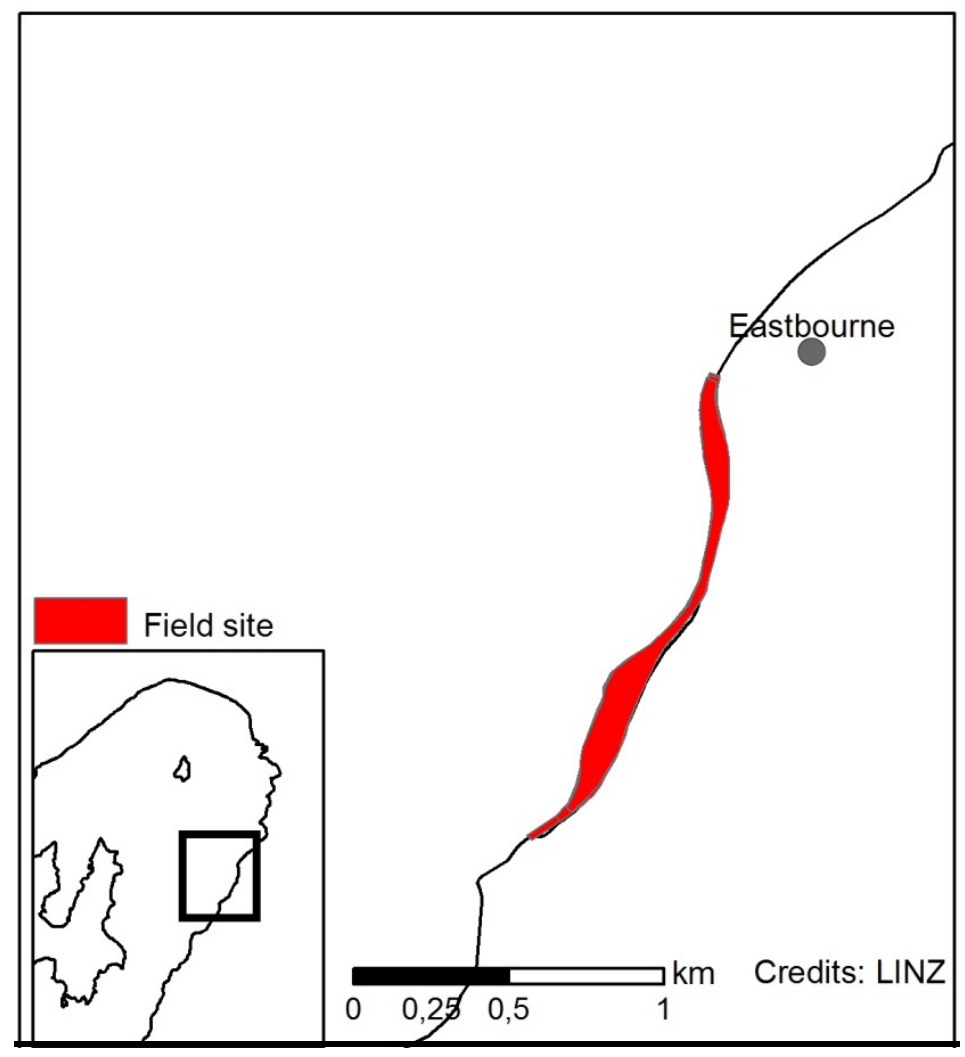

Figure 5.3: Field site location for Senecio spp. experiment. Red= field site area. 


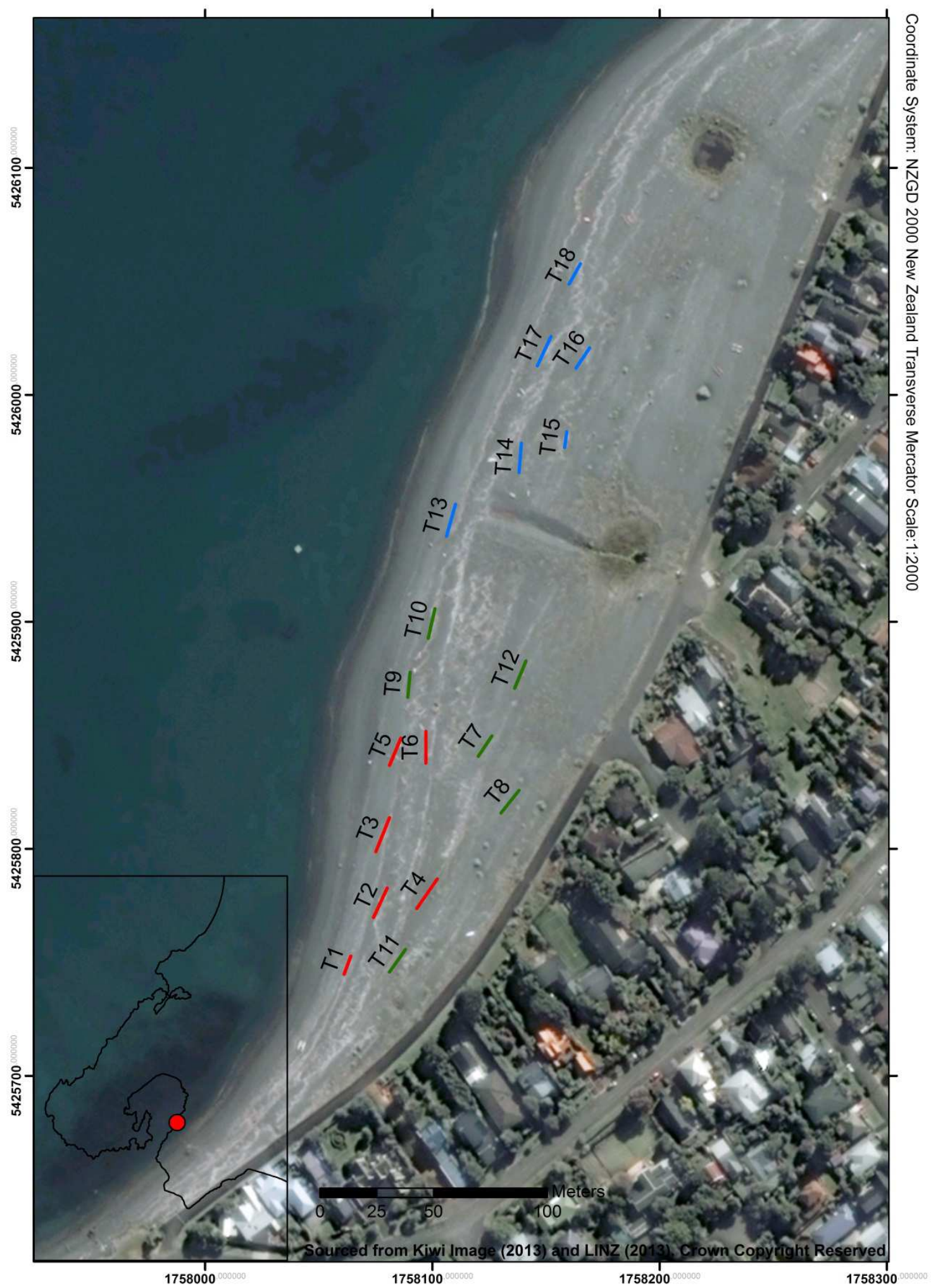

Figure 5.4: Map shows transect locations of the field experiment. $\mathrm{T}=$ transect. Red lines = transects with S. lautus versus S. elegans, green lines = transects with S. elegans versus S. skirrhodon and blue lines = transects with S. lautus versus S. skirrhodon. 


\subsubsection{Data collection}

\section{Survey of naturally occurring populations}

I conducted surveys over three field seasons from April 2010 until April 2012. In the first survey, quadrats ( $2 \times 2 \mathrm{~m}$ square nested within a $6 \times 6 \mathrm{~m}$ square) were located at random points across each field site. For subsequent surveys the quadrats were located along transects in an adaptive fashion to increase their intersection with the 'bands' of coastal Senecio spp. that typically grow parallel to the sea (pers. observation). Consequently, the procedure was repeated at the first occurrence of Senecio spp. Plants. Since my aim was, not only to quantify linkage strengths between insect herbivores (the frequency of which the association was observed), but also to identify whether or not plant density affects insect host plant choice, I nested quadrats. This meant that the $2 \times 2 \mathrm{~m}$ square was nested in the $6 \times 6$ square as in the first survey, but a minimum spacing of $2 \mathrm{~m}$ between the outer quadrat and the next outer quadrat was set.

Quadrats were located along a transect at $8 \mathrm{~m}$ intervals $(2 \mathrm{~m}$ gap between $6 \mathrm{~m}$ quadrats). In the case of several consecutive empty quadrats, the next quadrat was placed over the next available Senecio spp. plant as the start of a new transect and the procedure was repeated. Each random point of the first survey (or the transects of the other surveys) formed the centre of a $2 \mathrm{~m}$ quadrat which was nested within a $6 \mathrm{~m}$ edge length quadrat (referred to as small (inner) and big (outer) quadrats respectively (Fig. 5.5). I recorded GPS coordinates for the $6 \mathrm{~m}$ quadrat.

Within the $2 \mathrm{~m}$ quadrat I recorded the following general parameters: number of plants of each Senecio species and species present within the quadrat (Senecio spp. and all other plants). I recorded information from every individual Senecio spp. plant within the quadrat for the first survey. In subsequent surveys I only recorded measurements of up to 9 plants. To select these nine plants I divided the quadrat into $1650 \times 50 \mathrm{~cm}$ subquadrats and in quadrats with more than 9 Senecio plants, the Senecio focal plants were chosen closest to the internal intersections (see points labelled 1-9 in Fig. 5.6). If the nine plants (or less) were not evenly distributed they were all recorded regardless. I recorded the selected subquadrat ID (Fig. 5.6 for explanation) for each plant and 
counted all plants within a $50 \mathrm{~cm}$ radius circle $\left(\right.$ area $=0.8 \mathrm{~m}^{2}$ ) of the investigated plant to research the effect of fine scale plant density on insect herbivore host plant choice. I noted for all Senecio spp. in which subquadrat they were located. For each focal plant I recorded: height, diameter, state of flowering (how many flower buds, how many flowers in bloom, how many flowers that have finished flowering), health score (how many discoloured leaves out of ten counted from the bottom up to the top of the plant), and feeding damage (by slugs etc. using the same counting approach as with health score leaves). In addition, I also recorded presence-absence of fungal-infestations. In the first survey all flower heads were searched, but in subsequent surveys only up to ten flower heads were opened and searched for seed head predators. I searched the whole plant for no longer than $10 \mathrm{~min}$ in total, and recorded all aphids, leaf miners, lepidopteran larvae, gallers and stem borers and all other insects I observed. I only recorded the number of conspecifics and hetero-specifics of the investigated Senecio spp. within the big quadrat (shaped like a square annulus, excluding $2 \mathrm{~m}$ quadrat plant counts with an area of $32 \mathrm{~m}^{2}$ ). Senecio sterquilinus is an endemic relict species (associated with bird colonies and their guano) and due to conservation legislation its stems could not be sampled destructively as conducted for the other species. 


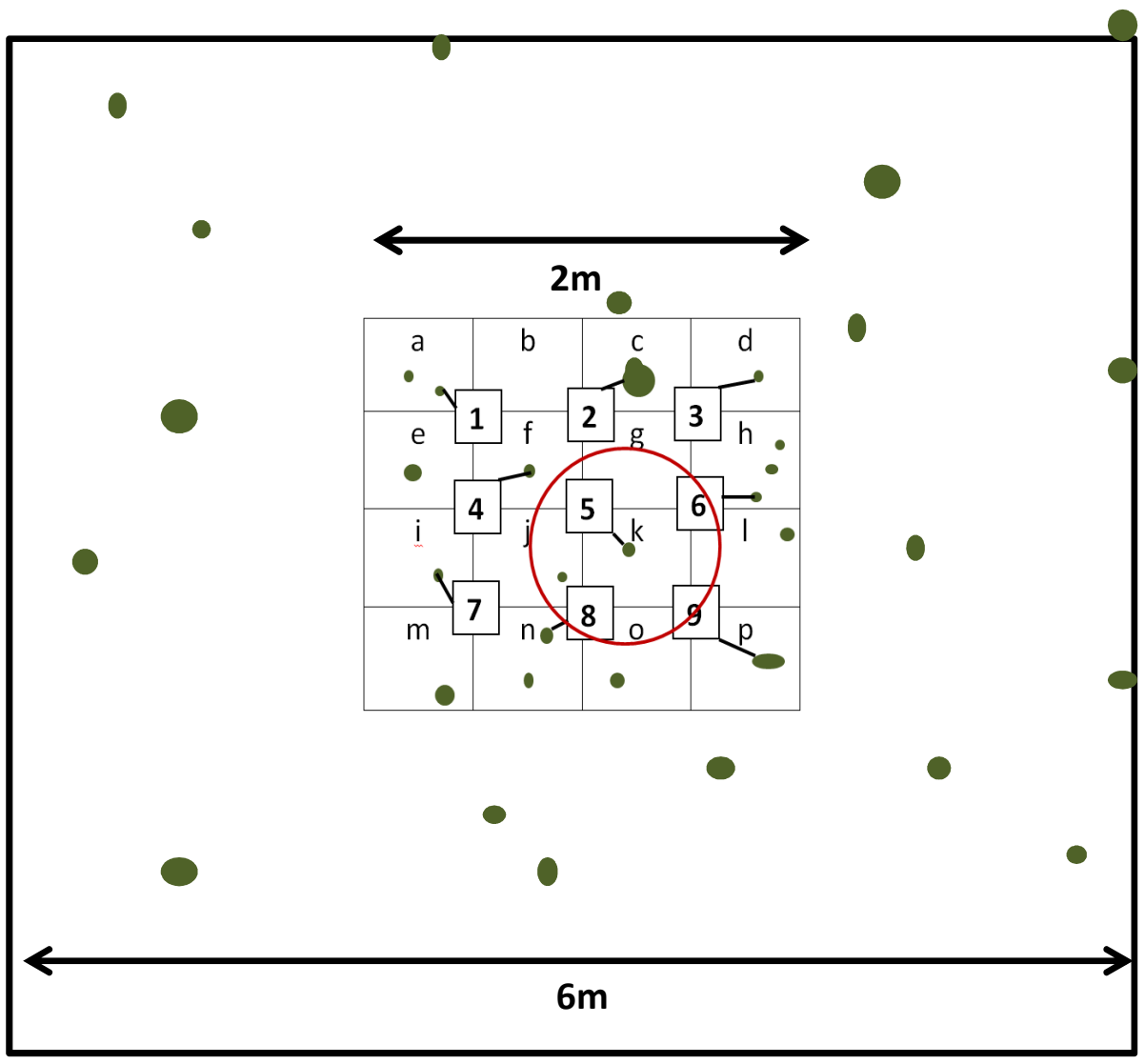

Figure 5.5: Nested quadrat design is shown with the small $2 \mathrm{~m}$ quadrat where 9 plants were selected and Senecio spp. density within a $50 \mathrm{~cm}$ radius circle $\left(\right.$ area $=0.8 \mathrm{~m}^{2}$ ) was measured. The black big quadrat represents the $6 \mathrm{~m}$ quadrat (area of the annulus $=32 \mathrm{~m}^{2}$ ) in which Senecio spp.-plants were only counted but not further measured. 


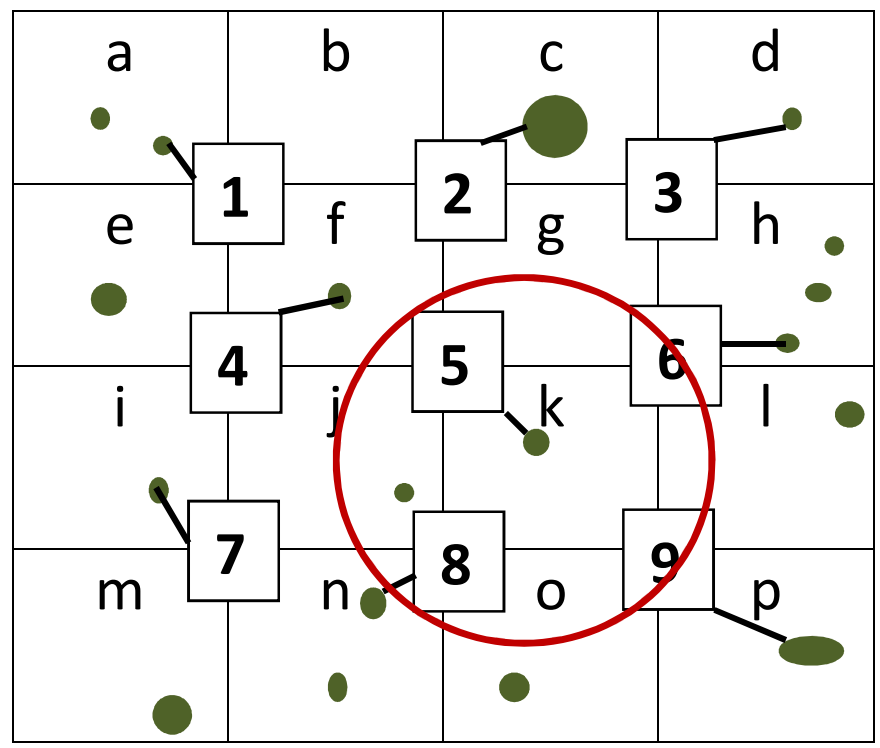

Figure 5.6: Subsampling design within a single $2 \times 2 \mathrm{~m}$ quadrat. Letters show $50 \mathrm{~cm}$ subquadrats. Numbers show idealised locations for all nine focal plants and green dots show hypothetical plants of varying sizes. Black lines indicate which plant would be a surveyed plant. The red circle shows the $50 \mathrm{~cm}$ radius circle in which all plants were counted (area $=0.8 \mathrm{~m}^{2}$ ).

\section{Experimental setup}

The experiment focused on small scale plant densities, therefore a short distance between the experimental units was deemed efficient to test for effects of plant density on insect colonization. Out of the greenhouse grown Senecio spp. plants, 120 adult plants each of S. lautus, S. skirrhodon and S. elegans were used in a manipulative field experiment to test how plant density (introduced verses native species and introduced vs. introduced species) affects insect herbivore colonization. All experimental plants were initially grown under controlled settings in the Victoria University of Wellington greenhouse using seed collected from Eastbourne and Tarakena Bay (Wellington South Coast). Before transplanting into the field, plants were hardened-off on the roof of the university building for 2 weeks. To acclimatize the plants to salt spray, plants were frequently sprayed with seawater during this period. To avoid premature insect colonization plants were protected on the roof by a mesh cage. All plants were planted into $12 \mathrm{~cm}$ high pots which were filled with a 2:1:1 mixture of coarse sand type 2 (2-5 $\mathrm{mm}$ ), standard seedling potting mix and standard compost. I added plant saturizer aid to the potting mixture (according to specifications from the manufacturer Debco). At the 
bottom of each pot a piece of artificial sponge was laid to aid with water retention. In the wild, healthy coastal Senecio spp. are often rooted in sponges in the tideline (pers. observation). One small shovel of potting mix (roughly $400 \mathrm{~g}$ ), was added on top of the artificial sponge piece. On top of that half a shovel (roughly $200 \mathrm{~g}$ ) of expanded crystal rain (water absorbing polymer used for hanging baskets to ensure plants do not dry out) was added before the seedling was planted and the pot filled with potting mix. Prior to transplanting plants into the field, the height, $\mathrm{min} / \mathrm{max}$ width, number of flowers, health score, feeding damage, and largest leaf were measured for each plant. I set up six transects of each S. lautus vs. S. skirrhodon, S. lautus vs. S.elegans and S.skirrhodon vs. S.elegans parallel to the sea with a minimum distance of $20 \mathrm{~m}$ between transects. Each transect consists of ten plants of each of the two Senecio species, which were distributed into seven units (a-g) with varying plant densities, which had the following setup (Fig.5.7 and Table 5.1). Six transects per species combination were used to test for spillover effects of insect herbivores from native to introduced Senecio spp. plants at fine scales.

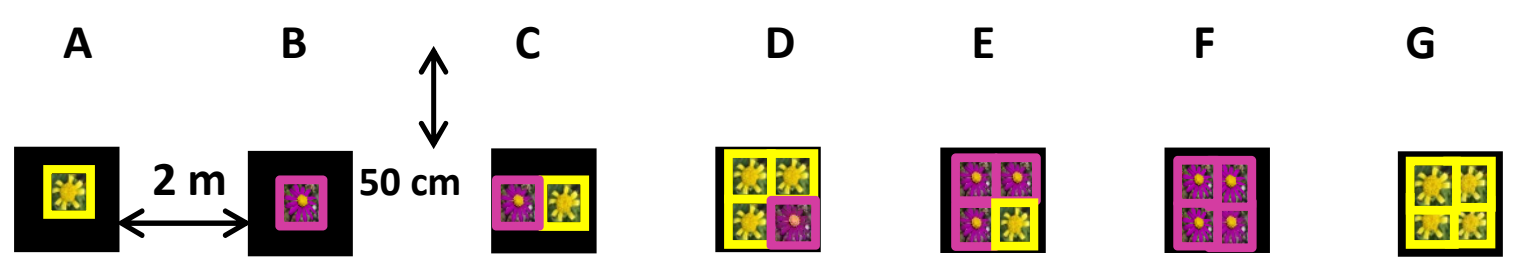

$12 \mathrm{~m}$

Figure 5.7: Schematic experimental setup of one transect. Each small yellow square represents one $S$. lautus pot plant, each purple square represents one $S$. elegans pot plant. A minimum distance of $20 \mathrm{~m}$ was kept between transects. A-F = units of the transect.

Experimental plants were monitored in a similar way as Senecio spp. plants for naturally occurring Senecio spp. plants to research the influence of plant properties (plant morphology) on insect herbivore host choice. For each plant I recorded: height, diameter, state of flowering (how many flower buds, how many flowers in bloom, how many flowers that have finished flowering), health score (how many discoloured leaves out of ten counted from the bottom up to the top of the plant), and feeding damage (by 
slugs etc., same counting approach as with the health score system). In addition, I also recorded presence-absence of fungal-infestations. Up to ten flower heads were opened and searched for seed head predators. I searched the whole plant for no longer than 10 min in total, and recorded all aphids, leaf miners, lepidopteran larvae, gallers and stem borers and all other insects I observed. I recorded all Asteraceae within $50 \mathrm{~cm}$ of each Senecio spp. plant (area $=0.8 \mathrm{~m}^{2}$ ). Small Asteracea are defined as smaller than $25 \mathrm{~cm}$ in height. Plants were monitored once every month for insect herbivores. Due to vandalism it was not possible to use some of the data and the experiment was terminated earlier than anticipated. Data presented here show the first two months of monitoring.

Table 5.1: Plant combinations of units.

\begin{tabular}{cccc}
\hline Unit name & $\begin{array}{c}\text { No of native S. lautus } \\
\text { plants }\end{array}$ & $\begin{array}{c}\text { No of introduced S. } \\
\text { elegans plants }\end{array}$ & Total plants \\
\hline A & 1 & 0 & 1 \\
B & 0 & 1 & 1 \\
C & 1 & 1 & 2 \\
D & 3 & 1 & 4 \\
E & 1 & 3 & 4 \\
F & 0 & 4 & 4 \\
G & 4 & 0 & 4 \\
\hline Total & 10 & 10 & 20 \\
\hline
\end{tabular}

\subsubsection{Data analysis}

\section{Natural survey}

I used the bipartite package (Dormann et al. 2008) from the statistical program R (R Core Team 2012) to construct a quantitative food web using the complete data set of all numbers and types of insect herbivores on all Senecio spp. plants. Since not all data met statistical assumptions of normality despite transformation, I used the Kruskall Wallis test (a nonparametric test) to test for host preferences of insect herbivores between the different plant species. Number of insects present was used as the dependent variable (with separate tests per herbivore species) and plant species was the independent 
variable. If quadrats were empty (from the first surveys where random points were used to locate the quadrats), they were removed from all analyses. I used percent infestation of the flower heads as the dependent variable for the density of $S$. fascigera larvae to account for differences in the methodological approach in sampling all flower heads for the first survey, but only ten in all other surveys. I was interested in identifying the main effects of plant density of congeneric and heterospecific plants on insect herbivore host choice. Plant size was included as a covariate. Therefore I used linear mixed effect models (LME) to test for the effects of plant size, conspecific density and hetero-specific density upon insect herbivore numbers. Plant size was first calculated as the cube-root of an index of volume, which was subsequently log-transformed to improve normality. In the equation minwidth + maxwidth = diameter:

$$
\left(\log \left(\text { height } *((\min w i d t h+\max w i d t h) / 2)^{2}\right)^{1 / 3}\right)
$$

Density was measured at two spatial scales: firstly the number of plants within a $50 \mathrm{~cm}$ radius circle, and secondly the $6 \mathrm{~m}$ quadrat (excluding the plant counts from the $50 \mathrm{~cm}$ and the $2 \mathrm{~m}$ quadrat nested within). A complete explanation of terms can be found in Table 5.2. Site, quadrat and sub quadrat were included as nested random effects. I tested each insect herbivore species for each Senecio species individually, for the effect of surrounding conspecific density, by using linear models (plant size was accounted for as a predictor). Model residuals were tested for normal distribution and data were transformed to achieve normality. If the data showed near normal distribution, and thus no other distribution could be specified, LMEs were applied as no current available nonparametric test allows for nestedness of random effects. Where boxplots were used, boxes and whiskers are by $R$ default (boxes encompass the interquartile range (IQR). Whiskers extend to the end of the range except for the outliers ( $>1.5$ times the range). 
Table 5.2: Explanation of variables used in the linear models. All variables are continuous. Insect herbivore $(\mathrm{IH})$ was used as dependent variable.

\begin{tabular}{|c|c|c|c|c|}
\hline Symbol & Variable & Range & Description & Unit \\
\hline \multirow[t]{2}{*}{$\mathrm{IH}$} & Insect herbivore & $0-2$ per flower & $\begin{array}{l}\text { S. fascigera in flower heads } \\
\text { (SHPF) }\end{array}$ & count/flower \\
\hline & SHPF or SHPS & $0-47$ & S. fascigera in stems (SHPS) & count/ plant \\
\hline PS & Plant size & $0-3$ & $\begin{array}{l}\log (\text { height* }((\text { minwidth+maxwidth } \\
\left.\left./ 2)^{2}\right)^{\wedge}(1 / 3)\right)\end{array}$ & $\mathrm{cm}$ \\
\hline $50 \mathrm{cmSL}$ & $\begin{array}{l}50 \mathrm{~cm} \text { density of } \\
\text { S. lautus }\end{array}$ & $0-67$ & $\begin{array}{l}\text { number of } S \text {. lautus } 50 \mathrm{~cm} \text { around } \\
\text { focal plant }\end{array}$ & count \\
\hline $50 \mathrm{cmSE}$ & $\begin{array}{l}50 \mathrm{~cm} \text { density of } \\
\text { S. elegans }\end{array}$ & $0-15$ & $\begin{array}{l}\text { number of S. elegans } 50 \mathrm{~cm} \\
\text { around focal plant }\end{array}$ & count \\
\hline $6 \mathrm{mSL}$ & $\begin{array}{l}6 \mathrm{~m} \text { density of } \mathrm{S} . \\
\text { lautus }\end{array}$ & 0-199 & $\begin{array}{l}\text { density of } S \text {. lautus within } 6 \mathrm{~m} \\
\text { quadrat }\end{array}$ & count \\
\hline $6 \mathrm{mSE}$ & $\begin{array}{l}6 \mathrm{~m} \text { density of } S . \\
\text { elegans }\end{array}$ & $0-44$ & $\begin{array}{l}\text { density of } S \text {. elegans within } 6 \mathrm{~m} \\
\text { quadrat }\end{array}$ & count \\
\hline
\end{tabular}

\section{Experiment}

Dead plants were replaced and after 4 weeks incorporated in the monitoring. I assumed that all plants from the original experiment had influenced insect herbivore host choice for the first monitoring. For the second monitoring I used the actual plant numbers available from the first monitoring.

Where boxplots were used, boxes and whiskers are by $\mathrm{R}$ default (boxes encompass the interquartile range (IQR). Whiskers extend to the end of the range except for the outliers (>1.5 times the range).I used the Kruskall Wallis test as a nonparametric method to test for host preferences of insect herbivores between the different plant species, as normality was not always achieved despite data transformation. I used the bipartite package (Dormann et al. 2008) for the statistical program R (R Core Team 2012) to construct a quantitative food web using the complete data set from both monitoring rounds. The complete data set was split up between monitoring data sets for the density analysis. I tested each Senecio species individually for the effect of surrounding conspecific density by using LMEs (plant size was accounted for as a predictor). Model residuals were tested for normal distribution and data was transformed to achieve normality. If the data showed near normal distribution and thus no other distribution could be specified, LMEs were applied as no current available non-parametric test allows 
for nestedness of random effects. Transect and unit were included in the LMEs as nested random effects. For density effects of conspecifics it was necessary to pool congeneric species to gain a sufficient sample size to apply the LMEs (all model terms see Table 5.3).

Table 5.3: Model variables used for LMEs of the experiment. First repetition = one month after planting, second monitoring was two months after planting. Insect herbivore was the dependent variable.

\begin{tabular}{|c|c|c|c|}
\hline Variable & Range & Description & Unit \\
\hline insect herbivore & $0-16$ & $\begin{array}{l}\text { all IHs individually per plant except } S \text {. fascigera in } \\
\text { flowers (proportion) }\end{array}$ & $\begin{array}{l}\text { count/plant or } \\
\text { count/flower }\end{array}$ \\
\hline plant size & $0-5$ & $\log \left(\right.$ height* $\left.\left((\text { minwidth }+ \text { maxwidth } / 2)^{\wedge} 2\right)^{\wedge}(1 / 3)\right)$ & $\mathrm{cm}$ \\
\hline conspecific counts & $0-3$ & counts of surrounding conspecific plants & counts \\
\hline heterospecific counts & $0-3$ & counts of surrounding heterospecific plants & counts \\
\hline $\begin{array}{l}\text { heterospecific counts } \\
\text { in second repetition }\end{array}$ & $0-6$ & pooled heterospecific counts due to low sample size & counts \\
\hline
\end{tabular}




\section{CHAPTER 5}

\subsection{Results}

A complete list for all insect species recorded on both natural surveys and the experimental monitoring can be found in Table 5.4. 
Table 5.4: Associations between insect herbivores and occasional incidental records of insect herbivore parasitoids are shown for all Senecio spp. investigated (SL = S. lautus, ST=S. sterquilinus, $\mathrm{SE}=$ S. elegans, SS = S. skirrhodon, SV = S. vulgaris). Senecio glastifolius is not extra listed, but only N. annulata specimens were found on it during the survey of natural populations. For $S$. angulatus only plant hoppers were recorded (Hemiptera). Numbers indicate relative abundance $(0=$ not found, $1=$ occasionally found, $\mathbf{2}$ = common, $\mathbf{3}$ = abundant). If there was only one record per insect herbivore this is noted with $x$. Question marks were used to indicate that there is no information available for this species in that cell.

\begin{tabular}{|c|c|c|c|c|c|c|c|c|}
\hline Order & Family & Scientific name & Seasonality & $S L$ & $\begin{array}{l}S \\
E\end{array}$ & $\begin{array}{l}S \\
S\end{array}$ & $\begin{array}{l}S \\
T\end{array}$ & SV \\
\hline Acari & NA & NA & December & 2 & 2 & 2 & 2 & $?$ \\
\hline Diptera & Agromyzidae & $\begin{array}{l}\text { Chromatomyia } \\
\text { syngenesiae }\end{array}$ & Spring & 2 & 3 & 1 & 2 & ? \\
\hline Diptera & Melanagromyza & $\begin{array}{l}\text { Melanagromyza } \\
\text { senecionella }\end{array}$ & NA & $\begin{array}{l}\text { rar } \\
\mathrm{e}\end{array}$ & 0 & 0 & 1 & $?$ \\
\hline Diptera & Tephritidae & $\begin{array}{l}\text { Sphenella } \\
\text { fascigera }\end{array}$ & $\begin{array}{l}\text { More at peak of } \\
\text { summer }\end{array}$ & 3 & 2 & 2 & 4 & 1 \\
\hline Hemiptera & $\begin{array}{l}\text { Aphidoidea } \\
\text { (Superfamily) }\end{array}$ & NA & Early spring & 3 & 3 & 3 & ? & ? \\
\hline Hemiptera & Flatidae & Siphanta acuta & In early Feb & 2 & 2 & 2 & & ? \\
\hline Homoptera & Cercopidae & $\begin{array}{l}\text { Philaenus } \\
\text { spumarius (L.) }\end{array}$ & Early in the season? & $?$ & 2 & 2 & $?$ & $?$ \\
\hline Hymenoptera & Pteromalidae & $\begin{array}{l}\text { Pteromalidae spp } \\
\text { parasitoid }\end{array}$ & Peak of season & 1 & $?$ & $?$ & ? & $?$ \\
\hline Lepidoptera & Arctiidae & $\begin{array}{l}\text { Nyctemera } \\
\text { annulata }\end{array}$ & $\begin{array}{l}\text { Common throughout } \\
\text { the year }\end{array}$ & 3 & 3 & 3 & 3 & 3 \\
\hline Lepidoptera & Crambidae & Udea flavidalis & NA & ? & $\begin{array}{l}1 \\
x\end{array}$ & $?$ & $?$ & ? \\
\hline Lepidoptera & Geometridae & NA & $\begin{array}{l}\text { In early February } \\
\text { very common }\end{array}$ & 4 & 4 & 4 & 1 & ? \\
\hline Lepidoptera & Geometridae & $\begin{array}{l}\text { Phrissogonus } \\
\text { laticostatus }\end{array}$ & Peak of season & $?$ & $?$ & $x$ & $?$ & $?$ \\
\hline Lepidoptera & Nepticulidae & Stigmella ogygia & NA & $?$ & & & 2 & $?$ \\
\hline Lepidoptera & Noctuidae & $\begin{array}{l}\text { Helicoverpa } \\
\text { armigera }\end{array}$ & NA & ? & $x$ & $?$ & ? & $?$ \\
\hline Lepidoptera & Pyralidae & $\begin{array}{l}\text { Patagonoides } \\
\text { farinaria }\end{array}$ & Common & 3 & 2 & 2 & 3 & ? \\
\hline Lepidoptera & Tortricidae & tortricid spp. & Rare & 1 & $?$ & $?$ & $?$ & ? \\
\hline Lepidoptera & & Asterivora colpola & Early in the season? & & $x$ & $x$ & & \\
\hline Nematocera & Cecidomyiidae & $\begin{array}{l}\text { undescribed } \\
\text { species }\end{array}$ & Early in the season? & $\begin{array}{l}\text { rar } \\
\mathrm{e}\end{array}$ & 1 & 0 & 2 & ? \\
\hline
\end{tabular}




\subsubsection{Survey of naturally occurring populations}

\section{Species linkages and interactions strengths}

Figure 5.8 shows a quantitative food web for all main associations encountered during the field surveys. It shows that most insect herbivores used all Senecio species but proportions were higher on native $S$. lautus which also provided the sample set with the most plants investigated. 
Geometridae larvae lepdiopteran leaf miner

aphids

lepidopteran larvae

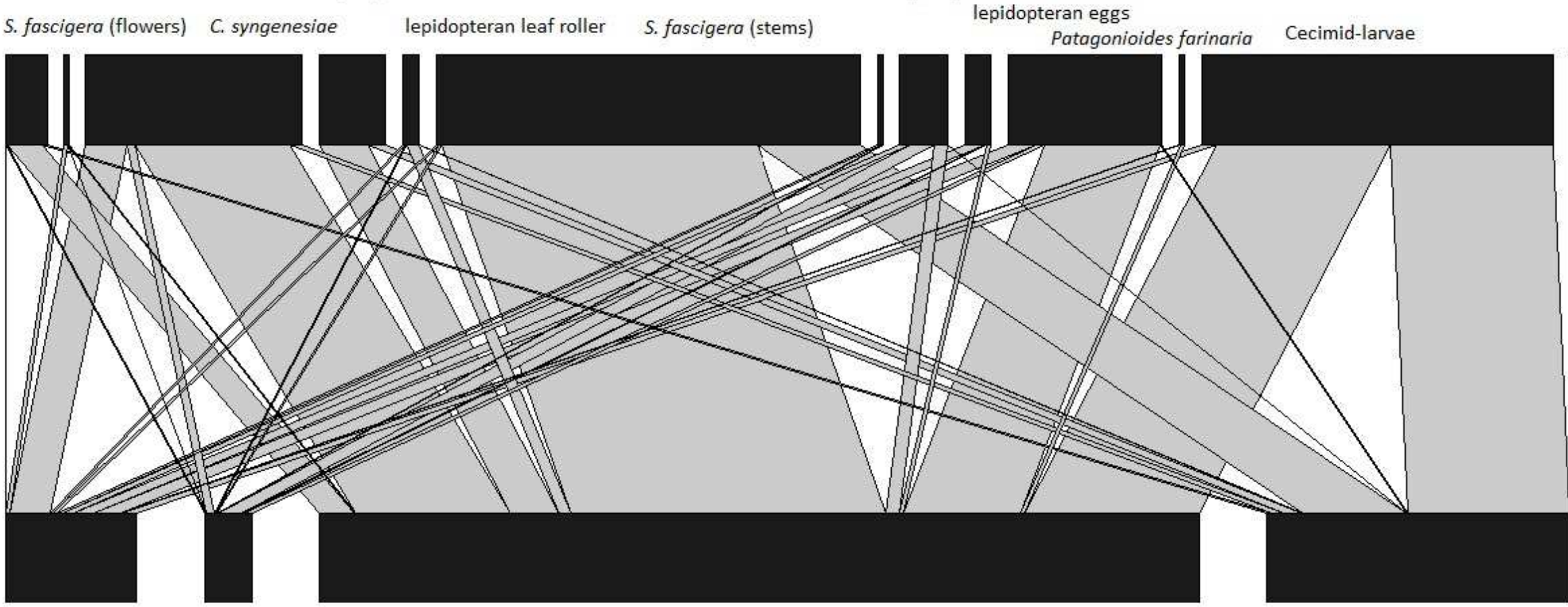

Senecio elegans $(n=124)$

Senecio lautus $(n=619)$

Senecio sterquilinus $(n=54)$

Senecio skirrhodon $(n=79)$

Figure 5.8: Quantitative food web of the main insect herbivores found during the survey of natural populations. Each connection line between an herbivore and the Senecio spp. represents the association between the two. The thickness of the line (grey) and the plant species bar (black) are proportional to the number of specimens. The naming of insect herbivores goes from left to the right. Due to space restriction they are placed at varying heights to be included in the graph. 
The Kruskall Wallis test showed that host choice differed significantly between insect herbivores for Senecio spp. plants (Table 5.5, Figure 5.9 and Figure 5.10). The KruskallWallis rank sum test showed significant differences for Senecio species choice for S. fascigera in flower heads and in stems (Table 5.5). Prevalence of S. fascigera in flower heads and stems was highest for S. sterquilinus, followed by S. lautus. Infestation rates for both S. elegans and S. skirrhodon were less than half the value observed in $S$. sterquilinus and S. lautus. The Kruskall-Wallis rank sum test showed significant differences for Senecio species choice for C. syngenesiae (Table 5.5).

Table 5.5: Results of a Kruskal-Wallis rank sum test, testing the null hypothesis that insect herbivores are equally prevalent across the four Senecio species.

\begin{tabular}{lrrr}
\hline Insect herbivore & chi- squared & df & p-value \\
\hline SHPS (S. fascigera in stems) & 87.948 & 3 & $<0.001$ \\
SHPF (S. fascigera in flower heads) & 84.331 & 3 & $<0.001$ \\
leaf miners & 29.569 & 3 & $<0.001$ \\
leaf roller & 1.612 & 3 & 0.657 \\
cecidomyiid larvae & 14.375 & 2 & 0.008 \\
lepidopteran larvae & 30.011 & 3 & 0.001 \\
P. farinaria & 8.877 & 3 & 0.031 \\
other larvae & 2.761 & 3 & 0.430 \\
\hline
\end{tabular}

Mean leaf infestation by Chromatomyia syngenesiae was highest for S. elegans (Fig. 5.9). No significant differences were found for leaf rollers (Table 5.5) and the overall rate of infestations was low on all Senecio species (Figure 5.9). 
Flowers with S.fasicgera

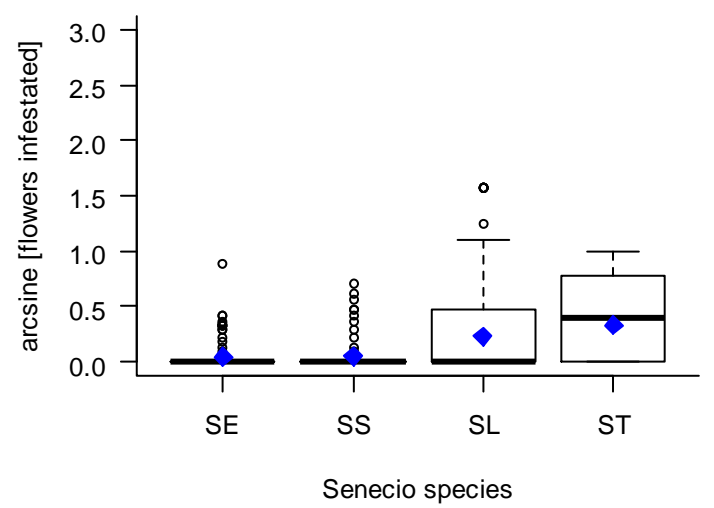

Leaf infestation with Chromatomyia syngenesiae

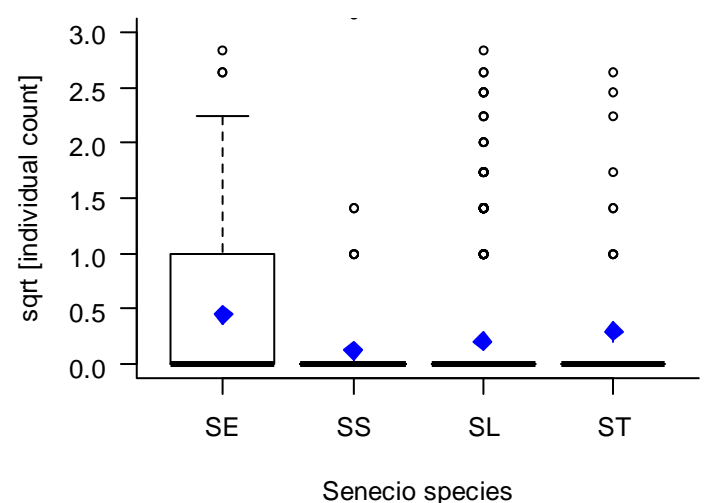

Stems with S.fasicgera

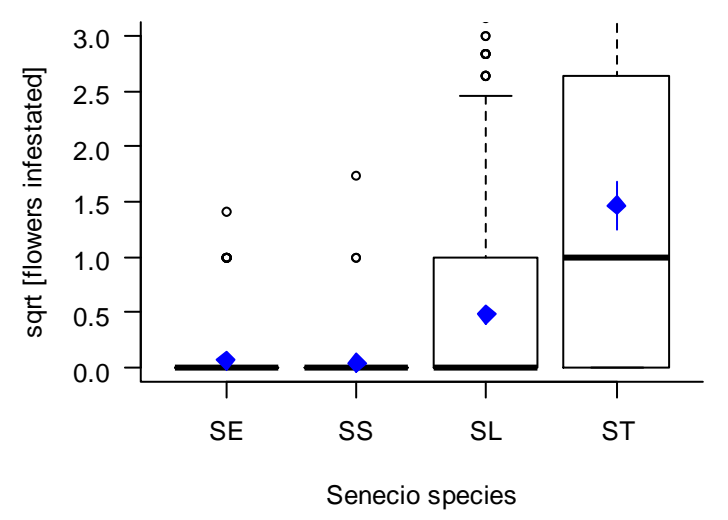

Leafroller [lepidopteran larvae]

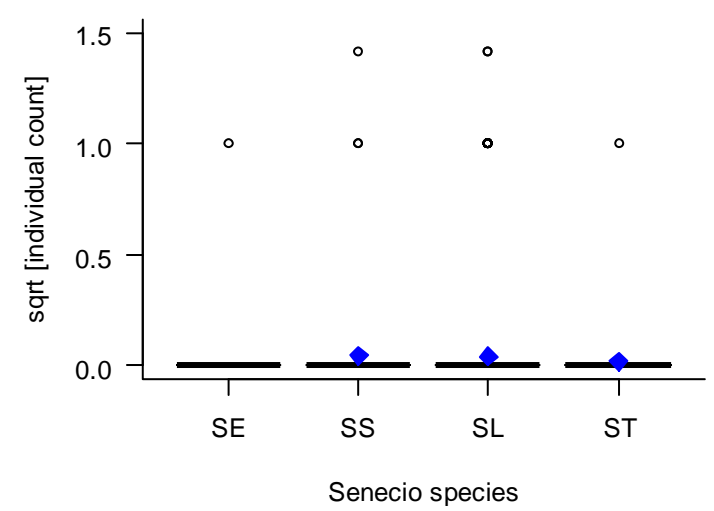

Figure 5.9: Species interaction linkage strengths part 1: (SE $=S$. elegans with $n=124, S S=S$. skirrhodon with $n=80, S L=S$. lautus with $n=618$ and $S T=S$. sterquilinus with $n=54)$. $X$-axis displays the investigated Senecio species, $y$-axis displays the squareroot transformed counts of the insect herbivore per plant unless otherwise given (clockwise: flowers with $S$. fascigera, stems with $S$. fascigera, leaves infested with Chromatomyia syngenesiae and leaf roller (lepidopteran larvae)). Blue diamonds = mean values $\pm \mathrm{SE}$. 
Cecidomyiid larval abundances showed significant differences in abundance across the four different Senecio species ( $p<0.0001$, Table 5.5). Cecidomyiid fly larvae showed high abundances on S. sterquilinus compared to S. lautus where cecidomyiid fly larvae were still occasionally observed (Fig. 5.10). Only one specimen of a cecidomyiid fly larva was observed on S. elegans, and none on S. skirrhodon. Lepidopteran larvae infestation numbers differed significantly between Senecio spp. $(p<0.0001$, Table 5.5). Counts of lepidopteran larvae were highest on S. skirrhodon (Fig. 5.10). For all other Senecios spp, investigated counts of lepidopteran larvae were very low.

Patagoniodes farinaria infestation numbers differed significantly between Senecio spp. $(p=0.031)$ (Table 5.5). Patagoniodes farinaria counts were highest on S. elegans, followed by S. lautus, S. skirrhodon and then S. sterquilinus (which could not be searched destructively). Occasionally other larvae were encountered, but no significant differences were found (Table 5.5). Likewise, no significant differences were found between Senecio species for Melanagromyza senecionella, and all aphids (Table 5.5 and Figure 5.1). 
Cecidomyiid larvae

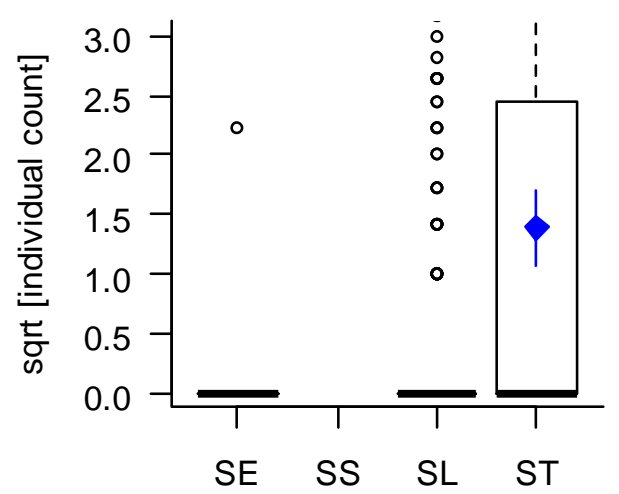

Senecio species

Stems with Patagonoides farinaria

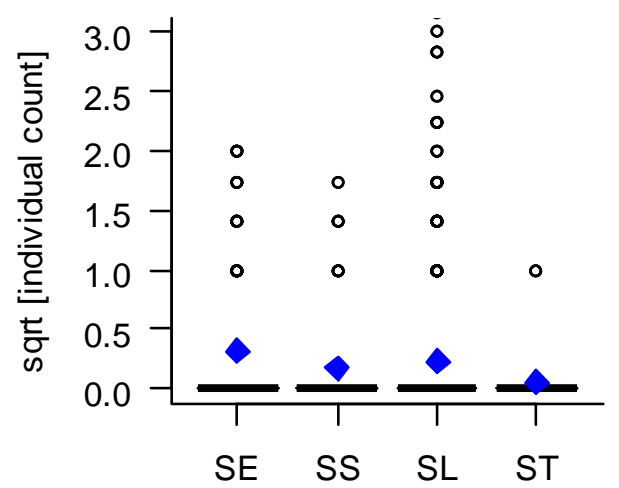

Senecio species
Lepidopteran larvae

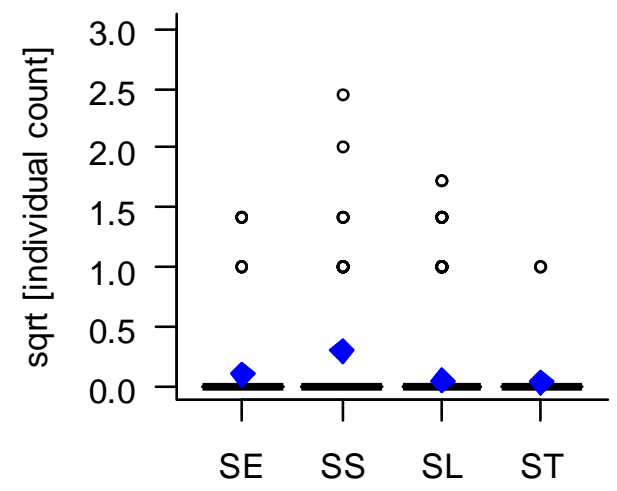

Senecio species

other larvae

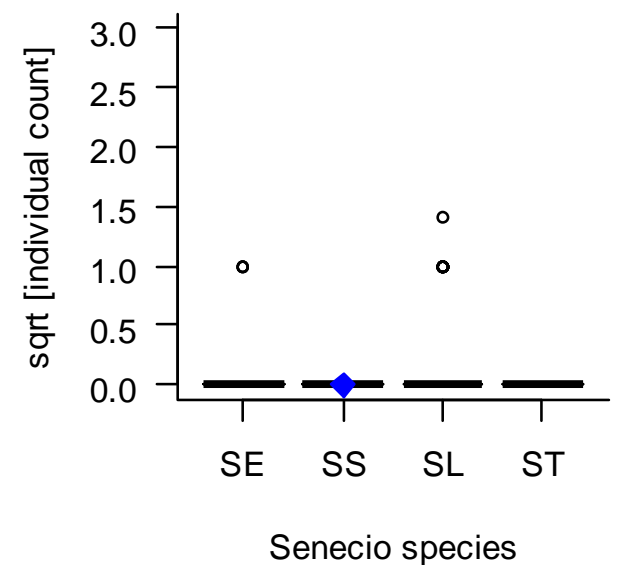

Figure 5.10: Species interaction linkage strengths part 2: $x$-axis displays the investigated Senecio species ( $\mathrm{SE}=$ S. elegans with $\mathrm{n}=124$, $\mathrm{SS}=$ S. skirrhodon with $\mathrm{n}=80, \mathrm{SL}=S$. lautus with $\mathrm{n}=618$ and $\mathrm{ST}=\mathrm{S}$. sterquilinus with $n=54), y$-axis displays the squareroot transformed individual counts of the insect herbivore (clockwise: Cecidomyiid larvae, lepidopteran larvae, stems with Patagonoides farinaria (Lepidoptera), and all other larvae). Blue diamonds = mean values $\pm \mathrm{SE}$. 


\subsubsection{Plant morphology and insect herbivore host plant choice}

Out of the variables measured, only plant size showed a significant influence on insect herbivore host plant choice. Occurrence of insects was positively influenced by plant size in all models for all plant species, regardless of which insect species was investigated. Only the datasets for $S$. elegans and $S$. lautus had sufficient numbers for further testing. See Table 5.6 for detailed LME-model values for insect herbivores on S. lautus and Fig. 5.11 for the positive influence of plant size on S. fascigera in both stems and flower heads on S. elegans and S. lautus. The influence of plant size was stronger for S. lautus compared to S. elegans (see Fig. 5.11). 
a)

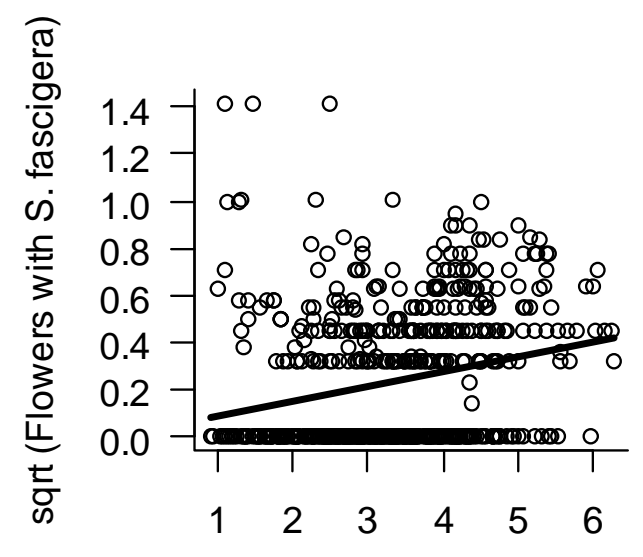

$\log [\mathrm{S}$. lautus plant size] $(\mathrm{cm})$

c)

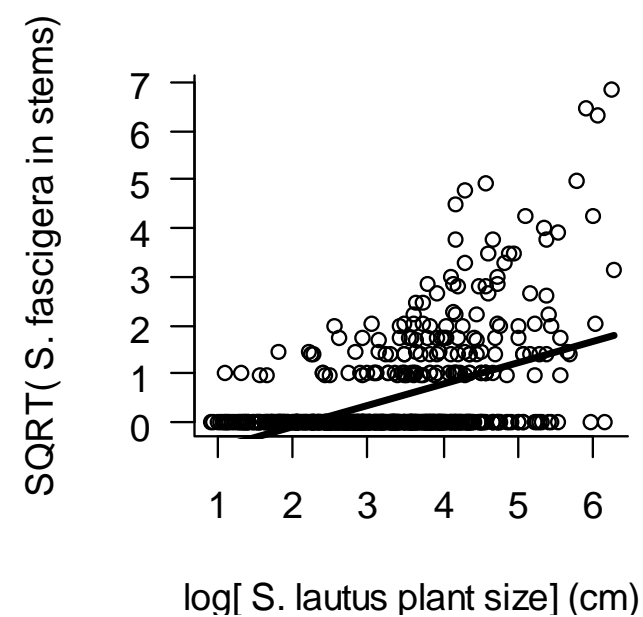

b)

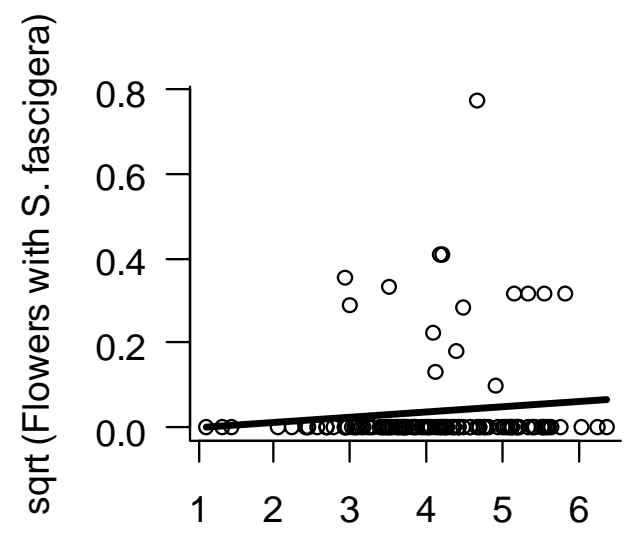

$\log [$ S. elegans plant size $](\mathrm{cm})$

d)

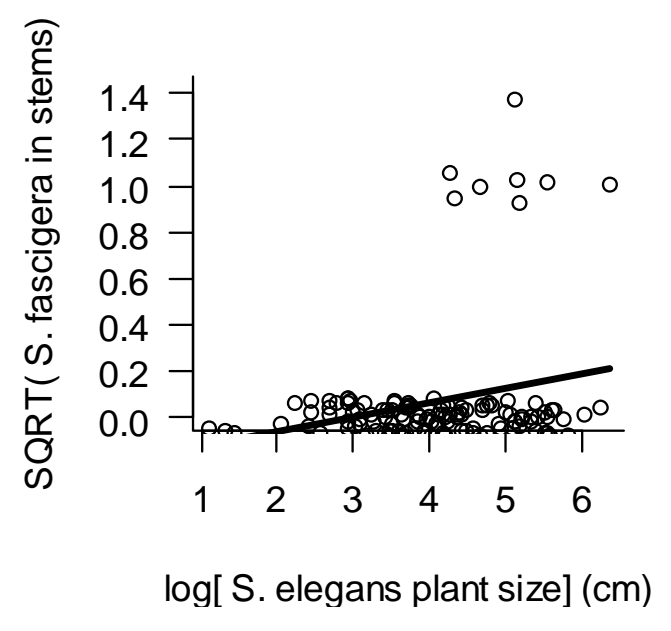

Figure 5.11: Sphenella fascigera infestations are shown for: (a) Senecio lautus flowers,(b) S. elegans flowers,(c) S. lautus stems and (d) S. elegans stems against log transformed plant size. Data points have been "jittered" to reduce overlap and improve visualisation of the trend.

\section{Plant density effects oninsect herbivore abundance}

\section{Influence of conspecifics}

Correlations between predictors were not very high (Fig. A $\vee 5$ and Table A $\vee 1$ in Appendix) and thus the predictors were used in the LME.

I tested the influence of plant density on S. fascigera within a Senecio species, measuring plant density in neighbourhoods of increasing size. As the number of conspecific plants 
in the neighbourhood increased, the number of $S$. fascigera per plant reduced, particularly at the fine scale measures of plant density (for flowers: $F_{1,131}=3.875, p=$ 0.051 and for stems $F_{1,131}=17.477, p<0.0001$, for complete model see Table 5.6 and Table 5.7 respectively). The relationship between plant counts and infestation rates with S. fascigera on S. lautus was more influential for S. fascigera in stems compared to $S$. fascigera in flower heads (Fig. 5.12). The relationship between coarse scale conspecific counts and S. fascigera infestations was not significant for infestations in stems or flowers (Fig. 5.12, Table 5.7 and Table 5.6).

Table 5.6: Anova summary for the complete LME for S. fascigera (sqrt-transformed) as response variable in flower heads of $S$. lautus (SL). Site, quadrat and subquadrat were included as nested random effects.

\begin{tabular}{|c|c|c|c|c|c|}
\hline Predictor for S. fascigera in flowers of SL & effect & numDF & denDF & F-value & p-value \\
\hline plant size (log transformed) & + & 1 & 131 & 37.412 & $<0.0001$ \\
\hline $\begin{array}{l}\text { fine scale density of } S \text {. lautus }(50 \mathrm{~cm} \log \\
\text { (counts)) }\end{array}$ & - & 1 & 131 & 3.875 & 0.051 \\
\hline $\begin{array}{l}\text { coarse scale density of } S \text {. lautus }(6 \mathrm{~m} \text { log } \\
\text { (counts)) }\end{array}$ & + & 1 & 105 & 0.631 & 0.429 \\
\hline $\begin{array}{l}\text { fine scale density of } S \text {. elegans }(50 \mathrm{~cm} \text { log } \\
\text { (counts)) }\end{array}$ & - & 1 & 131 & 2.744 & 0.100 \\
\hline $\begin{array}{l}\text { coarse scale density of } S \text {. elegans }(6 \mathrm{~m} \text { log } \\
\text { (counts)) }\end{array}$ & - & 1 & 105 & 0.786 & 0.377 \\
\hline
\end{tabular}

Table 5.7: Anova summary for the complete LME for S. fascigera (sqrt-transformed) as response variable in stems of $S$. lautus (SL). Site, quadrat and subquadrat were included as nested random effects.

\begin{tabular}{|c|c|c|c|c|c|}
\hline Predictor for S. fascigera in stems of SL & pos/neg & numDF & denDF & F-value & p-value \\
\hline plant size (log transformed) & + & 1 & 131 & 130.019 & $<0.0001$ \\
\hline $\begin{array}{l}\text { fine scale density of S. lautus }(50 \mathrm{~cm} \text { log } \\
\text { (counts)) }\end{array}$ & - & 1 & 131 & 17.477 & $<0.0001$ \\
\hline $\begin{array}{l}\text { coarse scale density of } S \text {. lautus }(6 \mathrm{~m} \text { log } \\
\text { (counts)) }\end{array}$ & + & 1 & 105 & 0.204 & 0.653 \\
\hline $\begin{array}{l}\text { fine scale density of S. elegans }(50 \mathrm{~cm} \mathrm{log} \\
\text { (counts)) }\end{array}$ & - & 1 & 131 & 5.845 & 0.017 \\
\hline $\begin{array}{l}\text { coarse scale density of } S \text {. elegans }(6 \mathrm{~m} \text { log } \\
\text { (counts)) }\end{array}$ & + & 1 & 105 & 0.057 & 0.812 \\
\hline
\end{tabular}


Fine scale density: Flowers with S.fascigera

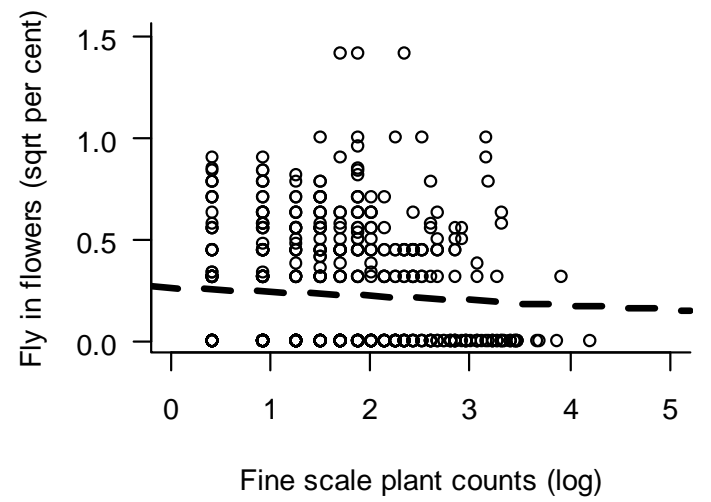

Coarse scale density: Flowers with S.fascigera

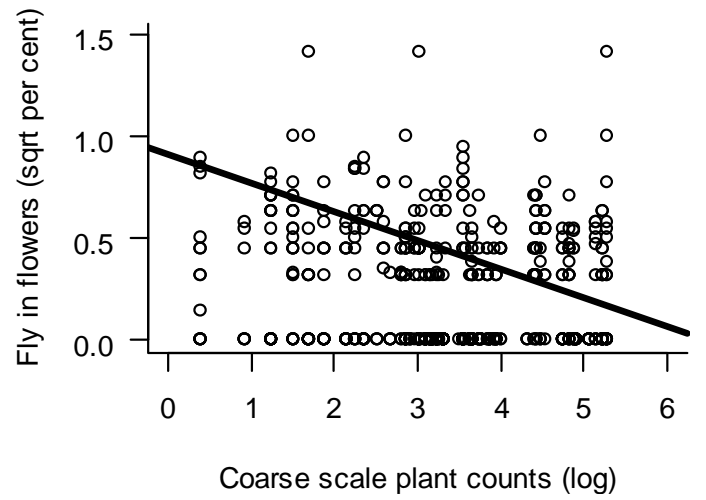

Fine scale density: Stems with S.fascigera

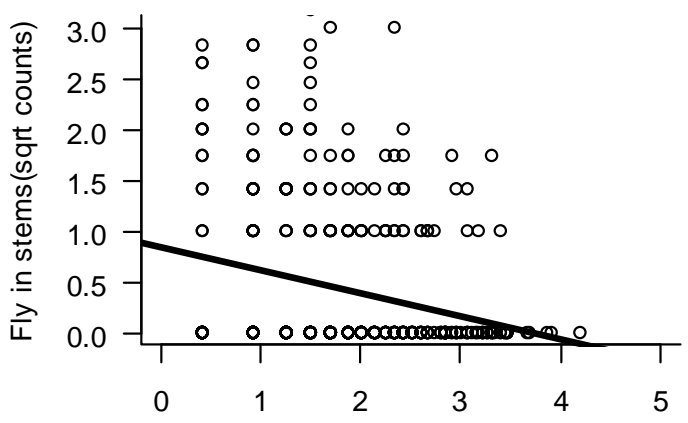

Fine scale plant counts (log)

Coarse scale density: Stems with S.fascigera

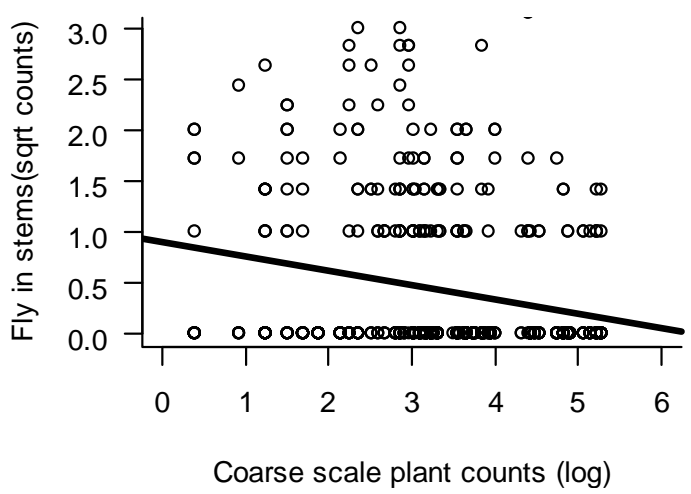

Figure 5.12: Sphenella fascigera infestations on stems and flower heads of $S$. lautus with S. lautus densities within $50 \mathrm{~cm}$ (area $=0.8 \mathrm{~m}^{2}$ ) and $6 \mathrm{~m}\left(a r e a=32 \mathrm{~m}^{2}\right.$ ) around the focal plant. The fitted line shows the simple linear model of $\mathrm{S}$. fascigera as the response variable with the associated density count as the only predictor. Solid lines show a significant relationship in the simple linear model, dashed lines show that the predictor was not significant.

On S. elegans, no relationship was evident between fine or coarse scale density of conspecific plants and S. fascigera infestations in the stems or flower heads (Fig. 5.13). Data distribution was not normal enough for any further modelling and the model for $P$. farinaria on S. lautus plants did not provide a good enough sample size for further analysis. 
Fine scale density: Flowers with S.fascigera

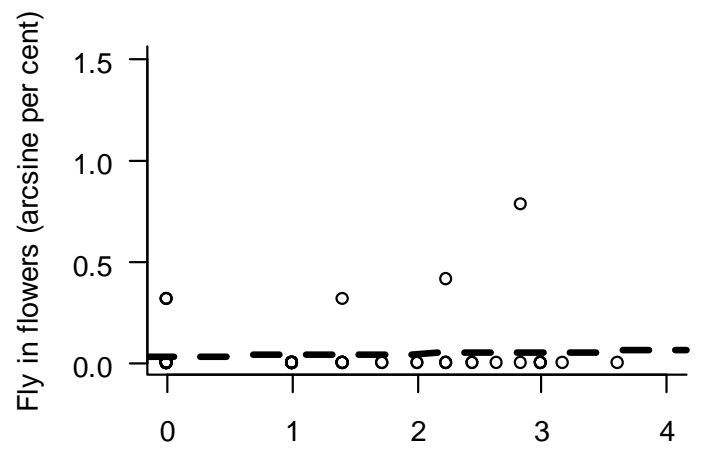

Fine scale plant counts (sqrt)

Coarse scale density: Flowers with S.fascigera

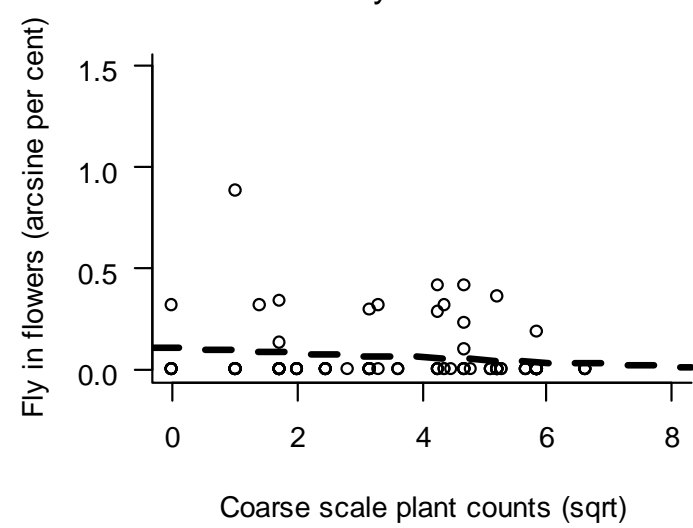

Fine scale density: Stems with S.fascigera

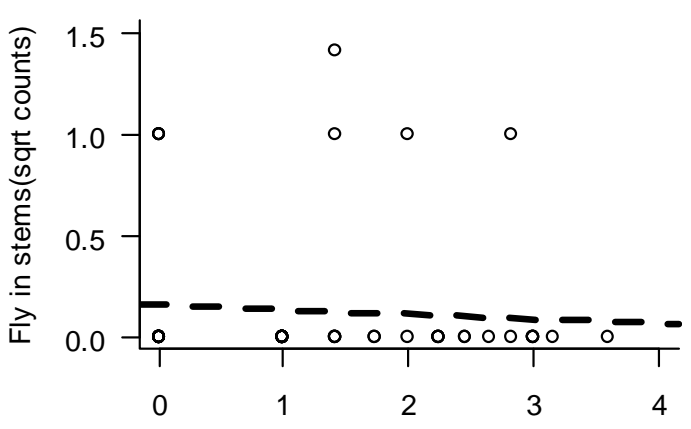

Fine scale plant counts (sqrt)

Coarse scale density: Stems with S.fascigera

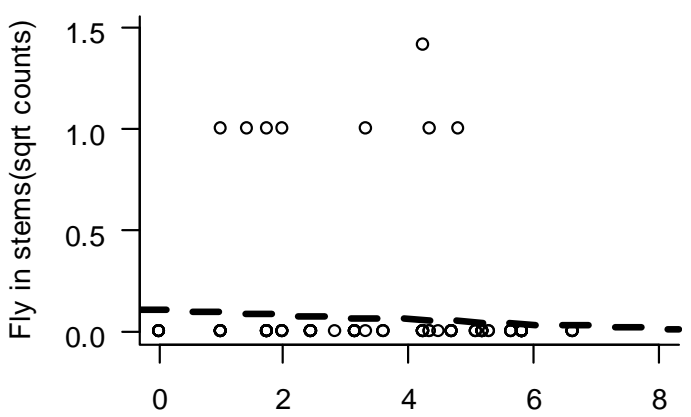

Coarse scale plant counts (sqrt)

Figure 5.13: Sphenella fascigera infestations on stems and flower heads of S. elegans with S. elegans densities within $50 \mathrm{~cm}\left(\right.$ area $=0.8 \mathrm{~m}^{2}$ ) and $6 \mathrm{~m}\left(\right.$ area $=32 \mathrm{~m}^{2}$ ) around the focal plant. The fitted line shows the simple linear model of $\mathrm{S}$. fascigera as the response variable with neighbourhood density counts as the only predictor.

\section{Influence of heterospecifics}

The fine scale density of heterospecific (S. elegans) plant density was a significant predictor of $S$. fascigera infestations of $S$. lautus stems $\left(F_{1,131}=5.845, p=0.017\right)$, but not for S. fascigera on S. lautus within flower heads (Fig. 5.14 and Table 5.7 and Table 5.6). Coarse scale heterospecific density was not significant for stem or flower infestations of S. fascigera on S. lautus. 
Fine scale density: Flowers with S.fasicgera

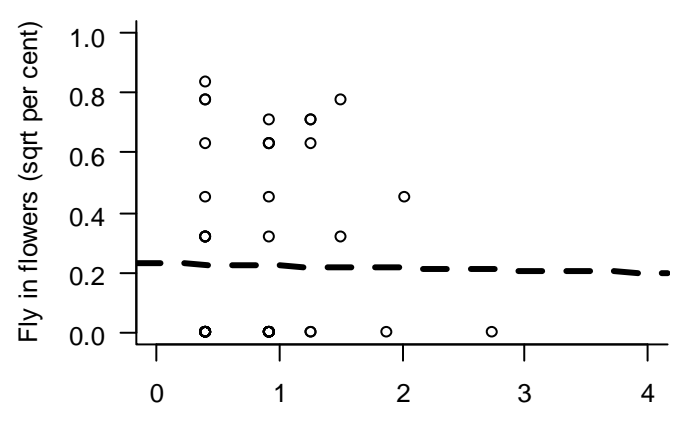

Fine scale plant counts (log)

Coarse scale density: Flowers with S.fasicgera

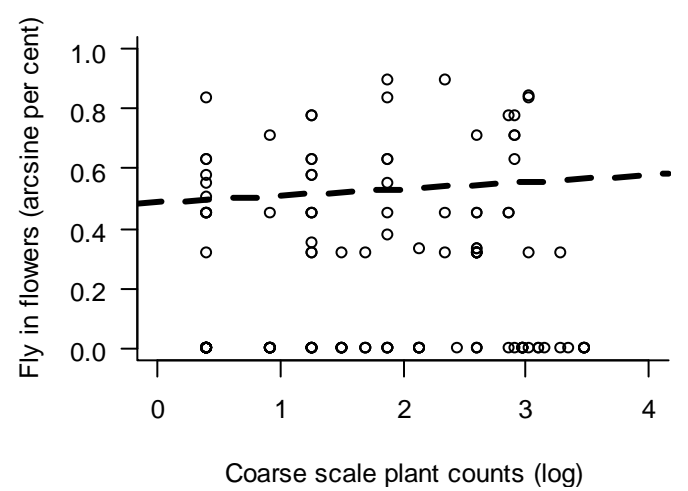

Fine scale density: Stems with S.fasicgera

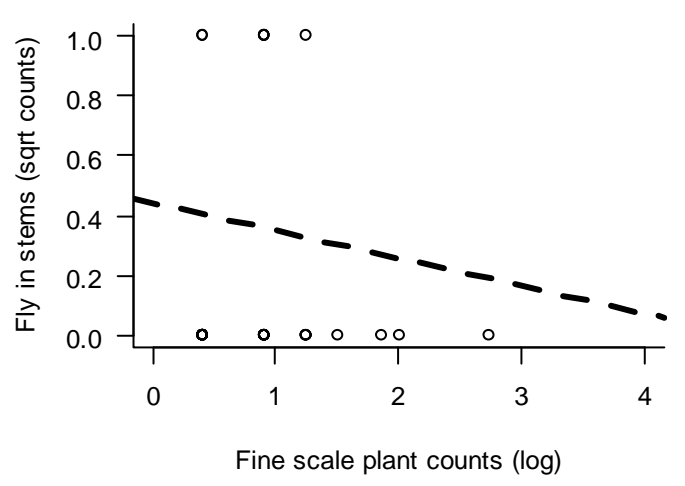

Coarse scale density: Stems with S.fasicgera

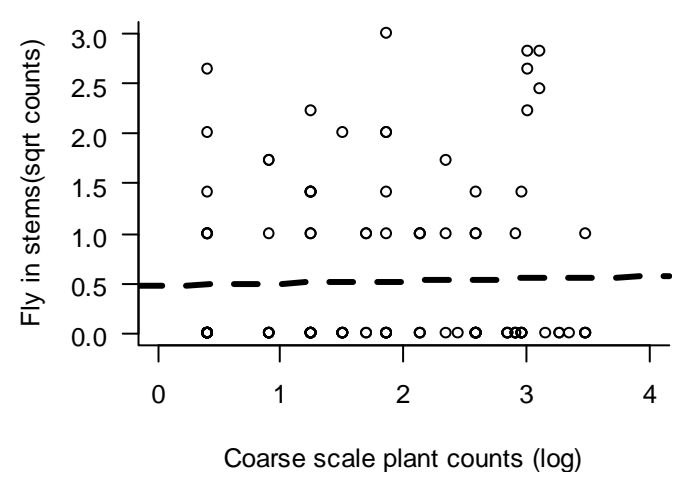

Figure 5.14: Incidence of Sphenella fascigera in stems and flower heads of S. lautus, as a function of S. elegans density at two different scales. Fine scale = number of plants within $50 \mathrm{~cm}\left(\operatorname{area}=0.8 \mathrm{~m}^{2}\right)$, coarse-scale $=$ number of plants within $6 \mathrm{~m}$ around the focal plant (area $\left.=32 \mathrm{~m}^{2}\right)$. The fitted line shows the simple linear model of $S$. fascigera as the response variable with the associated density count as the only predictor. Lines show a significant relationship in the simple linear model, dashed lines show that the predictor was not significant.

Data on S. fascigera infestations of S. elegans and the influence of S. lautus at fine and coarse scale was not sufficient enough for a parametric test, but showed a graphical trend for a negative influence of $S$. lautus at coarse scale densities on $S$. fascigera stem and flower infestation (Fig. 5.15). 
Fine scale density: Flowers with S.fasicgera

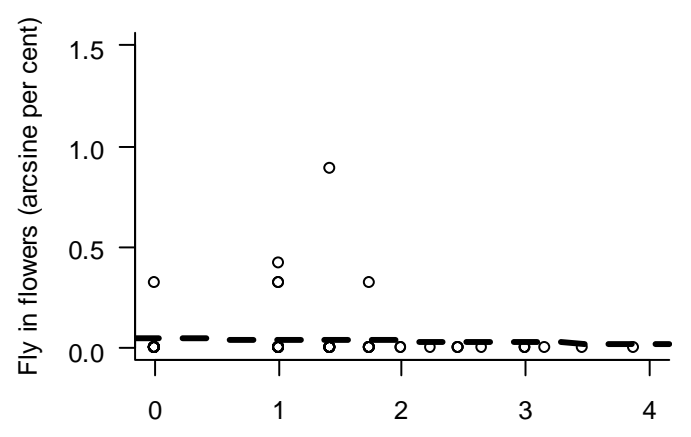

Fine scale plant counts (sqrt)

Coarse scale density: Flowers with S.fasicgera

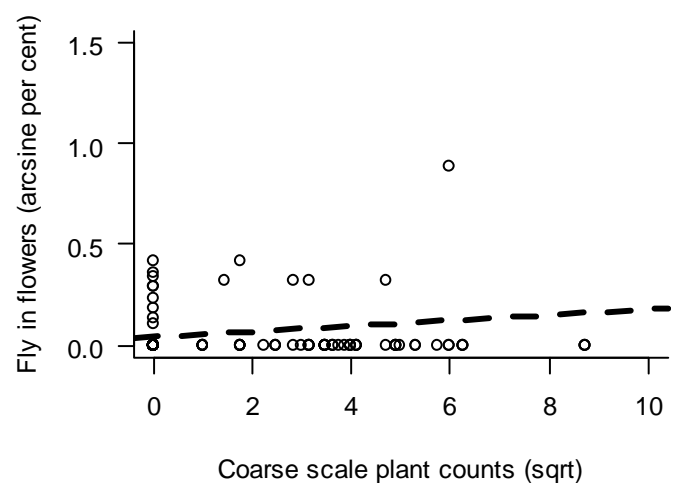

Fine scale density: Stems with S.fasicgera

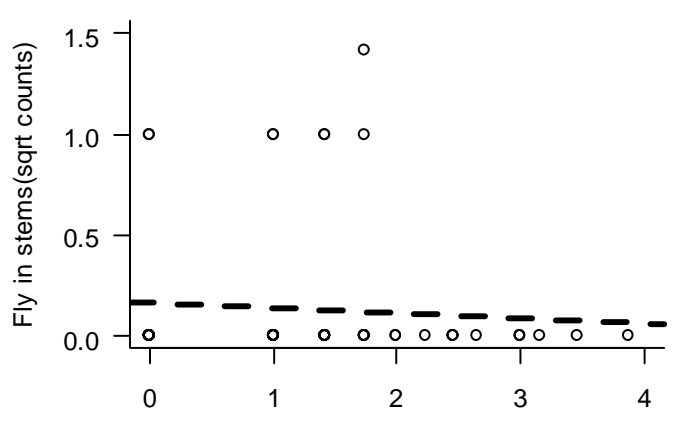

Fine scale plant counts (sqrt)

Coarse scale density: Stems with S.fasicgera

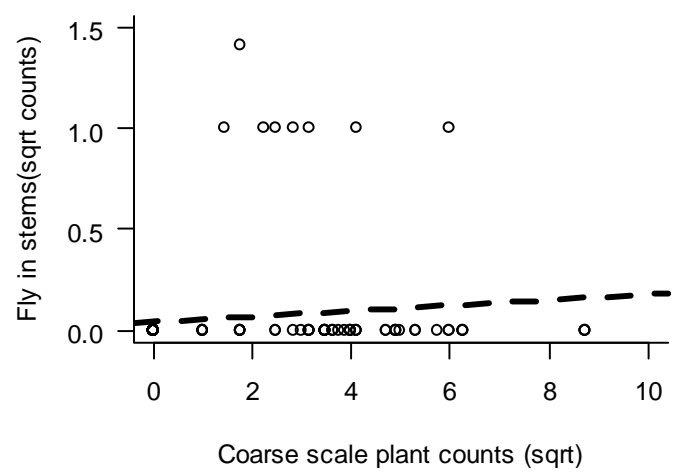

Figure 5.15: Incidence of Sphenella fascigera in stems and flower heads of S. elegans, as a function of $S$. lautus density at two different scales. Fine scale = number of plants within $50 \mathrm{~cm}\left(\right.$ area $\left.=0.8 \mathrm{~m}^{2}\right)$, coarsescale $=$ number of plants within $6 \mathrm{~m}$ around the focal plant $\left(\right.$ area $=32 \mathrm{~m}^{2}$ ). The fitted line shows the simple linear model of $\mathrm{S}$. fascigera as response variable with the associated density count as the only predictor. Lines show a significant relationship in the simple linear model, dashed lines show that the predictor was not significant.

A simple linear model showed a significant negative influence of fine scale and coarse scale density of conspecific $S$. lautus upon $P$. farinaria utilising $S$. lautus as a host plant (Fig. 5.16). In contrast, counts of heterospecific $S$. elegans showed a significant negative influence in the simple linear model (Fig. 5.16). 
Fine scale density: Number of $P$. farinaria

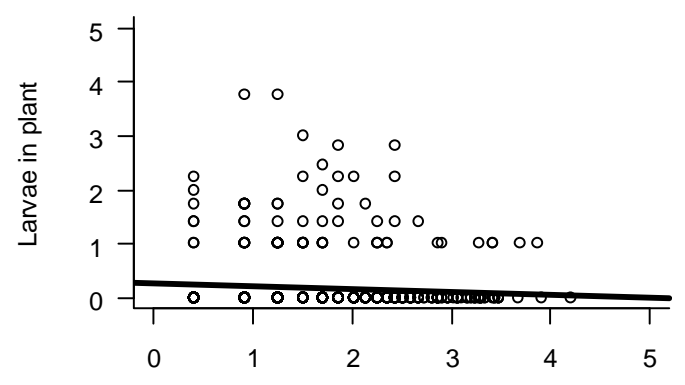

Fine scale SL plant counts (log)

Coarse scale density: Number of $P$. farinaria

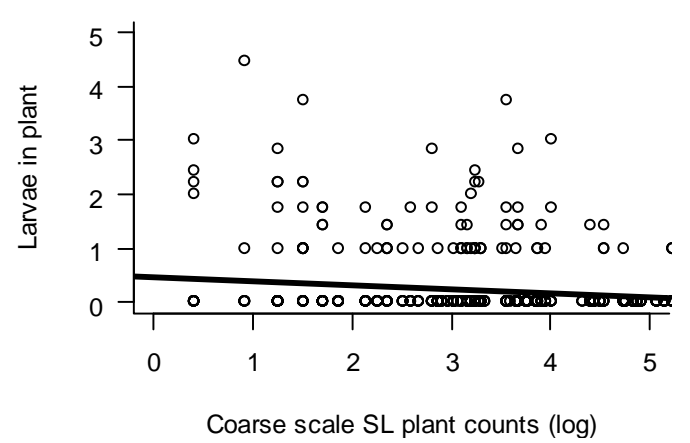

Fine scale density: Number of $P$. farinaria

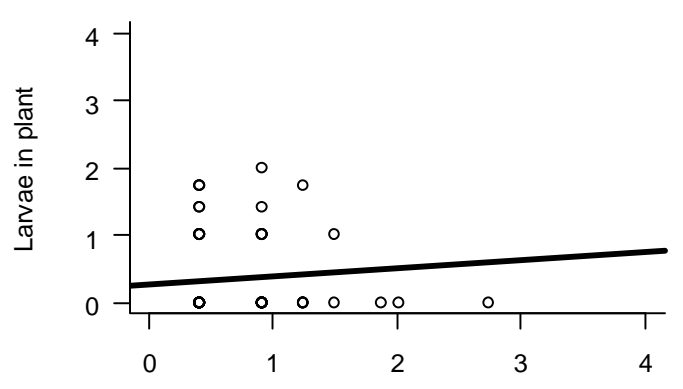

Fine scale SE plant counts (log)

Coarse scale density: Number of $P$. farinaria

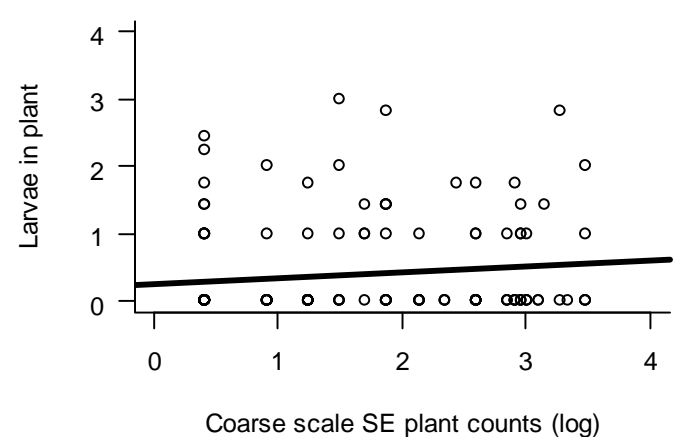

Figure 5.16: Patagoniodes farinaria counts per $S$. lautus plant and the interaction with fine scale conspecific ( $\mathrm{SL}=S$. lautus) and heterospecific ( $\mathrm{SE}=S$. elegans) plant counts on fine $\left(\mathrm{area}=0.8 \mathrm{~m}^{2}\right.$ ) and coarse scale $\left(\right.$ area $=32 \mathrm{~m}^{2}$ ). Lines show a significant relationship in the simple linear model.

\section{Combined effects of morphology (plant size) and plant density}

Plant size was a significant predictor of S. fascigera infestation rates within flower heads on S. lautus $\left(\mathrm{F}_{1,131}=37.412, \mathrm{p}<0.001\right.$, Table 5.6$)$. While fine scale conspecific density showed a marginally significant relationship $\left(F_{1,131}=3.875, p=0.051\right)$, all other plant densities were non-significant (Table 5.6, Table 5.7). 
The model for S. fascigera on S. elegans flower heads did not have sufficient data for further analysis.

Plant size $\left(F_{1,131}=130.019, p<0.001\right.$, $)$ showed a positive, fine scale conspecific plant density $\left(F_{1,131}=17.477, p<0.001,\right)$ and fine scale hetero-specific plant density showed a negative influence on S. fascigera infestations in stems of S. lautus (Table 5.8).

Table 5.8: Anova summary for the complete LME for S. fascigera (sqrt-transformed) as response variable in stems of $S$. lautus. Site, quadrat and subquadrat were included as nested random effects.

\begin{tabular}{|c|c|c|c|c|c|}
\hline Predictor for S. fascigera in stems of SL & pos/neg & numDF & denDF & F-value & p-value \\
\hline plant size (log transformed) & + & 1 & 131 & 130.019 & $<.0001$ \\
\hline $\begin{array}{l}\text { fine scale density of } S \text {. lautus }(50 \mathrm{~cm} \text { log } \\
\text { (counts)) }\end{array}$ & - & 1 & 131 & 17.477 & $<.0001$ \\
\hline $\begin{array}{l}\text { coarse scale density of } S \text {. lautus }(6 \mathrm{~m} \text { log } \\
\text { (counts)) }\end{array}$ & + & 1 & 105 & 0.204 & 0.653 \\
\hline $\begin{array}{l}\text { fine scale density of } S \text {. elegans }(50 \mathrm{~cm} \text { log } \\
\text { (counts)) }\end{array}$ & - & 1 & 131 & 5.845 & 0.017 \\
\hline $\begin{array}{l}\text { coarse scale density of } S \text {. elegans ( } 6 \mathrm{~m} \text { log } \\
\text { (counts)) }\end{array}$ & + & 1 & 105 & 0.057 & 0.812 \\
\hline
\end{tabular}

The model for S. fascigera in S. elegans stems did not have enough data for sufficient further analysis and the model for $P$. farinaria on $S$. lautus plants did not provide a good enough sample size for further analysis. 


\subsubsection{Plant density experiment}

\section{Species linkages}

\section{Density experiment}

The linkages expressed for the natural surveys between the focal plant species and the insect herbivores were mostly the same for the experimental setup, but less frequently recorded (Table 5.4).

\section{Species linkage-strengths}

The quantitative food web (Fig. 5.17) shows the interactions strengths (i.e. the number of associations between one plant species and one insect herbivore) between $S$. fascigera in stems, S. fascigera in flowers, Patagonoides farinaria, cecidomyiid larvae, Nyctemera annulata, leaf rollers (Lepidoptera), and Chromatomyia syngenesiae on $S$. elegans, S. lautus and S. skirrhodon. Both S. lautus and S. skirrhodon show more associations compared to S. elegans. However, the introduced dipteran leaf miner fly was most often observed on S. elegans, followed by S. lautus and S. skirrhodon. Sphenella fascigera in flowers was more often observed on S. lautus, followed by $S$. skirrhodon and S. elegans. 


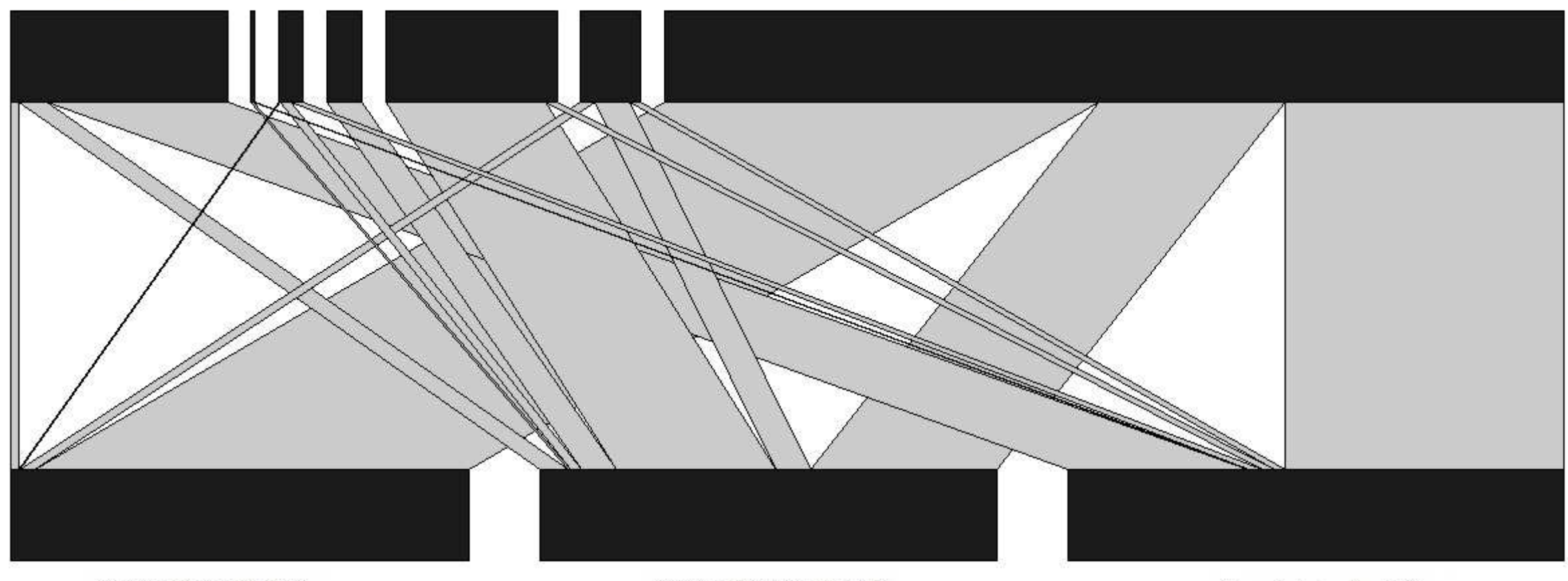

Senecio lautus $(n=172)$

Figure 5.17: Quantitative food web showing the observed interactions of both monitoring rounds of the experiment. 
Insect herbivore associations showed seasonality: in the first monitoring round in early December 2011 (approximately one month after planting) C. syngenesiae was the most frequently recorded insect herbivore compared to the second monitoring where it was only recorded a few times. The Kruskall-Wallis test showed no significant differences between Senecio spp. (Table 5.9) when $C$. syngenesiae was the dependent variable. The Kruskall-Wallis test further showed significant differences between host plant infestations for all three Senecio spp. and for numbers of leaf rollers, lepidopteran larvae, and aphids (Fig. 5.18 and Table 5.9).

Table 5.9: Kruskal-Wallis rank sum test for numbers of insect herbivores vs. Senecio species on the first monitoring round (one month after planting).

\begin{tabular}{llll}
\hline Insect versus Senecio species & chi-squared & df & p-value \\
\hline C. syngenesiae & 6.392 & 2 & 0.041 \\
leafroller & 6.544 & 2 & 0.379 \\
lepidopteran larvae & 9.709 & 2 & 0.008 \\
aphids & 11.837 & 2 & 0.003 \\
\hline
\end{tabular}


Leaf infestation with Chromatomyia syngenesiae

Leaf infestation with leafrollers

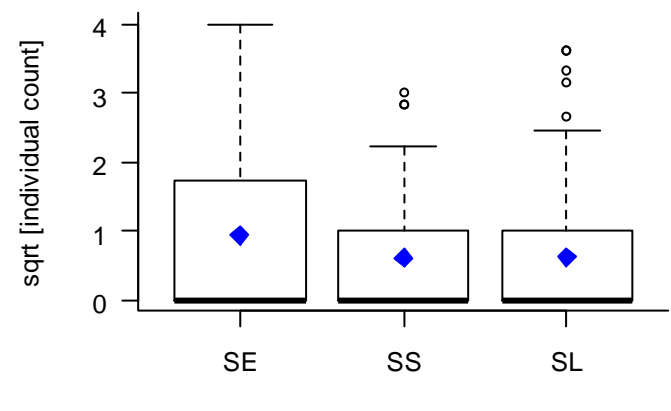

Senecio species

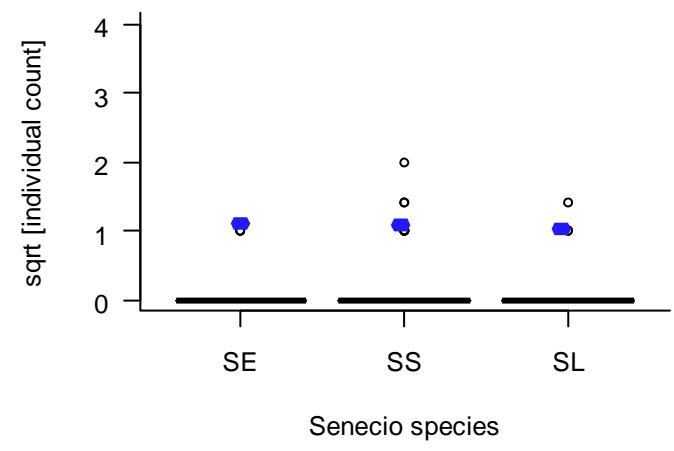

Lepidopteran larvae

Plants with aphids
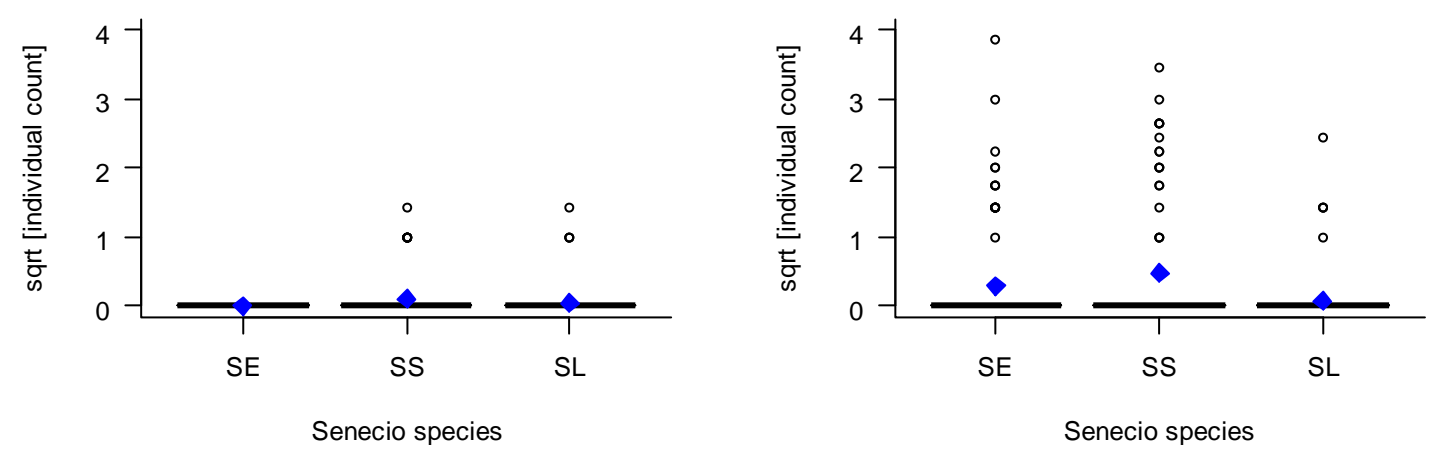

Figure 5.18: Species interaction linkage strengths: $x$-axis displays first monitoring round on Senecio spp.transects ( $\mathrm{SE}=$ S. elegans, $\mathrm{SS}=\mathrm{S}$. skirrhodon, $\mathrm{SL}=\mathrm{S}$. lautus), y-axis displays the squareroot transformed individual counts of the insect herbivore (clockwise: Chromatomyia syngenesiae, leaf rollers, lepidopteran larvae and aphids. Blue diamonds = mean values $\pm \mathrm{SE}$ ).

The second monitoring round took place in early January 2011, two months after all plants were planted. The second monitoring data set showed significant differences between host plant choice of $S$. fascigera in flowers and for lepidopteran larvae (Fig. 5.19 and Table 5.10).

No other associations were significant when tested with the Kruskall-Wallis test (Table 5.10). 
Table 5.10: Kruskal-Wallis rank sum test for insect herbivores vs. Senecio species on the second monitoring round in January.

\begin{tabular}{lllr}
\hline Insect versus Senecio species & chi-squared & df & p-value \\
\hline C. syngenesiae & 2.387 & 2 & 0.303 \\
leafroller & 1.147 & 2 & 0.564 \\
lepidopteran larvae & 30.749 & 2 & $<0.000$ \\
aphids & 1.466 & 2 & 0.481 \\
S. fascigera in flower heads & 61.269 & 2 & $<0.000$ \\
S. fascigera in stems & 2.387 & 2 & 0.303 \\
\hline
\end{tabular}

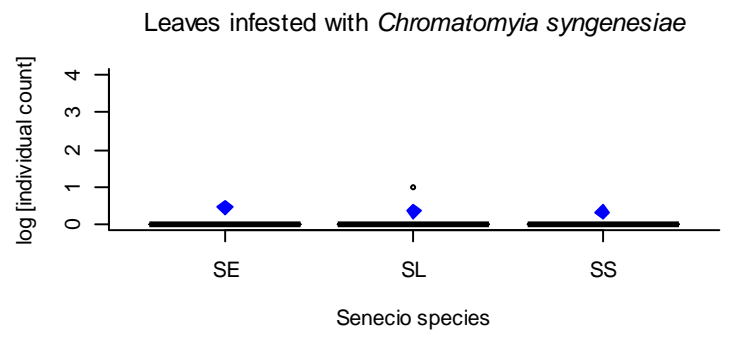

Lepidopteran larvae

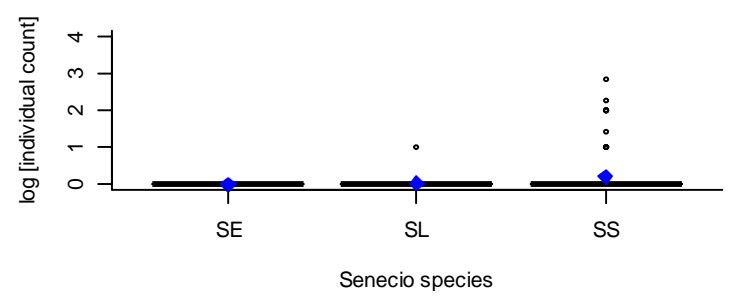

Flowers with S.fascigera

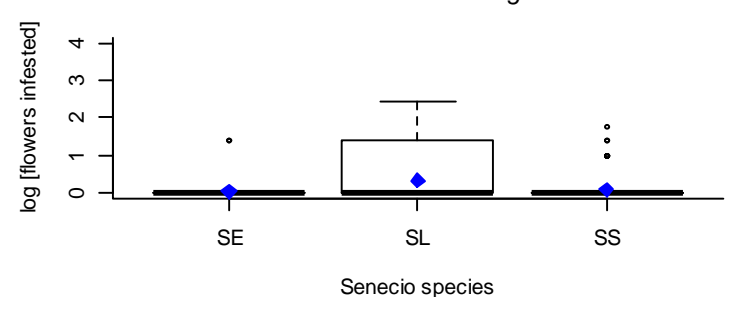

Leaves infested with leafrollers

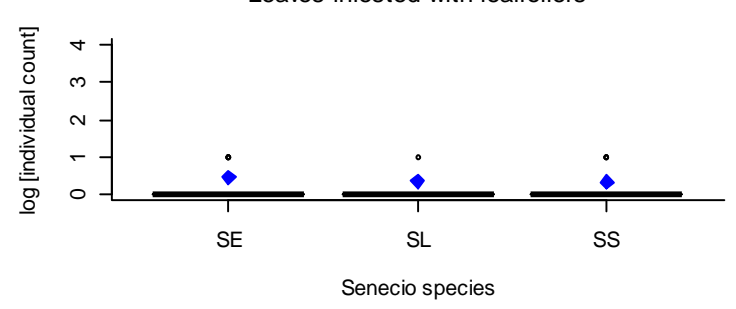

Plants with aphids

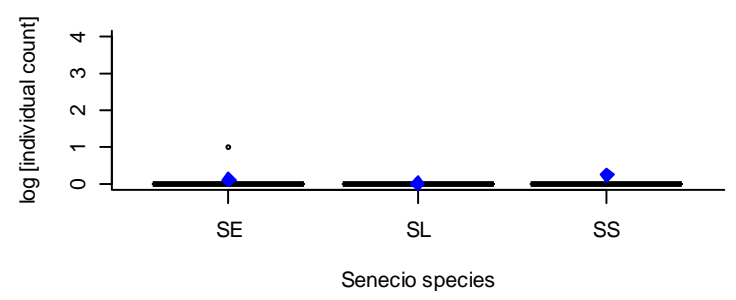

Stems with S.fascigera

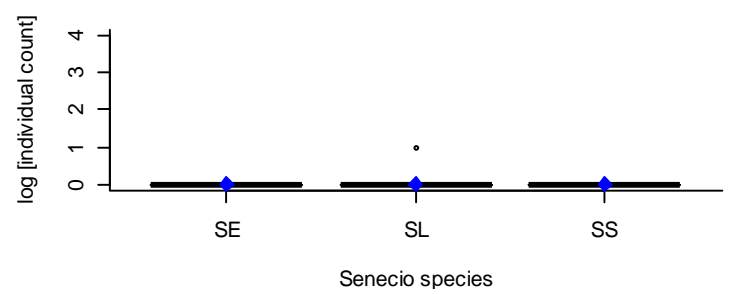

Figure 5.19: Species interaction linkage strengths: $x$-axis displays second monitoring round on Senecio spp.-transects (S E= S. elegans, SS = S. skirrhodon, $\mathrm{SL}=$ S. lautus), y-axis displays the sqrt-transformed individual counts of the insect herbivore (clockwise: Chromatomyia syngenesiae, leaf rollers, lepidopteran, aphids, flowers with $S$. fascigera and stems with $S$. fascigera. Blue diamonds = mean values $\pm \mathrm{SE})$. 
Plant morphology and insect herbivore host plant choice

Plant size showed a significant positive influence on $C$. syngenesiae infestations on all Senecio spp. observed (Fig. 5.20). The effect was significant for S. elegans (Fig 5.20c) in the first repetition.

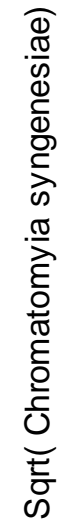

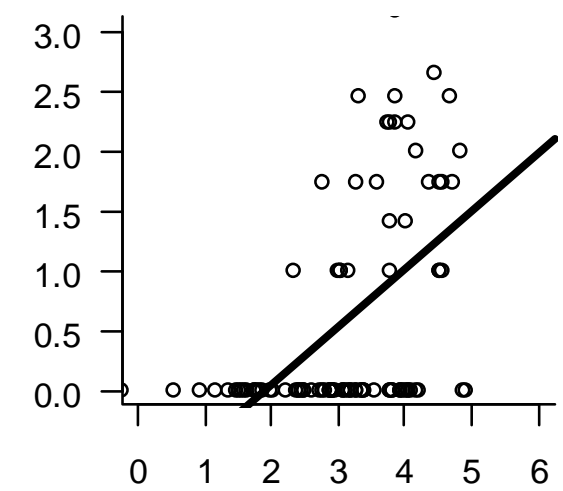

$\log [\mathrm{S}$. lautus plant size] $(\mathrm{cm})$

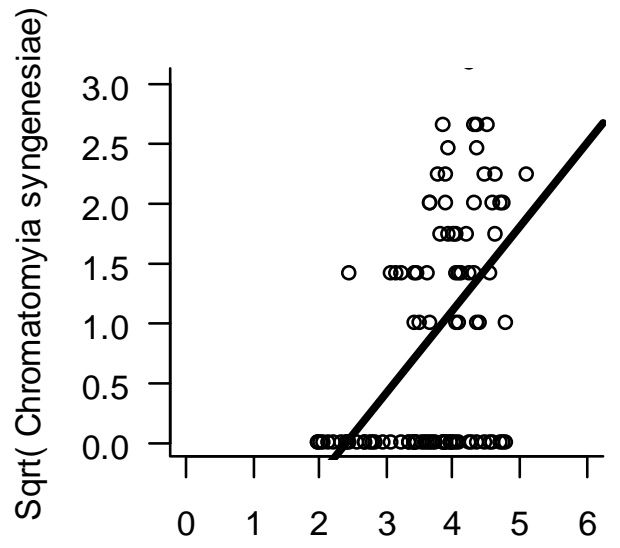

$\log [$ S. elegans plant size] $(\mathrm{cm})$

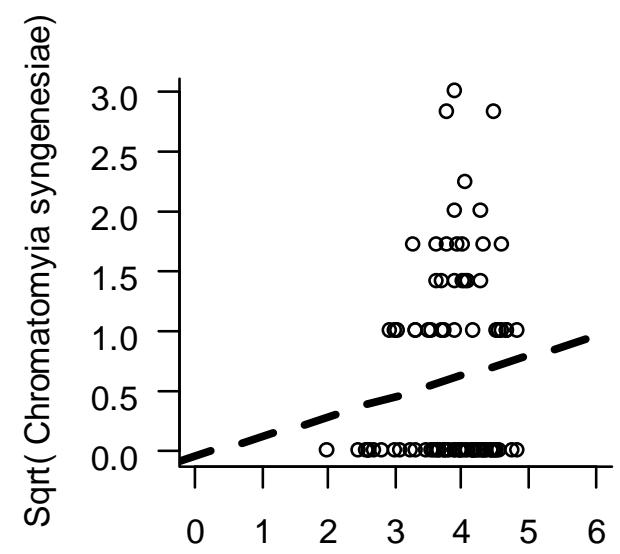

$\log [$ S. skirrhodon plant size] $(\mathrm{cm})$

Figure 5.20a-c: Chromatogmyia syngenesiae (sqrt-transformed) and plant size (log-transformed) from the first monitoring round (one month after planting). The fitted line shows the simple linear model of Chromatogmyia syngenesiae as the response variable with the associated density count as the only predictor. Solid lines show a significant relationship in the simple linear model, dashed lines show that the predictor was not significant. 
Within the second repetition, plant size showed a significant positive influence on $S$. fascigera infestations in flower heads on S. lautus and S. skirrhodon (Fig. 5.21). For S. elegans there was no significant effect of plant size on S. fascigera infestations detected (Fig. 5.21).

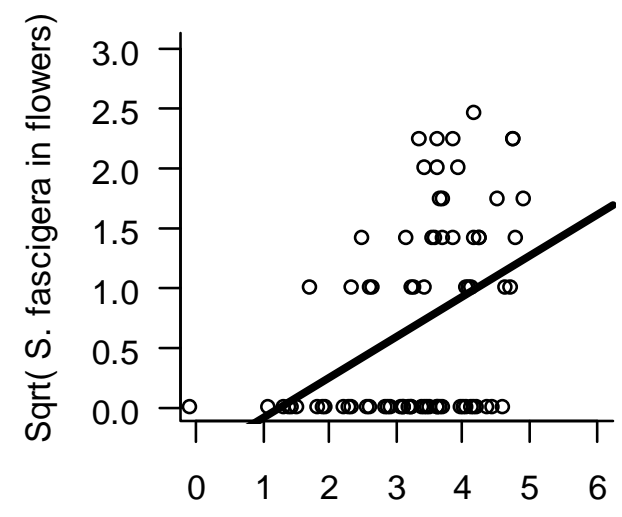

$\log [\mathrm{S}$. lautus plant size] $(\mathrm{cm})$

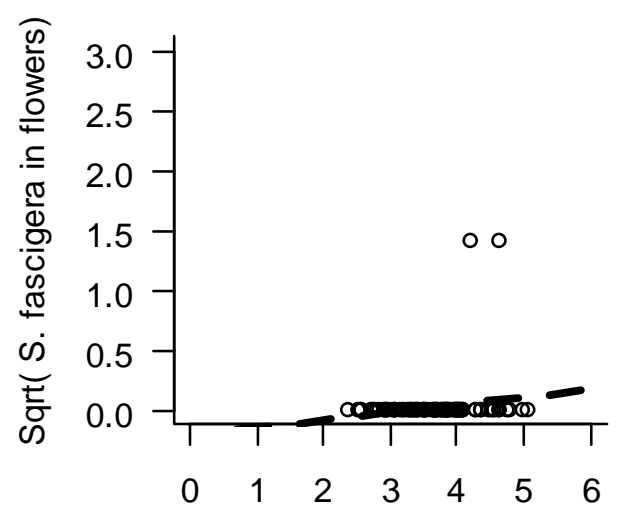

$\log [$ S. elegans plant size] $(\mathrm{cm})$

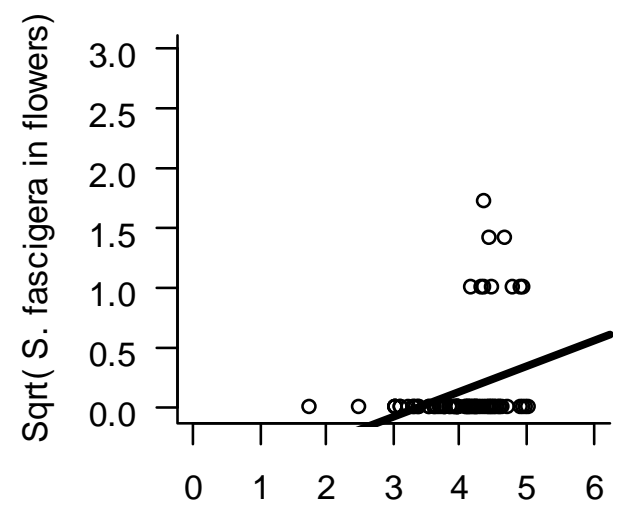

$\log [$ S. skirrhodon plant size] $(\mathrm{cm})$

Figure 5.21 a-c: Second repetition (monitoring after 2 months): Sphenella fascigera in flowers and plant size of $S$. lautus, S. elegans and S. skirrhodon. The fitted line shows the simple linear model of Sphenella fascigera in flowers as the response variable with the associated density count as the only predictor. Solid lines show a significant relationship in the simple linear model, dashed lines show that the predictor was not significant. 


\section{Other plant variables measured}

Largest leaf size varied significantly between plant species (Kruskal-Wallis test: chisquared $=170.4658, \mathrm{df}=2, \mathrm{p}$-value $<0.0001)$ and showed highest values for $S$. elegans, second highest for S. sterquilinus and third highest for S. lautus. No measurements were available for S. skirrhodon. Feeding damage and fungi infestation out of 10 leaves differed significantly (Table 5.11) between Senecio spp. S. skirrhodon and S. lautus showed the highest values for feeding damage and S. lautus showed the highest values for fungi (Fig.5.22).

Table 5.11: Kruskal Wallis rank sum test for feeding damage, health stress and fungi infestation out of 10 leaves.

\begin{tabular}{lccc}
\hline Variable versus Senecio species & chi-squared & df & p-value \\
\hline Feeding damage & 93.742 & 2 & $<0.0001$ \\
Health stress & 5.5272 & 2 & 0.063 \\
Fungi infestation & 22.635 & 2 & $<0.0001$ \\
\hline
\end{tabular}

I found the lowest discoloured leaf numbers on S. skirrhodon (Fig. 5.22). 

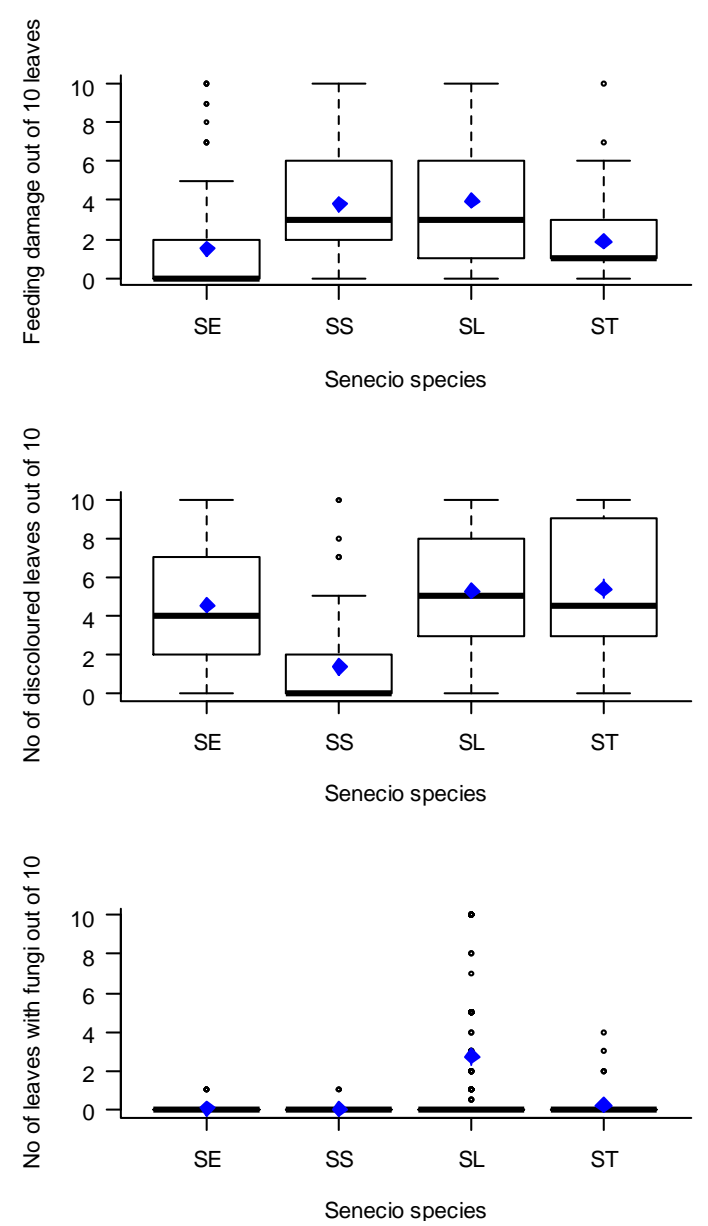

Figure 5.22: Feeding damage (upper graph), plant stress (discolouration of leaves) and leaves with fungi out of 10 leaves are shown per Senecio species. 


\subsubsection{Plant size, plant density and insect herbivore host plant choice}

No significant effect of conspecific plant density was detected for $C$. syngenesiae for $S$. lautus, S. elegans and S. skirrhodon (Fig. 5.23 and Table 5.12). Plant data were too scarce to analyse congeneric influence on the focal plant species per species. Therefore data were pooled and analysed with two congeneric species for each focal plant. However, there was no significant effect of congeneric density for $C$. syngenesiae numbers per plant for any of the plant species (Fig. 5.23 and Table 5.12). However, plant size was a significant positive predictor of $C$. syngenesiae counts on $S$. lautus $\left(F_{1,52}=34.160, p<\right.$ 0.001) (Table 5.12).

Table 5.12: Anova summary for the complete LME for $C$. syngenesiae (doublesqrt-transformed) as the response variable in stems of $S$. elegans. Transect and units were included as nested random effects. Congeneric density refers to $S$. skirrhodon and S. lautus counts (log-transformed).

\begin{tabular}{lllll}
\hline Predictor for $C$. syngenesiae & numDF & denDF & F-value & p-value \\
\hline Plant size $(\log )$ & 1 & 52 & 34.160 & $<.0001$ \\
Conspecific density $(\log )$ & 1 & 36 & 0.298 & 0.589 \\
Heterospecific density $(\log )$ & 1 & 36 & 0.019 & 0.890 \\
\hline
\end{tabular}




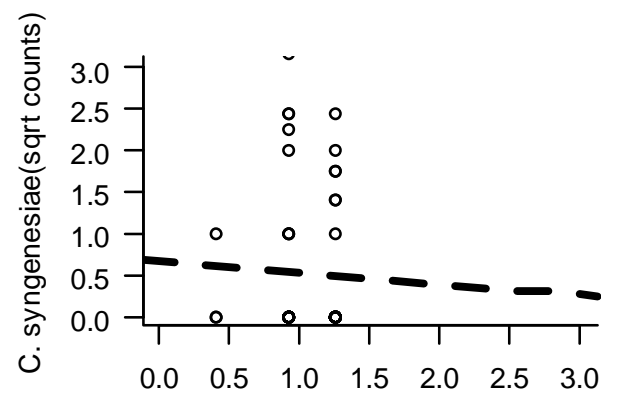

Conspecific counts of SL (log)

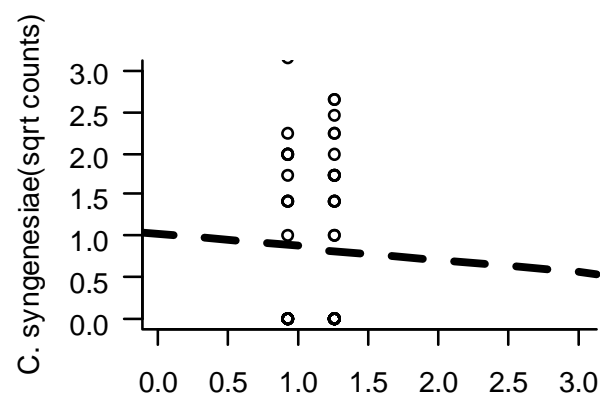

Conspecific counts of SE (log)

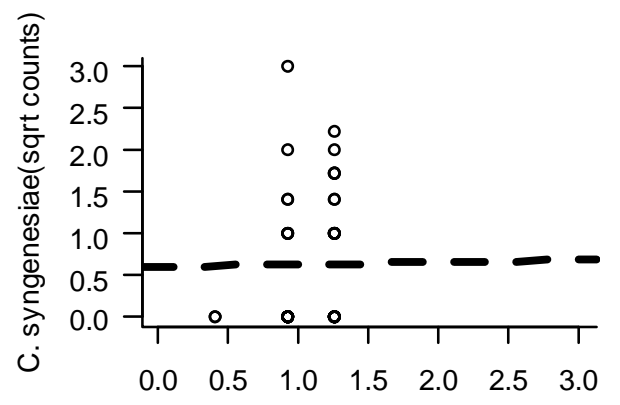

Conspecific counts of SS (log)

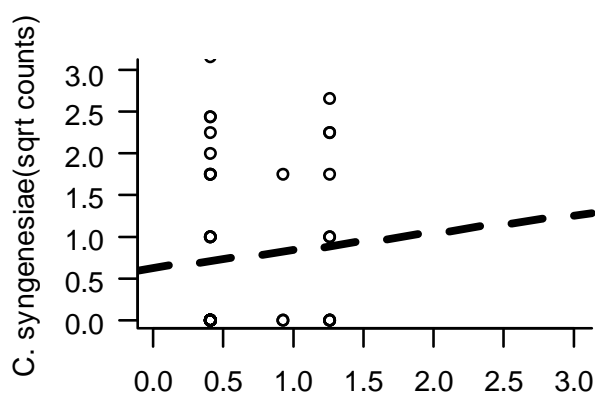

Congeneric counts of SL (log)

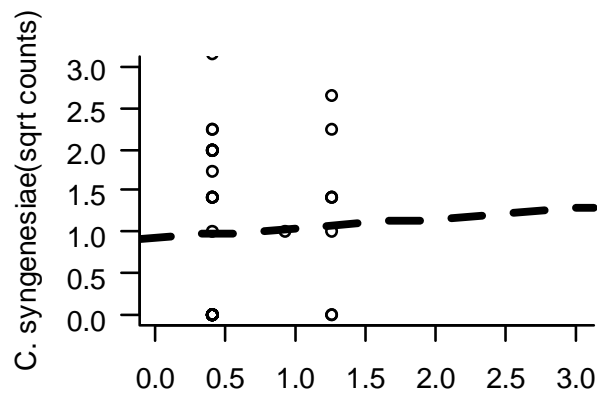

Congeneric counts of SE (log)

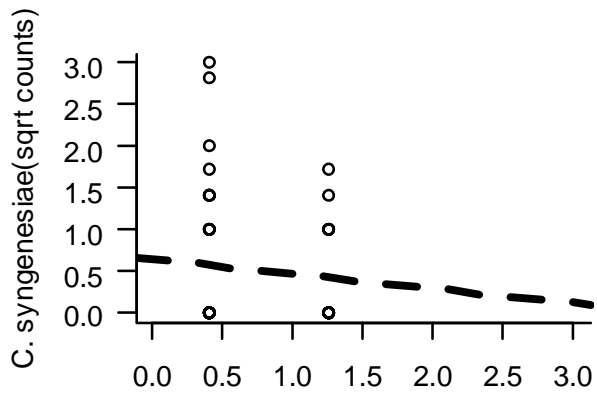

Congeneric counts of SS (log)

Figure 5.23a-c: $C$. syngenesiae in flowers and plant counts of S. lautus, S. elegans and S. skirrhodon for dataset one month after planting. The fitted line shows the simple linear model of $C$. syngenesiae as the response variable with the associated conspecific and congeneric (= heterospecific) density (includes all other Senecio spp. other than focal plant count as the only predictor). Solid lines show a significant relationship in the simple linear model, dashed lines show that the predictor was not significant. 
Conspecific density: Flowers with S.fasicgera

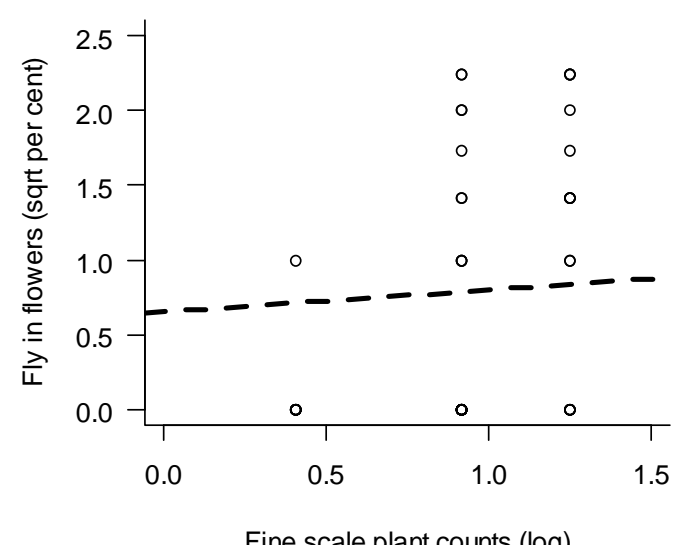

Fine scale plant counts (log)
Heterospecific density: Flowers with S.fasicgera

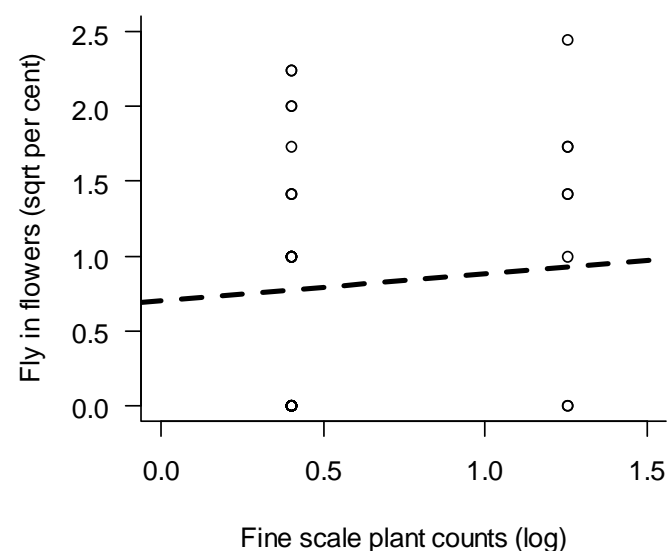

Figure 5.24: Second repetition (monitoring after 2 months): Sphenella fascigera in flowers of S. lautus and conspecific density of $S$. lautus (left) and congeneric density of S. elegans (right). The fitted line shows the simple linear model of Sphenella fascigera in flowers as the response variable with the associated density count as the only predictor. Solid lines show a significant relationship in the simple linear model, dashed lines show that the predictor was not significant. 


\subsubsection{Other plant densities and insect herbivore host plant choice}

C. syngenesiae infestation numbers were not significantly affected by surrounding Asteraceae with regards to any of the Senecio spp. Fig. 5.25 shows the effects of small and large Asteraceae within $50 \mathrm{~cm}$ radius of the focal plants, as well as of small and large other plants.

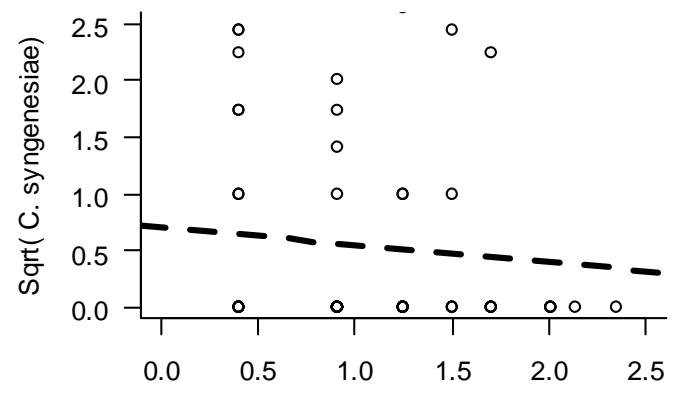

$\log [$ Fine scale density of small asteraceas] $(\mathrm{cm})$

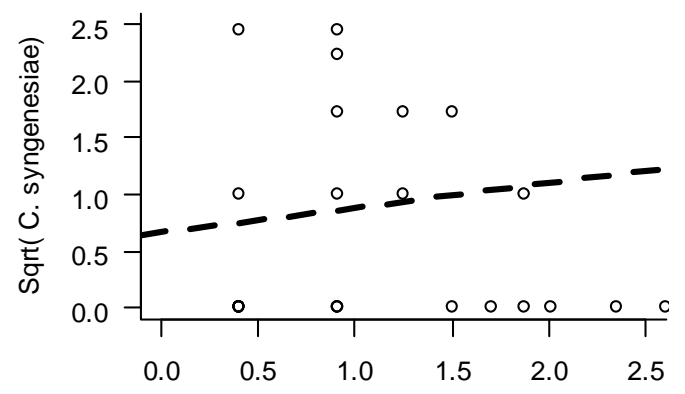

$\log [$ Fine scale density of other small plants] $(\mathrm{cm})$

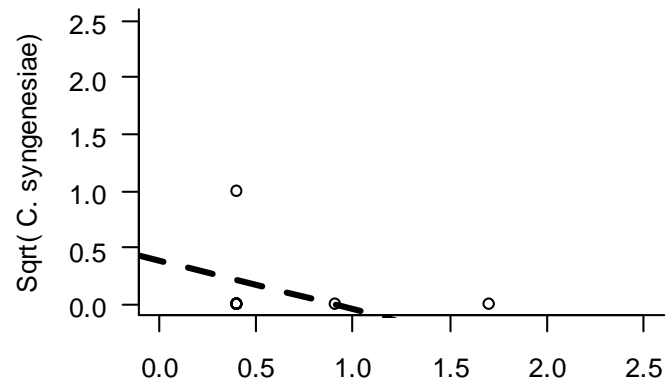

$\log [$ Fine scale density of large asteraceas] $(\mathrm{cm})$

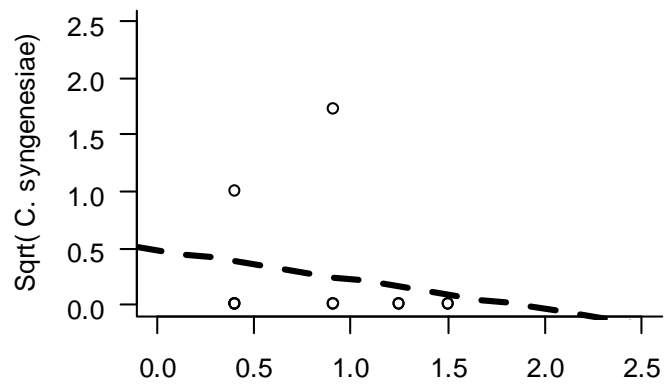

$\log [$ Fine scale density of other large plants] $(\mathrm{cm})$

Figure 5.25 a-c: $C$. syngenesiae in flowers and plant counts of $S$. lautus for the first repetition. The fitted line shows the simple linear model of $C$. syngenesiae as the response variable with the associated density of small Asteraceae, large Asteraceae, small other plants and large other plants. Solide lines show a significant relationship in the simple linear model, dashed lines show that the predictor was not significant. 
Sphenella fascigera infestations of flower heads of S. lautus were significantly positively influenced by the presence of large Asteraceae within $50 \mathrm{~cm}$ of the focal plant in the simple linear model (Fig. 5.26). This effect however, was not significant in a LME.

The presence of small Asteraceae, small other plants and large other plants was neither significant in the simple model nor in the LME.

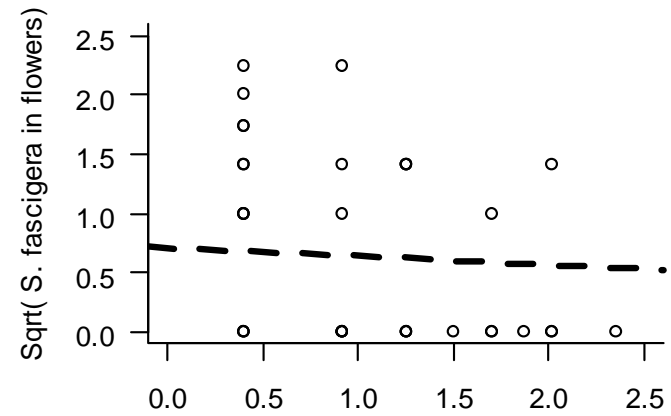

$\log [$ Fine scale density of small asteraceas] $(\mathrm{cm})$

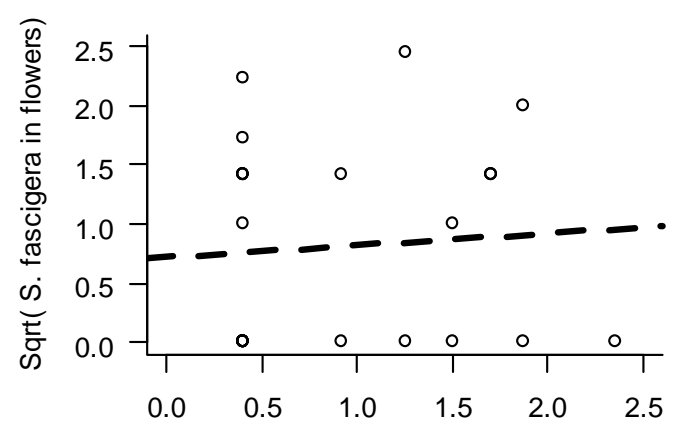

$\log [$ Fine scale density of other small plants] $(\mathrm{cm})$

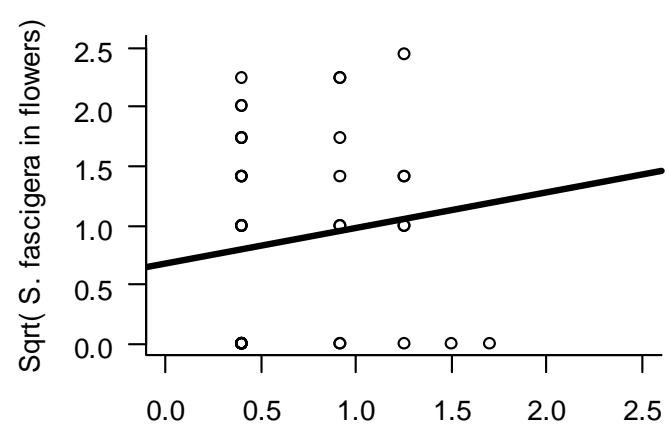

$\log [$ Fine scale density of large asteraceas] $(\mathrm{cm})$

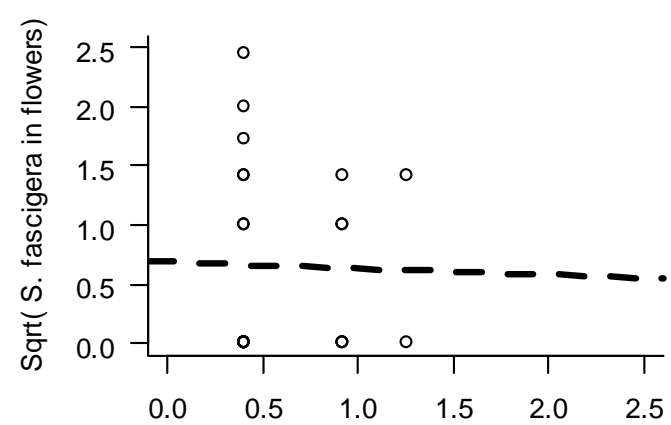

$\log [$ Fine scale density of other large plants] $(\mathrm{cm})$

Figure 5.26 a-c: Sphenella fascigera in flowers and plant counts of S. lautus for the second repetition. The fitted line shows the simple linear model of $S$. fascigera as the response variable with the associated density of small Asteraceae, large Asteraceae, small other plants and large other plants. Solid lines show a significant relationship in the simple linear model, dashed lines show that the predictor was not significant. 


\subsection{Discussion}

The natural survey and the experiment showed significant negative effects of conspecific and hetero-specific density for Senecio spp. colonization. Examining S. fascigera in the stems of S. lautus, fine scale conspecific density and hetero-specific density (S. elegans) showed a negative effect on insect abundance per plant. A trend for a negative effect of conspecific density was also evident for S. fascigera in flower heads of S. lautus. Plant size was a significant positive predictor of insect colonization. For all other insects encountered during the survey of naturally occurring populations, these effects were only significant in the simple linear model that did not consider the nestedness of the data given through multiple spatial scales. The manipulative field experiment supported the host choice preferences that the natural survey detected. It also provided some information on seasonal changes of insect colonization as leaf miners and aphids were encountered earlier in the season compared to stem borers and seed head predators, despite plants flowering for the entire duration of the experiment. Furthermore, the experiment supported the importance of plant size for insect herbivore host plant choice and provided empirical evidence for the importance of conspecific and heterospecific plant density despite a relatively small sample set.

My data showed the potential for indirect facilitation between native and introduced plants in the same genus through an influence on the colonisation rates of herbivorous insects i.e. hetero-specific densities affect insect abundance on focal plants. The resource concentration hypothesis $(\mathrm{RCH})$ predicts more specialised insect herbivores in dense plant patches compared to more isolated plants (Root 1973). In contrast, the resource dilution hypothesis (RDH) predicts higher herbivory on isolated plant patches (Otway et al. 2005). My data suggests support of the RDH opposed to the RCH, as insect herbivores showed a decrease in abundance when plant counts were higher at fine scales. Stephens and Myers (2012) demonstrated a more detrimental effect of insect herbivory when the RDH was supported, resulting in localized extinctions of plants. Field observations showed a high turnover of individual plants and very variable life spans suggesting this could also apply to coastal Senecio spp. The scale at which those patches were located is not specifically defined for the $\mathrm{RDH}$ or the $\mathrm{RCH}-\mathrm{I}$ chose a $50 \mathrm{~cm}$ radius 
circle (area $=0.8 \mathrm{~m}^{2}$ ) around the focal plant as fine plant density scale and a 6 metre quadrat as coarse plant scale $\left(32 \mathrm{~m}^{2}\right)$ - It remains possible that other patterns exist at different spatial scales compared to my study. Density of plants other than Senecio spp. did not significantly influence insect herbivore host plant choice. However, the dataset from the experiment was relatively small and it is possible that a larger sample size might provide significant results as the graphs indicated an interaction. Hambäck and Englund (2005) showed, with their revised model investigating the $\mathrm{RCH}$, that species identity and general search patterns for insects determine the host plant patch size and thus significantly aid in further enhancing our understanding of patch-density-insect herbivore density relationships. For New Zealand's coastal insect herbivores however, limited information is available and some species remain undescribed e.g. the cecidomyiidoyd fly larvae that I encountered in my surveys. Therefore my study contributes to the species knowledge as well as providing some insight into which spatial scales are important for host plant choice.

Plant size was a major predictor of insect colonization in addition to plant density. Consequently, I recorded more insect herbivores on bigger plants. Whether this is solely due to increased resource availability and a higher survival likelihood of the host plant and consequently the insect herbivores offspring, or whether the chemical defences of smaller plants are stronger remains unclear for my study organisms. While plant size might appear to be a trivial predictor, it has been shown to have a significant influence in insect herbivore host plant choice. For example Whitfeld et al. (2012) showed a positive influence of larger leaf biomass but a negative effect of tree size when they investigated tropical leaf miner host plant choice. Senecio spp. can vary in plant size from small prostrate flowering plants to large, almost bush-like plants (pers. observation). Plant size mattered more for $S$. fascigera in stems compared to S. fascigera in flowers. The size of flower heads varies between plants (pers. observation) but not as much as the plant size and thus the number of stems. Plant size can influence density dependent insect-herbivore-plant interactions where insect herbivores influence plant size and vice versa in interactions that are not currently well understood (Underwood and Halpern 2012). My data provide strong evidence that bigger plants are more attractive for insect herbivores. 
Phylogenetic distance was identified as one of the most important predictors for host plant choice in a review by Bertheau et al. (2010). Genetic analysis of the Australian $S$. lautus complex suggests that coastal Senecio spp. have evolved several times independently and further underlines the morphological plasticity of members of this species complex (Roda et al. 2013). Senecio glastifolius is in the New World clade of Senecio spp. (Pelser et al. 2007), while the focal species of my study are closely related to each other with the closest level of relatedness between hybridising S. lautus and $S$. sterquilinus (Ornduff 1964). Senecio elegans was shown to exhibit different plant chemical defences compared to S. skirrhodon and S. lautus, suggesting a more distant relationship compared to the relationship between S. lautus and S. skirrhodon (Wilcox 2012). Different ecotypes of a species might be able to support different insect herbivores. In my study I only considered field sites within Wellington to minimize geographic effects. However, Senecio spp. within the Wellington Region are relatively morphologically plastic (personal observation). McArt and Thaler (2013) were able to show that plant patches with a variety of different genotypes of a host plant showed increased abundance of an introduced herbivore but decreased the overall herbivore damage. It is not known if that could be the case for the investigated coastal Senecio spp., but remains a possible explanation for insect herbivore abundance.

Senecio lautus has the ability to develop heteroblastic leaves depending on exposure to environmental stress (Burns 2005). Leaf morphology could influence insect herbivore abundance, leaves with more surface area should be more attractive to leaf miners due to higher resource availability. It is possible that the introduced leaf miner $C$. syngenesiae was more frequently recorded on introduced $S$. elegans compared to $S$. skirrhodon or S. lautus, because S. elegans leaves show different morphological traits. They are frequently larger and contain different pyrrolizidine alkaloid concentrations (Wilcox 2012). However, the LME showed no significant effect of leaf size for leaf miner host plant choice - which is surprising given that any leaf miner larva, regardless of insect order, is dependent on the resources available from its leaf. However, I occasionally observed leaves with multiple leaf miners - suggesting that leaf size might not be as important as I originally assumed. Carrillo-Gavilán et al. (2012) found no support for the natural enemy hypothesis. In their study generalist herbivores did not discriminate 
between native and alien plants. C. syngenesiae is not Senecio spp. specific (Martin 2013) and thus fits the category of a relatively polyphagous species that is frequently recorded on other Asteraceae.

My results showed higher infestation rates for endemic S. fascigera and cecidomyiid fly larvae on the native Senecio species S. lautus and S. sterquilinus respectively, compared to introduced S. elegans and S. skirrhodon. This supports the findings of Fenner and Lee (2001) who compared seed head predators on Asteraceae in the UK and New Zealand and found that introduced Asteraceae were significantly less infested compared to native ones. Similarly, I found higher abundances for endemic cecidomyiid larvae on the native Senecio spp. (with only a few occasional observations on introduced Senecio spp.). In contrast to Waring (2010) who compared host choice of $N$. annulata of introduced and native Senecio spp. (but did not consider coastal Senecio spp. for his study) I recorded more lepidopteran larvae (mostly $N$. annulata) on introduced $S$. skirrhodon. One explanation for the different finding in my study could be that $N$. annulata, albeit specialising on Senecio spp., is recorded for all Senecio species investigated in my study and records exist across a wide range of Senecio spp. (see also Chapter 4). In addition, N. annulata caterpillars are highly mobile within Senecio spp. patches and change host plants when a previous host plant is grazed exhaustively and no longer sustains the food requirements of the caterpillar (pers. observation). Similarly, caterpillars let themselves fall off the leaves and curl up as a defence mechanism against predation (pers. observation). Sometimes, caterpillars change the host plant if suitable plants are in close proximity (approximately within $50 \mathrm{~cm}$ ) (pers. observation).

The higher abundances of cecidomyiid fly larvae and S. fascigera on S. sterquilinus opposed to S. lautus could be linked with S. sterquilinus' association with bird guano and therefore access to higher nutrient levels. Senecio sterquilinus is frequently described as a bigger plant than S. lautus (Webb et al. 1988). However, I could not support that with my own observations, as most S. sterquilinus plants I observed were of similar size to the S. lautus plants growing in close proximity with which it freely hybridises (Ornduff 1964). Nevertheless, when only morphological traits are considered, S. sterquilinus tends to have larger leaves and larger flower heads which were the main food sources of the 
investigated insect herbivores and thus could be an important difference for host choice. Senecio sterquilinus has a higher number of petals which might be linked to a higher number of inflorescences (due to the nature of the composed flower head as a member of the Asteracea plant family). Petal numbers are thought to be linked closely to seed packing within the flower head (numbers are according to Fibonacci) (Klar 2002). Therefore S. sterquilinus should be able to support more producing seeds per flower head than S. lautus. Ecological theory predicts plants with access to higher nutrient levels will tolerate higher rates of herbivory due to higher regeneration capabilities (i.e. context dependent defence) (Herms and Mattson 1992, Hendriks et al. 2009). High nutrient plants do not have to invest so much into plant volatiles as a defence mechanism because they can afford to lose plant tissue, as shown for cotton plants that invested less in plant volatiles when $\mathrm{N}$-fertilized (Chen and Schmelz 2008). Single records of S. sterquilinus infestations with both S. fascigera and cecidomyiid flies show the ability to support higher insect densities on smaller plants. These findings support the enemy release hypothesis (Keane and Crawley 2002), albeit without explicitly testing it (and only considering a few species), which predicts that introduced organisms escape their natural enemies in their new home ranges (White 2008). However, my results show that despite higher abundances and preferences for the native species, as in the case of $S$. fascigera and the cecidomyiid flies for native S. lautus and S. sterquilinus, both species have been recorded on the closely related introduced Senecio spp. This suggests either a possible host expansion, or early stages of a host shift by 'spill-over-effects'. Ultimately, host expansions might be a first step towards species radiation (Bennett and O'Grady 2012), shaping evolution according to the new species assemblages of introduced and native species with currently unpredictable consequences that merit further research.

Although it was beyond the scope of my study to look at fitness consequences into the next generation, the fact that $S$. fascigera consumes immature seeds suggests it will have a definite negative impact on lifetime reproductive success of the affected plant. Personal observations showed that plants in late summer can have larvae in almost every flower of a plant, reducing that plants seed production significantly. 
The apparent facilitation I was able to document for $S$. lautus when exposed to $S$. elegans on fine scales might be a short term effect. In the longer term extra S.elegans could help build up the population of $S$. fascigera thus increasing herbivore pressure on S. lautus. Modelling shows that a variety of population dynamics are possibly mediated through a shared herbivore (Schoolmaster 2008).

Despite not explicitly analysing direct effects of introduced Senecio spp. on native Senecio spp., the distribution of introduced coastal Senecio spp. suggests a direct competitive effect of the introduced species. I found only a few locations when searching for sites around Wellington where introduced and native Senecio spp. grew in direct proximity. Most beaches around Wellington are now dominated by either $S$. elegans or S. skirrhodon, one of the two introduced species, or either S. lautus and S. sterquilinus or one of the latter two, or their associated hybrids. My personal observations indicate that there might be direct competition between introduced and native Senecio spp. (see Fig. 5.27) that could potentially mitigate the positive effects I was able to demonstrate with this study. It will further enhance our understanding of interactions between members of a community to investigate direct competition between Senecios and apparent competition including a third trophic level (insect herbivore parasites). My additional chapter 7 provides some insights into the interactions between a previously unrecorded and thus undescribed parasitoid wasp and S. fascigera as host on S. lautus.

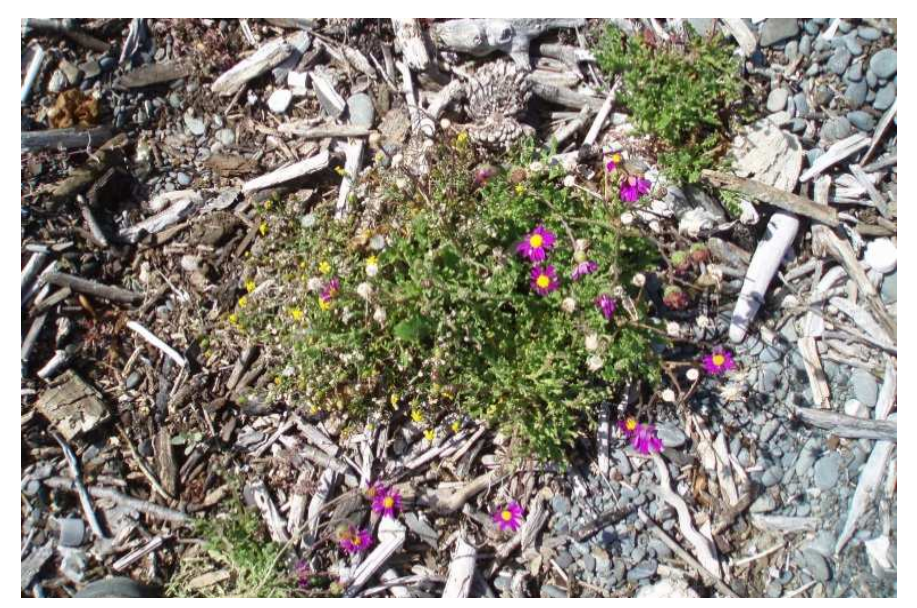

Figure 5.27: Possible direct competition between S. elegans (bottom left, middle and upper right) and $S$. lautus (only middle). 


\subsection{Conclusions}

My data have shown the importance of fine scale resource availability (host plants) for insect herbivores in coastal areas. Introduced species can have an apparent positive influence on the native species by mediating, on a small scale, the infestation of a native herbivore. However, despite a positive influence of the introduced Senecio on the focal native Senecio it is important to consider and quantify the long-term, population-level outcome of the interactions between the introduced and native species to predict future distributions and effects on the native plant and insect community. 
CHAPTER 5 


\section{CHAPTER 6}

\section{Summary and general discussion}

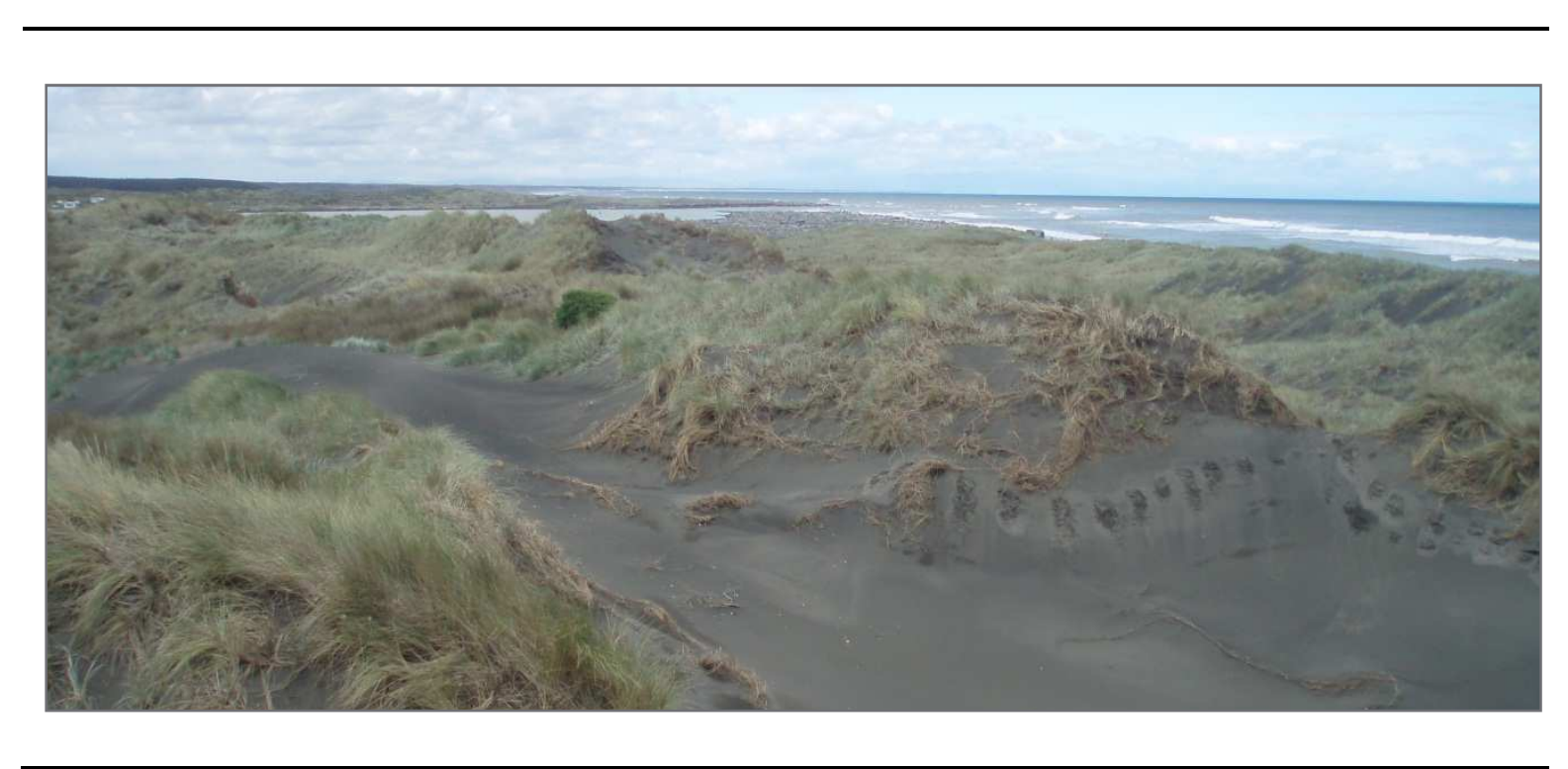

Dune field at Whitiau, West Coast, Lower North Island, NZ. 


\subsection{Outline of thesis}

My thesis compared two examples of interactions between native and introduced plants that occur sympatrically in New Zealand's coastal ecosystems. First, I investigated the direct competitive and facilitative effects of native and introduced grass species in a coastal sand dune environment examined in the context of the stress gradient hypothesis and whether the balance between competition and facilitation varied along an environmental gradient. Second, I undertook an investigation of indirect competition (apparent competition) between native and introduced Senecio spp. plants and their insect herbivores in a coastal environment to determine support for the resource dilution hypothesis which predicts higher insect herbivore numbers on isolated resource patches.

A summary of these two components is provided in this chapter followed by consideration of the biotic interactions and spatial scales involved. Finally, implications relevant to Coast Care group and coastal managing agencies for conservation and dune management of marram-dominated dunes and for the management of invasive weeds (such as Senecio spp.) on coastal dunes are discussed.

\subsection{Direct competition-vs- facilitation and the stress gradient hypothesis}

My thesis aimed to investigate direct and indirect competition of native and introduced species in coastal habitats. I researched direct competition by investigating the interaction between the common native sand binder grass spinifex (Spinifex sericeus) and the invasive sand binder marram grass (Ammophila arenaria) along an abiotic stress gradient determined by wind, sand movement, salt exposure, soil development and the topography of dunes. My experiment also had a conservation angle: to investigate the best method to convert marram-dominated dunes back to native spinifex dominated dunes in exposed sites while retaining some ground cover during the restoration process. My volunteers and I planted 
2475 spinifex seedlings in bare sand, live marram and herbicide-sprayed, dead marram grass over three locations (stations) at fore dunes, mid dunes and back dunes over 11 transects at two field sites. Performance of spinifex plant growth was monitored to assess the best restoration option and to test if the predictions of the stress gradient hypothesis apply (Chapter 2). Survival did not differ significantly between treatments but growth was better in sprayed marram plots closer to the sea at one field site compared to plantings further inland. This suggested a facilitative interaction between live spinifex and dead marram at the most seaward sites where stress was most severe compared to a more competitive interaction further inland. Consequently, the spinifex growth data supports the stress gradient hypothesis and thus showed better facilitation at the more seaward sprayed plots. However, apart from growth measurements my experiment did not provide support for the SGH. In addition to the effect of herbicide treatment, the initial cover of marram grass prior to spraying was a significant predictor of spinifex growth, with reduced growth of spinifex in plots that had a dense initial marram grass cover.

I also investigated the population dynamics of self-colonizing species at the same plots described above with and without plantings (Chapter 3 ). Most of the species I encountered were introduced pasture weeds and did not follow the pattern expected by the SGH over the environmental gradient, occurring along the length of each transect. The exotic coastal species Senecio elegans is not associated in its parts of its home range with marram grass and hence is not especially adapted to growing amongst it. Senecio elegans was the only plant that was facilitated by sprayed marram grass closest to the sea compared to live marram grass and also had higher abundance in sprayed marram grass plots compared to bare sand plots closer to the sea compared to plots further inland. Generally, most other weeds were facilitated by sprayed marram grass in a similar manner but they did not show a pattern as expected by the SGH. From a practical management point of view, planting into sprayed dead marram grass is therefore only worth the extra effort if the site is not weed-prone as growth of other introduced species are facilitated in the same manner as spinifex. 


\subsection{Indirect competition and the resource dilution hypothesis}

I researched indirect competition (apparent competition) between native and introduced plants and their insect herbivores. I started by reviewing current knowledge about native and introduced Senecio spp. as well as associated native and introduced insect herbivore food webs in New Zealand (Chapter 4). Surprisingly, there were few documented associations to allow comparison of my studies to Senecio spp.-insect associations elsewhere. My review showed no significant differences for the likelihood of non-native insects colonizing native or introduced plants. Most interactions recorded were leaf miners (both Lepidopteran and Dipteran) as well as other native and introduced Lepidoptera. Consequently, I chose coastal Senecio species to conduct my own Senecio spp.-insect food web surveys (Chapter 5). Here I was particularly interested in how colonisation of plants by insect herbivores was affected by the fine- and coarse-scale density of conspecific and heterospecific Senecio spp. and plant morphology. My results showed that insect herbivores favoured larger plants. Furthermore, a significant negative influence of conspecific and heterospecific plant density measured at the fine scale influenced host plant choice. Thus, high densities of introduced S. elegans in close proximity to a native $S$. lautus reduced the colonisation rate of the tephritid fly, $S$. fascigera, on to $S$. lautus. These results were confirmed in a field experiment where I manipulated plant densities between introduced S. elegans, S. skirrhodon and native S. lautus. These results support the resource dilution hypothesis which predicts higher insect herbivore numbers on isolated resource patches. Furthermore, my results also provide empirical evidence for a situation which may result in apparent facilitation of a native plant by an introduced plant "diverting away" the impacts of a shared herbivore. Taking biotic and abiotic influences into consideration, the implications from my study for conservation efforts on coastal dunes are that the net outcome of direct and indirect interactions is important to assess and mitigate the influence of an introduced species. I did not directly measure the impact of $S$. fascigera on Senecio spp. fitness. However, this insect herbivore feeds on immature seeds and plants in late summer are heavily infested (some plants have all flowers and stems colonized by S. fascigera). This strongly 
suggests a negative impact on lifetime reproduction success. Consequently, the apparent facilitation of $S$. lautus by $S$. elegans could be a short term effect. In the long term S. elegans could help to build up $S$. fascigera populations as it is an alternative host already and thus increase the herbivore pressure on S. lautus. Modelling shows that a variety of population dynamics are possible mediated through a shared herbivore (Schoolmaster 2008).

\section{Biotic interactions and spatial scales}

Recent research has emphasized the need to identify and quantify the effects of direct positive and negative interactions between species interactions. This includes considering both indirect positive and negative interactions between species simultaneously under varying abiotic conditions (e.g. Callaway and Walker 1997, Chaneton et al. 2010, Atwater et al. 2011, Lutscher and Iljon 2013). My research showed direct facilitative effects when spinifex seedlings are planted within sprayed marram grass. In effect, the dead marram grass exhibited a nurse plant effect (e.g. Franco and Nobel 1988, Franco et al. 1989) thus supporting the stress gradient hypothesis for spinifex growth only (Bertness and Callaway 1994). Indirect positive or negative effects are an important aspect of analysing the net-outcome of the SGH (e.g. (Malkinson and Tielbörger 2010). Weeds were facilitated by the protective effects of sprayed marram grass in the same manner as the growth of planted spinifex was enhanced. This indicates an indirect negative effect of sprayed marram grass on spinifex where, if present, weed species can become dominant at the expense of spinifex.

Senecio elegans, as one of the focal introduced plant species for my food web research, profited from facilitation provided by sprayed marram grass. It also exhibited a negative influence on insect herbivore colonization of native S. lautus. Unfortunately, it was not possible to test the stress gradient hypothesis and research the indirect effects of S. elegans on S. lautus simultaneously, as S. lautus was not present at any of the dune restoration experimental sites. In addition, the 
coastal sites used for the experiment of Chapter 5 were not sufficiently wide to provide a seaward to inland gradient to explore the SGH. However, it would be very interesting to research the net outcome of these direct and indirect interactions in a single model incorporating all species within a coastal community. While it would also be valuable to incorporate a third trophic species to further untangle food web interactions of Senecio spp., the data on introduced Senecio spp. at my study sites was too sparse for an analysis of parasitoid-insect herbivore interactions. Consequently, I focused on population dynamics and different density scales of the most common parasitoid (Pteromalus sp) found parasitizing Sphnella fascigera in Senecio lautus (Additional Chapter 7 in Appendix I page 209).

Figure 6.1 shows a summary of the interactions I researched with my thesis. Many more interactions are possible, but were beyond the scope of my study. In summary, abiotic and biotic factors (albeit these were not considered in my study) have both positive and negative direct effects on live and sprayed marram, which also positively and negatively impacts other investigated species (both blue and red arrows). Sprayed marram grass has a direct positive interaction with spinifex, introduced S. elegans and other plants. The Senecio species shows a positive direct effect on insect herbivores. Exotic $S$. elegans exhibits an indirect negative interaction on spinifex. 


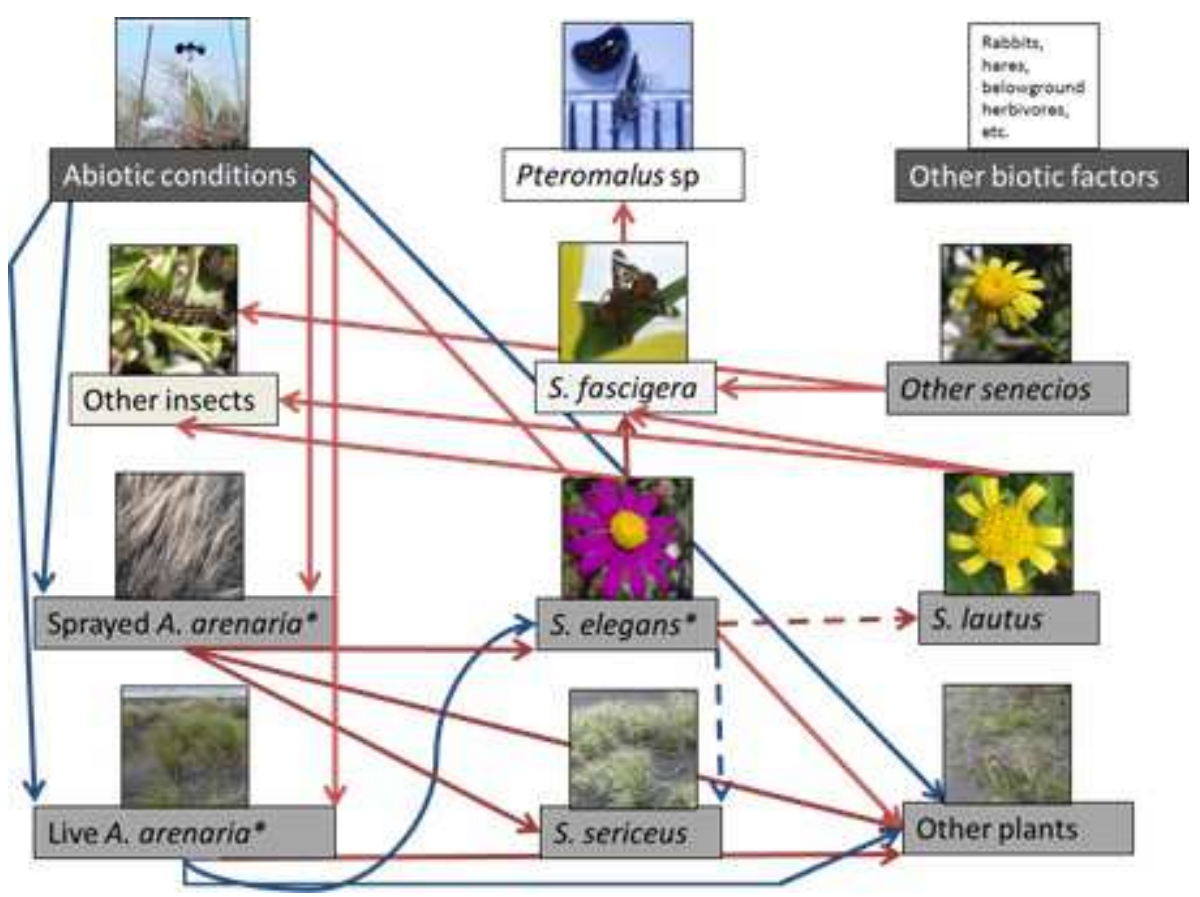

Figure 6.1: Interactions of my research: Blue arrows = negative direct interaction, red arrows = positive direct interaction, blue dashed arrow = indirect negative interaction, red dashed arrow = indirect positive interaction. Interactions that were not researched, but are assumed are not shown in the graph. Other abiotic factors were not incorporated in my study (except for browsing monitoring), but are probably exhibiting both direct and indirect effects on coastal sand dune communities.

Abiotic and biotic interactions take place at different spatial scales (e.g. Forey et al. 2009 for local and regional scales, Carranza et al. 2010 for landscape sale patterns, and a range of scales in Maltez-Mouro et al. 2010). My research considered two different spatial scales (i.e. fine scale plant density (= plants within $50 \mathrm{~cm}$, area $=$ $0.785 \mathrm{~m}^{2}$ ) and coarse scale plant density (= plants in a six metre square annulus, area $=32 \mathrm{~m}^{2}$ ) for the interactions between Senecio spp. and their insect herbivores which are not incorporated in this simplified model of Fig. 6.1. Stress gradient hypothesis interactions appear to depend on species identity. This dependence was emphasized in recent research where severely stressful conditions were found to diminish facilitative interactions usually expected by the SGH (Maestre et al. 2009). Similarly, the spatial scale at which insect herbivores are affected by host plant densities varies according to species or animal class (Hambäck and Englund 2005). It is possible, that my surveys and experiments did not comprise the full stress gradient and range of spatial scale at which these interactions occur. In particular 
for the SGH this could be the case as some of the weed species were not especially adapted to coastal conditions and hence might not have been able to persist at most seaward locations that were incorporated in my transect layout. Consequently, these weeds might follow the pattern expected by the SGH if a gradient that goes even further inland is considered.

\subsection{Contribution to current knowledge}

Most research on interactions between species along a stress gradient has focused on pairwise interactions using mostly native species (e.g. Le Roux and McGeoch 2010). There have been a few exceptions where entire communities have been studied along an environmental gradient (e.g. Armas et al. 2011) including where invasive species have been present (e.g. Santoro et al. 2012, Mason et al. 2012). My research demonstrates the complexity of interactions in a relatively species-poor, but highly dynamic temperate coastal dune system. Spinifex plant growth and colonisation of plots by the introduced S. elegans ) at one field site supported the stress gradient hypothesis (SGH, which predicts more facilitative interactions where stress is severe and more competitive interactions where stress is less severe (Bertness and Callaway 1994, Callaway and Walker 1997, Lortie and Callaway 2006, Brooker et al. 2007, Maestre et al. 2009).

It is often noted that native species persist for a long time (longer than expected) within patches of introduced plants before eventual out-competition (Atwater et al. 2011, Zarnetske et al. 2013). My results support this assumption, as spinifex was able to survive in live marram throughout the duration of the experiment (Chapter 2) despite very limited growth, possibly due to its better tolerance to salt spray at fore dunes. Nevertheless other studies have shown that in most situations native sand binders will eventually be eliminated at the site through the better introduced competitor (e.g. Hilton et al. 2005 for Ficinia spiralis). Intervention is therefore required to ensure native sand binders planted in invaded dunes will not eventually succumb to the competitive effects of the more aggressive marram grass. The 
sprayed marram grass option evaluated in my field trials has shown that this can be a practical method for converting marram grass dominated dunes to spinifex. This method is increasingly being used by Coast Care groups in many regions of New Zealand (David Bergin, Dunes Trust, pers. comm., 2013).

My dune restoration experiment was to my knowledge the first study that researched the SGH in a restoration context with a herbicide spray-killed invasive species and its influence on plant growth as well as recording population dynamics of self-colonizing species of a coastal dune community. I was able to show that dead plant material is less facilitative (potentially hindering) for planting survival if initial marram densities are too high, but facilitative at low to medium densities. Furthermore, species responses towards stress are indeed dependent on species identity.

My research on Senecio species indicates apparent facilitation between introduced S. elegans and native S. lautus at fine spatial scales via the shared seed head predator S. fascigera, but no significant influence of Senecio spp. density at coarser scales. In addition, the need for considering abiotic impacts on direct interactions has been emphasized. Senecio elegans was directly facilitated by sprayed marram. It will be crucial for our understanding of community structure to research the netoutcomes of direct and indirect interactions at different spatial scales as well as incorporating effects of abiotic resource limitations at a community level. Thereby my thesis provides a foundation for larger community level longer-term future studies.

\subsection{Implications for conservation and dune management}

Introduced species alter habitats in various ways (Niemelä and Mattson 1996, Drossel et al. 2000, McCann 2000, Pearson and Callaway 2003) and are the second biggest threat to biodiversity after habitat destruction (Pimentel et al. 2005). Coastal areas in New Zealand have been altered substantially with the introduction 
of marram grass and other weeds that now dominate coastal habitats in large parts of the country (Hilton et al. 2000, 2005, Bergin 2011). However, local Coast Care groups are endeavouring to reverse this degradation of dunes systems in many regions by replacing introduced species with appropriate coastal native species. Such volunteer groups in collaboration with local councils and the Department of Conservation spend a significant amount of volunteer time in restoration of their local beaches. Their enthusiasm is admirable but they still struggle with survival rates of native plants and knowledge about coastal species remains patchy. Throughout my research I had the chance to work closely with involved stakeholders: The Department of Conservation, the local Iwi, City Councils, weed control contractors, Coast Care groups and the general public including local residents. Collaboration with these parties further advanced my understanding of coastal ecosystem processes and their restoration initiatives. Complete planting loss was frequently reported for beaches with major erosion events, regardless of the planting approach - this is in accordance with my observations at Whitiau, where I had clustered treatment plots at a transect but lost the entire fore dune due to a massive winter storm regardless of planting regime. Volunteers who contributed to my research by planting spinifex according to my research design said it was significantly harder to plant into sprayed marram grass, suggesting this method should only be applied if the gains justify it, i.e. in an exposed environment where facilitation by providing shelter is necessary to promote the establishment and growth of spinifex. However, other weeds are a constant management problem in that scenario if weed sources are in close proximity. Consequently, I have developed management recommendations based on my own experiments, visits to restoration sites throughout the country and consultation with the various parties involved in dune restoration (Fig. 6.2). For degraded dunes dominated by marram grass on exposed sites, planting native sand binders is likely to succeed where there is no major erosion expected along fore dunes, and where re-invasion of marram or other weeds is less likely because of of reduced propagule sources. Planting establishment under the mentioned conditions is more successful if other human-induced factors such as rabbits are controlled and beach user access is managed. At such sites, the option evaluated in this thesis of using sprayed marram grass to facilitate the 
establishment of native sand binders is likely to be a practical method for restoration. On less exposed sites, choice of method for replacing marram grass with appropriate native species will depend on the presence of fauna sensitive to the use of herbicide sprays and the degree of exotic flora present.

Implications for dune management:
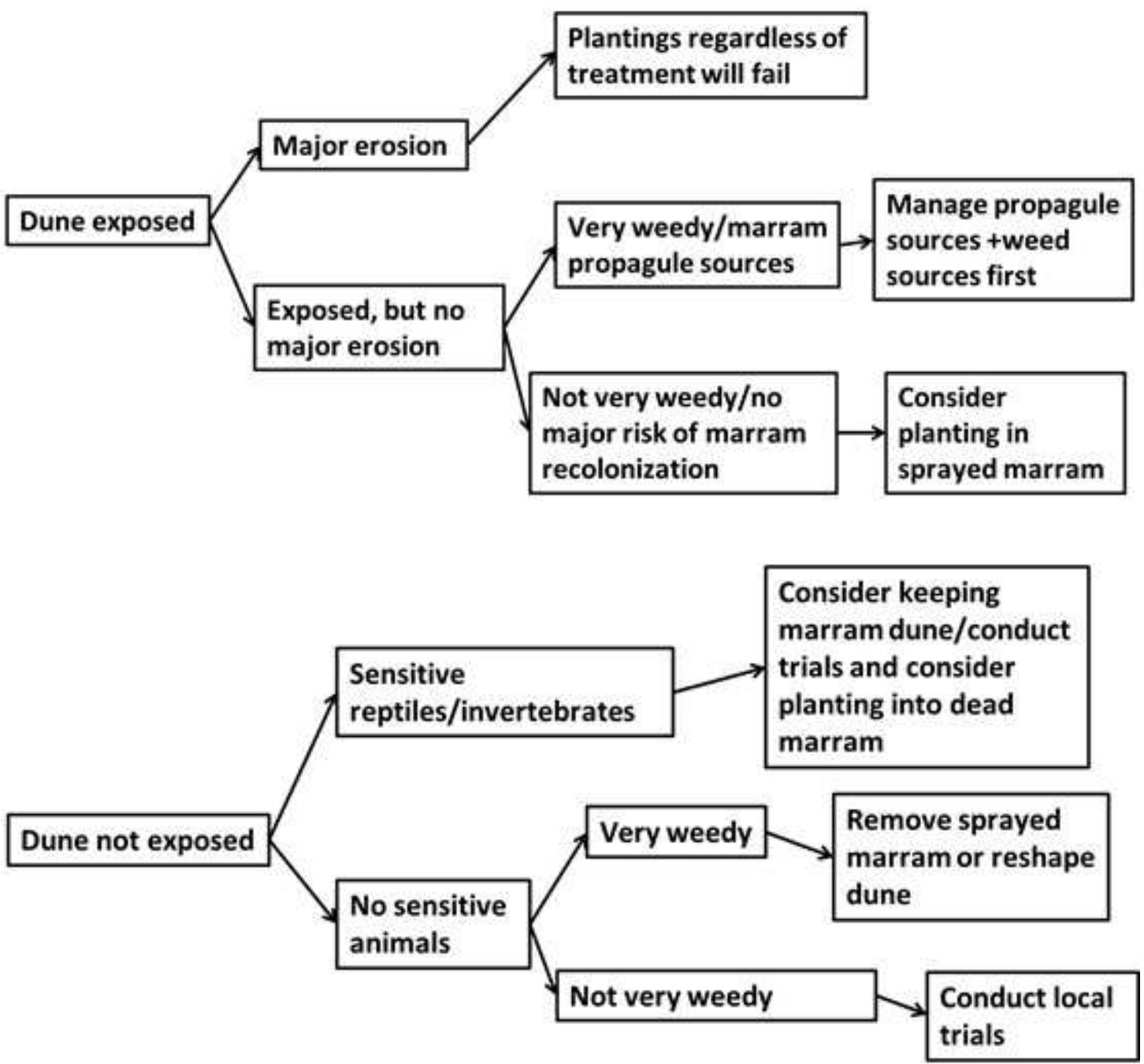

Figure 6.2: Recommendations for spinifex restoration planting depending on local site conditions. Based on Chapter $2 \& 3$ as well as on consultations with restoration stakeholders. 
My research indicates apparent facilitation of native $S$. lautus by introduced $S$. elegans at fine scales. However, it is questionable whether or not this effect indicates a positive net-outcome of for native S. lautus as I observed S. elegans encroachment into areas previously only inhabited by native S. lautus. This leaves scope for speculation about further invasion expansion and direct competition as discussed in Chapter 5. Introduced S. elegans and S. skirrhodon grew faster than native S. lautus in the greenhouse. Both introduced species starting flowering earlier and flowered longer compared to S. lautus. Consequently, the introduced species should have a direct competitive advantage against $S$. lautus in the wild giving them the opportunity to produce more seeds, for a longer period of time and with more efficient competition for space through better growth.

Coast Care groups frequently weed their local beaches to protect their restoration plantings and promote long term restoration. However, it is possible that indirect effects not only take place between two closely related Senecio spp. and their insect herbivores but also when weeding is done. In my experience S. elegans is frequently weeded while introduced S. skirrhodon is left in situ because it is mistaken for native S. lautus. Therefore S. skirrhodon experiences a colonization advantage at some of the managed beaches. It is currently unclear to what extent New Zealand's beaches are modified. It may be possible that even anemochore and thus very mobile species such as coastal Senecio spp. are limited in their recruitment - So far according to my consultations with Coast Care groups they did not actively plant native coastal Senecio spp. However, in Australian coastal systems, aggressive introduced Asteraceae such as bitou bush (Chrysanthemoides monilifera subsp. rotundata) may be depleting native seed banks as these are typically not very longlived and thus limit seedling recruitment of key native species (French et al. 2010). Furthermore, exotic plant invasion has been shown to inhibit native plant regeneration as demonstrated for invasive Lantana camara in south eastern Australia (Gooden et al. 2009). Further study is required to determine if exotic Senecio species on New Zealand dunes may be affecting native Senecio spp. populations especially where weed control is indiscriminate. Clear information on species identification to determine differences between exotic and native Senecio 
spp. is essential in weed control programmes targeting these species (see Appendix for photos of the morphological variety of the Senecio spp. considered in my study)

Development of long term restoration goals that embrace the wider ecosystem services provided by coastal dunes (as reviewed in Barbier et al. 2011) will be crucial for effective management of New Zealand's dunes. This includes the protection provided by well-managed dunes with a cover of appropriate native sand binders that will be more resilient than exotic species to erosion in the case of large storm events (Zarnetske et al. 2012). An understanding of dune processes where the aim is to restore and manage natural dune form and function using native plants will be essential as is the provision of practical guidelines to coastal communities and collaborating agencies so they can effectively restore and manage them.

\subsection{Concluding remarks}

My thesis has demonstrated the complexity of interactions in species-poor coastal dune systems. They are dependent on direct and indirect interactions of abiotic and biotic factors at different spatial scales and possibly temporal scales. More specifically my main conclusions are:

- Restoration plantings in dead, sprayed marram grass can follow the predictions from the SGH for growth and experience facilitation at fore dunes and a more competitive interaction at back dunes in comparison to plantings in live marram and bare sand.

- Whether or not a species follows the predictions of the SGH is highly dependent on species identity and on the stress gradient researched

Introduced species can exhibit an apparent facilitative effect on a closely related native congener at fine spatial scales, e.g. as demonstrated for the influence of introduced $S$. elegans on the shared seed head predator S. fascigera which was consequently less abundant on neighbouring native S. lautus. This facilitative effect may become negative, 
however when considered over longer time scales and larger spatial scales, if populations of the shared herbivore build up.

Future studies will face the challenge of manipulating a system at the community level to at least a second trophic level to entangle these complex interactions. Conservation managers need to be aware of the net-outcomes of interactions involving invading species to be able to assess adequately the long-term impact an introduced species can have on native plant (and animal) communities. 


\section{APPENDICES}

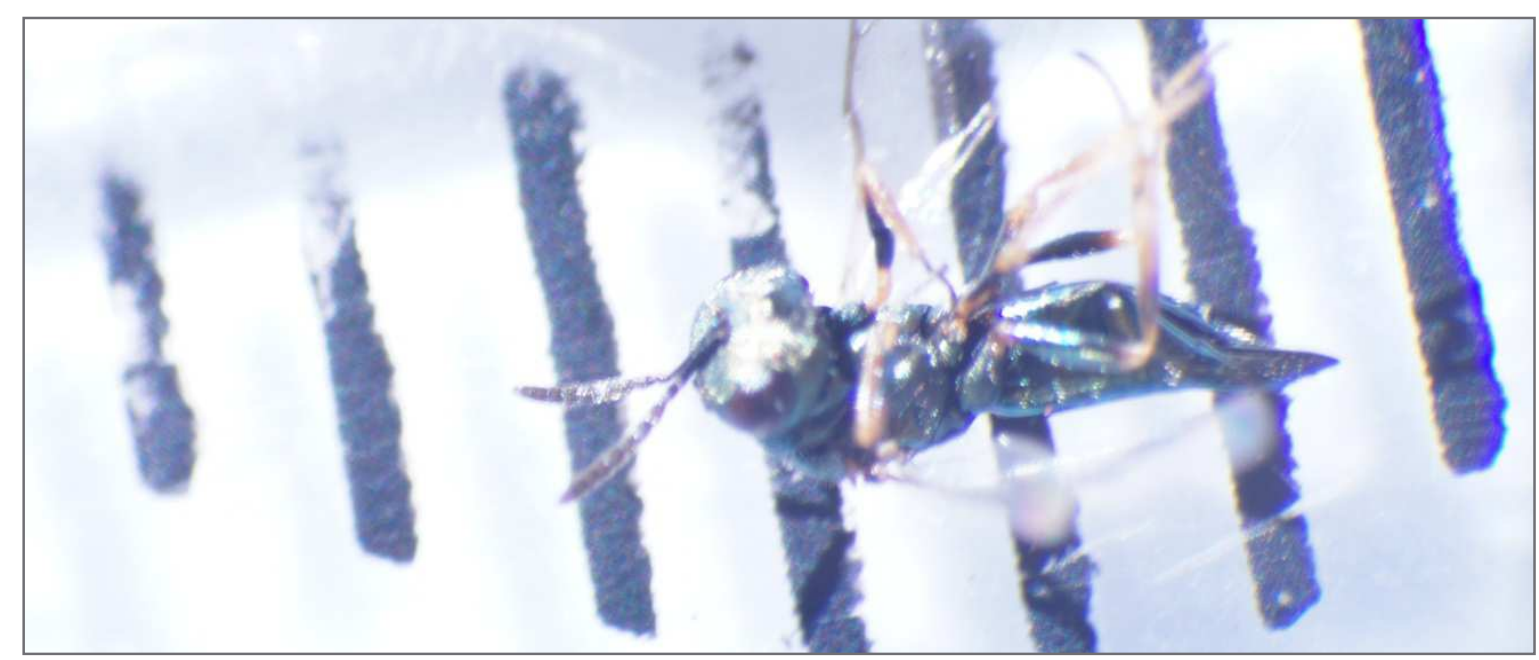

Specimen of Pteromalus sp on a milimiter scale. 


\title{
7 Tri-trophic interactions and the minimal effect of host microsite, plant properties and plant density on parasitism of Sphenella fascigera (Diptera)
}

\begin{abstract}
Parasitoid insects are important natural biocontrols of insect herbivores. How parasitoids choose particular hosts amongst many larvae on different plants is not fully understood. We investigated factors including host larval location on the plant, plant density and quality, host larval density, and other insect herbivores. Our model system was the coastal plant Senecio lautus and its tephretid herbivore Sphenella fascigera parasitized by an undescribed parasitoid wasp Pteromalus $\mathrm{sp}$. We recorded $S$. fascigera larvae and collected fly pupae for hatching of Ptermomalus sp. The overall rate of parasitism of S. fascigera was $25 \%$. There was no significant effect of larval location upon parasitism rate, or any other variables. One explanation could be the evolution of an efficient search strategy to locate all potential larvae, with equal probability. Future research on whether $S$. fascigera larvae on congeneric plants experience different rates of parasitism could be advantageous for understanding tritrophic interactions.
\end{abstract}

\subsection{Introduction}

About a quarter of all insects are parasites (Schoonhoven et al. 2007) and some might have potential as biocontrol agents for agricultural pests (i.e. crop damaging insect herbivores) (Aebi et al. 2006) or inhibit the success of insect herbivores which act as biocontrol agents (Paynter et al. 2010). Despite studies of the interactions between parasites and their hosts, a lack of knowledge remains for a great number of parasites and how they choose their hosts (reviewed in Lewinsohn, Novotny, \& Basset, 2005, 
Paynter et al., 2010)). Due to a lack of universal pattern, these interactions are thought to be species specific (Sasakawa et al. 2013).

The tritrophic interaction between plants, their insect herbivores and parasitoids have many different facets: plants evolve means to escape insect herbivores by developing deterrent chemicals to make themselves less attractive and less palatable (Pare and Tumlinson 2011). These chemical plant defences, however, have also been shown to encourage other plants to increase their plant volatile production when a nearby congener has been damaged by herbivory (Howe and Jander 2008). Plant volatiles may also act to attract parasites and other natural enemies of herbivorous insects (e.g. Ngumbi et al. 2012, Uefune et al. 2012, Chiappini et al. 2012). In some cases the plant volatiles are insect herbivore specific and therefore attract specific parasitoids targeting these insects (Moraes et al. 1998).

Tri-trophic interactions are an important component of larger more complicated food webs and exemplify the potential for indirect facilitative and competitive effects across lower trophic levels (Holt and Lawton 1993). Unlike direct competition and facilitation, that typically occurs between plants in close spatial proximity (Bertness and Callaway 1994, Brooker et al. 2007), mobile insects can mediate indirect interactions across larger spatial scales (Lynch and Kaplan 2006, van Veen et al. 2006, Wielgoss et al. 2012)., In particular, it is thought that predators (including parasites) generally act at larger spatial units than their prey/hosts (Östman and Ives 2003).

The resource concentration hypothesis (Root 1973) predicts a greater density of herbivores, and similarly more predators, in patches with a high amount of resources (i.e. high density stands of plants). Nevertheless, some studies showed opposite effects with fewer insect herbivores per plant in areas with high resource concentrations and more insects per plant on isolated plants (Karban and Courtney 1987). Hence, the resource dilution hypothesis (Otway et al. 2005), which predicts that isolated plants experience a higher insect herbivore load than plants within dense patches. Furthermore, this also positively affects parasite colonization (Williams et al. 2001). 
Empirical evidence distinguishes between two steps of host location by parasitoids: firstly, finding the host plant of the host insect host and secondly, locating suitable larval hosts on the plant (Vinson, 1975; Vinson, 1976). Both insect herbivores and parasitoids have been documented to use mainly visual (Ferreira Santos de Aquino et al. 2012) and chemical cues (Segura et al. 2012) to locate their hosts. Insect herbivores typically face a choice between many potential host plants, and are likely to evaluate plant properties (plant size, health, plant architecture) to maximise offspring survival (Egan and Ott 2007). More structurally complex plants are thought to provide shelter from enemies (i.e. parasites) by increasing the difficulty of the search for insect hosts (Obermaier et al. 2008). Potential insect hosts may escape from parasitism by seeking microsites that provide a refuge against discovery and attack. For example, the parasitoid wasp Venturia canescens (Gravenhorst) was unable to parasitize many potential host larvae of Plodia interunctealla (Hübner) due to a depth-refuge (Begon et al. 1995). Seeking refuge has implications for evaluating potential biological control agents success, as discussed by Lynch, Bowers, Begon, \& Thompson (1998). Hosts can also escape their parasitoids by changing their feeding behaviour or building up their own chemical and physical defences (Kraaijeveld et al. 2001, Takahashi-Nakaguchi et al. 2013).

Our study aimed to investigate the factors affecting parasitoid host choice at a range of scales. We studied a common coastal plant: Senecio lautus (Willd) (Asteraceae) which is frequently infested with Sphenella fascigera (Malloch) fly larvae which can either develop in galls in plant stems or within the flowerheads. In turn, the fly larvae may or may not be parasitized by Pteromalus sp, an undescribed parasitoid wasp.

Specifically we asked whether:

i) Location of the larval host within the plant is important to parasitoids. More precisely galls in plant stems are hypothesised to provide a more protected refuge than flowerheads (perhaps at the cost of lower quality nutrition for the fly larva)

ii) Plant density (a proximate measure of resource concentration) is positively or negatively related to parasitism rates,

iii) Plant properties (i.e. plant size, vigour and maturity) influence parasitism rates 


\subsection{Methods and materials}

\section{Study species and field sites}

Senecio lautus, Asteracea, was chosen as the focal plant species. Senecio lautus is a flowering annual or short-lived perennial herb with glaborous or sparsely hairy leaves which can be deeply divided and toothed, the leaves are heteroblastic (Burns 2005) and plants can vary tremendously in size (pers. observation). Leaf shape is an adaptation to wind and abiotic conditions- leaves can exhibit succulence when exposed to salt and wind and are generally more deeply serrated in more exposed areas (Burns 2005). Ray florets vary between 0 (rare), 7-13 (Webb et al. 1988). Plants can be found flowering year round (NZPC Network 2013) with a peak in summer. Typical habitats are coastal areas, especially shingle beaches and rocky areas (Webb et al. 1988). Like most plants in the seneciod tribe, Senecio spp contain pyrrolizidine alkaloids (Jeffrey et al. 1977). Their primary function appears to be to deter vertebrate and invertebrate herbivores ( $\mathrm{Hol}$ 2011). Due to their toxicity, however, some species of insect have evolved a general tolerance to alkaloids, and some specialist herbivores sequester it for their own defence (Nishida 1994, Nishida et al. 1994). Prominent examples of insect herbivores sequestering alkaloids from Senecio spp. include arctiid moths e.g. Nyctmera spp. (Benn et al. 1979). and Tyria spp. (Naumann et al. 2002).

Sphenella fascigera (Diptera: Tephretidae), formerly known as Tephritis fascigera, (revised by (Hancock and Drew 2003) was our focal insect herbivore. This endemic tephretid fly has larvae that develop in the immature seeds of flowerheads or through forming galls in the stems of Senecios (Martin 2013, personal observation). In captivity, S. fascigera can survive several months as adult flies (personal observation). Sphenella fascigera adults have been observed on a range of Senecio species in New Zealand including: S. bipinnatisectus Belcher; S. diaschides D.G.Drury; S. esleri Webb; S. glomeratus Poiret; S. hispidulus A. Rich; S. lautus G. Forst. Ex Willd.; S. minimus Poiret S. skirrhodon DC.; S. vulgaris (Martin 2013) and on S. elegans and S. sterquilinus (Orndorff) (pers. observation). To our knowledge, no parasitic wasps have been previously recorded from Sphenella fascigera. 
Pteromalus sp is an undescribed parasitiod wasp (pers. comm. Early and Schnitzler 2012) of the Pteromalidae family, which consists of over 70 species in New Zealand (Landcare Research, 2009). Most of the Pteromaliden are parasitoids and various types of parasitism are represented (Landcare Research, 2009). Pteromalus spp. have been used as biocontrol agents as in the case of the generalist pupal parasitoid Pteromalus puparum (L.), which was introduced to New Zealand to control Pieris rapae, but also spread to other hosts (L.) (Barron 2007). The modern day mixture of native and introduced insects in New Zealand also comprises other Pteromalus spp. as documented by Berry (2003) for Neopolycystus insectifurax Girault. The parasitoid species of the genus Megastigmus (Torymidae) is established in NZ and parasitizes Procecidochares alani (Tephritidae) on the mist flower Ageratina (= Eupatorium) riparia NZ (Schnitzler and Winks, pers. comm. 2012). Species of Megastigmus. and Pteromalus?. have also been recorded in New Zealnd and were found to parasitise Procecidochares utilis (Tephritidae) on Mexican devil weed Ageratina (= Eupatorium) adenophora. A Pteromalus? sp. is known to parasitise Tephritis cassiniar (Tephritidae) on Cassinia sp. (Asteraceae) (Schnitzler and Winks, pers. Comm. 2012).

Field sites were located around Wellington, New Zealand (see Fig. A.I.1) with monitored populations at shingle beaches at Owhiro Bay, Owhiro Beach, Moa Point (near Lyall Bay), Makara Beach, Petone, Breaker Bay and Eastbourne Beach. At Moa Point, Petone and Eastbourne populations of congeneric Senecio spp. (S. elegans and S. skirrhodon) were present within a few hundred meters of the sampling points. Other plant species commonly present at the field sites included: Coprosma repens, Anagallis arvensis var. arvensis, Glaucium flavum, Gaznia rigens, Chrysanthemoides monilifera, Sonchus oleraceus, Lobularia maritima, Brassica spp. Crepis capillaris, Leontodon taraxacoides, Taraxacum officinale, Atriplex prostrata, Galium spp. The vegetation occurred typically in bands following the tideline. Often coastal Senecio spp root in debris from the tideline and the sections with S. lautus were usually the areas with less immediate public access.

\section{Data collection}


Plants were surveyed between February-April 2012 when the majority of plants were mature. $2 \times 2 \mathrm{~m}$ quadrats, with an internal grid of $50 \mathrm{~cm}$ subquadrats, were laid out consecutively over the area where S. lautus was present.

The number of Senecio lautus individuals and other congenerics in each subquadrat was counted, differentiating between juveniles, adults and dead individuals. Each S. lautus plant was searched (i.e. opening every flowerhead and every stem gall) and all $S$. fascigera pupae encountered were collected for rearing in the laboratory where they were kept in plastic tubes $(4.5 \mathrm{~cm}$ height and $1 \mathrm{~cm}$ diameter) closed with cotton wool and stored at room temperature $\left(17-22^{\circ} \mathrm{C}\right)$. Larval stages of $S$. fascigera were also recorded, but not collected. The height and diameter of each plant was measured. Linear size was obtained using the formula:

$$
\text { Plant size }(\mathrm{cm})=\left[\text { height } *(\text { diameter } / 2)^{2}\right]^{1 / 3}
$$

This formula normalized the distribution of plant size by referring the value from a volume back to a linear value. We recorded the phenological state of the focal plant (assessed by counting the number of flowering buds $(=0)$, buds $(=1)$, mature flowers $(=$ $2)$, post-flowering flower head $(=3)$ and dried-out flower heads $(=4)$ ), the number of branches at the base of the plant, plant vigour (categorized from 0 (dead)-5 (very healthy)) and the presence of other insects on the plant. The $2 \times 2 \mathrm{~m}$ quadrat was nested within a larger $6 \times 6 \mathrm{~m}$ quadrat, and the number of Senecio plants surrounding each $2 \times 2 \mathrm{~m}$ quadrat (but within the $6 \times 6 \mathrm{~m}$ quadrat was recorded). A total of 4740 flowerheads, from 356 plants located in $682 \times 2$ m quadrates were searched for pupae across all sites. 


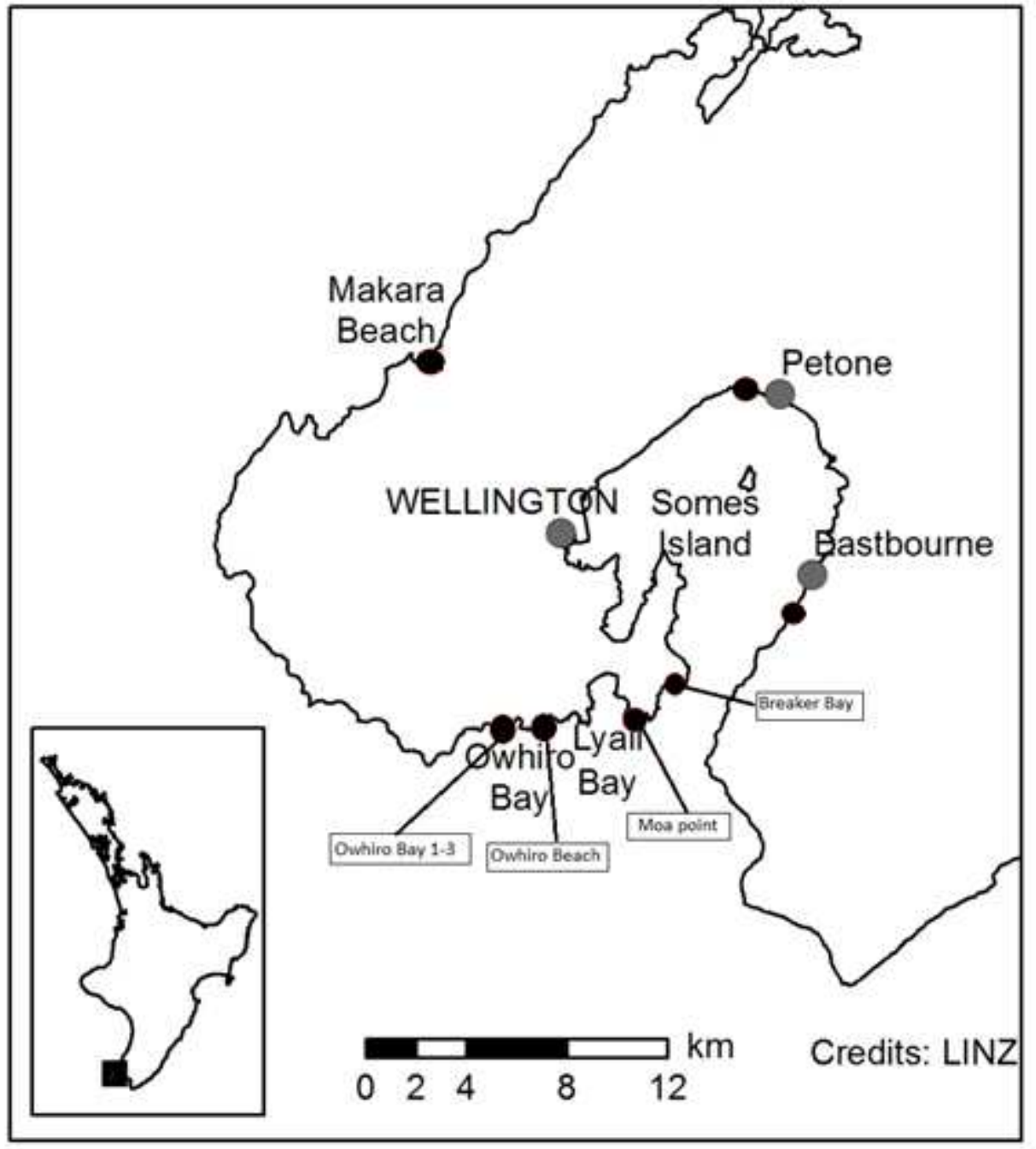

Fig. A I.1: Map showing the locations of the natural S. lautus populations sampled in this study (black points). Grey points mark urban areas. 


\section{Data analysis}

We used linear mixed-effects models to investigate a variety of factors that might influence a parasitoid's host selection at a range of nested scales. The response variable was binary: either "parasitized" or "not parasitized" for each fly pupa, hence the error distribution was specified as 'binomial'. The independent variables were: the location in the plant (stem or flowerhead), the total number of flies in the plant, plant size, number of flowers on the plant, density of conspecific $S$. lautus in the $50 \mathrm{~cm}, 2 \mathrm{~m}$ or $6 \mathrm{~m}$ quadrats respectively, the presence of heterospecific Senecio plants, plant maturity, plant vigour and the presence of other insects on the focal plant (i.e. cecimidoyiid larva or Nyctmera annulata Boisduval (magpie moth) caterpillars)). Unique identifiers for each individual plant, nested within quadrat, nested within site, were added as random effects.

Stepwise backward deletion of variables was used to obtain a parsimonious description of important variables which influenced parasitism. The model with the lowest AIC was retained as the best model. A type II ANOVA was performed for the model. In addition, all predictors were also tested individually in separate models to check the stability of the results in the face of potential cross-correlations between variables. All data analysis was conducted using the statistical software R (R Core Team 2012). Linear mixed-effect models were fitted using the package Ime4 (Bates et al. 2012).

\subsection{Results}

One thousand, four hundred and twenty fly larvae or pupae were observed across 356 plants. A total of 58 wasps were reared from 236 viable pupae giving an overall rate of parasitism of 0.246 (Table 1). A total of 328 collected pupae produced nothing. $30 \%$ of flowerheads examined contained fly larvae or pupae. The greatest number of flies recorded on one plant was 39, from a plant at Owhiro Bay, $20 \mathrm{~cm}$ high and $28.5 \mathrm{~cm}$ diameter with 72 flowerheads and 4 major stems.

When tested individually, none of the measured variables had a significant influence on the rate of parasitism of $S$. fascigera larvae. With respect to our primary question, 29 of 
145 pupae recovered from stems were parasitized, as opposed to 29 out of 90 pupae recovered from flowerheads. In a single-factor test, this difference in rates (20\% vs. $32 \%$ ) was not significant $(F=3.392, d f=1, P=0.066)$, and the variable was not retained in the minimum adequate model.

With respect to plant density, both the fine-scale $(50 \mathrm{~cm})$ and coarse-scale $(6 \mathrm{~m})$ measures of conspecific density had a weak (non-significant, $0.05<P<0.1$ ) effect of increasing rates of parasitism (Table 3). Fly density had no significant effect on wasp parasitism rates.

Plant maturity was the only variable to show marginal significance in both the singlevariable test and the parsimonious model: older plants hosted pupae with a slightly higher rate of parasitism. Plant size, plant vigour and the number of branches showed no significant influence on parasitism rates (Table 3).

None of the variables were significant in the full model. With backward stepwise variable elimination the AIC of the model was reduced by 101.5. The most parsimonious model included the following predictor variables: the total number of insects in the plant, density of $S$. lautus in the $6 \mathrm{~m}$ quadrat, plant maturity, plant vigour, and the presence of other insects. As in the single-variable models, a positive trend was found for the influence of plant maturity $(p$-value $=0.079)($ Table 2$)$, i.e. parasitism rates were slightly higher in larvae recovered form more mature plants. 
Table A I.1: Summary statistics of fly and parasitoid incidence by site.

\begin{tabular}{|c|c|c|c|c|c|c|c|c|c|}
\hline Site & $\begin{array}{c}\text { No. } \\
\text { of } 2 \mathrm{~m} \\
\text { quadrats }\end{array}$ & $\begin{array}{c}\text { No. } \\
\text { of } \\
\text { plants }\end{array}$ & $\begin{array}{l}\text { No. of } \\
\text { flower } \\
\text { heads }\end{array}$ & $\begin{array}{l}\text { Total } \\
\text { of } \\
\text { flies }^{1}\end{array}$ & $\begin{array}{c}\text { No of } \\
\text { pupae } \\
\text { collected }^{2}\end{array}$ & $\begin{array}{l}\text { Hatched } \\
\text { flies }^{3}\end{array}$ & $\begin{array}{c}\text { Hatched } \\
\text { wasps }^{3}\end{array}$ & $\begin{array}{c}\text { Fly } \\
\text { density } \\
\text { per } \\
\text { nlant }^{4}\end{array}$ & $\begin{array}{c}\text { Rate of } \\
\text { parasitism }\end{array}$ \\
\hline $\begin{array}{c}\text { Breaker } \\
\text { Bay }\end{array}$ & 4 & 7 & 50 & 14 & 6 & 4 & 0 & 2.00 & 0 \\
\hline Eastbourne & 6 & 15 & 670 & 7 & 11 & 0 & 0 & 0.47 & 0 \\
\hline $\begin{array}{c}\text { Makara } \\
\text { Beach }\end{array}$ & 2 & 2 & 15 & 1 & 0 & 0 & 0 & 0.50 & 0 \\
\hline Moa Point & 3 & 9 & 183 & 6 & 3 & 0 & 0 & 0.67 & 0 \\
\hline $\begin{array}{c}\text { Owhiro Bay } \\
1\end{array}$ & 29 & 181 & 2336 & 660 & 486 & 91 & 32 & 3.65 & 0.260 \\
\hline $\begin{array}{c}\text { Owhiro Bay } \\
2\end{array}$ & 9 & 95 & 949 & 526 & 232 & 49 & 20 & 5.54 & 0.289 \\
\hline $\begin{array}{c}\text { Owhiro Bay } \\
3\end{array}$ & 4 & 15 & 57 & 39 & 7 & 1 & 1 & 2.60 & 0.5 \\
\hline $\begin{array}{c}\text { Owhiro } \\
\text { Beach }\end{array}$ & 7 & 21 & 318 & 165 & 63 & 23 & 3 & 7.86 & 0.115 \\
\hline Petone & 1 & 7 & 162 & 2 & 2 & 1 & 0 & 0.29 & 0 \\
\hline$N A^{5}$ & 3 & 4 & NA & NA & 13 & 9 & 2 & NA & 0.181 \\
\hline Total & 68 & 356 & 4740 & 1420 & 823 & 178 & 58 & 3.99 & 0.246 \\
\hline
\end{tabular}

${ }^{1}$ Total number of flies includes all larvae and pupae, ${ }^{2}$ collected pupae are all the closed pupae found, ${ }^{3}$ hatched flies and parasitoids numbers are found after rearing in the laboratory and hatching of the pupae, ${ }^{4}$ fly density per plant is the total number of flies divided by the number of plants, rate of parasitism is the number of hatched wasps divided by the sum of the hatched wasps and flies (i.e. all hatched pupae). ${ }^{5} \mathrm{NA}$ means that site information is missing.

Table A I.2: Rate of parasitism depending on the location of the pupa in the stem or flowerhead of the plant.

\begin{tabular}{ccccc}
\hline Location & Parasitoid & No parasitoid & $\mathbf{n}$ & Rate of parasitism \\
\hline Flower head & 29 & 61 & 90 & 0.32 \\
Stem & 29 & 116 & 145 & 0.20 \\
\hline Total & 58 & 177 & 235 & 0.25 \\
\hline
\end{tabular}


Table A I.3: Results of a multi-variable (stepwise deletion) minimum adequate model and single-variable linear models for parasitism rate of $S$. fascigera by Pteromalus sp. NA = single value beta coefficients are not applicable for multi-level factors. NS $=$ not significant, $\cdot=$ marginal significance when: $0.05<P$-value $<0.1$

\begin{tabular}{|c|c|c|c|c|c|}
\hline \multirow[t]{2}{*}{ variable } & \multicolumn{2}{|c|}{$\begin{array}{c}\text { Minimum adequate } \\
\text { model }\end{array}$} & \multicolumn{3}{|c|}{ Variables tested one by one } \\
\hline & $\begin{array}{c}\text { Beta } \\
\text { coefficient }\end{array}$ & $\begin{array}{l}p \text { - } \\
\text { value }\end{array}$ & $\begin{array}{l}\text { Beta } \\
\text { coefficient }\end{array}$ & $\begin{array}{l}p- \\
\text { value }\end{array}$ & Significance \\
\hline \multicolumn{6}{|l|}{ 1. Location on plant } \\
\hline flowerhead-vs-stem & dropped & & -0.634 & 0.066 & . \\
\hline $\begin{array}{l}\text { 2. Other plant-level } \\
\text { factors }\end{array}$ & & & & & \\
\hline total number of flies & -0.182 & 0.473 & -0.220 & 0.403 & NS \\
\hline Other insects & NA & 0.447 & NA & 0.306 & NS \\
\hline \multicolumn{6}{|l|}{ 2. Plant attributes } \\
\hline Maturity & 0.517 & 0.079 & 0.483 & 0.085 & . \\
\hline Vigour & $\begin{array}{l}\text { peaked at vig. } \\
=3\end{array}$ & 0.324 & NA & 0.244 & NS \\
\hline Total flowers & dropped & & -0.078 & 0.696 & NS \\
\hline Size & dropped & & -0.393 & 0.116 & NS \\
\hline $\begin{array}{l}\text { 3. Neighbourhood plant } \\
\text { densities }\end{array}$ & & & & & \\
\hline \# S. lautus within $50 \mathrm{~cm}$ & dropped & & 0.565 & 0.051 & . \\
\hline \#S. lautus within $2 \mathrm{~m}$ & dropped & & 0.299 & 0.319 & NS \\
\hline \# S. lautus within $6 \mathrm{~m}$ & 0.456 & 0.230 & 0.728 & 0.056 & . \\
\hline $\begin{array}{l}\text { \# other Senecio plants } \\
\text { within } 2 \mathrm{~m}\end{array}$ & dropped & & NA & & \\
\hline
\end{tabular}

\subsection{Discussion}

We tested a range of factors for their influence on parasitism of fly larvae. These factors ranged from fine-scale differences between different locations on the plant (e.g. stem vs flowerhead), through to properties of the plant (such as plant height and maturity) and finally neighbourhood effects of the density of other conspecifics and con-generic plants. None of the variables showed a significant effect. We found some weakly supported trends $(0.05<\mathrm{P}<0.1)$ for the influence of stem vs flowerhead, plant maturity and plant density when tested in single-factor models.

In general, insect larvae that inhabit galls are thought to benefit from increased protection from parasitoid attack - especially if the gall is thick and the parasitoid's ovipositor is relatively short (Ito and Hijii 2004). Although parasitism of S. fascigera 
larvae recovered from stem galls was two-thirds that the rate of larvae in flowerheads, this difference was not statistically significant with our sample size, and, the variable for "stem-vs-gall" was eliminated from the minimum adequate model, suggesting it has only a small influence on parasitoid attraction. Hence, there is little evidence that stem galls provide significant protection in comparison to larval development in flowerheads, for Sphenella fascigera.

Throughout this study only one fly larva was found per flowerhead of S. lautus, with the exception of a single instance of two larvae. Whether that is the result of flies only laying one egg per flowerhead or only one larvae surviving is unknown, although if it were the case of competitive exclusion we might expect to see more instances of two immature larvae per flowerhead. In the closely related $S$. sterquilinus, however, it is not uncommon to observe two S. fascigera larvae within one single flowerhead (S. Krejcek pers. obs.). Given that S. sterquilinus has larger flower heads, and its association with bird guano which would lead to a higher nutrient status, the distribution of only single larvae of $S$. fascigera in S. lautus flowerheads might be a necessity of resourcelimitation. Therefore a mechanism to escape parasitism by increasing clutch size (e.g.(Freese and Zwölfer 1996) is unlikely in this interaction.

The use of stems might be a strategy to avoid intra-specific competition when fly densities are high.

If plant properties were a crucial factor for parasitoid attraction, an influence of plant size and plant vigour would have been expected, supporting the plant vigour hypothesis (Price 1991). However, that was not the case as only plant maturity showed a positive trend for parasitism rates which is consistent with the findings of Souza-Filho et al. (2009), who showed with their study on fruit flies (Tephretidae and Lonchaeidae) that seasonality is important for some host-parasitoid interactions. We observed a succession of insect herbivores throughout the season, with insect herbivores such as $S$. fascigera occurring later in spring, peaking in summer after aphids and leaf miners have mostly disappeared. A positive relationship between numbers of seed head predators and plant maturity is expected as larvae develop within flower heads. 
Finally, we tested for the effect of local plant density at different spatial scales around each focal plant $(50 \mathrm{~cm}, 2 \mathrm{~m}$ and $6 \mathrm{~m}$ ) and found a marginally significant trend indicating a negative relationship between conspecific plant density (at $50 \mathrm{~cm}$ and $6 \mathrm{~m}$ scales) and rates of wasp parasitism. The resource dilution hypothesis (Otway et al. 2005) predicts that isolated patches are more heavily infested with insect herbivores and thus more likely to be searched by parasitoids, if these are generalists (Thomas 1989). Another explanation for the possible attraction of insect herbivores to isolated patches could to spread the risk from large vertebrate herbivores to host plants (Williams et al. 2001).

Pteromalus sp. is an undescribed species (pers. comm. Early and Schnitzler 2012) and to our knowledge there are no previous records of other hosts. Nevertheless, there is the potential that it uses other insects on other plants which might influence distributions of wasps amongst S. fascigera larvae. Anecdotal evidence from a congeneric species (Duan et al. 1996) suggests a close relationship between Pteromalus spp. and their tephretid hosts. Despite taking into consideration plant spatial distribution, plant properties and host larvae location, none of the factors was provided a significant explanation of the variation in parasitism rates. It is possible that we did not investigate the most influential factor for wasp attraction, but some authors (Vinson 1976, Xu et al. 2010) have suggested that parasitoid host location can also follow a random distribution. In other words, it appears that the combination of environmental cues and foraging behaviour utilised by Pteromalus sp. have adapted it to exploit all available Sphenella fasigera hosts in S. lautus with almost equal probability, regardless of where the host is located on the plant, the size and quality of the plant or the density of host plants.

Taking this research one step further, it would be interesting to compare rates of parasitism of Sphenella fascigera located on other Senecios, both native and introduced species. Sphenella fascigera has been recorded on S. sterquilinus, S. elegans, $S$. skirrhodon, S. glastifolius, S. vulgaris (Krejcek et al., unpublished data 2013). A recently adopted host plant shift by Sphenella fascigera to an introduced plant species might yet reveal a refuge of $S$. fascigera larvae from parasitism by Pteromalus sp. Understanding tri-trophic relationships within the context of novel food webs of native and introduced 
species is an area of growing ecological importance as the indirect effects of introduced species may be mediated by altered parasitoid-herbivore interactions. 


\section{APPENDIX II}

\section{Marram grass (Ammophila arenaria)}

Marram grass is a sand binding grass native to Europe (Huiskes 1979). As a highly specialized dune grass it flourishes close to the sea as one of the major sand binders in its native range where it is limited in its growth by root damaging nematods (Putten et al. 2005). Marram growth is fast and it reproduces both sexually and via rhizomes. These features make it very effective in colonizing new areas (Huiskes 1979). Compared to the native pingao and spinifex it quickly grows in dense tufts to a height up to one metre (Willis 1965) which is higher than the natives. After its first record in Wellington in 1873 (Wendelken 1974) marram was widely used to stabilize often human-induced and naturally occurring parabolic migratory dunes in New Zealand, and became widely distributed throughout the country (Hilton et al. 2006). Marram grass was chosen over the native sand binders such as spinifex and pingao because of its fast-growing nature. Compared to spinifex and pingao, marram grass dunes tend to be much steeper and higher (Esler 1970) where there is substantial sand supply and a high wind environment (Hart et al. 2012).

\section{Pingao (Ficinia spiralis, formerly known as Desmoschoenus spiralis)}

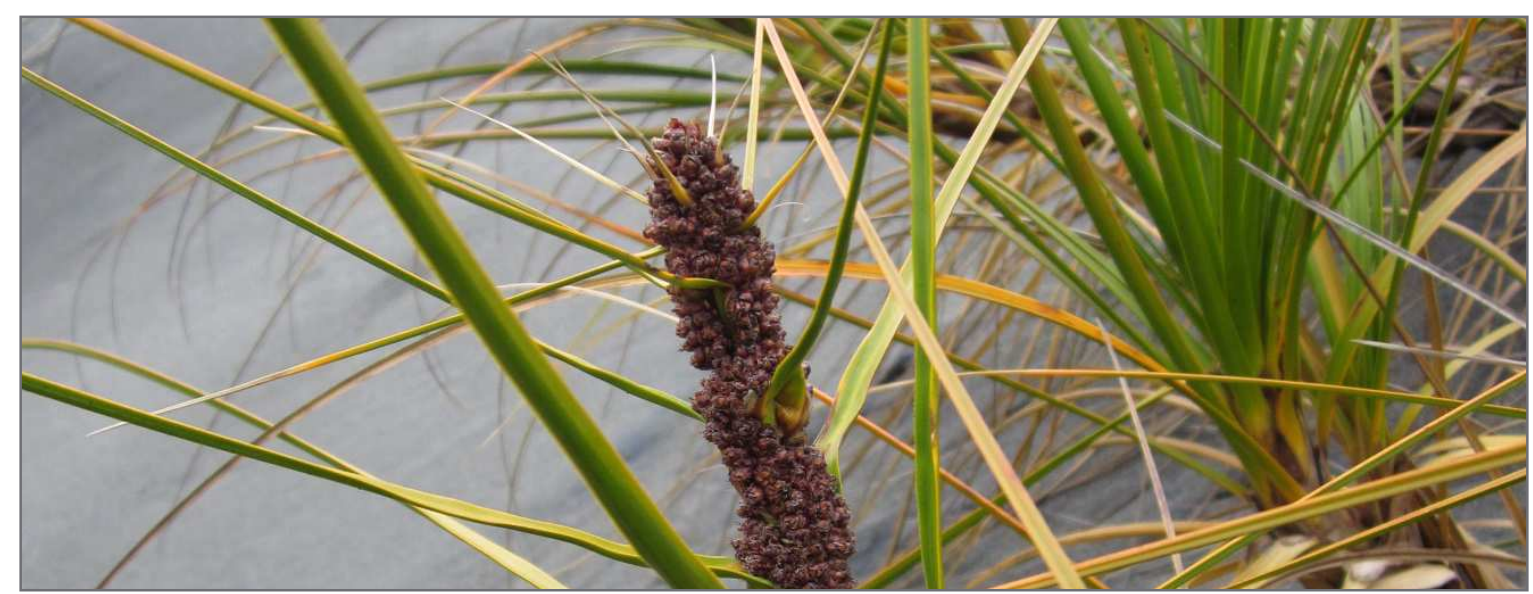

Figure A II.1: Pingao at Tapuarau (Photo by Stephen Hartley). 
This endemic sedge grows less high compared marram grass, and has high cultural significance for Maori (used for traditional weaving). Pingao exhibits less vigorous growth compared to marram grass and spinifex. It is the only major sand binding species that can persist in the more southern places where spinifex is not occurring due to low temperatures. On sites such as Stewart Island it can occur in almost pure mono-species stands (Hilton et al. 2005).

\section{Initial differences of plants from different nurseries}

Initial height and leaf length differences between plants from different nurseries were singnificant. However, at the time of monitoring there was no significant difference between nurseries anymore.

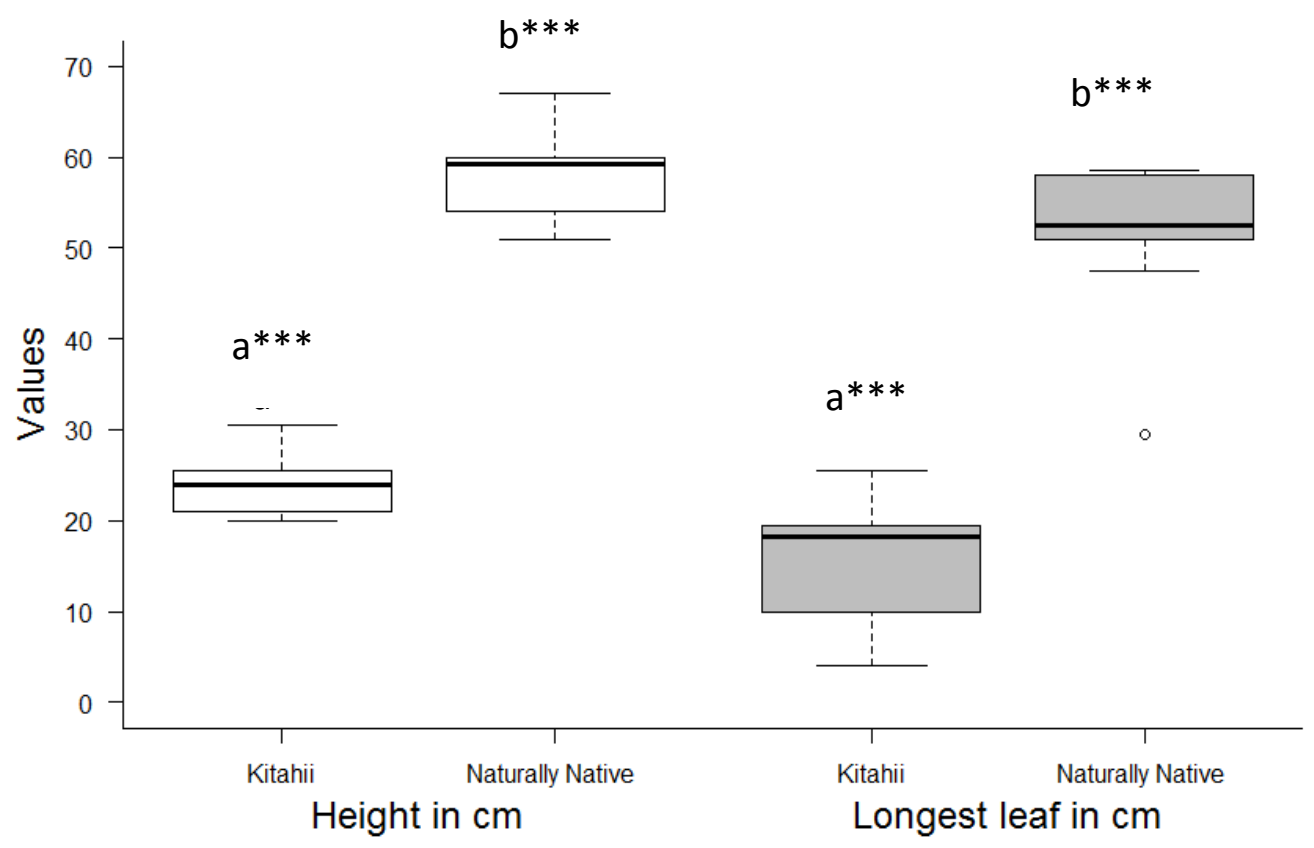

Figure A II.2: Initial spinifex height in $\mathrm{cm}$ and the length of the longest leaf in $\mathrm{cm}$ are split up between different nurseries. Kitahii nursery plants are from the local iwi nursery and the Naturally Native nursery plants are grown commercially. T-test for height: $t=-17.9102, \mathrm{df}=16.927, \mathrm{p}$-value $=1.946 \mathrm{e}-12$. $\mathrm{T}$-test for longest leaf: $t=-10.4604, \mathrm{df}=17.005, \mathrm{p}$-value $=7.948 \mathrm{e}-09$. 


\section{User defined function for $\mathbf{R}$ to generate relative graphs for Chapter $\mathbf{2}$ and 3:}

Kindly provided by Stephen Hartley (2012).

\#user-defined function (currently uses size for June 12)

plot.rel.diff $=$ function(data.df) \{

"data.df <- subset(data.df, size >0)"

"Plot.means <- tapply(log(data.df\$size), list(data.df\$treatment, data.df\$station, data.df\$transect), mean, na.rm = TRUE)"

"Plot.Ns <- tapply(log(data.df\$size), list(data.df\$̦treatment, data.df\$station, data.df\$়ransect), length)"

\#swap the commenting out to use Nbreadth

"\#data.df <- subset(data.df, Nbreadth > 0)"

"\#Plot.means <- tapply(log(data.df\$Nbreadth), list(data.df\$treatment, data.df\$station, data.df\$́transect), mean, na.rm = TRUE)"

"\#Plot.Ns <- tapply(log(data.df\$\$Nbreadth), list(data.df\$়treatment, data.df\$station, data.df\$̦transect), length)"

"Plot.diffs.MrtB <- Plot.means[2,,] - Plot.means[1,,] \# Marram rel.to Bare"

"Plot.diffs.SrtB <- Plot.means[3,,] - Plot.means[1,,] \# Sprayed rel.to Bare"

"MrtB. mean <- rowMeans(Plot.diffs.MrtB, na.rm = TRUE) "

\#mean relative difference Marram rt Bare

"MrtB.sd <- c(sd(Plot.diffs.MrtB[1,], na.rm = TRUE), sd(Plot.diffs.MrtB[2,], na.rm = TRUE), sd(Plot.diffs.MrtB[3,], na.rm = TRUE))" $\quad$ "\#sd of 5 plots at station 1, 2 and 3"

"MrtB.N <- c(table(is.finite(Plot.diffs.MrtB[1,]))[2], table(is.finite(Plot.diffs.MrtB[2,]))[2], table(is.finite(Plot.diffs.MrtB[3,]))[2])"

"MrtB.N <- apply(data.frame(MrtB.N, dim(Plot.diffs.MrtB)[2]), MARGIN = 1, min, na.rm = TRUE)"

MrtB.se <- MrtB.sd/sqrt(MrtB.N)

"SrtB.mean <- rowMeans(Plot.diffs.SrtB, na.rm = TRUE) "

\#mean relative difference Sprayed rt Bare

"SrtB.sd <- c(sd(Plot.diffs.SrtB[1,], na.rm = TRUE), sd(Plot.diffs.SrtB[2,], na.rm = TRUE), sd(Plot.diffs.SrtB[3,], na.rm = TRUE))" $\quad$ "\#sd of 5 plots at station 1, 2 and 3"

"SrtB.N <- $\quad c($ table(is.finite(Plot.diffs.SrtB[1,]))[2], table(is.finite(Plot.diffs.SrtB[2,]))[2], table(is.finite(Plot.diffs.SrtB[3,]))[2])"

"SrtB.N <- apply(data.frame(SrtB.N, dim(Plot.diffs.SrtB)[2]), MARGIN = 1, min, na.rm = TRUE)"

SrtB.se <- SrtB.sd/sqrt(SrtB.N)

"plot $(x=c(1,2,3,5,6,7), y=c((M r t B . m e a n)$, SrtB.mean), $x l a b=$ "'Station"'", ylab = "'Size relative to bare"'", ylim $=c(-0.2,0.3)$, pch $=21$, las $=1$, cex $=1.6$, xaxt $=" " n " " \prime) "$

"arrows $(x 0=c(1,2,3)$, y0 = MrtB.mean - MrtB.se, y1 = MrtB.mean + MrtB.se, code = 3, angle = 90, length $=0.2$ ) \#add standard errors to plot"

"arrows $(x 0=c(5,6,7), y 0=$ SrtB.mean - SrtB.se, y1 $=$ SrtB.mean + SrtB.se, code = 3, angle = 90, length $=0.2$ ) "

"abline(0,0, Ity = 2)"

"axis(side $=1$, at $=c(1,2,3,5,6,7)$, labels $=c(1,2,3,1,2,3)) "$

"text(2,2, "'Marram"")" 
"text(6,2, "'Sprayed"")"

"return(list(Plot.means, MrtB.mean, MrtB.N, SrtB.mean, SrtB.N))"

\}

PCoA on conductivity, organic matter and sandmovement at Whitiau

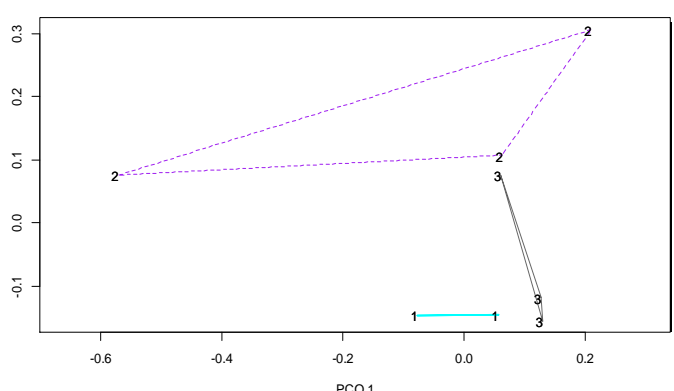

PCoA on conductivity, organic matter and sandmovement at Tapuarau

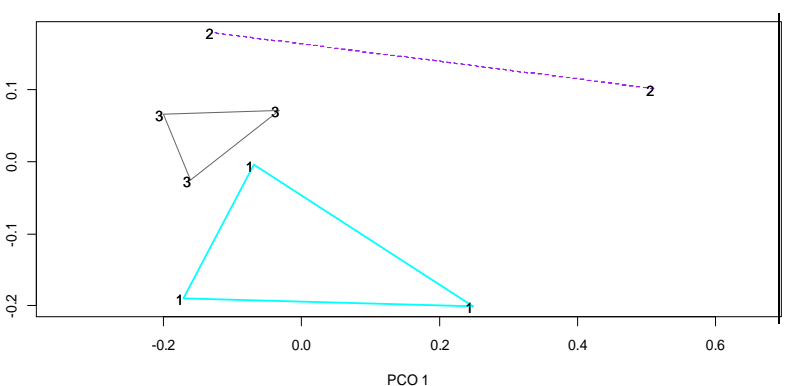

Figure A II.3: PCOA of conductivity, organic matter and sand movment at Whitiau (left graph) and Tapuarau (right graph). 


\section{Calystegia soldanella L. Sp. PI. 1753, 159 (sand convolulus)}

Calystegia soldanella is a native, but not endemic perennial coastal herb with a white and pinkish flower and kidney shaped leaves. It has a creeping rhizome with spreading and branching stems (Webb et al. 1988). The plants flower usually between October and March. Due to its widespread distribution (compromises Southern and Northern temperate regions) it is known to be adapted to early succession marram stands in Northern Europe (Smith and Lockwood 2010). Physical dormancy is exhibited by C. soldanella's seeds and the species is acknowledged as an important fore-dune species, which is able to trap sand to a certain extent (Ko et al. 2004).

\section{Sonchus oleraceus (Puha)}

Sonchus oleraceus naturalized in 1832 in New Zealand. Its homerange includes Europe, North Africa and Western Asia (NZPC Network 2013). The yellow flowering annual/biannual plant is widely distributed in New Zealand.

\section{Senecio elegans (purple groundsel),}

Senecio elegans L., Sp. PI. 869 (1753), also commonly known as purple groundsel is an introduced South African plant, which is sometimes cultivated for its ornamental values with the purple or purplish pink (rarely pale or white) 12-17 or sometimes more ray florets and yellow discs (Popay et al. 2010). Leaves are usually hairy, becoming almost glaborous when older on the top and are deeply serrated (petiole < lamina, often leaves are toothed. Flower times have been stated in (Webb et al. 1988) from Sep-Nov. The leaves are deeply serrated. Plant size can vary tremendously from flowering plants with a height of $15 \mathrm{~cm}$ up to $1.30 \mathrm{~m}$ (personal observation). Depending on its location within the dune system stressed plants can exhibit red colouring and succulence of leaves. Seeds are predominantly anemochore (wind dispersed) distributed.

Senecio elegans has been shown to outcompete native coastal plants (Weedbusters 2013) and is currently managed by some of the local coast care groups. 


\section{Lagurus ovatus L (hares tail)}

Lagurus ovatus was introduced to New Zealand in 1873 from the mediterrean (Network 2013). It has been introduced from its native ranges (i.e. Southern Europe, North Africa and Western Asia) to various temperate countries including Australia, the UK, parts of North and South America (Queensland Government 2011). The most distinctive feature of this small annual grass (up to around $60 \mathrm{~cm}$ in height) are its whitish eggshaped flowers which often remain long after flowering. The leaves are tufted at the base of the plant with hairy leaf sheaths. Lagurus ovatus is regarded as an environmental weed in Australia where it frequently invades coastal habitats via seed.

\section{Orobanche minor (broomrape) exotic}

Orobanche minor is a non-photosynthetic parasitic plant which prefers Fabaceae and Asteraceae as hosts, albeit it can also parasitise Ranunculaceae and Poaceae. Its flowers can vary in colour from yellowish to purplish. This species is native to Southern Europe but has been widely spread and is now a very common parasite (Webb et al. 1988). Orobranche minor can be a problem where Fabaceae are used to improve pastures or prepare the soil for other crops (Ross et al. 2004).

\section{Conyza canadensis (L.) Cronquist (fleabean) exotic}

Conyza canadensis is a fully naturalized annual herb which is native to North and South America. Lifestock often avoid fleabean due to its bitter taste. According to the weed fact sheets in Australia, each of the plants is capable of producing up to 110000 seeds and is difficult to control with herbicides as it is capable of becoming resistant to them (Widderick and Wu 2013).

\section{Dandelions}

Leontodon taraxacoides, Crepis capillaris, Hypochoeris radicata and Taraxacum officinales occur at both field sites. These 'dandelions' are all members of the asteraceaplant family and are dispersed by wind (i.e. anemochore). They are all naturalized pasture weeds. Taraxacum officinale is managed only in a few circumstances (more when asthetics are concerned on turfs etc), which can be difficult as the dandelions considered here are able to survive in low nutrient conditions and are able to resprout from their tap roots (Harrington 2013) 


\section{Legumes (clovers and others)}

Lotus pedunculatus, Trifolium repens, Trifolium pratense and Trifolium arvense occur on both field sites. These introduduced Fabaceae are all capable of fixing nitrogen and thus change soil conditions. They were introduced for agricultural reasons to improve the soils. Lotus pedunculatus forms a persistent seedbank and large parts of its above ground parts break down in winter, giving rhizome fragments the chance to develop independently (Sheath 1975). Similarly, Trifolium repens is also capable of reproducing via seeds and vegetative (Chapman 1983). Large plants of Trifolium arvense, which was unintentionally introduced in the late $19^{\text {th }}$ century, are capable of producing up to 20000 seeds (Palmer 972) and hence are considered pioneering plants which possibly get eventually replaced by grasses and swards.

Table A III.1: Plant species used for the PcoA for Whitiau and Tapuarau. Only presence and absence data was used in the PcoA (yes=present, no=absent).

\begin{tabular}{lll}
\hline Species & Whitiau & Tapuarau \\
\hline Convolvulus calystegia & yes & yes \\
Conyza canadensis & yes & yes \\
Coprosma acerosa & yes & no \\
Ficinia nodosa & yes & no \\
Fabaceae spp. & yes & yes \\
Dandelions & yes & yes \\
Lachnagrostis billardierei & yes & yes \\
Lagurus ovatus & yes & yes \\
Orobranche minor & yes & no \\
Oxalis spp. & yes & no \\
Senecio elegans & yes & yes \\
Sonchus oleraceus & yes & yes \\
Pimelia arenaria & no & yes \\
Trifolium pratense & no & yes \\
\hline
\end{tabular}


Table A III.2: Complete species list of all plants recorded at Whitiau and Tapuarau. * = rare, $1=$ station 1, $\mathbf{2}=$ station 2, 3 = station 3.

\begin{tabular}{|c|c|c|c|c|}
\hline Family & Species & common name & Station & Status \\
\hline \multirow[t]{9}{*}{ Asteraceae } & Conyza canadensis & canadian fleabean & $1 *, 2,3$ & exotic \\
\hline & Crepis capillaris & $\begin{array}{l}\text { smooth } \\
\text { hawksbeard }\end{array}$ & $1,2,3$ & exotic \\
\hline & Hypochoeris radicata & catsear & $1,2,3$ & exotic \\
\hline & Leontodon taraxacoides & hawkbit & $1,2,3$ & exotic \\
\hline & Ozothamnus leptophyllus & Tauhinu & 2,3 & native \\
\hline & Senecio elegans & purple groundsel & $1,2,3$ & exotic \\
\hline & Senecio glastifolius & pink ragwort & $1^{*}, 3^{*}$ & exotic \\
\hline & Sonchus olearaceus & puha & $1 *, 2,3$ & exotic \\
\hline & Taraxacum officinale & dandelion & $1,2,3$ & exotic \\
\hline Atripliceae & Atriplex prostrata & orache & $1,2,3$ & exotic \\
\hline Convolvulaceae & Calestygia soldanella & sand convolvulus & $1 *, 2,3$ & native dune plant \\
\hline \multirow[t]{3}{*}{ Cyperaceae } & Carex pumila & sand sedge & 3 & native \\
\hline & Ficinia nodosa & knobby clubrush & 2,3 & native \\
\hline & Ficinia spiralis & Pingao & $1,2,3$ & endemic \\
\hline \multirow[t]{5}{*}{ Fabaceae } & Lotus pedunculatus & $\begin{array}{l}\text { Greater Bird's-foot } \\
\text { Trefoil }\end{array}$ & 2,3 & exotic \\
\hline & Lupinus arboreus & tree lupine & 2,3 & exotic \\
\hline & Trifolium arvense & hares foot clover & 2,3 & exotic \\
\hline & Trifolium pratense & red clover & 2,3 & exotic \\
\hline & Trifolium repens & White clover & 2,3 & exotic \\
\hline Orobanchaceae & Orobranche minor & broom rape & $1 *, 2,3$ & exotic \\
\hline Oxilidaceae & Oxalis sp. & oxalis & 2,3 & exotic \\
\hline \multirow[t]{5}{*}{ Poaceae } & Ammophila arenaria & marram grass & $1,2,3$ & $\begin{array}{l}\text { exotic, } \\
\text { weed }\end{array}$ \\
\hline & Holcus lanatus & Yorkshire grass & 3 & exotic \\
\hline & Lagurus ovatus & Hares tail & 2,3 & exotic \\
\hline & Lachnagrostis billardierei & sand wind grass & 2,3 & native \\
\hline & Spinifex sericeus & spinifex & $1,2,3$ & native sandbinder \\
\hline Polygonaceae & Muehlenbeckia complexa & creeping wire vine & 3 & native \\
\hline Primulaceae & Anagallis arvensis var. arvensis & scarlet & $3 *$ & exotic \\
\hline Rubiaceae & Coprosma acerosa & sand coprosma & $1^{*}, 2,3$ & $\begin{array}{l}\text { declining due to } \\
\text { marram grass }\end{array}$ \\
\hline Solanaceae & Solanum chenopodioides & nightshade & $2 *, 3 *$ & exotic \\
\hline \multirow[t]{2}{*}{ Thymelaeaceae } & & & & \\
\hline & Pimelia villosa & sand daphne & $2^{*}, 3^{*}$ & endemic \\
\hline
\end{tabular}




\section{APPENDIX IV}

Table A IV.1a: Senecio spp. and their biostatus; origin; year of introduction or first record; geographic range within NZ, and habitat. Introduced species are marked with an asterisk and natives are emphasised with bold font.

\begin{tabular}{|c|c|c|c|c|c|}
\hline Senecio spp. & biostatus & origin & year & geographic range & Habitat \\
\hline $\begin{array}{l}\text { S. angulatus } \\
\text { L.f.* } \\
\text { S. banksii } \\
\text { Hook. f. }\end{array}$ & $\begin{array}{l}\text { exotic } \\
\text { endemic }\end{array}$ & $\begin{array}{l}\text { South } \\
\text { Africa } \\
\text { NZ }\end{array}$ & $\begin{array}{l}1940 \\
\text { NA }\end{array}$ & $\begin{array}{l}\text { NI, SI until Nelson } \\
\text { east coast from Bay of } \\
\text { Plenty to Castlepoint }\end{array}$ & $\begin{array}{l}\text { Waste places, } \\
\text { scrubland, coastal areas } \\
\text { Usually on coastal } \\
\text { cliffs, often limestone, } \\
\text { less common on cliffs } \\
\text { inland to 600m in } \\
\text { Hawke's Bay }\end{array}$ \\
\hline $\begin{array}{l}\text { S. } \\
\text { bipinnatisectus } \\
\text { *Belcher }\end{array}$ & exotic & Australia & 1916 & $\begin{array}{l}\text { NI, SI Malborough Sounds } \\
\text { and Lincoln }\end{array}$ & $\begin{array}{l}\text { Waste places, coastal } \\
\text { sites, pasture, forest } \\
\text { margins and clearings }\end{array}$ \\
\hline $\begin{array}{l}\text { S. biserratus } \\
\text { Belcher }\end{array}$ & $\begin{array}{l}\text { non- } \\
\text { endemic, } \\
\text { wild }\end{array}$ & $\begin{array}{l}\text { NZ, } \\
\text { Tasmania } \\
\text { and S.E. } \\
\text { Australia }\end{array}$ & NA & $\begin{array}{l}\text { N.: local in N. and S. } \\
\text { Auckland, and Wellington } \\
\text { Province, S.: Otago, } \\
\text { Southland, and collected } \\
\text { once from S. Canterbury; } \\
\text { St.; A. }\end{array}$ & $\begin{array}{l}\text { Coastal habitats } \\
\text { including forest } \\
\text { margins and waste } \\
\text { places, rarely inland. }\end{array}$ \\
\hline $\begin{array}{l}\text { S. diaschides } \\
\text { D.G.Drury* }\end{array}$ & exotic & $\begin{array}{l}\text { Eastern } \\
\text { Australia }\end{array}$ & 1975 & Northland to Auckland & $\begin{array}{l}\text { Mostly waste places } \\
\text { and coastal sites, also } \\
\text { swamps, pasture and } \\
\text { cultivated ground }\end{array}$ \\
\hline S. elegans L. * & exotic & $\begin{array}{l}\text { South } \\
\text { Africa }\end{array}$ & 1935 & $\begin{array}{l}\text { Northland, Bay of Plenty, } \\
\text { coastal Wellington, } \\
\text { Hawkes's Bay, S: } \\
\text { Blenheim, coastal } \\
\text { Canterbury, Otago and } \\
\text { Southland }\end{array}$ & $\begin{array}{l}\text { Sand dunes, sandy } \\
\text { coastal sites, occasional } \\
\text { in waste places inland }\end{array}$ \\
\hline S. esleri Webb* & exotic & NA & NA & NA & NA \\
\hline S. glastifolius* & exotic & $\begin{array}{l}\text { South } \\
\text { Africa }\end{array}$ & 1969 & $\begin{array}{l}\text { Gisborne, Havelock, } \\
\text { Mana, Wellington, SI: } \\
\text { Motueka, Christchurch }\end{array}$ & $\begin{array}{l}\text { Waste places, hillsides, } \\
\text { pasture, scrubland and } \\
\text { riverbeds }\end{array}$ \\
\hline $\begin{array}{l}\text { S. glomeratus } \\
\text { Poiret }\end{array}$ & $\begin{array}{l}\text { non- } \\
\text { endemic, } \\
\text { wild }\end{array}$ & $\begin{array}{l}\text { NZ, } \\
\text { Australia, } \\
\text { W. USA }\end{array}$ & NA & N, S: Troughout, St.; Ch. & $\begin{array}{l}\text { waste places, } \\
\text { especially roadsides } \\
\text { and stonly sites, forest } \\
\text { margins and clearings, } \\
\text { coastal sands and cliffs, } \\
\text { also in shrubland, } \\
\text { grassland, and swamps } \\
\text { from sea level to } \\
1000 \mathrm{~m}\end{array}$ \\
\hline
\end{tabular}


Table A IV.2b: Senecio spp. and their biostatus; origin; year of introduction or first record; geographic range within NZ, and habitat. Introduced species are marked with an asterisk and natives are emphasised with bold font.

\begin{tabular}{|c|c|c|c|c|c|}
\hline Senecio spp & biostatus & origin & year & geographic range & Habitat \\
\hline $\begin{array}{l}\text { S. hispidulus } \\
\text { A.Rich }\end{array}$ & $\begin{array}{l}\text { non- } \\
\text { endemic, } \\
\text { wild }\end{array}$ & $\begin{array}{l}\text { NZ, } \\
\text { Australia }\end{array}$ & NA & $\begin{array}{l}\text { N: Northland, vicinity of } \\
\text { Auckland, Coromandel, } \\
\text { Opotiki District, } \\
\text { Wellington Province; S.: } \\
\text { Nelson, Marlborough, N. } \\
\text { Canterbury. }\end{array}$ & $\begin{array}{l}\text { Waste places, forest } \\
\text { margins and } \\
\text { clearings, coastal } \\
\text { sites, riverbeds and } \\
\text { damp areas. }\end{array}$ \\
\hline $\begin{array}{l}\text { S. lautus G. Forst. } \\
\text { Ex Willd. }\end{array}$ & $\begin{array}{l}\text { non- } \\
\text { endemic, } \\
\text { wild }\end{array}$ & $\begin{array}{l}\text { NZ } \\
\text { possibly } \\
\text { Australia }\end{array}$ & NA & $\begin{array}{l}\text { N: throughout, mainly } \\
\text { coastal, occasional } \\
\text { inland; S.: coastal } \\
\text { Marlborough, Nelson, } \\
\text { Westland (N. of } \\
\text { Greymouth) and } \\
\text { Canterbury S. to Raikaia } \\
\text { R. Ch. }\end{array}$ & $\begin{array}{l}\text { Coastal cliffs, turf, } \\
\text { sand and rocks }\end{array}$ \\
\hline S. minimus Poiret & $\begin{array}{l}\text { non- } \\
\text { endemic, } \\
\text { wild }\end{array}$ & $\begin{array}{l}\text { NZ, } \\
\text { Australia } \\
\text { and W. } \\
\text { USA }\end{array}$ & NA & N.; S.; St.L throughout; C. & $\begin{array}{l}\text { waste places, open } \\
\text { forest, forest margins } \\
\text { and clearings, } \\
\text { occasionally in } \\
\text { shrubland, swamps } \\
\text { and coastal habitats. }\end{array}$ \\
\hline $\begin{array}{l}\text { S. quadridentatus } \\
\text { Labill }\end{array}$ & $\begin{array}{l}\text { non- } \\
\text { endemic, } \\
\text { wild }\end{array}$ & $\begin{array}{l}\text { NZ, } \\
\text { Australia, } \\
\text { Indonesia }\end{array}$ & NA & $\begin{array}{l}\text { N.; S.; throughout; } \\
\text { especially common in E. } \\
\text { South Id. }\end{array}$ & $\begin{array}{l}\text { waste places, } \\
\text { riverbeds and other } \\
\text { stony places, cliffs } \\
\text { and rock outcrops, } \\
\text { also occasional in } \\
\text { shrubland and } \\
\text { grassland, sea level } \\
\text { to } 1000 \mathrm{~m}\end{array}$ \\
\hline $\begin{array}{l}\text { S. radiolatus F. } \\
\text { Muell. Supsp. } \\
\text { Antipodus (Kirk) } \\
\text { C.J. Webb }\end{array}$ & endemic & NZ & NA & $\begin{array}{l}\text { Ch. (subspecies } \\
\text { radiolatus), Ant (subsp. } \\
\text { Antipdus (Kirk) C. Webb) }\end{array}$ & $\begin{array}{l}\text { coastal habitats, } \\
\text { open forest grassland }\end{array}$ \\
\hline $\begin{array}{l}\text { S. rufiglandulosus } \\
\text { Colenso }\end{array}$ & endemic & NZ & NA & N.; S.: $38^{\circ}$ to $43^{\circ}$. & $\begin{array}{l}\text { Lowland to subalpine } \\
\text { stream sides, forest } \\
\text { margins, shrubland, } \\
\text { banks, cliffs and } \\
\text { roadsides. }\end{array}$ \\
\hline $\begin{array}{l}\text { S. scaberulus } \\
\text { (Hook. f.) D. } \\
\text { Drury }\end{array}$ & endemic & NZ & NA & $\begin{array}{l}\text { N: Northland S. to } \\
\text { Hauraki Gulf including } \\
\text { offshore islands, Puru R. } \\
\text { and Raglan (S. Auckland); } \\
\text { S. : collected from } \\
\text { Piction, Akaroa, and } \\
\text { Dunedin, but not seen } \\
\text { recently; Ch. }\end{array}$ & $\begin{array}{l}\text { Coastal habitats, } \\
\text { scrubland, forest } \\
\text { margins and } \\
\text { clearings }\end{array}$ \\
\hline
\end{tabular}


Table A IV.3c: Senecio spp. and their biostatus; origin; year of introduction or first record; geographic range within NZ, and habitat. Introduced species are marked with an asterisk and natives are emphasised with bold font.

\begin{tabular}{|c|c|c|c|c|c|}
\hline Senecio spp. & biostatus & origin & year & geographic range & Habitat \\
\hline $\begin{array}{l}\text { S. } \\
\text { skirrhodon } \\
\text { DC. }\end{array}$ & exotic & $\begin{array}{l}\text { Madagaskar, } \\
\text { Mozambique } \\
\text { to South Africa }\end{array}$ & 1920 & $\begin{array}{l}\text { Whangarei, Auckland, } \\
\text { Tauranga, Waikato, } \\
\text { Napier, Palmerston } \\
\text { North, coastal } \\
\text { Wellington, S: } \\
\text { Westport, Christchurch, } \\
\text { Dunedin }\end{array}$ & $\begin{array}{l}\text { Coastal sites, waste } \\
\text { places, inland mainly as } \\
\text { a weed of railway lines, } \\
\text { yards and ballast }\end{array}$ \\
\hline $\begin{array}{l}\text { S. } \\
\text { sterquilinus } \\
\text { Ornd. }\end{array}$ & endemic & NZ & NA & $\begin{array}{l}\text { N.; S.: known only from } \\
\text { the type locality } \\
\text { (Hawke's Bay), } \\
\text { Brothers Is and } \\
\text { Stephens Id (Cook } \\
\text { Strait), and Punakaiki } \\
\text { (near Greymouth). }\end{array}$ & $\begin{array}{l}\text { Seabird nesting } \\
\text { grounds, coastal } \\
\text { habitats }\end{array}$ \\
\hline $\begin{array}{l}\text { S. sylvaticus } \\
\text { L. * }\end{array}$ & exotic & Europe & 1878 & throughout $\mathrm{NI}$ and $\mathrm{SI}$ & $\begin{array}{l}\text { waste plaes, forest } \\
\text { margins, pasture and } \\
\text { stony sites from coastal } \\
\text { areas to } 1000 \mathrm{~m}\end{array}$ \\
\hline S. vulgaris* & exotic & $\begin{array}{l}\text { Europe, } \\
\text { Africa, Asia }\end{array}$ & 1867 & $\begin{array}{l}\text { throughout } \mathrm{NI} \text { and } \mathrm{SI} \\
\text { except Westland }\end{array}$ & $\begin{array}{l}\text { waste places, cultivated } \\
\text { land, gardens, rierbeds } \\
\text { and stony sites, from } \\
\text { coastal areas to } 700 \mathrm{~m}\end{array}$ \\
\hline $\begin{array}{l}\text { S. } \\
\text { wairauensis } \\
\text { Belcher }\end{array}$ & endemic & NZ & NA & N.: S.: throughout, St. & $\begin{array}{l}\text { stony or wet sites in } \\
\text { open forest, forest } \\
\text { margins and clearings, } \\
\text { shrubland, grassland, or } \\
\text { disturbed areas, mostly } \\
\text { from } 600-1500 \mathrm{~m} \text { but } \\
\text { reaching sea level in } \\
\text { some areas }\end{array}$ \\
\hline
\end{tabular}




\section{STUDY SPECIES}

Senecio lautus (Wild., Sp. PI. 3: 1981 (1803), also commonly known as shore groundsel is an yellow flowering annual or shortlived perennial herb with glaborous or sparsely hairy leaves which can be deeply divided and toothed, the leaves are heteroblastic (Burns 2005) and plants vary tremendously in size. Leaf shape is an adaptation to wind and abiotic conditions- Leaves can exhibit succulence when exposed to salt and wind and are generally deeper serrated in more exposed areas. Ray florets vary between 0 (rare), 713. Plants can be found flowering year round with a peak in summer. Typical habitats are coastal areas, especially shingle beaches and rocky areas (Webb et al. 1988). There has been a controversy if plants in Australia are part of the same species or not, however, (Ornduff 1964) stated they were sufficiently different and are therefore no longer part of the species complex of S. lautus. However, the debate seems to be not fully ended. Despite the recognition of several subspecies within the species complex of S. lautus, for the purposes of this study we only distinguished between S. lautus and $S$. sterquilinus as they thrive on different abiotic conditions (with S. sterquilinus dependent on bird guano for healthy plants). Since $S$. lautus is known to be especially variable within the Wellington region, I considered plants with up to 13 rayflorets as S. lautus, recorded plants with typical S. sterquilinus leaf morphology but less than 18 rayflorets as potential S.lautus $x$ S. sterquilinus hybrids, as they are known to hybridize sympatrically (Webb et al. 1988)

Senecio sterquilinus, Ornd., Trans. Roy. Roy. Soc. N. Z. 88: 68 (1960) also commonly known as guano groundsel (Webb et al. 1988) is a range-restricted relict endemic yellow flowering senecio-species in New Zealand. It is strongly associated with nesting birds and therefore vulnerable to declines in shore nesting bird colonies. Compared to S. lautus, $S$. sterquilinus tends to grow to a bigger size, has more ray florets, and more numerous bracts. Only plants with more than 18 rayflorets were considered to be $S$. sterquilinus 
(after discussion with Wellington DOC botanist, John Sawyer (pers. comm.). To my knowledge, no previous recordings of insect herbivores on $S$. sterquilinus have been published. I conducted my S. sterquilinus surveys on Matiu/Somes Island, but due to the anemorechore distribution specimens of $S$. sterquilinus have been recorded in Petone and Evans Bay (NZPC Network 2013) and around Breaker Bay (Dorset Point) and occasionally on the Southcoast (personal observations).

\section{Introduced Senecio spp.}

Senecio elegans L., Sp. PI. 869 (1753), also commonly known as purple groundsel is an introduced South African plant, which is sometimes cultivated for its ornamental values with the purple or purplish pink (rarely pale or white) 12-17 or sometimes more rayflorets and yellow discs (Webb et al. 1988). Leaves are usually hairy, becoming almost glaborous when older on the top and are deeply serrated (petiole < lamina, often leaves are toothed. Flower times have been stated in NZ flora from Sep-Nov (Webb et al. 1988), but within the Wellington region we have observed S. elegans flowering year round. The leaves are deeply serrated (Popay et al. 2010). Similar to S. lautus plant size can vary tremendously from flowering plants with a height of $15 \mathrm{~cm}$ or up to $1.30 \mathrm{~m}$ (personal observation).

Senecio elegans has been found to outcompete native coastal plants (Weedbusters 2013) and is currently managed by some the coast care groups (pers. comm). It is has an additional alkaloid that is absent in S. lautus and S. skirrhodon (Wilcox 2012). When S. elegans leaves are crushed they smell distinctively different compared to $S$. lautus and $S$. skirrhodon (personal observation).

Senecio skirrhodon DC., Prodr. 6: 401 (1838), also commonly known as gravel groundsel is an annual or short-lived perennial plant (sometimes becoming woody at the base) introduced to New Zealand (native range is Madagaskar to Mozambique to South Africa) around 1920. S. skirrhodon has between 11-17 ray florets which are bright yellow; discs are golden yellow (Webb et al. 1988, Popay et al. 2010). Compared to S. lautus the colour is warmer (i.e. more towards orange than the slightly greenish ray florets of some S. lautus varieties). The leaves are usually less divided and toothed. Similar to other 
senecios S. skirrhodon is possibly poisonous due to its alkaloid concentrations (Wilcox 2012). This species grows at coastal sites, but can also flourish at inland sites. It is often found at railway tracks, river gravel banks and urban wasteland. On beaches it is often found at beaches with frequent recreational visitors (personal observation).

\section{Other introduced Senecio spp. occasionally searched for insect herbivores}

Senecio glastifolius, also commonly known as 'holly leaved senecio' is an introduced plant that can reach up to $2 \mathrm{~m}$ in height and develop a woody base. The flowers are pink or mauve with yellow discs (Webb et al. 1988, Popay et al. 2010), flowering time is between September-November. It was first introduced to Wellington and has now spread across the lower North Island with potential to expand its range significantly if no management actions are taken (pers.comm Beautrais, 2012). Usually S. glastiolius grows further back compared to the other focal plants in coastal areas and was thus less frequently searched for insect herbivores compared to the other plants in our study.

Senecio vulgaris also commonly known as 'groundsel' is a widespread weed that is native to Europe, Asia and North Africa. It has deeply serrated leaves and no ray florets. Similar to ragwort it is poisonous to stock. Von Borstel et al. (1989) documented the potential of S. vulgaris for hybridisation with other Senecio spp. It only occasionally occurs in our study as it tends to colonize waste places more than coastal sites (personal observation).

\section{INSECT HERBIVORES}

Sphenella fascigera (formerly known as Tephritis fascigera, name revised by (Hancock and Drew 2003): An endemic tephretid (i.e. fruit fly family) seed head predator fly that either has larvae developing in seed heads of Senecio spp. or forms galls in the stems of Senecio (pers. obvservation). In captivity they can survive several months as adult flies (personal observation). Sphenella fascigera has been observed on S. bipinnatisectus Belcher; S. diaschides D.G.Drury; S. esleri Webb; S. glomeratus Poiret; S. hispidulus A.Rich; S. lautus G. Forst. Ex Willd.; S. minimus Poiret S. skirrhodon DC.; S. vulgaris (Martin 2013)and on S. elegans, S.sterquilinus (Orndorff). Tephritid flys are known for 
their signalling with their pigmented wings during courtship. To our knowledge no parasitoid wasps have been previously recorded from Sphenella fascigera (but see additional Chapter 7 in the appendix).

Patagonoides farinaria (blue stem borer) Patagoniodes farinaria (Turner, 1904), Pyralidae, Lepidoptera (moths \& butterflies) is an endemic species with caterpillars feeding on shoots of native and adventive Senecio species. Previously it has been recorded on: S. bipinnatisectus Belcher, S. esleri Webb, S. hispidulus A.Rich, S. lautus G. Forst. Ex Willd, S. minimus Poiret, S. skirrhodon DC. (Martin 2013) and on S. sterquilinus, S. elegans (personal observations).

Nyctemeria annulata (magpie moth) is an endemic diurnal moth (Lepidoptera, superfamily: Noctuoidea, family: Arctiidae) known to feed on native and introduced senecios. Yellowish eggs are laid in clusters of about 20 eggs on the underside of Senecio spp. leaves. The moth larvae (also commonly known as 'woolly bears') are covered in black hair. Caterpillars can move actively to reach neighbouring plants if the original host plant is no longer providing enough food. The endemic $N$. annulata is known to hybridise with the Australian introduced species N. amica. Hybrid moths have longer hairs at the head region and are therefore easily distinguished from $N$. annulata. Within our study we only encountered pure $N$. annulata. The magpie moth has been previously recorded on: S. esleri Webb, S. elegans (personal observation), S. glastifolius (pers. obs.), S. hispidulus A. Rich, S. lautus G. Forst. Ex Willd, S. minimus Poiret, S. radiolatus F. Muell. Supsp. Antipodus (Kirk) C.J. Webb, S. rufiglandulosus Colenso, S. skirrhodon DC., S. sterquilinus (personal observation), S. sylvaticus L., and S. vulgaris

Chromatomyia syngenesiae Hardy, 1849, order: Diptera, superfamily: Opomyzoidea, family: Agromyzidae (Lindquist et al. 1984).The larvae of this introduced fly mine leaves in Asteraceae and other plants. Chromatomya syngenesiae has been recorded (Martin, 2013) on S. hispidulus A. Rich, S. bipinnatisectus Belcher, S. esleri Webb, S. elegans (personal observation), S. glomeratus Poiret, S. lautus G. Forst. Ex Willd, S. minimus 
Poiret, S. quadridentatus Labill, S. radiolatus F. Muell. Supsp. Antipodus (Kirk) C.J. Webb, S. rufiglandulosus Colenso, S. skirrhodon DC, S. sterquilinus (Orndorff) (personal observation), S. vulgaris and a number of plants that occur in the same coastal communities as our focal Senecio spp. (i.e.: Crepis sp.; Cirsium vulgare, Plantago sp., Sonchus asper; Taraxacum officinale, Trifolium repens). 


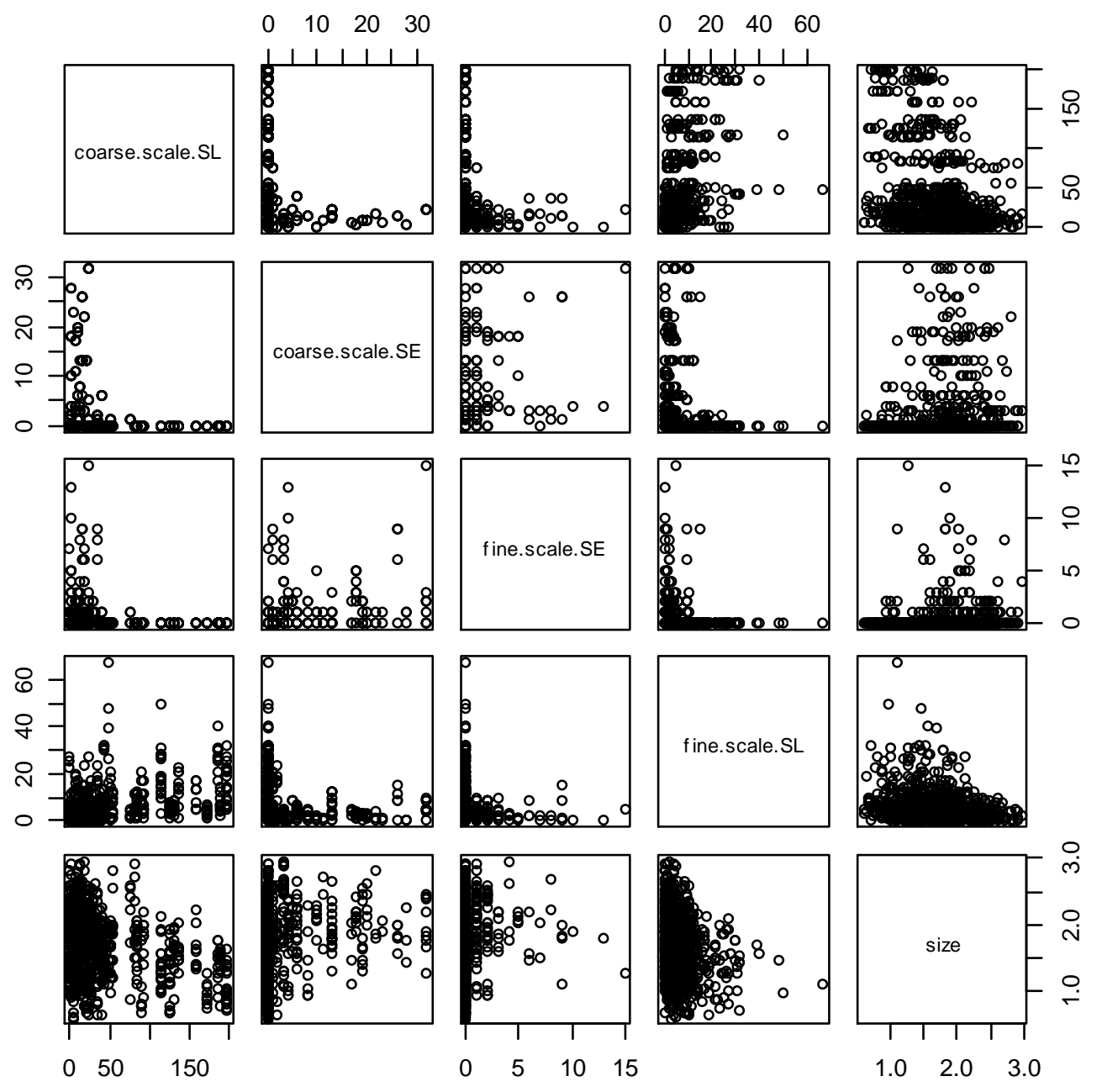

Figure A V.1: Correlation between predictors of the LME: size (plant size), fine scale SL, fine Scale SE, coarse scale SE and coarse scale SL are shown as correlation graphs. SL = Senecio lautus, SE = Senecio elegans.

Table A V.1: Correlation coefficients of predictors used in the LME for Sphenella fascigera in stems and flower heads..

\begin{tabular}{l|lllll} 
Correlation table & coarse.scale.SL & coarse.scale.SE & fine.scale.SE & fine.scale.SL & $\begin{array}{l}\text { plant } \\
\text { size }\end{array}$ \\
\hline coarse.scale.SL & 1 & NA & -0.1425515 & 0.4043674 & -0.32174 \\
coarse.scale.SE & NA & 1 & NA & NA & NA \\
fine.scale.SE & -0.1425515 & NA & 1 & -0.1223418 & 0.119477 \\
fine.scale.SL & 0.4043674 & NA & -0.1223418 & 1 & -0.24682 \\
size & -0.3217449 & NA & 0.1194766 & -0.2468187 & 1
\end{tabular}



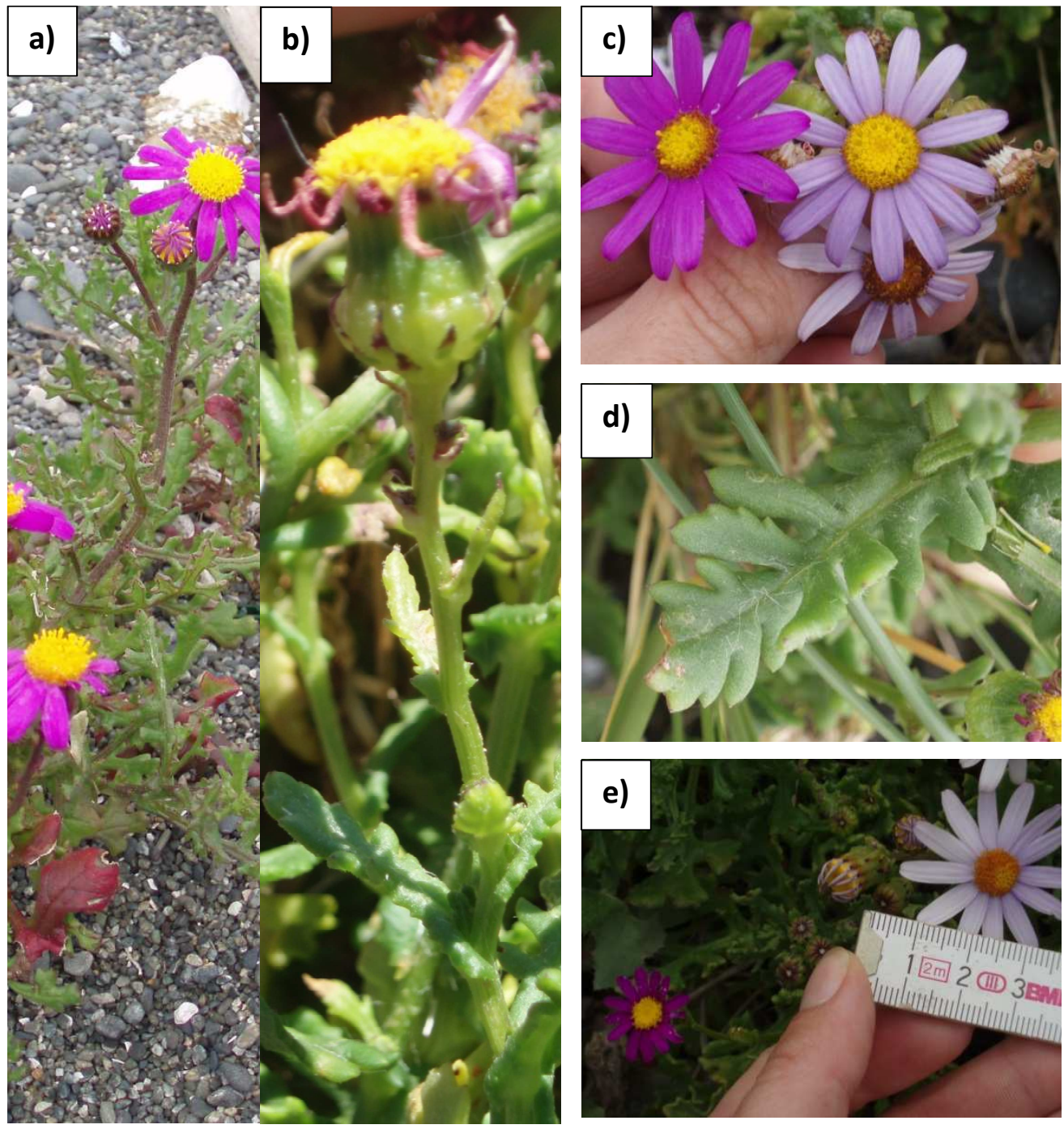

Figure A V.2: Senecio elegans: a) typical plant, b) leaves = lobbed like $S$. lautus (hybrid?), c = flower in typical pink and in light purple, $d=$ unusual leaf, resembles more $S$. lautus than $S$. elegans, but flower (edge of photo) is purple, albeit a bit smaller than the average $S$. elegans flower, e= small flower of typical colouring and large flower in pale rose, almost white. 

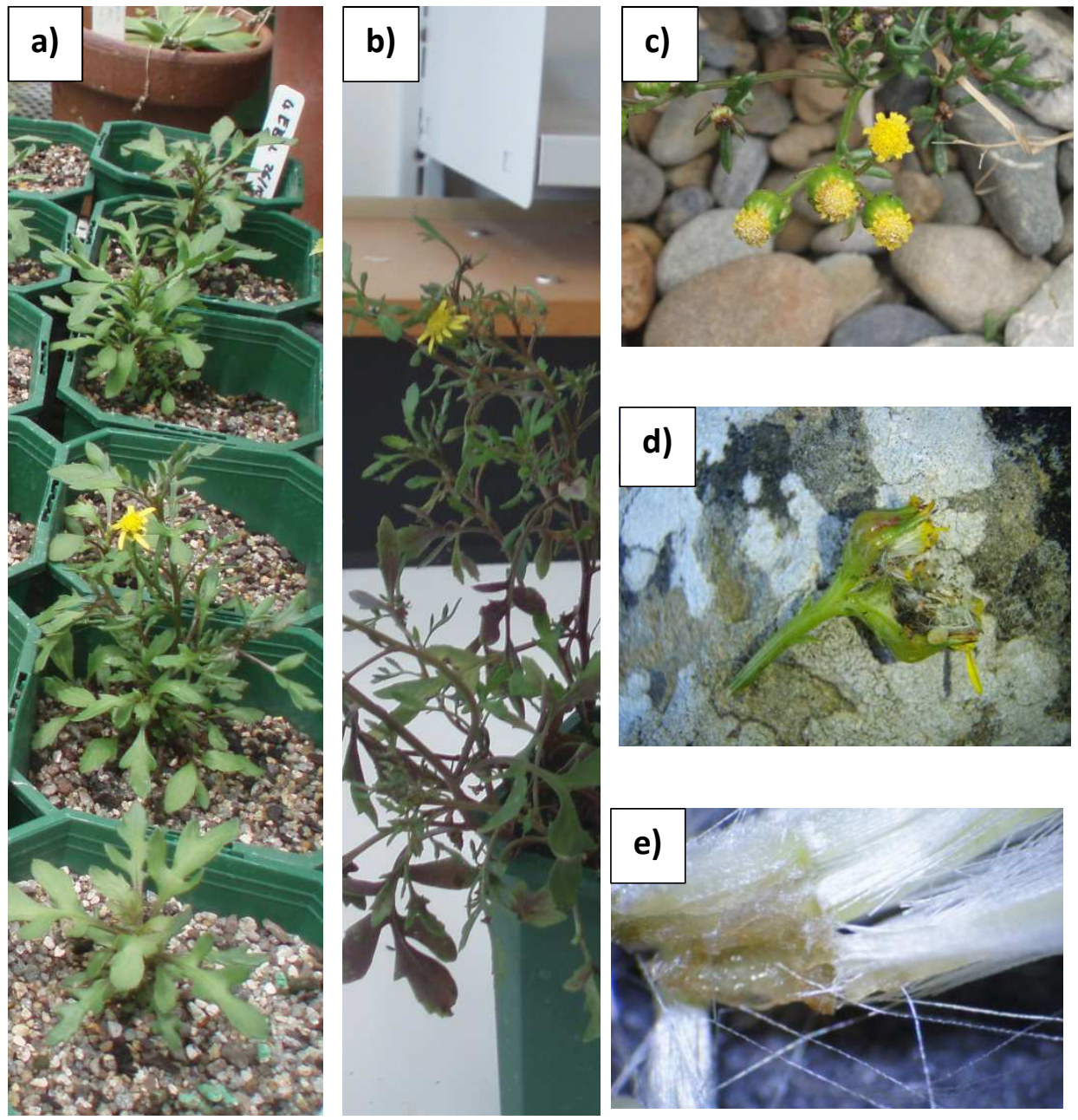

Figure A V.3: Senecio lautus: a) development of heteroblastic leaves, b) deeply lobbed leaves (origin Petone), c) rayless form, d) dissected flower head. 

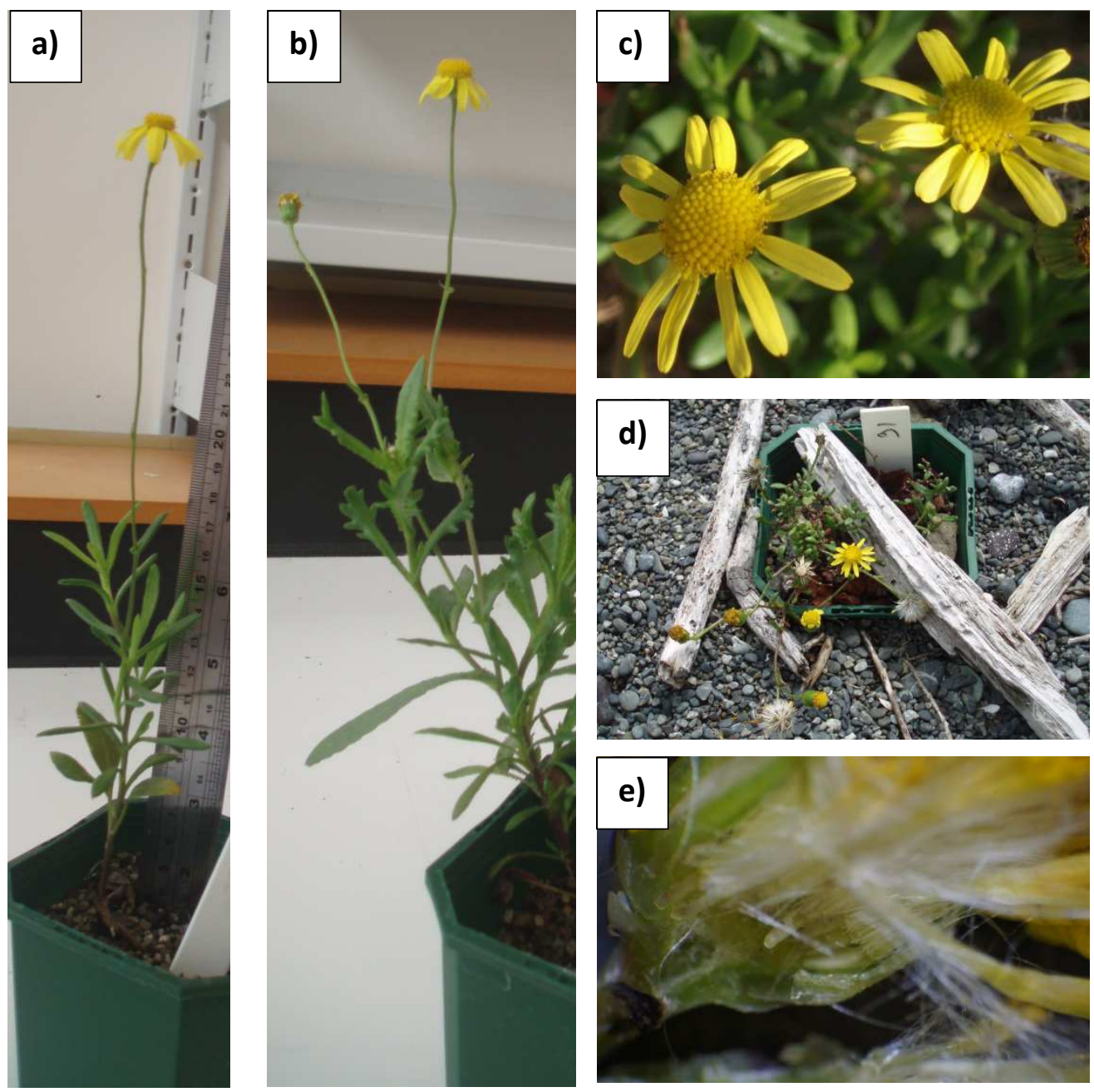

Figure A V.4: Senecio skirrhodon: a) unlobbed leaves, b) leaves $=$ heteroblastic/lobbed, $c=$ typical flower, $d=$ dissected flower head 

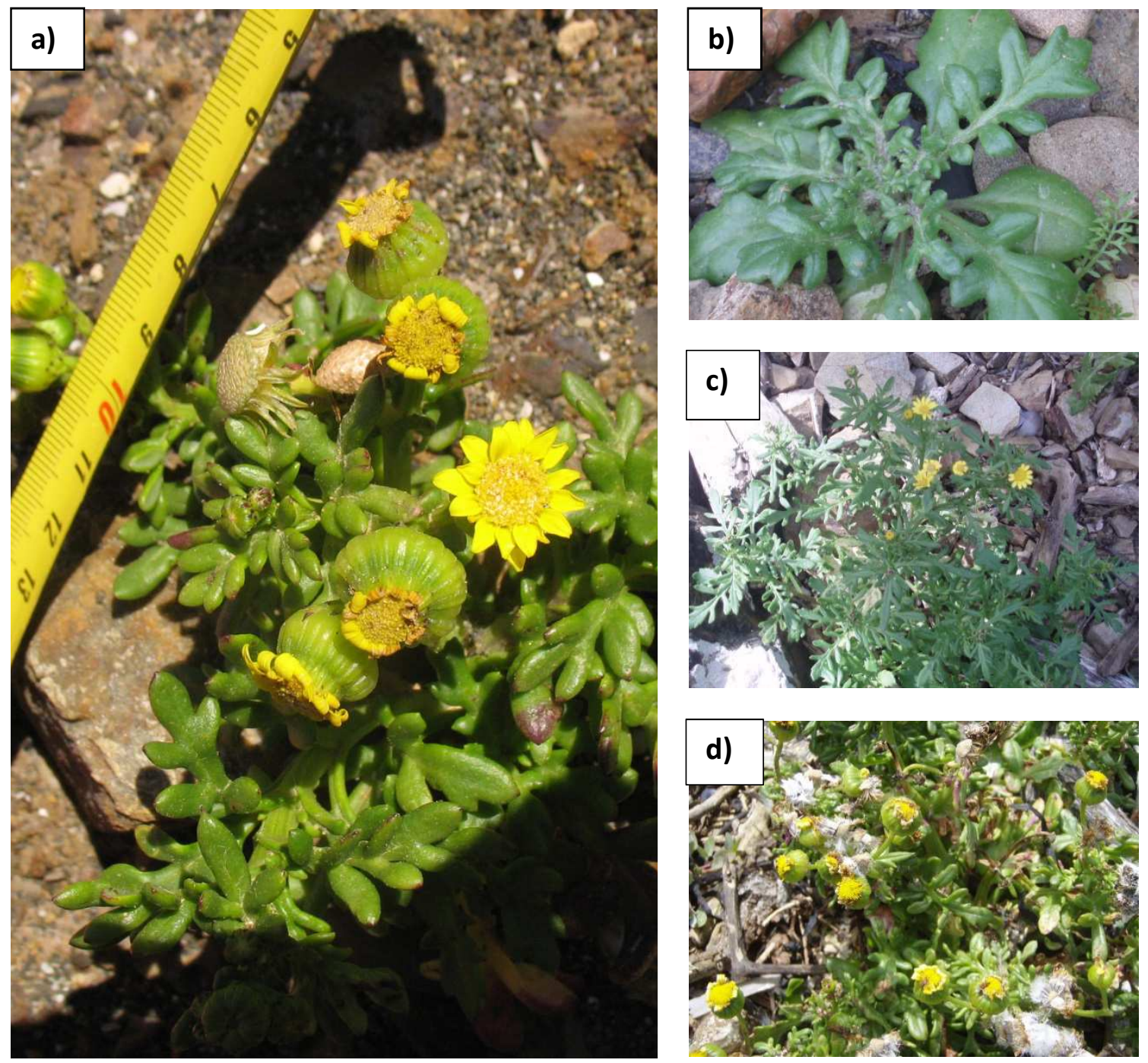

Figure A V.5: Senecio sterquilinus: a) S. sterquilinus on Matiu/Somes Island, b) deeply lobbed leaves (origin Petone), c) hybrid between S. sterquilinus and S. lautus (less than 20 rayflorets), d) Mature $S$. sterquilinus, finished flowering. 

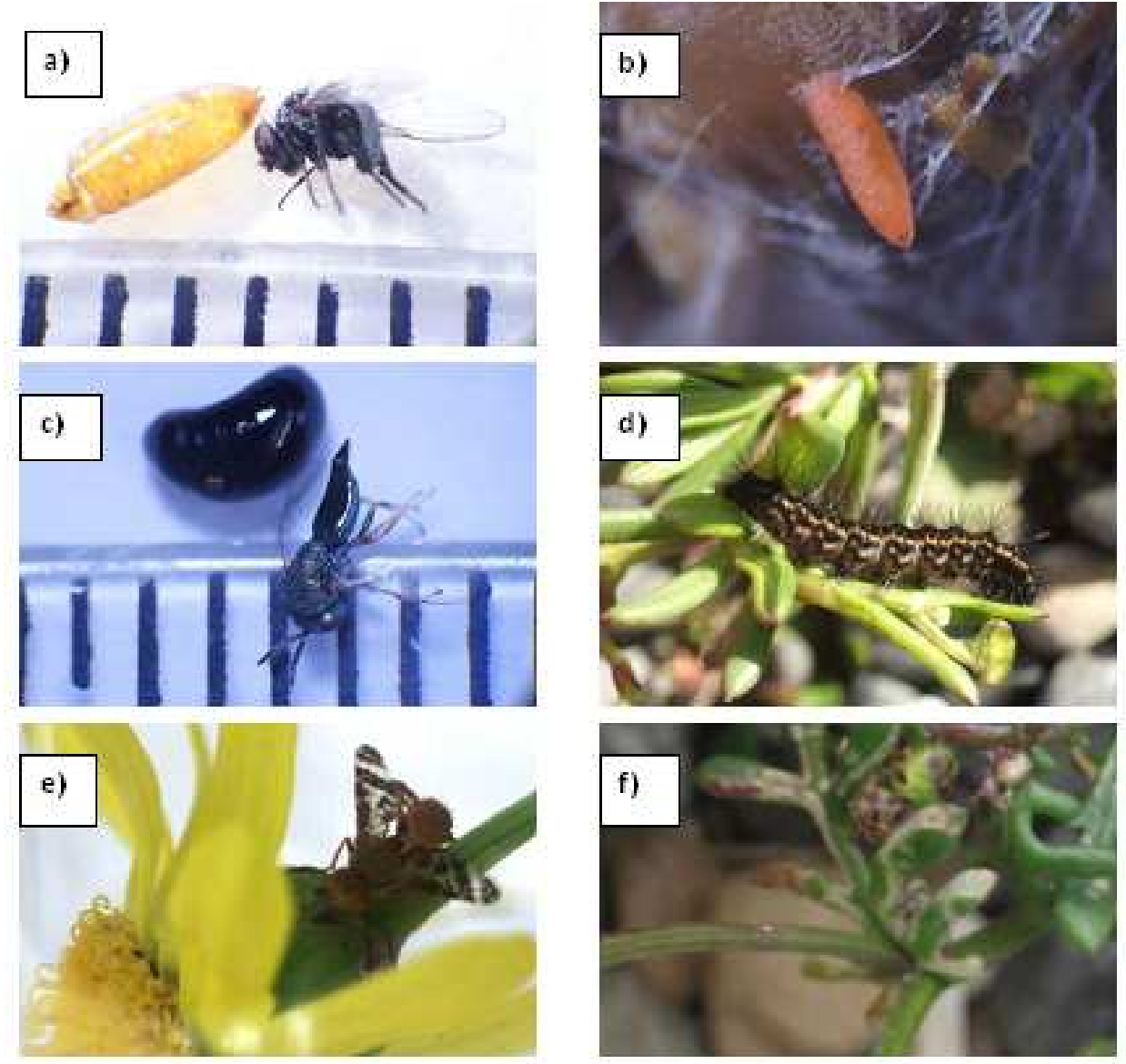

Figure A V.6: Insects: a) Melanagromyza senecionella, b) Cecimidoyiid larvae, c) Pteromalus sp., d) Nyctemera annulata caterpillar, e) Mating Sphenella fascigera, f) leafminer trace (Chromatomya syngenesiae) 


\section{REFERENCES}

Aebi, A., K. Schonrogge, G. Melika, A. Alma, G. Bosio, A. Quacchia, L. Picciau, Y. Abe, S. Moriya, K. Yara, G. Seljak, and G. N. Stone. 2006. 9 Parasitoid recruitment to the globally invasive chestnut gall wasp Dryocosmus kuriphilus. Pages 101-121 in K. Ozaki, J. Yukawa, T. Ohgushi, and R. Price, editors. Galling. Tokyo, Japan.

Ahmed, M., and J. Ogden. 1987. Population dynamics of the emergent conifer Agathis australis (D. Don) Lindl.(kauri) in New Zealand I. Population structures and tree growth rates in mature stands. New Zealand Journal of Botany 25:217-229.

Alexander, R. B., E. W. Boyer, R. a Smith, G. E. Schwarz, and R. B. Moore. 2007. The Role of Headwater Streams in Downstream Water Quality. Journal of the American Water Resources Association / AWRA 43:41-59.

Ali, J. G., and A. Agrawal. 2012. Specialist versus generalist insect herbivores and plant defense. Trends in Plant Science 17:293-302.

Allen, G. S., B. G. Griffith, and J. W. Ker. 1951. A comparison of several regeneration survey methods in terms of cost and usefulness. B.C. Lumberman 35:66-96.

Allen, R., and T. Partridge. 1992. Ecology of Kunzea ericoides (A. Rich.) J. Thompson (kanuka) in east Otago, New Zealand. New Zealand Journal of Botany 30:135-149.

Allesina, S., D. Alonso, and M. Pascual. 2008. A general model for food web structure. Science (New York, N.Y.) 320:658-61.

Allstadt, A., T. Caraco, F. Molnár, and G. Korniss. 2012. Interference competition and invasion: spatial structure, novel weapons and resistance zones. Journal of Theoretical Biology 306:46-60.

Alpert, P., E. Bone, and C. Holzapfel. 2000. Invasiveness, invasibility and the role of environmental stress in the spread of non-native plants. Perspectives in Plant Ecology, Evolution and Systematics 3:52-66.

Alvarez-Rogel, J., J. J. Martinez-Sanchesz, L. C. Blazquez, and C. M. M. Semitiel. 2006. A conceptual model of salt marsh plant distribution in coastal dunes of southeastern Spain. Wetlands 26:703-717.

Ando, Y., S. Utsumi, and T. Ohgushi. 2010. Community structure of insect herbivores on introduced and native Solidago plants in Japan. Entomologia Experimentalis et Applicata 136:174-183. 
Armas, C., S. Rodríguez-Echeverría, and F. I. Pugnaire. 2011. A field test of the stressgradient hypothesis along an aridity gradient. Journal of Vegetation Science 22:818-827.

Assem, J. van den. 1967. Territory in the three-spined stickleback Gasterosteus aculeatus L.: an experimental study in intra-specific competition. Behaviour. Supplement:170.

Atwater, D. Z., C. M. Bauer, and R. M. Callaway. 2011. Indirect positive effects ameliorate strong negative effects of Euphorbia esula on a native plant. Plant Ecology 212:1655-1662.

Baas, A. C. W. 2002. Chaos, fractals and self-organization in coastal geomorphology: simulating dune landscapes in vegetated environments. Geomorphology 48:309328.

Baker, M. R., R. L. Kitching, C. a M. Reid, and F. Sheldon. 2012. Coleoptera (Chrysomelidae, Coccinellidae, Curculionoidea) in sclerophyll woodland: variation in assemblages among host plants, and host specificity of phytophagous and predatory beetles. Australian Journal of Entomology 51:145-153.

Bañuelos, M.-J., and J. Kollmann. 2011. Effects of host-plant population size and plant sex on a specialist leaf-miner. Acta Oecologica 37:58-64.

Barbier, E. B., S. D. Hacker, C. Kennedy, E. W. Koch, A. C. Stier, and B. R. Silliman. 2011. The value of estuarine and coastal ecosystem services. Ecological Monographs 81:169-193.

Barron, M. C. 2007. Retrospective modelling indicates minimal impact of non-target parasitism by Pteromalus puparum on red admiral butterfly (Bassaris gonerilla) abundance. Biological Control 41:53-63.

Bates, D., M. Maechler, and B. Boulder. 2012. Ime4: Linear mixed-effects models using S4 classes.

Beautrais, J. 2012. Personal communication with J. Beautrais. Victoria University of Wellington.Wellington/New Zealand 2012.

Begon, M., S. M. Sait, and D. J. Thompson. 1995. Persistence of a parasitoid-host system: refuges and generation cycles? Proceedings of the Royal Society of London Series B: Biological Sciences 260:131-137.

Bellingham, P., R. Duncan, W. Lee, and R. Buxton. 2004. Seedling growth rate and survival do not predict invasiveness in naturalized woody plants in New Zealand. Oikos 106:308-316.

Benn, M., J. Degrave, C. Gnanasundaram, and R. Hutchins. 1979. Host-plant pyrrolizidine alkaloids in Nyctemera annulata Boisduval: Their persistence through the life-cycle and transfer to a parasite. Experientia 35:731-732. 
Bennett, G. M., and P. M. O'Grady. 2012. Host-plants shape insect diversity: phylogeny, origin, and species diversity of native Hawaiian leafhoppers (Cicadellidae: Nesophrosyne). Molecular Phylogenetics and Evolution 65:705-17.

Berendse, F., E. Lammerts, and H. Olff. 1998. Soil organic matter accumulation and its implications for nitrogen mineralization and plant species composition during succession in coastal dune slacks. Plant Ecology:71-78.

Bergin, D. 2008a. Performance of indigenous species three years after planting on a backdune, Ohwia Spit, Eastern Bay of Plenty. Pages 1-26 Dune Restoration Trust. Rotorua.

Bergin, D. 2011. Spinifex Kowhangatara- ecology, habitat and growth. Pages 1-12. Rotorua.

Bergin, D., and P. FitzSimons. 1997. Management of marram grass in the restoration of indigenous coastal dune vegetation in Australia and New Zealand. Pacific Coasts and Ports '97: Proceedings of the 13th Australasian Coastal and Ocean Engineering Conference and the 6th Australasian Port and Harbour Conference 1.

Bergin, D., and J. Herbert. 1997. Revegetation of Coastal Sand Dunes in New Zealand using Indigenous Species. Pacific Coasts and Ports '97: Proceedings of the 13th Australasian Coastal and Ocean Engineering Conference and the 6th Australasian Port and Harbour Conference 1:1-6.

Bergin, D., and M. Kimberley. 1999. Rehabilitation of coastal foredunes in New Zealand using indigenous sand-binding species. Science for Conservation 122:1-52.

Bergin, D. O. 2008b. Establishment of the indigenous sand binder spinifex (Spinifex sericeus) along the sand dunes of Christchurch. Pages 1-27. Rotorua.

Berry, J. A. 2003. Neopolycystus insectifurax Girault (Hymenoptera: Pteromalidae) is established in New Zealand, but how did it get here? New Zealand Entomologist 26:113-114.

Bertheau, C., E. G. Brockerhoff, G. Roux-Morabito, F. Lieutier, and H. Jactel. 2010. Novel insect-tree associations resulting from accidental and intentional biological "invasions": a meta-analysis of effects on insect fitness. Ecology Letters 13:506-15.

Bertness, M. D., and R. Callaway. 1994. Positive interactions in communities. Trends in Ecology \& Evolution 9:191-3.

Bleasdale, J. K. A. 1960. Studies on plant competition. In Biology of Weeds, Symp. Brit. ecol. Soc. Pages 133-142.

Bolker, B., and S. Pacala. 1999. Spatial moment equations for plant competition: understanding spatial strategies and the advantages of short dispersal. The American Naturalist 153:575-602. 
Bonsall, M. B., and M. P. Hassell. 1997. Apparent competition structures ecological assemblages. Nature 388:371-373.

Von Borstel, K., L. Witte, and T. Hartmann. 1989. Pyrrolizidine alkaloid patterns and populations of Senecio vulgaris, S. vernalis and their hybrids. Phytochemistry 28:1635-1638.

Briese, D., and A. Walker. 2002. A new perspective on the selection of test plants for evaluating the host-specificity of weed biological control agents: the case of Deuterocampta quadrijuga, a potential insect control agent of Heliotropium amplexicaule. Biological Control 25:273-287.

Brockerhoff, E. G., B. I. P. Barratt, J. R. Beggs, L. L. Fagan, M. K. N. Kay, C. B. Phillips, and C. J. Vink. 2010. Impacts of exotic invertebrates on New Zealand's indigenous species and ecosystems. New Zealand Journal of Ecology 34:158-174.

Brooker, R. W. 2006. Plant-plant interactions and environmental change. The New Phytologist 171:271-84.

Brooker, R. W., F. T. Maestre, R. M. Callaway, C. L. Lortie, L. A. Cavieres, G. Kunstler, P. Liancourt, K. Tielbörger, J. M. J. Travis, F. Anthelme, C. Armas, L. Coll, E. Corcket, S. Delzon, E. Forey, Z. Kikvidze, J. Olofsson, F. Pugnaire, C. L. Quiroz, P. Saccone, K. Schiffers, M. Seifan, B. Touzard, and R. Michalet. 2007. Facilitation in plant communities: the past, the present, and the future. Journal of Ecology 96:18-34.

Brown, J., D. Davidson, and O. Reichman. 1979. An experimental study of competition between seed-eating desert rodents and ants. American Zoologist 19:1129-1143.

Bruno, J. 2000. Facilitation of cobble beach plant communities through habitat modification by Spartina alterniflora. Ecology 81:1179-1192.

Bruno, J. F., and M. I. O'Connor. 2005. Cascading effects of predator diversity and omnivory in a marine food web. Ecology Letters 8:1048-1056.

Bruno, J. F., J. J. Stachowicz, and M. D. Bertness. 2003. Inclusion of facilitation into ecological theory. Trends in Ecology \& Evolution 18:119-125.

Burns, K. 2005. Plastic heteroblasty in beach groundsel (Senecio lautus). New Zealand Journal of Botany 43:665-672.

Callaway, R. M. 2007. Positive interactions and interdependence in plant communities. Page 416. Dordrecht: Springer.

Callaway, R. M. 1992. Effect of Shrubs on Recruitment of Quercus Douglasii and Quercus Lobata in California. Ecology 73:2118-2128.

Callaway, R. M., and L. R. Walker. 1997. Competition and facilitation: a synthetic approach to interactions in plant communities. Ecology 78:1958-1965. 
Cameron, E. 1935. A Study of the Natural Control of Ragwort (Senecio jacobaea L .). Journal of Ecology 23:265-322.

Carranza, M. L., M. Carboni, S. Feola, and A. T. R. Acosta. 2010. Landscape-scale patterns of alien plant species on coastal dunes: the case of iceplant in central Italy. Applied Vegetation Science 13:135-145.

Carrillo-Gavilán, A., X. Moreira, R. Zas, M. Vilà, and L. Sampedro. 2012. Early resistance of alien and native pines against two native generalist insect herbivores: no support for the natural enemy hypothesis. Functional Ecology 26:283-293.

Case, T. J., and M. E. Gilpin. 1974. Interference competition and niche theory. Proceedings of the National Academy of Sciences,71:3073-3077.

Cates, R. G. 1980. Feeding Patterns of Monophagous, Oligophagous and Polyphagous Insect Herbivores: The Effect of Resource Abundance and Plant Chemistry. Oecologia 31:22-31.

Cavieres, L., M. T. K. Arroyo, A. Penaloza, M. Molina-Montenegro, and C. Torres. 2002. Nurse effect of Bolax gummifera cushion plants in the alpine vegetation of the Chilean Patagonian Andes. Journal of Vegetation Science 13:547-554.

Cereto, C. E., G. O. Schmidt, a. G. Martins, T. T. Castellani, and B. C. Lopes. 2011. Nesting of ants (Hymenoptera, Formicidae) in dead post-reproductive plants of Actinocephalus polyanthus (Eriocaulaceae), a herb of coastal dunes in southern Brazil. Insectes Sociaux 58:469-471.

Červinka, J., M. Šálek, E. Padyšáková, and P. Šmilauer. 2013. The effects of local and landscape-scale habitat characteristics and prey availability on corridor use by carnivores: A comparison of two contrasting farmlands. Journal for Nature Conservation 21:105-113.

Chaneton, E. J., C. Noemi Mazía, and T. Kitzberger. 2010. Facilitation vs. apparent competition: insect herbivory alters tree seedling recruitment under nurse shrubs in a steppe-woodland ecotone. Journal of Ecology 98:488-497.

Chapman, D. F. 1983. Growth and demography of Trifolium repens stolons in grazed hill pastures. Journal of Applied Ecology 20:597-608.

Chen, Y., and E. Schmelz. 2008. Cotton plant, Gossypium hirsutum L., defense in response to nitrogen fertilization. Journal of Chemical Ecology 34:1553-1564.

Chiappini, E., G. Salerno, A. Berzolla, A. lacovone, M. Cristina Reguzzi, and E. Conti. 2012. Role of volatile semiochemicals in host location by the egg parasitoid Anagrus breviphragma. Entomologia Experimentalis et Applicata 144:311-316.

Clay, K. 2003. Conservation biology: Parasites lost. Nature 421:585-586. 
Clutton-Brock, T. H., D. Green, M. Hiraiwa-Hasegawa, and S. D. Albon. 1988. Passing the buck: resource defence, lek breeding and mate choice in fallow deer. Behavioral Ecology and Sociobiology 23:281-296.

Cockayne, L. 1911. Report on the dune-areas of New Zealand: their geology, botany, and reclamation. Page 76. Wellington/New Zealand.

Cousins, W. 2004. Towards a first-order earthquake loss model for New Zealand. Getting the message across and moving ahead: In Proceedings, 2004 Conference of the New Zealand Society for Earthquake Engineering (pp. 19-21).

Crain, C. M., B. R. Silliman, S. L. Bertness, and M. D. Bertness. 2004. Physical and biotic drivers of plant distribution across estuarine salinity gradients. Ecology 85:25392549.

Crawley, M. J., and J. E. Harral. 2001. Scale dependence in plant biodiversity. Science 291:864-868.

Crews, T. E. 1999. The presence of nitrogen fixing legumes in terrestrial communities: evolutionary vs ecological considerations. Biogeochemistry 46:233-246.

D'Antonio, C., and L. a. Meyerson. 2002. Exotic plant species as problems and solutions in ecological restoration: a synthesis. Restoration Ecology 10:703-713.

Daehler, C. C. 2003. Performance comparisons of co-occurring native and alien invasive plants: Implications for conservation and restoration. Annual Review of Ecology, Evolution and Systematics 34:183-211.

Daehler, C., and N. Dudley. 2002. Impact of the black twig borer, an introduced insect pest, on Acacia koa in the Hawaiian Islands. Micronesica 6:35-53.

Dahm, J., G. Jenks, and D. Bergin. 2005. Community-based dune management for the mitigation of coastal hazards and climate change effects: A guide for local authorities.

Dangremond, E. M., E. A. Pardini, and T. M. Knight. 2010. Apparent competition with an invasive plant hastens the extinction of an endangered lupine. Ecology 91:2261-71.

Darwin, C. 1859. On the origins of species by means of natural selection. London: Murray.

Davis, J. M., Nufio, C.R and D.R. Papaj2011. Resource quality or competition: why increase resource acceptance in the presence of conspecifics? Behavioral Ecology. $\operatorname{arr} 042$ 
Dayton, P. K. 1971. Competition, disturbance, and community organization: the provision and subsequent utilization of space in a rocky intertidal community. Ecological Monographs 41:351-389.

Department of Conservation. 2010. New Zealand Coastal Policy Statement 2010. Page 30. Wellington/New Zealand.

Dethier, V. 1954. Evolution of feeding preferences in phytophagous insects. Evolution 8:33-54.

Didham, R. K., J. M. Tylianakis, N. J. Gemmell, T. a Rand, and R. M. Ewers. 2007. Interactive effects of habitat modification and species invasion on native species decline. Trends in Ecology \& Evolution 22:489-96.

Diez, J. M., P. a Williams, R. P. Randall, J. J. Sullivan, P. E. Hulme, and R. P. Duncan. 2009. Learning from failures: testing broad taxonomic hypotheses about plant naturalization. Ecology Letters 12:1174-83.

Dormann, C., B. Gruber, and J. Fründ. 2008. Introducing the bipartite package: analysing ecological networks. R news 8/2:1-11.

Dow AgroSciences. 2000. Gallant * NF Herbicide:1-4.

Drossel, B., P. G. Higgs, and A. J. McKane. 2000. The influence of predator-prey population dynamics on the long-term evolution of food web structure. Journal of Theoretical Biology, 208(1), 91-107.

Drossel, B., and A. McKane. 2002. Modelling food webs. arXiv preprint nlin/0202034:134.

Duan, J. J., M. F. Prucell, and H. Messing. 1996. Parasitoids of non-target tephritid flies in hawaii: implications for biological control of fruit fly pests. Entomophaga 41:245256.

Duncan, R. 1991. Competition and the coexistence of species in a mixed podocarp stand. Journal of Ecology 79:1073-1084.

Dunne, J. a, R. J. Williams, and N. D. Martinez. 2002. Food-web structure and network theory: The role of connectance and size. Proceedings of the National Academy of Sciences of the United States of America 99:12917-22.

Early, J. and R. F. Schnitzler, 2012. Personal communication. Auckland Museum and Landcare Research. Auckland. Auckland/New Zealand 2012.

Edelman, T. 1972. Chapter 70 Dune erosion during storm conditions. Coastal Engineering Proceedings 1:1305-1312. 
Egan, S. P., and J. R. Ott. 2007. Host plant quality and local adaptation determine the distribution of a gall-forming herbivore. Ecology 88:2868-2879.

Emery, N., P. Ewanchuk, and M. Bertness. 2001. Competition and salt-marsh plant zonation: stress tolerators may be dominant competitors. Ecology 82:2471-2485.

Eränen, J. K., and M. V. Kozlov. 2008. Increasing intraspecific facilitation in exposed environments : consistent results from mountain birch populations in two subarctic stress gradients. Oecologia 117:1569-1577.

Esler, A. E. 1970. Manawatu sand dune vegetation. Proceedings of the New Zealand Ecological Society 17:41-46.

Fagundes, M., and G. W. Fernandes. 2011, September. Insect herbivores associated with Baccharis dracunculifolia (Asteraceae): responses of gall-forming and free-feeding insects to latitudinal variation.

Fenner, M., and W. G. Lee. 2001. Lack of pre-dispersal seed predators in introduced Asteraceae in New Zealand. New Zealand Journal of Ecology 25:95-99.

Ferreira Santos de Aquino, M., A. M. Dias, M. Borges, M. C. B. Moraes, and R. A. Laumann. 2012. Influence of visual cues on host-searching and learning behaviour of the egg parasitoids Telenomus podisi and Trissolcus basalis. Entomologia Experimentalis et Applicata 145:162-174.

Forey, E., B. Chapelet, Y. Vitasse, M. Tilquin, B. Touzard, and R. Michalet. 2008. The relative importance of disturbance and environmental stress at local and regional scales in French coastal sand dunes. Journal of Vegetation Science 19:493-502.

Forey, E., C. Lortie, and R. Michalet. 2009. Spatial patterns of association at local and regional scales in coastal sand dune communities. Journal of Vegetation Science 20:916-925.

Fowler, S. V., P. Syrett, and P. Jarvis. 2000. Will expected and unexpected non-target effects, and the new Hazardous Substances and New Organisms Act, cause biological control of broom to fail in New. Proceedings of the $X$ International symposium on biological control of weeds. Montana State University, Bozeman, Montana,173-186.

Franco, A. A. C., P. S. Nobel, A. C. Franco, and L. Angeles. 1989. Effect of nurse plants on the microhabitat and growth of cacti. Journal of Ecology 77:870-886.

Franco, A. C., and P. S. Nobel. 1988. Interactions Between Seedlings of Agave Deserti and the Nurse Plant Hilaria Rigida. Ecology 69:1731-1740.

Franks, S. J. 2003. Facilitation in multiple life-history stages: evidence for nucleated succession in coastal dunes: 1-11. 
Frantzen, J., and H. Müller-Schärer. 2006. Modeling the impact of a biocontrol agent, Puccinia lagenophorae, on interactions between a crop, Daucus carota, and a weed, Senecio vulgaris. Biological Control 37:301-306.

Freese, G., and H. Zwölfer. 1996. The problem of optimal clutch size in a tritrophic system: the oviposition strategy of the thistle gallfly Urophora cardui (Diptera, Tephritidae). Oecologia 108:293-302.

French, K., T. J. Mason, and N. Sullivan. 2010. Recruitment limitation of native species in invaded coastal dune communities. Plant Ecology 212:601-609.

Funk, D. T., C. Schlesinger, Richard, and F. J. Ponder. 1979. Autumn-Olive as a Nurse Plant for Black Walnut. Botanical Gazette 140:110-114.

Gadgil, R. 1983. Biological nitrogen fixation in forestry-research and practice in Australia and New Zealand. Pages 317-332 Springer Netherlands.

Gadgil, R., and F. Ede. 1998. Application of scientific principles to sand dune stabilization in New Zealand: past progress and future needs. Land Degradation \& Development 9:131-142.

Gadgil, R. L. 2006a. Marram grass- Friend or Foe? CDVN Technical Bulletin 5:33.

Gadgil, R. L. 2006b. Marram grass Friend or Foe. Pages 1-33 CDVN Technical Bulletin. New Zealand Forest Research Institute Limited, Rotorua.

Gao, Q., M. Yu, X. Yang, and J. Wu. 2001. Scaling simulation models for spatially heterogeneous ecosystems with diffusive transportation. Landscape Ecology 16:289-300.

Glasby, G. P. 1991. Journal of the Royal Society of A review of the concept of sustainable management as applied to New Zealand. Journal of the Royal Society of New Zealand 21:61-81.

Gómez-Aparicio, L., Zamora, R., Gómez, J. M., Hódar, J. A., Castro, J., \& Baraza, E. 2004. Applying plant facilitation to forest restoration: a meta-analysis of the use of shrubs as nurse plants. Ecological Applications, 14(4), 1128-1138.

Gooden, B., K. French, and P. J. Turner. 2009. Invasion and management of a woody plant, Lantana camara L., alters vegetation diversity within wet sclerophyll forest in southeastern Australia. Forest Ecology and Management 257:960-967.

Green, R. E. 1997. The influence of numbers released on the outcome of attempts to introduce exotic bird species to New Zealand. Journal of Animal Ecology 66:25-35.

Greenway, H., and R. Munns. 1980. Mechanisms of salt tolerance in nonhalophytes. Annual review of plant physiology 31:149-190. 
Grime, J. 1977. Evidence for the existence of three primary strategies in plants and its relevance to ecological and evolutionary theory. American naturalist 111:11691194.

Hacker, S. D., and S. D. Gaines. 1997. Some implications of direct positive interactions for community species diversity. Ecology 78:1990.

Haegen, W. Vander, and R. Degraaf. 1996. Predation on artificial nests in forested riparian buffer strips. The Journal of Wildlife Management 60:542-550.

Hambäck, P. a., and Gãף. Englund. 2005. Patch area, population density and the scaling of migration rates: the resource concentration hypothesis revisited. Ecology Letters 8:1057-1065.

Hamzaoğlu, E., Ü. Budak, and A. Aksoy. 2009. A new taxon of Senecio ( Asteraceae ) from Turkey : Senecio inops Boiss . \& Balansa subsp . karamanicus Hamzaoğlu \& Budak. Turk J Bot 33:285-289.

Hancock, D. L., and R. A. i. Drew. 2003. A new genus and new species, combined and records of tephritinae (Diptera: Tephretidae) in Australia, New Zealand and the South Pacific. Austri:141-158.

Hansen, D. M., H. C. Kiesbüy, C. G. Jones, and C. B. Müller. 2007. Positive indirect interactions between neighboring plant species via a lizard pollinator. The American naturalist 169:534-42.

Hanski, I. 2001. Spatially realistic theory of metapopulation ecology. Naturwissenschaften 88:372-381.

Harrington, K. 2013. Hawkbit. http://www.hortinfo.co.nz/factsheets/fs140-98.asp.

Harrison, S., and C. Thomas. 1991. Patchiness and spatial pattern in the insect community on ragwort Senecio jacobaea. Oikos 62:5-12.

Hart, A. T., M. J. Hilton, S. J. Wakes, and K. J. M. Dickinson. 2012. The impact of Ammophila arenaria foredune development on downwind aerodynamics and parabolic dune development. Journal of Coastal Research 279:112-122.

Hayward, M. W., M. Hofmeyr, J. O'Brien, and G. I. H. Kerley. 2006. Prey preferences of the cheetah (Acinonyx jubatus) (Felidae: Carnivora): morphological limitations or the need to capture rapidly consumable prey before kleptoparasites arrive? Journal of Zoology 270:615-627.

Heger, T., and H. Böhmer. 2005. Die Einwanderung des Schmalblättrigen Greiskrautes (Senecio inaquidens DC.) nach Mitteleuropa-Analyse eines komplexen biogeographischen Problems. Erdkunde:34-49. 
Heleno, R. H., R. S. Ceia, J. a Ramos, and J. Memmott. 2009. Effects of alien plants on insect abundance and biomass: a food-web approach. Conservation biology: the journal of the Society for Conservation Biology 23:410-9.

Helms, K. R., and S. B. Vinson. 2003. Apparent facilitation of an invasive mealybug by an invasive ant. Insectes Sociaux 50:403-404.

Hendriks, R. J. J., L. Luijten, and J. M. van Groenendael. 2009. Context-dependent defence in terrestrial plants: the effects of light and nutrient availability on plant resistance against herbivory. Entomologia Experimentalis et Applicata 131:233242.

Henneman, M. L., and J. Memmott. 2001. Infiltration of a Hawaiian community by introduced biological control agents. Science (New York, N.Y.) 293:1314-6.

Herms, D., and W. Mattson. 1992. The dilemma of plants: to grow or defend. Quarterly Review of Biology 67:283-335.

Hesp, P. 2002. Coastal sand dunes-form and function. Massey University, CDVN Technical Bulletin.

Hesp, P. A. 2001. The Manawatu dunefield: environmental change and human impacts. New Zealand Geographer 57:33-40.

Hill, R., A. Gourlay, and S. Fowler. 2000. The biological control program against gorse in New Zealand. Proceedings of the $X$ International Symposium on Biological Control of Weeds:909-917.

Hilton, M., M. Duncan, and A. Jul. 2005. Processes of Ammophila arenaria (marram grass) invasion and indigenous species displacement, Stewart Island, New Zealand. Journal of Coastal Research 21:175-185.

Hilton, M., N. Harvey, A. Hart, K. James, and C. Arbuckle. 2006. The Impact of Exotic Dune Grass Species on Foredune Development in Australia and New Zealand: a case study of Ammophila arenaria and Thinopyrum junceiforme. Australian Geographer 37:313-334.

Hilton, M., U. Macauley, R. Henderson, and M. John. 2000. Inventory of New Zealand's active dunelands. Page 34. Wellington.

Hol, W. H. G. 2011. The effect of nutrients on pyrrolizidine alkaloids in Senecio plants and their interactions with herbivores and pathogens. Phytochemistry reviews: proceedings of the Phytochemical Society of Europe 10:119-126.

Holt, R. D. 1977. Predation, apparent competition and the structure of prey communities. Theoretical Population Biology1 12:197-229. 
Holt, R. D., and J. H. Lawton. 1993. Apparent competition and enemy-free space in insect host-parasitoid communities. The American Naturalist 142:623-645.

Honrado, J., J. Vicente, A. Lomba, P. Alves, J. A. Macedo, R. Henriques, H. Granja, and F. B. Caldas. 2010. Fine-scale patterns of vegetation assembly in the monitoring of changes in coastal sand-dune landscapes. Web Ecology:1-14.

Howe, G. a, and G. Jander. 2008. Plant immunity to insect herbivores. Annual Review of Plant Biology 59:41-66.

Howe, H. E., and J. Smallwood. 1982. Ecology of seed dispersal. Annual Review of Ecology and Systematics 13:201-228.

Huiskes, A. H. L. 1979. Ammophila arenaria (L.) Link (Psamma arenaria (L.) Roem et Schult.: Clamagrostis arenaria (L.) Roth). Journal of Ecology 67:363-382.

Human, K., and D. Gordon. 1996. Exploitation and interference competition between the invasive Argentine ant, Linepithema humile, and native ant species. Oecologia 105:405-412.

Huxel, G. 1999. Rapid displacement of native species by invasive species: effects of hybridization. Biological Conservation 89:143-152.

Ito, M., and N. Hijii. 2004. Roles of gall morphology in determining potential fecundity and avoidance of parasitoid attack in Aphelonyx glanduliferae. Journal of Forest Research 9:93-100.

Jacquemart, A.-L., V. Vanparys, and P. Meerts. 2013. Generalist versus specialist herbivores on the invasive Senecio inaequidens and a native related species: What makes the difference? American Journal of Plant Sciences 4:386-394.

Jaeger, R. 1970. Potential extinction through competition between two species of terrestrial salamanders. Evolution 24:632-642.

Jamieson, S. L. 2010. Sand dune restoration in New Zealand: methods, motives, and monitoring.

Jeffrey, C., P. Halliday, M. Wilmot-Dear, and S. Jones. 1977. Generic and sectional limits in Senecio (Compositae): I. Progress report. Kew bulletin 32:47-67.

Jones, C. G., and R. M. Callaway. 2007. The third party. Journal of Vegetation Science 18:771-776.

Jones, C. G., J. H. Lawton, and M. Shachak. 1997. Positive and negative effects of organisms as physical ecosystem engineers. Ecology 78:1946-1957.

Jordán, F., A. Takács-Sánta, and I. Molnár. 1999. A reliability theoretical quest for keystones. Oikos 86:453-462. 
Joshi, J., and K. Vrieling. 2005. The enemy release and EICA hypothesis revisited: incorporating the fundamental difference between specialist and generalist herbivores. Ecology Letters 8:704-714.

Jungerius, P., and F. Van der Meulen. 1988. Erosion processes in a dune landscape along the Dutch coast. Catena 15:217-228.

Kacelnik, A., P. A. Cotton, L. Stirling, and J. Wright. 1995. Food allocation among nestling starlings: sibling competition and the scope of parental choice. Proceedings: Biological Sciences 259:259-263.

Kaplan, I., and R. F. Denno. 2007. Interspecific interactions in phytophagous insects revisited: a quantitative assessment of competition theory. Ecology Letters 10:977994.

Karban, R., and S. Courtney. 1987. Intraspecific Host Plant Choice: Lack of Consequences for Streptanthus tortuosus (Cruciferae) and Euchloe hyantis (Lepidoptera: Pieridae). Oikos 48:243-248.

Kareiva, P., J. Floberg, and T. N. Conservancy. 2008. Endangered Species. Pages 12461253 General Ecology.

Kawai, T., and M. Tokeshi. 2007. Testing the facilitation-competition paradigm under the stress-gradient hypothesis: decoupling multiple stress factors. Proceedings. Biological sciences / The Royal Society 274:2503-8.

Keane, R., and M. Crawley. 2002. Exotic plant invasions and the enemy release hypothesis. Trends in Ecology \& Evolution 17:164-170.

Kenis, M., M.-A. Auger-Rozenberg, A. Roques, L. Timms, C. Péré, M. J. W. Cock, J. Settele, S. Augustin, and C. Lopez-Vaamonde. 2008. Ecological effects of invasive alien insects. Biological Invasions 11:21-45.

Klar, A. J. S. 2002. Fibonacci' s flowers. Nature 417:585.

Ko, J., H. Park, B. Min, and H. Cha. 2004. Effects of Various Pretreatments on Seed Germination of Calystegia soldanella (Convolvulaceae), a Coastal Sand Dune Plant 47:396-400.

Koch, E. W., E. B. Barbier, B. R. Silliman, D. J. Reed, G. M. Perillo, S. D. Hacker, E. F. Granek, J. H. Primavera, N. Muthiga, S. Polasky, B. S. Halpern, C. J. Kennedy, C. V Kappel, and E. Wolanski. 2009. Non-linearity in ecosystem services: temporal and spatial variability in coastal protection. Frontiers in Ecology and the Environment 7:29-37.

Konlechner, T., and M. J. Hilton. 2010. Ammophila arenaria (marram grass) persistence through seedling recruitment. Pages 390-393 In 17th Australasian weeds 
conference. New frontiers in New Zealand: together we can beat the weeds. Christchurch.

Kraaijeveld, a R., E. C. Limentani, and H. C. Godfray. 2001. Basis of the trade-off between parasitoid resistance and larval competitive ability in Drosophila melanogaster. Proceedings. Biological sciences / The Royal Society 268:259-61.

Kunin, W., S. Hartley, and J. Lennon. 2000. Scaling down: on the challenge of estimating abundance from occurrence patterns. The American Naturalist 156:560-566.

Kwiatkowska, A., and E. Symonides. 1986. Spatial distribution of species diversity indices and their correlation with plot size. Vegetatio 68:99-102.

Landcare Research. 2009- Checklist of New Zealand Hymenoptera v7.0. http://www.landcareresearch.co.nz/resources/collections/nzac/holdings/primarytype-specimens-hymenoptera/checklist-hymenoptera (accessed 10/07/2014) . Accessed: 10/07/2014.

Lange, P. J. De, P. B. Heenan, D. R. Given, D. A. Norton, C. Ogle, P. N. Johnson, and E. K. Cameron. 1999. New Zealand Journal of Botany Threatened and uncommon plants of New Zealand. New Zealand Journal of Botany 37:37-41.

Lau, J. A., and S. Y. Strauss. 2005. Insect herbivores drive important indirect effects of exotic plants on native communities. Ecology 86:2990-2997.

Lawrence, M. E. 1985. Senecio L. (Asteraceae) in Australia: Reproductive biology of a genus found primarily in unstable environments. Australian Journal of Botany 33:197.

Lawton, J. 1983. Plant architecture and the diversity of phytophagous insects. Annual review of entomology 28:23-39.

Lawton, J. H. 2000. Community ecology in a changing world. Pages 59-81; 92-93 Community ecology in a changing world. Ecology Instititute, Olendorf/Luhe, Germany.

Leppänen, S. a, E. Altenhofer, A. D. Liston, and T. Nyman. 2012. Phylogenetics and evolution of host-plant use in leaf-mining sawflies (Hymenoptera: Tenthredinidae: Heterarthrinae). Molecular phylogenetics and evolution 64:331-41.

Levine, S. H. 1976. Competitive Interactions in Ecosystems. The American Naturalist 110:903-910.

Lewinsohn, T. M., V. Novotny, and Y. Basset. 2005. Insects on $p$ lants: Diversity of Herbivore Assemblages Revisited. Review Literature And Arts Of The Americas:597620. 
Lindborg, R., and O. Eriksson. 2004. Historical landscape connectivity affects present plant species diversity. Ecology 85:1840-1845.

Lindquist, R. K., M. L. Casey, N. Helyer, and N. E. A. Scopes. 1984. Leafminers on greenhouse chrysanthemum: control of Chromatomya syngenesiae and Liriomyza trifolii. Journal of Agric. Entomology 1:256-263.

Liu, H., and P. Stiling. 2006. Testing the enemy release hypothesis: a review and metaanalysis. Biological Invasions 8:1535-1545.

Lortie, C. J., and R. M. Callaway. 2006. Re-analysis of meta-analysis: support for the stress-gradient hypothesis. Journal of Ecology 94:7-16.

Lutscher, F., and T. Iljon. 2013. Competition, facilitation and the Allee effect. Oikos 122:621-631.

Lynch, L. D., R. G. Bowers, M. Begon, and D. J. Thompson. 1998. A dynamic refuge model and population regulation by insect parasitoids. Journal of Animal Ecology 67:270279.

Lynch, M., and I. Kaplan. 2006. Host-plant-mediated competition via induced resistance: interactions between pest herbivores on potatoes. Ecological Applications 16:855864.

Macel, M. 2011. Attract and deter: a dual role for pyrrolizidine alkaloids in plant-insect interactions. Phytochemistry reviews: proceedings of the Phytochemical Society of Europe 10:75-82.

Macel, M., M. Bruinsma, S. M. Dijkstra, T. Ooijendijk, H. M. Niemeyer, and P. G. L. Klinkhamer. 2005. Differences in effects of pyrrolizidine alkaloids on five generalist insect herbivore species. Journal of Chemical Ecology 31:1493-1508.

Maestre, F. T., R. M. Callaway, F. Valladares, and C. J. Lortie. 2009. Refining the stressgradient hypothesis for competition and facilitation in plant communities. Journal of Ecology 97:199-205.

Maestre, F. T., F. Valladares, and J. F. Reynolds. 2005. Is the change of plant-plant interactions with abiotic stress predictable? A meta-analysis of field results in arid environments. Journal of Ecology 93:748-757.

Maestre, F. T., F. Valladares, and J. F. Reynolds. 2006. The stress-gradient hypothesis does not fit all relationships between plant-plant interactions and abiotic stress: further insights from arid environments. Journal of Ecology 94:17-22.

Malkinson, D., and K. Tielbörger. 2010. What does the stress-gradient hypothesis predict? Resolving the discrepancies. Oikos 119:1546-1552. 
Maltez-Mouro, S., F. T. Maestre, and H. Freitas. 2010. Co-occurrence patterns and abiotic stress in sand-dune communities: Their relationship varies with spatial scale and the stress estimator. Acta Oecologica 36:80-84.

Maron, J. L., and M. Vila. 2001. When do herbivores affect plant invasion? Evidence for the natural enemies and biotic resistance hypotheses. Oikos 95:361-373.

Martin, M., and J. Harding. 1981. Evidence for the evolution of competition between two species of annual plants. Evolution 35:975-987.

Martin, N. 2013. Plant-SyNZTM database. Landcare Research, Auckland. http://plantsynz.landcareresearch.co.nz/SearchForm.aspx. Last accessed: June 2013.

Martinez, H.D.R. 2013. http://cran.r-project.org/web/packages/phia/vignettes/phia.pdf, last accessed July 2014.

Martinez, M. L., and J. G. Garcia-Frankco. 2008. "Plant-plant interactions in coastal dunes" in Coastal Dunes. Pages 205-220. Springer, Berlin, Heidelberg.

Mason, T. J., K. French, and K. Russell. 2012. Are competitive effects of native species on an invader mediated by water availability? Journal of Vegetation Science 23:657666.

Matlack, G. 1994. Vegetation dynamics of the forest edge--trends in space and successional time. Journal of Ecology 82:113-123.

McArt, S. H., and J. S. Thaler. 2013. Plant genotypic diversity reduces the rate of consumer resource utilization. Proceedings. Biological sciences / The Royal Society 280:20130639.

McArt, S., R. Halitschke, J. Salminen, and J. Thaler. 2012. Leaf herbivory increases plant fitness via induced resistance to seed predators. Ecology 94:966-975.

McCann, K. S. 2000. The diversity-stability debate. Nature 405:228-33.

McGilchrist, C. A., and B. R. Trenbath. 1971. A Revised Analysis of Plant Competition Experiments. Biometrics 27:659-671.

McGlone, M. 1989. The Polynesian settlement of New Zealand in relation to environmental and biotic changes. New Zealand journal of Ecology 12:115-129.

McIntire, E. J. B., and A. Fajardo. 2013. Facilitation as a ubiquitous driver of biodiversity. The New phytologist.

McIntyre, S., S. Lavorelt, and R. M. Tremont. 1995. Plant life-history attributes: their relationship to in herbaceous disturbance response vegetation. Journal of Ecology 83:31-44. 
McQueen, D. 1993. A review of interaction between naturalised woody plants and indigenous vegetation in New Zealand. Tuatara 32:31-55.

Meijden, E. Van Der. 1996. Plant defence, an evolutionary dilemma : contrasting effects of (specialist and generalist) herbivores and natural enemies. Entomologia Experimentalis et Applicata 80:307-310.

Menge, B. 1995. Indirect effects in marine rocky intertidal interaction webs: patterns and importance. Ecological monographs 65:21-74.

Menge, B. A., and J. P. Sutherland. 1987. Community Regulation: Variation in Disturbance, Competition, and Predation in Relation to Environmental Stress and Recruitment. The American Naturalist 130:730-757.

Minor, E. S., S. M. Tessel, K. a M. Engelhardt, and T. R. Lookingbill. 2009. The role of landscape connectivity in assembling exotic plant communities: a network analysis. Ecology 90:1802-9.

Minot, E. 1981. Effects of interspecific competition for food in breeding blue and great tits. The Journal of Animal Ecology 50:375-385.

Montès, N. 2009. A non-destructive method to estimate biomass in arid environments: A comment on. Journal of Arid Environments 73:599-601.

Moraes, C. De, W. Lewis, P. Pare, H. T. Alborn, and J. H. Tumlinson. 1998. Herbivoreinfested plants selectively attract parasitoids. Nature 393:570-573.

Moreno-Casasola, P. 1984. Sand movement as a factor in the distribution of plant communities in a coastal dune. Vegetatio 65:67-76.

Moreno-Casasola, P. 1988. Patterns of plant species distribution on coastal dunes along the Gulf of Mexico. Journal of Biogeography 15:787-806.

Morris, R. J., O. T. Lewis, and H. C. J. Godfray. 2004. Experimental evidence for apparent competition in a tropical forest food web. Nature 428:310-313.

Mountainspring, S., and J. Scott. 1985. Interspecific competition among Hawaiian forest birds. Ecological Monographs 55:219-239.

Murakami, M., and S. Nakano. 2000. Species-specific bird functions in a forest-canopy food web. Proceedings. Biological sciences / The Royal Society 267:1597-601.

Murray, B. R., P. H. Thrall, a. M. Gill, and A. B. Nicotra. 2002. How plant life-history and ecological traits relate to species rarity and commonness at varying spatial scales. Austral Ecology 27:291-310.

Naumann, C., T. Hartmann, and D. Ober. 2002. Evolutionary recruitment of a flavindependent monooxygenase for the detoxification of host plant-acquired 
pyrrolizidine alkaloids in the alkaloid-defended arctiid moth Tyria jacobaeae. Proceedings of the National Academy of Sciences of the United States of America 99:6085-90.

NZ Plant Conservation Network. 2013. http://www.nzpen.org.nz/page.aspx?contact_us. Accessed: $25^{\text {th }}$ of June 2013.

Ngumbi, E., M. Jordan, and H. Fadamiro. 2012. Comparison of associative learning of host-related plant volatiles in two parasitoids with different degrees of host specificity, Cotesia marginiventris and Microplitis croceipes. Chemoecology 22:207215.

Nguyen-Ngoc, D., T. Nguyen-Huu, and P. Auger. 2012. Effects of fast density dependent dispersal on pre-emptive competition dynamics. Ecological Complexity 10:26-33.

Niemelä, P., and W. Mattson. 1996. Invasion of North American forests by European phytophagous insects. BioScience 46:741-753.

Nishida, R. 1994. Sequestration of plant secondary compounds by butterflies and moths. Chemoecology 5/6:127-138.

Nishida, R., M. Rothschild, and R. Mummeryt. 1994. A cyanoglucoside, Sarmentosin, from the magpie moth Abraxas grossulariata, Geometridae: Lepidoptera. Phytochemistry 36:37-38.

NIWA. 2013. Monthly rainfall and temperature. http://www.niwa.co.nz/ourscience/climate.

Noonburg, E., and J. Byers. 2005. More harm than good: when invader vulnerability to predators enhances impact on native species. Ecology 86:2555-2560.

Norton, D., J. W. Herbert, and A. E. Beveridge. 1988. The ecology of Dacrydium cupressinum: a review. New Zealand journal of ... 26:37-62.

Novotny, V., and Y. Basset. 2005. Host specificity of insect herbivores in tropical forests. Proceedings. Biological sciences / The Royal Society 272:1083-90.

Nufarm. 2013. Roundup herbicide renew. http://www.nufarm.co.nz/Assets/18014/.

O'Dowd, D. J., P. T. Green, and P. S. Lake. 2003. Invasional "meltdown" on an oceanic island. Ecology Letters 6:812-817.

O'Neill, R. V., C. T. Hunsaker, S. P. Timmins, B. L. Jackson, K. B. Jones, K. H. Riitters, and J. D. Wickham. 1996. Scale problems in reporting landscape pattern the regional scale. Landscape Ecology 11:169-180. 
Obermaier, E. L., A. N. Heisswolf, H. A. N. S. J. O. Poethke, B. A. Randlkofer, and T. O. Meiners. 2008. Plant architecture and vegetation structure: Two ways for insect herbivores to escape parasitism. Eur. J. Entomol. 105:233-240.

Olff, H., J. Huisman, and B. F. Van Tooren. 1993. Species dynamics and nutrient accumulation during early primary succession in coastal sand dunes. Journal of Ecology 81:693-706.

Opdam, P. 1991. Metapopulation theory and habitat fragmentation: a review of holarctic breeding bird studies. Landscape Ecology 5:93-106.

Ornduff, R. 1964. Evolutionary pathways of the Senecio lautus alliance in New Zealand and Australia. Evolution 18:349-360.

Orrock, J. L., M. S. Witter, and O. J. Reichman. 2008. Apparent competition with an excotic plant reduces native plant establishment. Ecology 89:1168-1174.

Osborne, J. W. 2002. Notes on the use of data transformations. Data transformation and normality. Practical Assessment, Research\& Evaluation 8.

Östman, Ö., and A. R. Ives. 2003. Scale-dependant indirect interactions between two prey species through a shared predator. Oikos 102:505-514.

Otsamo, A., G. Adjers, T. S. Hadi, J. Kuusipalo, and R. Vuokko. 1997. Evaluation of reforestation potential of 83 tree species planted on Imperata cylindrica dominated grassland. New Forests 14:127-143.

Otway, S. J., A. Hector, and J. H. Lawton. 2005. Resource dilution effects on specialist insect herbivores in a grassland biodiversity experiment. Journal of Animal Ecology 74:234-240.

Pacala, S. W., and M. J. Crawley. 1992. Herbivores and plant diversity. The American Naturalist 140:243-260.

Padilla, F. M., and F. I. Pugnaire. 2006. The role of nurse plants in the restoration of degraded environments. Frontiers in Ecology and the Environment 4:196-202.

Palmer, T. P. 972. Variation in flowering time among and within populations of Trifolium arvense L . in New Zealand. New Zealand Journal of Botany 10:59-68.

Pare, P. W., and J. H. Tumlinson. 1999. Plant volatiles as a defense against insect herbivores. Plant physiology 121 (2):325-331.

Parolin, P., A. C. Oliveira, M. T. F. Piedade, F. Wittmann, and W. J. Junk. 2002. Pioneer trees in Amazonian floodplains: three key species form monospecific stands in different habitats. Folia Geobotanica 37:225-238. 
Paynter, Q., S. V. Fowler, A. Hugh Gourlay, R. Groenteman, P. G. Peterson, L. Smith, and C. J. Winks. 2010. Predicting parasitoid accumulation on biological control agents of weeds. Journal of Applied Ecology 47:575-582.

Pearson, D. E., and R. M. Callaway. 2003. Indirect effects of host-specific biological control agents. Trends in Ecology \& Evolution 18:456-461.

Pearson, D. E., and R. M. Callaway. 2008. Weed-biocontrol insects reduce native-plant recruitment through second-order apparent competition. Ecological applications : a publication of the Ecological Society of America 18:1489-500.

Peet, R., T. Wentworth, and P. White. 1998. A flexible, multipurpose method for recording vegetation composition and structure. Castanea 63:262-274.

Peeters, P. J. 2002. Correlations between leaf structural traits and the densities of herbivorous insect guilds. Biological Journal of the Linnean Society 77:43-65.

Pegman, A. P. M., and G. L. Rapson. 2005. Plant succession and dune dynamics on actively prograding dunes, Whatipu Beach, northern New Zealand. New Zealand Journal of Botany 43:223-244.

Pellissier, L., K. Anne Bråthen, J. Pottier, C. F. Randin, P. Vittoz, A. Dubuis, N. G. Yoccoz, T. Alm, N. E. Zimmermann, and A. Guisan. 2010. Species distribution models reveal apparent competitive and facilitative effects of a dominant species on the distribution of tundra plants. Ecography 33:1004-1014.

Pelser, P. B., R. J. Abbott, H. P. Comes, J. J. Milton, M. Möller, M. E. Looseley, G. V Cron, J. F. Barcelona, A. H. Kennedy, L. E. Watson, R. Barone, F. Hernández, and J. W. Kadereit. 2012. The genetic ghost of an invasion past: colonization and extinction revealed by historical hybridization in Senecio. Molecular ecology 21:369-87.

Pelser, P. B., B. Nordenstam, J. W. Kadereit, and L. E. Watson. 2007. An ITS phylogeny of tribe Senecioneae (Asteraceae) and a new delimitation of Senecio $\mathrm{L}$. Taxon 56:1077-1104.

Pemadasa, M., P. Greig-Smith, and P. Lovell. 1974. A quantitative description of the distribution of annuals in the dune system at Aberffraw, Anglesey. The Journal of Ecology 62:379-402.

La Peyre, M. K. G., J. B. Grace, E. Hahn, and I. A. Mendelssohn. 2001. The importance of competition in regulating plant species abundance along a salinity gradient. Ecology 82:62-69.

Picoli, S., R. S. Mendes, E. K. Lenzi, and L. C. Malacarne. 2012. Scale-invariant structure of size fluctuations in plants. Scientific reports 2:1-3.

Pimentel, D. 1961. Species diversity and insect population outbreaks. Annals of the Entomological Society of America 54:76-86. 
Pimentel, D. (Ed) 2002. Introduction: non-native species in the world. In: Biological Invasions: economic and environmental costs of alien plant, animal and microbe species. CRC Press.

Pimentel, D., R. Zuniga, and D. Morrison. 2005. Update on the environmental and economic costs associated with alien-invasive species in the United States. Ecological Economics 52:273-288.

Pimm, S., G. Russell, J. L. Gittleman, and T. M. Brooks. 1995. The future of biodiversity. Science 269:347-350.

Polis, G. 1991. Complex trophic interactions in deserts: an empirical critique of food-web theory. American Naturalist 138:123-155.

Polis, G. A., and D. R. Strong. 1996. Food web complexity and community dynamics. The American Naturalist 147:813-846.

Polis, G., W. B. Anderson, and R.D. Holt. 1997. Toward an integration of landscape and food web ecology: the dynamics of spatially subsidized food webs. Annual review of ecology and systematics 28:289-316.

Popay, I., P. Champion, and T. James. 2010. An illustrated guide to common weeds of New Zealand. New Zealand Plant Protection Society, New Zealand (Ed. 3).

Poulter, B., S. S. Qian, and N. L. Christensen. 2008. Determinants of coastal treeline and the role of abiotic and biotic interactions. Plant Ecology 202:55-66.

Power, M., and W. Dietrich. 2002. Food webs in river networks. Ecological Research 17:451-471.

Prado, P. I., and T. M. Lewinsohn. 2004. Compartments in insect-plant associations and their consequences for community structure. Journal of Animal Ecology, 73(6:, 1168-1178.

Price, P., C. Bouton, and P. Gross. 1980. Interactions among three trophic levels: influence of plants on interactions between insect herbivores and natural enemies. Annual Review of Ecology and Systematics 11:41-65.

Price, P. W. 1991. The plant vigor hypothesis and herbivore attack. Oikos 62:244-251.

Price, P. W. 1997. Insect ecology. Page 607. Third. John Whiley and Sons, Inc., New York, USA.

Prokopy, R. J., and E. D. Owens. 1983. Visual Detection of Plants by Herbivorous Insects. Annual Review of Entomology 28:337-364.

Putten, W. H. Van Der. 2003. Plant Defense Belowground and Spatiotemporal Processes in Natural Vegetation. Ecology 84:2269-2280. 
Putten, W. H. Van Der, G. W. Yeates, H. Duyts, C. S. Reis, and G. Karssen. 2005. Invasive plants and their escape from root herbivory: a worldwide comparison of the rootfeeding nematode communities of the dune grass Ammophila arenaria in natural and introduced ranges. Biological Invasions 7:733-746.

Pywell, R. F., J. M. Bullock, D. B. Roy, L. Warman, K. J. Walker, and P. Rothery. 2003. Plant traits as predictors of performance in ecological restoration. Journal of Applied Ecology 40:65-77.

Queensland Government. 2011. Hare's tail, Lagurus ovatus. http://keyserver.lucidcentral.org/weeds/data/03030800-0b07-490a-8d040605030c0f01/media/Html/Lagurus_ovatus.htm. Accessed: 10/06/2013

Quinn, J. 2000. Effects of pastoral development. Pages 208-229 in K. J. Collier and M. J. Winterbourn, editors. New Zealand stream invertebrates: ecology and implimentations for mangement. Caxton Press, Christchurch/New Zealand.

R Core Team. 2012. R: A language and environment for statistical computing. $R$ Foundation for Statistical Computing. Vienna, Austria.

Raudenbush, S., and A. Bryk. 2002. Hierarchical linear models: Applications and data analysis methods. SAGE Publications, Incorporated.

Rejmanek, M., and D. M. Richardson. 1996. What attributes make some plant species more invasive.pdf. Ecology 77:1655-1661.

Rich, L. N., M. S. Mitchell, J. a. Gude, and C. a. Sime. 2012. Anthropogenic mortality, intraspecific competition, and prey availability influence territory sizes of wolves in Montana. Journal of Mammalogy 93:722-731.

Richardson, D., and P. Pyšek. 2006. Plant invasions: merging the concepts of species invasiveness and community invasibility. Progress in Physical Geography 30:409431.

Rochefort, L., E. V. G. Groeneveld, and A. Masse. 2007. Polytrichum strictum as a NursePlant in Peatland Restoration. Restoration Ecology 15:709-719.

Roda, F., L. Ambrose, G. M. Walter, H. L. Liu, A. Schaul, A. Lowe, P. B. Pelser, P. Prentis, L. H. Rieseberg, and D. Ortiz-Barrientos. 2013. Genomic evidence for the parallel evolution of coastal forms in the Senecio lautus complex. Molecular Ecology 22:2941-2952.

Root, R. B. 1973. Organization of a Plant-Arthropod Association in Simple and Diverse Habitats : The Fauna of Collards (Brassica oleracea. Ecological Monographs 43:95124. 
Ross, K. C., J. B. Colquhoun, and C. A. Mallory-smith. 2004. Small broomrape ( Orobranche minor) germination and early development in response to plant species. Weed Science 52:260-266.

Le Roux, P. C., and M. a McGeoch. 2010. Interaction intensity and importance along two stress gradients: adding shape to the stress-gradient hypothesis. Oecologia 162:733-45.

Russell, E. 1989. Enemies hypothesis: a review of the effect of vegetational diversity on predatory insects and parasitoids. Environmental Entomology 18:590-599.

Sakai, A. K., F. W. Allendorf, J. S. Holt, D. M. Lodge, J. Molofsky, K. A. With, S. Baughman, R. J. Cabin, J. E. Cohen, N. C. Ellstrand, D. E. Mccauley, P. O. Neil, I. M. Parker, J. N. Thompson, and S. G. Weller. 2001. The population biology of invasive species. Annual Review of Ecology and Systematics 32:305-332.

Santoro, R., T. Jucker, M. Carboni, and A. T. R. Acosta. 2012. Patterns of plant community assembly in invaded and non-invaded communities along a natural environmental gradient. Journal of Vegetation Science 23:483-494.

Sasakawa, K., K. Uchijima, H. Shibao, and M. Shimada. 2013. Different patterns of oviposition learning in two closely related ectoparasitoid wasps with contrasting reproductive strategies. Die Naturwissenschaften 100:117-24.

Scherber, C., M. J. Crawley, and S. Porembski. 2003. The effects of herbivory and competition on the invasive alien plant Senecio inaequidens (Asteraceae). Diversity and Distributions 9:415-426.

Schnitzler, R.F., C. Winks, 2012. Personal communication with R. F. Schnitzler and C. Winks. Landcare Research, Auckland. Auckland/New Zealand 2012.

Schoolmaster, D. R. 2008. Recruitment limitation modifies the net effects of shared enemies on competitively inferior plants. Journal of Ecology 96:114-121.

Schoonhoven, L. M., J. J. A. van Loon, and M. Dicke. 2007. Insect-Plant Biology. Oxford University Press, Oxford/UK.

Seabloom, E. W., W. S. Harpole, O. J. Reichman, and D. Tilman. 2003. Invasion, competitive dominance, and resource use by exotic and native California grassland species. Proceedings of the National Academy of Sciences of the United States of America 100:13384-9.

Segura, D. F., M. M. Viscarret, S. M. Ovruski, and J. L. Cladera. 2012. Response of the fruit fly parasitoid Diachasmimorpha longicaudata to host and host-habitat volatile cues. Entomologia Experimentalis et Applicata 143:164-176.

Sengupta, D. 2012. A robust linear mixed effects model with application to method comparison studies. The University of Texas at Dallas. 
Settle, W., and L. Wilson. 1990. Invasion by the variegated leafhopper and biotic interactions: parasitism, competition, and apparent competition. Ecology 71:14611470.

Sheath, G. W. 1975. Lotus pedunculatus -an agricultural plant? Proceedings N.Z. Grassland Association:160-168.

Shreve, F. 1931. Physical conditions in sun and shade. Ecology 12:96-104.

Simpson, M. J. A. 1974. Spinifex hirsutus in Canterbury. Canterbury Botancial Society Journal 7:18-19.

Singer, M., D. Rodrigues, J. Stireman III, and Y. Carrière. 2004. Roles of food quality and enemy-free space in host use by a generalist insect herbivore. Ecology 85:27472753.

Smith, P. H., and P. A. Lockwood. 2010. Monitoring Sea Bindweed (Calystegia soldanella) on the Sefton Coast, Merseyside, in 2010. BSBI News 115:25-29.

Sollins, P., P. Homann, and B. Caldwell. 1996. Stabilization and destabilization of soil organic matter: mechanisms and controls. Geoderma 74:65-105.

Souza-Filho, M. F., a Raga, J. a Azevedo-Filho, P. C. Strikis, J. a Guimarães, and R. a Zucchi. 2009. Diversity and seasonality of fruit flies (Diptera: Tephritidae and Lonchaeidae) and their parasitoids (Hymenoptera: Braconidae and Figitidae) in orchards of guava, loquat and peach. Brazilian Journal of Biology = Revista brasleira de biologia 69:31-40.

Spence, H., D. Bergin, and M. Dean. 2007. Ten years of research and implementation, Dune Restoration Trust of New Zealand. Plant Ecology 238:89-94.

Sponseller, R., J. Heffernan, and S. Fisher. 2013. On the multiple ecological roles of water in river networks. Ecosphere 4:1-14.

Stegelmeier, B., J. Edgar, S. Colegale, D. R. Gardner, T. K. Schoch, R. A. Coulombe, and R. J. Molyneux. 1999. Pyrrolizidine alkaloid plants, metabolism and toxicity. Journal of Natural Toxins 8:95-116.

Steinmetz, J., S. Kohler, and D. Soluk. 2003. Birds are overlooked top predators in aquatic food webs. Ecology 84:1324-1328.

Stephens, A. E. a., and J. H. Myers. 2012. Resource concentration by insects and implications for plant populations. Journal of Ecology 100:923-931.

Stiling, P., A. Rossi, and M. Cattell. 2003. Associational resistance mediated by natural enemies. Ecological Entomology 28:587-592. 
Sugiura, S., and H. Taki. 2012. Scale-dependent effects of habitat area on species interaction networks: invasive species alter relationships. BMC ecology 12:1-12.

Sullivan, J., P. a. Williams, and S. M. Timmins. 2007. Secondary forest succession differs through naturalised gorse and native kānuka near Wellington and Nelson. New Zealand Journal of Ecology 31:22-38.

Sullivan, J., C. J. Winks, and S. V. Fowler. 2008. Novel host associations and habitats for Senecio-specialist herbivorous insects in Auckland. New Zealand Journal of Ecology 32:219-224.

Sykes, M. T., and J. B. Wilson. 1991. Vegetation of a Coastal Sand Dune System in Southern New Zealand Vegetation of a coastal sand dune system in southern New Zealand. Journal of Vegetation Science 2:531-538.

Symons, F., and G. Beccaloni. 1999. Phylogenetic indices for measuring the diet breadths of phytophagous insects. Oecologia 119:427-434.

Takahashi-Nakaguchi, A., Y. Matsumoto, M. Yamamoto, K. Iwabuchi, Y. Totsuka, T. Sugimura, and K. Wakabayashi. 2013. Demonstration of cytotoxicity against wasps by pierisin-1: a possible defense factor in the cabbage white butterfly. PloS One 8(4):e60539.

Terzi, I. 2008. Allelopathic effects of Juglone and decomposed walnut leaf juice on muskmelon and cucumber seed germination and seedling growth. African Journal of Biotechnology 7:1870-1874.

Thomas, C. 1989. Predator-herbivore interactions and the escape of isolated plants from phytophagous insects. Oikos 55:291-298.

Thompson, J. N. 1978. Within-patch structure and dynamics in Pastinaca sativa and resource availability to a specialized herbivore. Ecology 59:443-448.

Thuiller, W., M. B. Araújo, and S. Lavorel. 2003. Generalized models vs. classification tree analysis: Predicting spatial distributions of plant species at different scales. Journal of Vegetation Science 14:669-680.

Tilman, D., and P. M. Kareiva. 1997. Spatial ecology: the role of space in population dynamics and interspecific interactions. Vol. 30. Princeton University Press.

Tomasetto, F., R. P. Duncan, and P. E. Hulme. 2013. Environmental gradients shift the direction of the relationship between native and alien plant species richness. Diversity and Distributions 19:49-59.

Tosh, N. D., A. Vialatte, X. Vitrac, and F. Jean. 2011. Phytophagy on phylogenetically isolated trees : why hosts should escape their relatives. Ecology Letters. 
Turner, M. G., V. H. Dale, and R. H. Gardner. 1989a. Predicting across scales: Theory development and testing. Landscape Ecology 3:245-252.

Turner, M., R. O'Neill, R. Gardner, and B. Milne. 1989b. Effects of changing spatial scale on the analysis of landscape pattern. Landscape Ecology 3:153-162.

Turner, R., and P. Chapell. 2013. NIWA: Seasonal climate summary, national climate summary: Summer 2012/2013. Page 13.

Turner, R. M., S. M. Alcorn, G. Olin, and J. A. Booth. 1966. The influence of shade, soil , and water on saguaro seedling establishment. Botanical Gazette 127:95-102.

Tylianakis, J. M., T. Tscharntke, and O. T. Lewis. 2007. Habitat modification alters the structure of tropical host-parasitoid food webs. Nature 445:200-205.

Uefune, M., Y. Choh, J. Abe, K. Shiojiri, K. Sano, and J. Takabayashi. 2012. Application of synthetic herbivore-induced plant volatiles causes increased parasitism of herbivores in the field. Journal of Applied Entomology 136:561-567.

Underwood, N., and S. L. Halpern. 2012. Insect herbivores, density dependence, and the performance of the perennial herb Solanum carolinense. Ecology 93:1026-35.

Underwood, A.J., Chapman, M.G. and S.D Connell. 2000. Observations in ecology: you can't make progress on processes without understanding the patterns. Journal of Experimental Marine Biology and Ecology., 250, 97-115.

Underwood, A.J. 1997 Experiments in ecology: their logical design and interpretation using analysis of variance. Cambridge University Press, p. 240.

Valiente-Banuet, A., and E. Ezcurra. 1991. Shade as a cause of the association between the cactus Neobuxbaumia tetetzo and the nurse plant Mimosa luisana in teh Tehuacan Valley, Mexico. Journal of Ecology 79:961-971.

Van Veen, F. J. F., R. J. Morris, and H. C. J. Godfray. 2006. Apparent competition, quantitative food webs, and the structure of phytophagous insect communities. Annual Review of Entomology 51:187-208.

Vilà, M., J. L. Maron, and L. Marco. 2005. Evidence for the enemy release hypothesis in Hypericum perforatum. Oecologia 142:474-9.

Vinson, S. 1976. Host selection by insect parasitoids. Annual Review of Entomology 21:109-133.

Vinson, S. B. 1975. Biochemical coevolution between parasitoids and their hosts. Pages 14-48 in P. W. Price, editor. Evolutionary strategies of parasitic insects and mites. First edition. Springer US, Texas/USA. 
De Visser, S. N., B. P. Freymann, and H. Olff. 2011. The Serengeti food web: empirical quantification and analysis of topological changes under increasing human impact. The Journal of Animal Ecology 80:484-94.

Vitousek, P., H. Mooney, J. Lubchenco, and J. Melillo. 1997. Human domination of Earth's ecosystems. Science 277:494-499.

Vorburger, C., and G. Ribi. 1999. Aggression and competition for shelter between a native and an introduced crayfish in Europe. Freshwater Biology 42:111-119.

Wardle, D. a., K. S. Nicholson, and a. Rahman. 1995. Ecological effects of the invasive weed species Senecio jacobaea L. (ragwort) in a New Zealand pasture. Agriculture, Ecosystems \& Environment 56:19-28.

Waring, S. 2010. Apparent competition between native and exotic plants mediated by a native insect herbivore. Lincoln University, Christchurch/New Zealand.

Watling, J. I., C. R. Hickman, and J. L. Orrock. 2011. Predators and invasive plants affect performance of amphibian larvae. Oikos 120:735-739.

Webb, C. J. 1988. Notes on the Senecio lautus complex. New Zealand Journal of Botany 26:481-484.

Webb, C., W. Sykes, and P. Garnock-Jones. 1988. Flora of New Zealand: volume 4. Naturalised Pteridophytes, Gymnosperms, dicotyledons. Pages 265-287 Christchurch: New Zealand, Department of Scientific and Industrial Research, Christchurch.

Weedbusters. 2013. Purple groundsel Senecio elegans. http://www.weedbusters.org.nz/downloads/WeedPDF/Purple groundsel_130625214624.pdf. Accessed: 29/05/2013

Weiblen, G. D., C. O. Webb, V. Novotny, Y. Basset, and S. E. Miller. 2006. Phylogenetic dispersion of host use in a tropical insect herbivore community. Ecology 87:S62-75.

Weir, T. L., H. P. Bais, and J. M. Vivanco. 2003. Intraspecific and interspecific interactions mediated by a phytotoxin, (-)-catechin, secreted by the roots of Centaurea maculosa (spotted knapweed). Journal of Chemical Ecology 29:2397-412.

Wendelken, W. 1974. New Zealand experience in stabilization and afforestation of coastal sands. International Journal of Biometeorology 18:145-158.

Werner, P. A. 1977. Colonization success of a " biennial " plant species : experimental field studies of species cohabitation and replacement. Ecology 58:840-849.

White, E. 2008. Indirect interactions between alien and native Senecio species as mediated by insects. Queensland University of Technology. 
White, E., J. Wilson, and A. Clarke. 2006. Biotic indirect effects: a neglected concept in invasion biology. Diversity and Distributions:443-455.

Whitfeld, T., V. Novotny, S. Miller, and J. Hrcek. 2012. Predicting tropical insect herbivore abundance from host plant traits and phylogeny. Ecology 93:211-222.

Widderick, M., and H. Wu. 2013. Weed 7. Fleabane. http://www.agric.wa.gov.au/objtwr/imported_assets/content/pw/weed/major/fle abane.pdf. Accessed: 15/05/2013

Wielgoss, A., Y. Clough, B. Fiala, A. Rumede, and T. Tscharntke. 2012. A minor pest reduces yield losses by a major pest: plant-mediated herbivore interactions in Indonesian cacao. Journal of Applied Ecology 49:465-473.

Wiens, J. 1989. Spatial scaling in ecology. Functional ecology 3:385-397.

Wilcox, M. 2012. Pyrrolizidine alkaloids: An ecological comparison of intraspecific phytochemical defence across native and introduced Senecio species, and their role in insect-plant interactions. Victoria University of Wellington.

Wildová, R., D. E. Goldberg, and T. Herben. 2012. The contrasting roles of growth traits and architectural traits in diversity maintenance in clonal plant communities. The American Naturalist 180:693-706.

Williams, I. S., T. H. Jones, and S. E. Hartley. 2001. The role of resources and natural enemies in determining the distribution of an insect herbivore population. Ecological Entomology 26:204-211.

Williams, P., C. Ogle, S. Timmins, G. La Cock, and V. Reid. 1999. Biology and ecology of Senecio glastifolius and its spread and impacts in New Zealand. Page 17. Wellington/New Zealand.

Williams, R. J., and N. D. Martinez. 2000. Simple rules yield complex food webs. Nature 404:180-3.

Willis, A. 1965. The influence of mineral nutrients on the growth of Ammophila arenaria. The Journal of Ecology 53:735-745.

Wilson, J. B., and M. T. Sykes. 1999. Is zonation on coastal sand dunes determined primarily by sand burial or by salt spray? A test in New Zealand dunes. Ecology Letters 2:233-236.

Wilson, J. R. U., E. E. Dormontt, P. J. Prentis, A. J. Lowe, and D. M. Richardson. 2009. Something in the way you move: dispersal pathways affect invasion success. Trends in Ecology \& Evolution 24:136-44. 
Winkler, I. S., C. Mitter, and S. J. Scheffer. 2009. Repeated climate-linked host shifts have promoted diversification in a temperate clade of leaf-mining flies. Proceedings of the National Academy of Sciences of the United States of America 106:18103-8.

Wolfe, L. M. 2002. Why alien invaders succeed: support for the escape-from-enemy hypothesis. The American naturalist 160:705-11.

Xu, D., J. D. Reeve, X. Wang, and M. Xiao. 2010. Developmental variability and stability in continuous-time host-parasitoid models. Theoretical Population Biology 78:1-11.

Yela, J. L., and J. H. Lawton. 1997. Insect herbivore loads on native and introduced plants: a preliminary study. Entomologia Experimentalis et Applicata 85:275-279.

Yizhaq, H., Y. Ashkenazy, and H. Tsoar. 2007. Why do active and stabilized dunes exist under the same climatic conditions? Physical Review Letters 98:1-4.

Yoshida, K. 2008. The relationship between the duration of food web evolution and the vulnerability to biological invasion. Ecological Complexity 5:86-98.

Zarnetske, P., T. C. Gouhier, S. D. Hacker, E. W. Seabloom, and V. A. Bokil. 2013. Indirect effects and facilitation among native and non-native species promote invasion success along an environmental stress gradient. Journal of Ecology 101(4): 905-915.

Zarnetske, P. L., S. D. Hacker, E. W. Seabloom, P. Ruggiero, J. R. Killian, T. B. Maddux, and D. Cox. 2012. Biophysical feedback mediates effects of invasive grasses on coastal dune shape. Ecology 93:1439-50.

Ziska, L., and F. Caulfield. 2000. Rising CO2 and pollen production of common ragweed (Ambrosia artemisiifolia L.), a known allergy-inducing species: implications for public health. Functional Plant Biology 27:893-898.

Zuur, A., E. N. leno, N. J. Walker, A. A. Saveliev, and G. M. Smith. 2009. Mixed effects models and extensions in ecology with R. (M. Gail, K. Krickeberg, J. M. Samet, A. Tsiatis, and W. Wong, Eds.). Springer, New York, USA.

Zuur, A., E. leno, and G. Smith. 2007. Analysing ecological data. Vol. 650. Springer, New York, USA. 